\title{
On monopoly pricing : essays in microeconomics
}

Citation for published version (APA):

Haan, M. A. (1998). On monopoly pricing : essays in microeconomics. [Doctoral Thesis, Maastricht University]. Universiteit Maastricht. https://doi.org/10.26481/dis.19980702mh

Document status and date:

Published: 01/01/1998

DOI:

10.26481/dis.19980702mh

Document Version:

Publisher's PDF, also known as Version of record

\section{Please check the document version of this publication:}

- A submitted manuscript is the version of the article upon submission and before peer-review. There can be important differences between the submitted version and the official published version of record.

People interested in the research are advised to contact the author for the final version of the publication, or visit the DOI to the publisher's website.

- The final author version and the galley proof are versions of the publication after peer review.

- The final published version features the final layout of the paper including the volume, issue and page numbers.

Link to publication

\footnotetext{
General rights rights.

- You may freely distribute the URL identifying the publication in the public portal. please follow below link for the End User Agreement:

www.umlib.nl/taverne-license

Take down policy

If you believe that this document breaches copyright please contact us at:

repository@maastrichtuniversity.nl

providing details and we will investigate your claim.
}

Copyright and moral rights for the publications made accessible in the public portal are retained by the authors and/or other copyright owners and it is a condition of accessing publications that users recognise and abide by the legal requirements associated with these

- Users may download and print one copy of any publication from the public portal for the purpose of private study or research.

- You may not further distribute the material or use it for any profit-making activity or commercial gain

If the publication is distributed under the terms of Article $25 \mathrm{fa}$ of the Dutch Copyright Act, indicated by the "Taverne" license above, 
Printed by Universal Press, Veenendaal http://www.xs4all.nl/ thesis 


\section{ON MONOPOLY PRICING;}

Essays in Microeconomics

\section{PROEFSCHRIFT}

ter verkrijging van de graad van doctor aan de Universiteit Maastricht, op gezag van de Rector Magnificus, Prof. dr. A.C. Nieuwenhuijzen Kruseman, volgens het besluit van het College van Decanen, in het openbaar te verdedigen op donderdag 2 juli 1998 om 16.00 uur

door

Marten Adriaan Haan 
Promotores:

Prof. dr. J.A.H. Maks

Prof. dr. J. Muysken

Beoordelingscommissie:

Prof. dr. H.J.M. Peters (voorzitter)

Prof dr. P. van Cayseele (Katholieke Universiteit Leuven, België)

Dr. Th. Ziesemer 


\section{Acknowledgements}

This thesis consists of most of the research I did as a Ph.D.-student (AIO) at the University of Maastricht, from 1993-1997. Part of it was conducted when visiting the Catholic University of Leuven in 1997.

Many people have contributed. First, I thank my supervisors, Hans Maks and Joan Muysken, for coaching me towards this result, and for never failing to stress the importance of intuition and the bigger picture. Second, I thank the committee, consisting of Hans Peters, Patrick van Cayseele, and Thomas Ziesemer, who meticulously read and commented on every detail of this thesis, and prevented some embarrassing errors. With my colleague-AIOs in Maastricht, Frank Bunte, Thomas Zwick, I had many discussions on Microeconomics in general and Industrial Organization in particular, which helped shape the ideas put forward in this thesis. I also had many helpful discussions, although in a different way, with Sylvia Beenen and Francien Schijlen, secretaries at the Department of Economics. I enjoyed cooperating with Stuart Dixon and Hans Dewachter.

I am very grateful to Patrick van Cayseele, who was willing to host me in Leuven, and provided me there with a stimulating environment, and ditto discussions. In Leuven, Yohanes Riyanto and Hilde Smets read and gave comments on virtually the entire thesis, and made my stay particularly enjoyable. Thanks. I am heavily indebted to NAKE, the Dutch Network of Economics, which provides the educational part of the All-schap, and does so in an excellent way. This education proved decisive for this thesis. The best way to show that is by noting that both chapter 7 and chapter 9 were originally written for two NAKE-courses, respectively Deregulation, taught by Eric van Damme and Raymond Gradus, and Intertemporal Choice, taught by Arie Kapteyn and Peter Kooreman.

I thank family and friends, and thank and apologize to everyone I 
should have thanked, but forgot to. Finally, but most importantly, I thank Christa Bouwman who, during the last four years, helped and supported me in every possible way, which includes making detailled and thoughtful comments on the entire thesis. 


\section{Contents}

1 Introduction and Overview $\quad 7$

2 Monopoly Pricing 13

2.1 Introduction . . . . . . . . . . . . . . 13

2.2 The Standard Model . . . . . . . . . . . . . . . . 14

2.3 Some Reasons for Setting a Lower Price . . . . . . . . . 16

2.3.1 Introduction . . . . . . . . . . 16

2.3 .2 Multiple Goods . . . . . . . . . . . . . 16

2.3 .3 Limit Pricing . . . . . . . . . . . . . . . . 18

2.3 .4 Durable Goods . . . . . . . . . . . . . . 19

2.3 .5 Fairness .................... 22

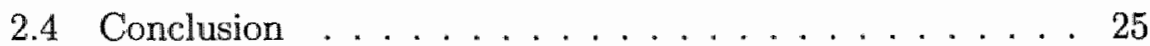

3 Limit Pricing - A Survey 27

3.1 Introduction . . . . . . . . . . . 27

3.2 Bain . . . . . . . . . . . . . . . . . . 28

3.3 Static Limit Pricing . . . . . . . . . . . . . . . . 30

3.3.1 The Bain-Sylos-Modigliani Model . . . . . . . 30

3.3 .2 Contestable Markets . . . . . . . . . . . . . . 34

3.3.3 The Harrod-Chamberlin model . . . . . . . 35

3.3 .4 Discussion . . . . . . . . . . . . 36

3.4 Dynamic Limit Pricing . . . . . . . . . . . . . . . . . 37

3.4 .1 Introduction ................. 37

3.4.2 Deterministic Dynamic Limit Pricing . . . . . . . . 38

3.4.3 Probabilistic Dynamic Limit Pricing . . . . . . . 41

3.5 The Friedman Critique . . . . . . . . . . . 43

3.6 Equilibrium Limit Pricing . . . . . . . . . . . . . . . 44

3.7 Conclusion ...................... 46 
4 Equilibrium Limit Pricing $\quad 49$

4.1 Introduction. . . . . . . . . . . . . . . 49

4.2 A Model With Two Types . . . . . . . . . . . . 50

4.3 A Model With A Continuum of Types . . . . . . . . 57

4.4 A Model With A Continuum of Types And Two-Sided Uncertainty ..................... 62

4.5 A Survey of The Literature . . . . . . . . . . 65

4.5 .1 Introduction . . . . . . . . . . . 65

4.5.2 Multiple Incumbents . . . . . . . . . . . . . 67

4.5.3 Multiple Potential Entrants . . . . . . . . 68

4.5 .4 Multiple Markets . . . . . . . . . . . . . . 68

4.5.5 Multiple Signals . . . . . . . . . . . 69

4.5 .6 Other Literature . . . . . . . . . . . . . . . 69

4.6 Conclusion . . . . . . . . . . . . . . . . 70

4.7 Appendix . . . . . . . . . . . . . . . . 71

5 Stackelberg and Cournot Competition under Equilibrium Limit Pricing $\quad \mathbf{8 1}$

5.1 Summary and Overview . . . . . . . . . 81

5.2 Introduction . . . . . . . . . . . . . 81

5.3 The Standard Model . . . . . . . . . . . . . . . 83

5.4 The Entry Deterrence Model . . . . . . . . . . . 85

5.5 Equilibrium with Cournot Competition . . . . . . . 87

5.6 Equilibrium with Stackelberg Competition . . . . . . . . . 92

5.7 Cournot and Stackelberg Compared . . . . . . . . . . 94

5.8 Conclusion . . . . . . . . . . . . . . . 97

5.9 Appendix . . . . . . . . . . . . . . . . . 97

6 Vaporware as a Means of Entry Deterrence 103

6.1 Summary and Overview . . . . . . . . . . . 103

6.2 Introduction . . . . . . . . . . . . . 103

6.3 The Model . . . . . . . . . . . . . . . . 106

6.4 Equilibrium with Perfect Information . . . . . . . . . . 109

6.5 Equilibrium with Imperfect Information . . . . . . . . . 110

6.6 Vaporware as a Means of Entry Deterrence? . . . . . . . 114

6.7 The Welfare Implications of Vaporware . . . . . . . . 116

6.8 Conclusion . . . . . . . . . . . . . 117 
7 Cruising Taxis on Hotelling's Main Street

7.1 Summary and Overview .......................... 119

7.2 Introduction . . . . . . . . . . . . . . . 119

7.3 The Model . . . . . . . . . . . . . . . . 121

7.4 Solving The Model . . . . . . . . . . . . . . . 124

7.5 The Deregulation Equilibrium . . . . . . . . . . 126

7.6 Social Welfare. . . . . . . . . . . . . . . 129

7.7 Deregulation Is Not Optimal . . . . . . . . . 130

7.8 A Numerical Example . . . . . . . . . . . . . . . 132

7.9 Discussion and Conclusion . . . . . . . . . . 133

7.10 Appendix . . . . . . . . . . . . . . 134

8 Promising Politicians, Rational Voters, and Election Out$\begin{array}{ll}\text { comes } & 137\end{array}$

8.1 Summary and Overview . . . . . . . . . . . . 137

8.2 Introduction . . . . . . . . . . . . . 137

8.3 The Candidates' Objective Function . . . . . . . . . . 140

8.4 A Maximal Support Model . . . . . . . . . . . . . . 141

8.5 A Digression: More Candidates . . . . . . . . . . . . 147

8.6 A Median Voter Model . . . . . . . . . . . . . . . . 148

8.7 Conclusion . . . . . . . . . . . . . . . 151

9 A Fairness Explanation to Intertemporal Choice Anomalies

9.1 Summary and Overview . . . . . . . . . . . 155

9.2 Introduction . . . . . . . . . . . . . . . . . . . . . . . . . . . .

9.3 A Thought Experiment . . . . . . . . . . . . 159

9.4 Fairness . . . . . . . . . . . . . . . . 162

9.5 A Formalization of the Thought Experiment . . . . . . 163

9.6 Explaining the Anomalies . . . . . . . . . . 165

9.7 Conclusion . . . . . . . . . . . . . . . . . . . 168

9.8 Appendix . . . . . . . . . . . . . . . . . . . 168

$\begin{array}{ll}10 \text { Summary and Conclusion } & 171\end{array}$ 



\section{Chapter 1}

\section{Introduction and Overview}

This thesis is based on the theory of monopoly pricing. Textbook theory tends to suggest that when a monopolist decides which price to set, he will simply equate marginal revenue and marginal cost, given a demand and cost structure. A considerable literature, however, points out that there are cases in which doing so is not necessarily the best option. This thesis gives a survey of that literature, in chapters 2 through 4 . Extensions and applications are given as well, in chapters 5 through 7 . Finally, it is shown that insights from the theory of monopoly pricing can also be applied to other fields in economics. These applications can be found in chapters 8 and 9 . The thesis thus contains a literature survey, in chapters 2 through 4 , and five separate papers. These six parts are self-contained and can be read separately. As a consequence, there is at times some overlap between the different parts.

In chapter 2 I survey the theory of monopoly pricing. I show that the basic result, a monopolist firm equating marginal revenue and marginal cost, does not always hold. Four reasons are given why this might not be the case ${ }^{\mathrm{l}}$. First, if a monopolist produces several goods that are complements, he may choose to restrain price on one good, in order to promote sales on another. Second, a monopolist may practice limit: pricing. In that case he sets a price below monopoly price to try to con-

\footnotetext{
${ }^{1}$ Throughout this thesis, the assumption is maintained that a monopoly acts as a profit maximizing entity. Therefore, theories that suggest that monopolies do not maximize profits, are not considered. For a review of these, see Holmstrom and Tirole (1989), especially section 4.5. Also, it is assumed that the monopolist cannot prevent arbitrage, and, hence, is not able to price discriminate. For more on price discrimination, see for example Phlips (1983).
} 
vince other firms that entry into this industry is not profitable. Third, if a monopolist sells a durable good, he will also be inclined to charge a price lower than the monopoly price. In this case, if the monopolist sets a high price, consumers will simply postpone their purchase, and wait until prices drop. Fourth, consumers may feel that the monopolist abuses his position. If they do, they may refuse to buy the good for the monopoly price altogether, if they feel that doing so would cause the monopolist to earn unfair profits. The monopolist is then forced to set a lower price.

In all four cases the price set by the monopolist is lower than the standard monopoly price. This does not imply, however, that welfare is always higher as a result. In the durable goods case, it is. The same holds in the multiple product case. But the net welfare effect in the fairness model is ambiguous. For limit pricing, welfare effects depend on the particular model that is used.

Chapter 3 focuses on limit pricing. The chapter surveys three strands of literature that try to model the concept. In static limit pricing models, an incumbent monopolist tries to deter entry by choosing some behavior (e.g. setting a price or a quantity) that he will not change in the future, even if entry should occur. By making such a commitment, limit pricing is possible in equilibrium. Dynamic limit pricing models assume that entry can be postponed by using a limit price. Using this assumption, the optimal dynamic pricing policy of the incumbent is derived. Both static and dynamic limit pricing models, however, suffer from one major shortcoming. In any consistent model, the behavior of both the incumbent and the potential entrant should be determined endogenously. In dynamic limit pricing this is not the case for the potential entrant's behavior. In static limit pricing models it is not the case for the incumbent's behavior. Therefore, limit pricing appears to be a phenomenon that cannot be derived as an equilibrium in a model in which both the incumbent and the potential entrant are rational maximizing agents.

Milgrom and Roberts (1982) provide a way out of this problem. Their model, and the literature that emerged from it, is discussed in chapter 4. Milgrom and Roberts introduce asymmetric information. In their model, a potential entrant is uncertain about the marginal cost the incumbent monopolist faces, whereas the incumbent himself does know how high these costs are. Suppose, for simplicity, that the incumbent can have either high or low cost. Entry is profitable if and only if the incumbent's costs are high. The incumbent will then set a price lower 
than his monopoly price, in an attempt to convince a potential entrant that the incumbent's costs are low and entry is not profitable. In chapter 4 I provide a generalization of this approach. I show that the Milgrom and Roberts model is a special case of the framework developed in this chapter. Also, using this framework greatly simplifies the discussion of the literature.

Chapter 5 is the first application, Stackelberg and Cournot competition under equilibrium limit pricing. It is a direct application of the Milgrom and Roberts limit pricing model, and shows that limit pricing can have surprising effects on the outcome of different competition regimes. It is well known that with Stackelberg competition, prices are lower than with Cournot competition. In chapter 5 I show that, in a limit pricing context, this result can be reversed. The threat of Stackelberg competition rather than Cournot competition in the post-entry period, will make entry less attractive for the potential entrant, and entry deterrence less attractive for the incumbent. Therefore, average prices, given that post-entry competition is Stackelberg, can be higher than when post-entry competition is Cournot.

Chapter 6, Vaporware as a means of entry deterrence, is another application of the Milgrom and Roberts model. In fact, it combines the theories of limit pricing and durable goods, both discussed in chapter 2 . In the computer industry, incumbent monopolists are often accused of using vaporware, the untruthul pre-announcement of a new version of their product. By claiming they have a new version, they may be able to deter entry. The model in chapter 6 shows that this can indeed be the case. In the model, the incumbent can have either of two types: he does have a new version of his product, or he does not. The monopolist uses first period quantity as a signal. Both the consumers and a potential entrant do not know which type of incumbent they face. As an additional complexity, the good produced can be durable. This is the case if, but only if, there is no new good in the next period. I show that it is an equilibrium for the incumbent always to claim that he has a new product, i.e. to engage in vaporware. This practice is shown to be anticompetitive, both when the incumbent does, and when he does not have a new version.

Chapter 7, Cruising Taxis on Hotelling's Main Street, also takes us back to the theory of chapter 2. There we saw that a monopolist, for several reasons, might be inclined to set a price much lower than the static monopoly price. In those cases, the difference between the price 
set by a monopolist and the price prevailing with perfect competition, can be much lower than standard theory suggests. Chapter 7 shows that this may also be true for exactly the opposite reason. We can have circumstances in which the price set in a market with perfect competition is much higher than standard theory suggests. Chapter 7 studies the cruising taxi market. I show that, in this market, absent entry barriers, a price results that is higher than the one that maximizes social welfare. In the rnarket equilibrium, prices are too high, and the number of taxis too low. Yet, industry profits equal zero. In this market, a regulated fare can thus be welfare enhancing.

The next chapter, Promising politicians, rational voters and election outcomes, applies the Milgrom and Roberts model to an entirely different field: that of political science. It is a well known phenomenon that in elections, politicians always promise more than they are willing or able to deliver once in office. This poses a problem for the theory of rational agents. It is hard to believe that voters can be systematically fooled into believing such promises. Indeed, there is some proof that they cannot. But then one can wonder why politicians make these promises in the first place. Chapter 8 proposes a way to resolve this paradox. In the models in this chapter, two candidates compete in an election. In equilibrium, both candidates will promise more than they deliver. Yet voters are able to rationally infer the true policy position of each candidate, and act likewise. The intuition is the same as in Milgrom and Roberts. There an incumbent firm has to incur some costs, in the form of a lower pre-entry price, in order to convince a potential entrant of his true costs, and to convince her that entry is not profitable. In chapter 8 a candidate in an election has to incur some costs, in the form of a disutility from misrepresenting her true beliefs, in order to convince voters of his her true policy position, and to convince them that they are better off voting for her.

The final chapter, A Faimess Explanation to Intertemporal Choice Aromalies, again builds on the theory described in chapter 2. There we saw that a monopolist might be forced to set a price that is not too high, if consumers refuse to buy at the monopoly price, since they will feel exploited when doing so. People are thus willing to treat someone else badly, even at a cost to thernselves, if they feel badly treated by that person. This idea of fairness is applied in chapter 9 as well, but to an entirely different field: that of intertemporal choice. When making intertemporal decisions, people often do not behave in a way consistent 
with the rational model. Typically, four anomalies are found. Implicit discount rates are much higher than relevant interest rates, where theory predicts that they should be the same. Also, discount rates decline with time to be waited, and size of the sum at stake. Finally, discount rates for speeding up a reward are lower than discount rates for delaying one. Chapter 9 shows that all these anomalies can be explained in one simple model, if we assume that an individual regards such an intertemporal choice as a division of some amount of money between his current and his future self, and behaves according to the fairness model described above.

The following general conclusions can be drawn from this thesis. First, in competition policy, it is important to make a full analysis of the industry that is considered. Just looking at the number of firms is not enough to assess welfare effects. Obviously, this insight is hardly new. Especially the literature on entry barriers argued that public policy does not have to be to concerned with monopolized industries in which entry barriers are low. But the examples given in this thesis move beyond that. In chapter 7 we have a market in which, even if entry barriers are absent, a monopoly price is set. Also, the models in chapter 2 show that there are more circumstances in which the adverse effects of monopolies are much lower than the standard monopoly model suggests.

A second conclusion is that there are circumstances in which having private information can actually hurt economic agents, rather than being to their advantage. Both in limit pricing models and in the voting model described in chapter 8 , agents have to incur costs to convince others of the information they have. In both cases, they would be better off if their private information were common knowledge. But the welfare effects of this phenomenon are ambiguous. Limit pricing is desirable from a welfare point of view, compared with a case where the incumbent does not have any private information. The discussion in chapter 4 shows that the incumbent's desire to convince the potential entrant of his private information, might just as well lead to prices that are higher than the monopoly price. In chapter 8 , a situation without private information is desirable from a welfare point of view.

Third, this thesis shows how methods and insights from industrial organization theory can also be fruitfully applied to other, non-related fields. The same mechanism that causes incumbents to set a limit price in chapter 4 , also causes politicians to lie in chapter 8 . The same mechanism that causes monopolists to set a price lower than the standard 
monopoly price in chapter 2 , also causes individual agents to act in a way inconsistent with the standard lifecycle model in chapter 9. Hence, industrial organization theory is not only relevant to industrial economists.

Summarizing, this thesis deals with the theory of monopoly pricing. A survey of the literature is given in chapter 2. The survey focuses on theories in which a price is set below the standard monopoly price. One particular theory, that of limit pricing, is considered in more detail in chapter 3 . One strand in the limit pricing literature is especially important. That strand, equilibrium limit pricing, is discussed extensively in chapter 4 . Chapter 5 and 6 contain two new applications of equilibrium limit pricing. Chapter 7 considers an opposite case. Rather than a monopolist setting a price below the standard monopoly price, we there have a market with free entry, in which a price above the standard perfect competition price is set. Chapter 8 and 9 apply two of the theories discussed in chapter 2, to other fields in economics. Chapter 8 applies equilibrium limit pricing to political science. Chapter 9 applies fairness to intertemporal choice. Finally, the thesis contains an English conclusion and a Dutch summary. 


\section{Chapter 2}

\section{Monopoly Pricing}

\subsection{Introduction}

The standard textbook model of monopoly behavior suggests that a monopolist maximizes profits by equating marginal costs with marginal revenues. He then sets a price which exceeds marginal costs, and causes a deadweight welfare loss. But such a strategy does not necessarily maximize total profits. In order to do so, a monopolist might be forced to set his price below the static profit maximizing one. There are several reasons why this might be the case. First, a monopolist producing several goods may choose to lower price for one product in order to stimulate demand for another. Second, high profits may induce entry of other firms into the industry. Third, if the monopolist produces a durable good, setting a high price may induce rational consumers to postpone their purchase, in anticipation of a future price decrease. Fourth, consumers may simply boycott a firm which charges prices that are considered to be too high.

In all these cases the monopolist is better off setting a price closer to marginal cost than the standard analysis suggests. Less obvious are the welfare effects of this result. Not in all cases considered does a decrease in price also lead to an increase in social welfare. In this chapter, I elaborate on this theme. First, the standard model is discussed, and its welfare effects examined. Then I review theories which predict that monopolists set a lower price. I also study whether this lower price is caused by a loss in market power, and whether it implies higher welfare. One of the reasons mentioned, that of limit pricing, is treated briefly in 
this chapter, but is reviewed extensively in chapters 3 and $4 . .^{1}$

\subsection{The Standard Model}

Suppose a monopoly produces a single good, for which demand is given by $q=D(p)$. Here, $p$ denotes the price of the good, and $q$ the amount sold by the monopolist. Assume the inverse of the demand function exists, and is given by $p=P(q)$. The function $P(q)$ thus gives the price the monopolist can charge when it produces an amount $q$. Costs of producing the quantity $q$ are given by $C(q)$. Profits $\Pi$ as a function of quantity produced $q$ are thus $\Pi(q)=q \cdot P(q)-C(q)$. Maximizing profits with respect to quantity, the monopolist will produce a quantity $q^{m n}$ such that

$$
P\left(q^{m}\right)+q^{m} P^{\prime}\left(q^{m}\right)-C^{\prime}\left(q^{m}\right)=0 .
$$

A more convenient we to write this condition is by using the Lerner index. Note that, since elasticity of demand is defined by $\epsilon=-\frac{\partial q}{\partial p} \cdot \frac{p}{q}$, the inverse of this elasticity can be written $1 / \epsilon=-\frac{q}{p} \cdot \frac{\partial p}{\partial q}$. Writing $p^{m}$ for $P\left(q^{m}\right)$, dividing (2.1) by $p^{m}$ and rearranging then yields

$$
\frac{p^{m}-C^{\prime}(q)}{p^{m}}=\frac{1}{\epsilon}
$$

The left hand side of (2.2) is the Lerner index. It gives the relative markup the monopolist charges, above its marginal casts. From the formula it is clear that, since $\epsilon>0$, this markup is always positive. The monopolist thus always charges a price which exceeds marginal cost. From a social welfare point of view, this is not optimal. A social optimum requires that price equals marginal cost of production, a result that would also prevail if the market was one with perfect competition. Monopolistic pricing causes a deadweight welfare loss: by charging a price which is above marginal cost, the monopolist induces a loss in consumer surplus, which is larger than the increase in profits the monopoly obtains.

In the most simple case, we have constant marginal cost $c$, and linear dernand. The inverse demand curve can then be represented as $p=$

\footnotetext{
"Note that, as mentioned in chapter 1 , it is assumed that the monopolist is a profit maximizing firm that is not able to price discriminate.
} 


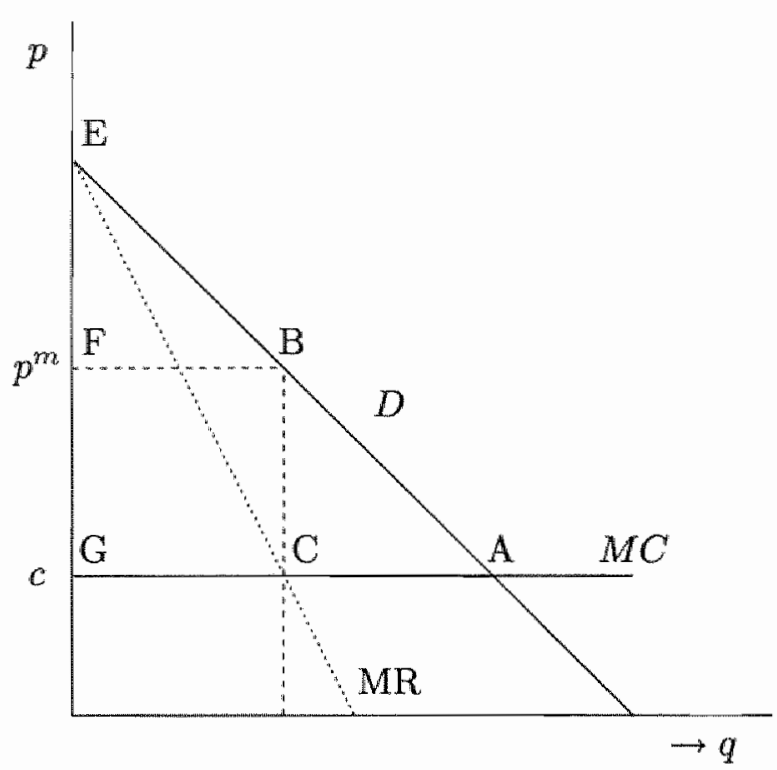

Figure 2.1: The standard monopoly model.

$a-b q$, with $a>c$ to ensure positive production. This case is represented in figure 2.1. In a competitive market, price would equal marginal cost, so market equilibrium is at point $A$, with competitive price $p^{c}=c$. Producers" profits are zero, whereas total consumer surplus is given by triangle $A G E$. A monopolist however, equates marginal revenue (given by $M R$ ) with marginal cost and thus sets a price $p^{m}=(c+a) / 2$, so market equilibrium is at point $B$. Monopoly profits therefore equal $C B F G$, and consumer surplus is given by $B E F$. Compared with a perfectly competitive market, there is a deadweight welfare loss equal to area $A B C$. From figure 2.1 it is easy to see that the closer the monopolist sets his price to marginal cost, the lower will be the deadweight welfare loss, and the higher social welfare.

We thus have the result that a static profit maximizing monopolist sets a price higher than marginal cost and in this way imposes a deadweight welfare loss on society. But a monopolist might not be able, or not be willing to maximize his profits in the way described above. In that case, he may set a price which is below $p^{m}$, which implies that the adverse effects of the monopoly are less extreme. In the next section I 
discuss some cases in which a monopolist may not fully exploit his static monopoly power by setting $p^{m}$.

\subsection{Some Reasons for Setting a Lower Price}

\subsubsection{Introduction}

The previous section described the pricing behavior of a monopolist that aims to maximize short term profits. By fully exploiting his monopoly power, he sets a price well above marginal costs of production, thus imposing a deadweight welfare loss. However, several theories have been put forward which argue that a profit-maximizing monopoly is not able to exercise market power in such a simple way. The monopolist is then forced to set a price lower than $p^{m}$ in figure 2.1. In this section I review these theories, and describe why monopolies may be willing to set a lower price than the one derived in section 2.2. First, when we have a multiproduct monopolist, it is not necessarily profit maximizing to set marginal revenue equal to marginal cost for every individual good produced. When two goods are complements, a lower price for one good increases demand for the other. Second, high prices in one period may induce entry into the industry. In order to deter entry, a monopolist may then choose to sacrifice some of his current profits, in order to maintain his position as a monopolist in the future. Third, if a monopolist produces a durable good and sets a high price initially, rational consumers will anticipate that he has an incentive to lower price in the future, and may therefore postpone their purchase. Finally, a monopolist may not be able to exploit his market power if consumers regard a monopoly price as unfair and therefore simply refuse to buy at that price altogether. The following subsections describe each of these explanations in turn.

\subsubsection{Multiple Goods}

Suppose the monopolist offers $n$ goods, rather than just one, and that he has monopoly power over each one of them. Demand for good $i$ is given by $q_{i}=D_{i}\left(p_{1}, \ldots p_{n}\right)$. Total costs equal $C\left(q_{1}, \ldots, q_{n}\right)$. Profits of the monopolist can be written $\Pi\left(q_{1}, \ldots, q_{n}\right)=\sum_{j} p_{j} q_{j}-C\left(q_{1}, \ldots, q_{n}\right)$. Maximizing profits with respect to every $p_{i}$, and using $q_{i}=D_{i}\left(p_{1}, \ldots, p_{n}\right)$, 
we obtain for every $i$,

$$
\sum_{j} p_{j} \frac{\partial D_{j}}{\partial p_{i}}+D_{i}-\sum_{j} \frac{\partial C}{\partial q_{j}} \frac{\partial D_{j}}{\partial p_{i}}=0 .
$$

Using cross-elasticity of demand $\epsilon_{i j}=\frac{\partial D_{j}}{\partial p_{i}} \cdot \frac{p_{i}}{D_{j}}$, this can be written

$$
D_{i}+\sum_{j} \frac{D_{j}}{p_{i}} \cdot p_{j} \cdot \epsilon_{i j}-\sum_{j} \frac{D_{j}}{p_{i}} \cdot \frac{\partial C}{\partial q_{j}} \cdot \epsilon_{i j}=0
$$

Collecting summation terms yields

$$
D_{i}+\sum_{j}\left(p_{j}-C_{j}^{\prime}\right) \cdot \frac{D_{j}}{p_{i}} \cdot \epsilon_{i j}=0
$$

which is equivalent with

$$
1+\frac{C_{i}^{\prime}-p_{i}}{p_{i}} \cdot \epsilon_{i}+\sum_{j \neq i} \frac{p_{j}-C_{j}^{\prime}}{p_{i} \cdot D_{i}} \cdot \epsilon_{i j} \cdot D_{j}=0 .
$$

Rearranging then yields

$$
\frac{p_{i}-C_{i}^{\prime}}{p_{i}}=\frac{1}{\epsilon_{i}}+\sum_{j \neq i} \frac{p_{j}-C_{j}^{\prime}}{p_{i} \cdot D_{i}} \cdot \frac{\epsilon_{i j}}{\epsilon_{i}} \cdot D_{j} .
$$

If the goods are complements, we have $\epsilon_{i j}<0$. From the above equation, the mark-up is lower than the Lerner index derived for the single good case in (2.2), provided that prices, quantities and markups are nonnegative. A monopolist producing several goods which are complements thus sets a price for each good which is lower than the monopoly price in the single good case. This is intuitive: with complementary goods, increasing the price of good $i$ not only decreases demand for good $i$, but also demand for good $j$. When setting a price for good $i$, the monopolist will take this adverse effect on demand for good $j$ into account, and therefore sets a price which is lower than the monopoly price in the single-good case. The negative external effect of raising prices of good $i$ on demand for good $j$ is internalized. Therefore, profit-maximizing prices will be lower.

There is ample evidence that firms do behave in this way. For example, video-game producers are known to sell their hardware even below 
marginal cost, and make their profits on selling software. Mobile-phone operators often give the phones for free, and make their profits on calls and subscriptions. If we interpret the different goods as produced at different points of time, the above analysis also allows for learning by doing. If a higher production in period 1 lowers marginal cost in period 2 , a monopolist will set a price lower than $p^{m}$ in period 1 , in order to lower costs and raise profits in period 2 (see Tirole 1988). In this case, complementarity between the two goods is on the cost side, rather than the demand side.

However, note that although in this analysis the monopolist does set a price for every good $i$ which is below the single good monopoly price $p^{\text {mb }}$, this is not caused by a loss in its market power. On the contrary: the monopolist lowers price on one of the goods it produces, in order to raise profits on another. Nevertheless, prices on both goods are lower than in the case in which we would have two monopolies, each producing one of the goods separately. Therefore, welfare in the multiproduct case is higher.

\subsubsection{Limit Pricing}

A firm which has a monopoly, may not be able to exercise monopoly power, if entry into the industry is possible. If setting a monopoly price $p^{m}$ induces entry, a monopolist may be better off setting a price $p^{l}<p^{m}$, if that price deters entry. Here, $p^{l}$ is called the limit price, a term coined by Bain (1949).

Suppose an incumbent firm has a monopoly, but a potential entrant can enter in the next period. Upon entry, the potential entrant has to incur some fixed costs $F$. Suppose there is a limit price $p^{l}<p^{m}$ such that the potential entrant will enter if and only if the incumbent firm sets a price $p>p^{l}$. The incumbent firm decides which price to set by comparing profits from setting $p^{m}$ in the first period and inducing entry, with profits of setting $p^{l}$ in the first period and deterring entry. If the latter is higher, it will set the limit price $p^{l}$, and deter entry by setting a price which is lower than monopoly price.

There are several reasons why such a $p^{l}$ can exist. If the potential entrant believes the incumbent will not change output upon entry, then a lower pre-entry price implies a higher output of the incumbent firm both before and after entry takes place. If that quantity is such that the entrant cannot earn a profit given the residual demand it faces, 
entry is deterred. In that case, the limit price $p^{l}$ is the price such that dernand in the first period just equals that quantity (see Modigliani 1958). Also, if the potential entrant is uncertain about the profits she ${ }^{2}$ makes when she enters, the price she observes may influence her entry decision. For example, when observing a low price, a potential entrant may conclude that the industry is not a very profitable one, so entry is not attractive. Alternatively, she may conclude that the incumbent firm is able to produce very efficiently, so entry is not profitable (see Bain 1949). This idea is formalized by Milgrom and Roberts (1982).

With a limit price, a monopoly cannot exercise market power, since he is constrained by potential, rather than actual entry. As its most extreme form, we have the theory of contestable markets (see for example Baumol (1982)). In that case sunk costs of entry are zero, information is perfect, and the incumbents' price cannot be changed when entry occurs. The monopoly then loses all of its market power and, in case there are no increasing returns to scale, sets price equal to marginal cost.

The theory of limit pricing thus suggests that under some circumstances, monopolists are not maximizing long-term profits if they set the static monopoly price, and are therefore not able to exercise their market power fully. However, several versions of the theory exist, and there is also a lot of criticism on the concept as well. In order to assess the welfare effects of limit pricing, we therefore have to study these models in more detail. In chapters 3 and 4 , I give a survey of the literature on limit pricing.

\subsubsection{Durable Goods}

Coase (1972) argued that a monopolist may not be able to exercise market power when producing a durable good. The argument is as follows. Suppose a monopolist produces a good with infinite durability. Demand for the services provided by the good is known and constant through time. Initially, the monopolist simply equates marginal revenues and marginal costs, setting the static monopoly quantity. For the sake of argument, assume that every consumer with a valuation higher than or equal to the monopoly price, will purchase the good. Since the goods sold have infinite durability, the monopolist is then faced with a residual demand curve $D(p)-q^{m}$. He can earn some additional profit by setting

${ }^{2}$ As a convention throughout the remainder of this thesis, I will refer to the in cumbent as being male, and the potential entrant as being female. 
a new, lower price, which maximizes profits given the new downward shifted residual demand curve he now faces. This process continues until price equals marginal cost.

But this story assumes that consumers are very naive, especially the ones with a high valuation for the product who already buy it in the first period. They can easily foresee that the price will drop substantially in the next period, yet they purchase the good now. If consumers are rational, they will anticipate the future price cut, and will not pay the monopoly price in the first place. Coase conjectured that in the most extreme case, if production is instantaneous, and price changes can occur in an infinitely short time period, the monopolist is not able to exercise market power whatsoever, and will set price equal to marginal cost. The conjecture was proven by Stokey (1981). Bulow (1982) used a simple two period model in which the argument can also be illustrated. His model is the following.

Suppose there are two periods in which a durable good can be sold. Inverse demand for the services provided by the good equals

$$
p=a-b Q
$$

with $Q$ the total stock of the good. The monopolist has to decide which amount $q_{1}$ and $q_{2}$ to sell in period 1 and 2. Assume for simplicity that costs of production are zero, and solve the model using backwards induction. First, suppose the monopolist has sold an amount $q_{\mathbb{1}}$ in period 1. Because of (2.8), inverse demand in period 2 equals $p=a-b\left(q_{1}+q_{2}\right)$, hence second period profits are maximized when setting

$$
q_{2}=\frac{1}{2 b}\left(a-b q_{1}\right)
$$

Now consider the first period. The price consumers are willing to pay in period 1 equals whatever they are willing to pay for the use of the good in period 1 , plus the discounted expected resale value in period 2 : $p_{1}=a-b q_{1}+\delta p_{2}$, with $\delta$ a discount factor. Using (2.9) we can find

$$
p_{2}=\frac{1}{2}\left(a-b q_{1}\right)
$$

hence we have

$$
p_{1}=\left(1+\frac{\delta}{2}\right)\left(a-b q_{1}\right)
$$


Total discounted profits equal

$$
\Pi_{S}=p_{1} q_{1}+\delta p_{2} q_{2}=\left(1+\frac{\delta}{2}\right)\left(a-b q_{1}\right) q_{1}+\frac{\delta}{4 b}\left(a-b q_{1}\right)^{2}
$$

using (2.9) through (2.11). Maxirnizing with respect to $q_{1}$ yields

$$
q_{1}=\frac{2 a}{b(4+\delta)}
$$

yielding profits

$$
\Pi_{S}=\frac{(2+\delta)^{2} a^{2}}{4 b(4+\delta)} .
$$

When the monopolist would be able to set monopoly quantity in both periods, for example by renting rather than selling his output, we would have $q_{1}=q_{2}=\frac{1}{2} \frac{a}{b}$, yielding profits

$$
\Pi_{R}=\frac{(1+\delta) a^{2}}{4 b} .
$$

For $\delta>0$ we thus have $\Pi_{R}>\Pi_{S}$ : profits from selling a durable good are lower than in case the monopolist is able to set monopoly price in both periods. For price, note that a consumer who uses the good in both periods pays a total discounted price of

$$
p_{R}=\frac{1}{2}(1+\delta) a,
$$

when the monopoly rents the good and, from (2.11) and (2.13),

$$
p_{S}=\frac{2+\delta}{4-\delta} a
$$

if the monopolist sells. Hence $p_{S}>p_{R}$ for $\delta \in(0,1)$.

In this model, the monopolist's market power is constrained by rational consumers, rather than by potential entrants, as was the case in the previous section. Note that in this case also, the necessity to set a lower price entails a loss in the monopolist's market power, and an unambiguous increase in total welfare. The monopolist's problem is that he cannot credibly commit not to lower price after he has set the monopoly price $p^{m}$. It is in his own (a priori) interest to stick to $p^{m}$, but 
after he has set this price, has sold $q^{m}$ and faces the residual demand curve, the monopolist has an incentive to lower price anyway. Therefore, the initial promise not to lower price is not credible. This problem can be solved by only leasing the good. In that case, the monopolist can credibly commit not to decrease price in the future, since in this case such a decrease would be to his own disadvantage.

\subsubsection{Fairness}

Apart from durable goods, there is another way in which consumers might constrain the monopolist's possibility to exploit its market power. Kahneman, Knetsch, and Thaler (1986) claim that in market transactions, agents are not only motivated by economic considerations, but also by notions of fairness: by how fair they feel treated by other agents. They use surveys to illustrate this. In these surveys, respondents regard monopolists who exploit market power as being highly unfair. For example, a grocery store which sets a higher price in communities where it does not face any competition, is regarded as being unfair by $77 \%$ of all respondents. People apparently view economic agents as being entitled to a reference profit. Firms are "allowed" to increase prices in order to protect that reference profit, but increasing prices in order to earn a profit which is higher than that reference profit, is considered unfair.

How people feel about firms charging monopoly prices is one thing, but it is more important if people are also willing to punish behavior they regard as being unfair, even at a cost to themselves. Only in that case will this feeling of fairness, or lack of fairness, influence monopoly behavior. Kahneman, Knetsch and Thaler argue that this is exactly the case. A well-known example is behavior in experimental ultimatum garnes (for a selective survey, see Thaler 1988). In an ultimatum game player 1 receives a certain amount of money, of which he has to offer part to player 2. Player 2 can choose either to accept or reject the offer. If she accepts, she receives the offer and player 1 can keep the rest of the amount. If she rejects, both players receive nothing. Naturally, the rational way to play this game is for player 1 to make the smallest possible offer, and for player 2 to accept. However, in experiments player 1 's average offer turns out to be much higher, and player 2 is often willing to reject a positive offer. Thus, apparently people are willing to hurt people who are hurting them, even at a cost to themselves.

This notion of fairness is formalized by Rabin (1993). He models 
players' payoffs in such a way that they get extra utility from being nice to someone who is being nice to them, but also from being nasty to someone who is being nasty to them. Players are making a tradeoff between material payoffs and payoffs out of faimess considerations. If this behavior is relevant in real market transactions, a monopolist is restricted in exercising market power. Suppose consumers consider monopoly prices as being unfair, and are willing to punish a monopolist setting them, even at their own costs. In that case, the monopolist might be forced to set a lower price, in order to induce consumers to buy the good.

Rabin (1993) models fairness as follows. Consider a two-player normal form game with pure strategy sets $A_{1}$ and $A_{2}$. Let $\pi_{i}: A_{1} \times A_{2} \rightarrow \mathbf{R}$ be player $i$ 's material payoff. The strategies actually chosen by the two players are given by $a_{1}$ and $a_{2}$. Player $j$ 's belief about what strategy player $i$ is choosing, is denoted by $b_{i}$. Finally, $c_{i}$ represents player $i$ 's beliefs about what player $j$ believes player i's strategy is. Obviously, in any equilibrium $a_{i}=b_{i}=c_{i}, i=1,2$. Player $i$ 's kindness to player $j$ is defined as

$$
f_{i}\left(a_{i}, b_{j}\right)=\frac{\pi_{j}\left(b_{j}, a_{i}\right)-\pi_{j}^{e}\left(b_{j}\right)}{\pi_{j}^{h}\left(b_{j}\right)-\pi_{j}^{\min }\left(b_{j}\right)}
$$

Here, $\pi_{j}^{\min }\left(b_{j}\right)$ is the payoff player $j$ gets if player $i$ takes the action that minimizes $j$ 's payoff, given $i$ 's belief that $j$ is playing $b_{j}$. It thus represents the minimum $i$ can "give" to $j$, given $b_{j}$. Similarly, $\pi_{j}^{h}$ is the highest amount $i$ can give, $\pi_{j}$ is what he actually gives, and $\pi_{j}^{e}\left(b_{j}\right)$ is some reference point against which to judge whether or not player $i$ is treating player $j$ kindly. If $i$ gives $j$ more than her "share" (thus: $\pi_{j}^{c}$ ), the numerator of (2.17) is larger than zero, and player $i$ treats player $j$ "kind". If, on the other hand, $i$ gives $j$ less than her share, the numerator is negative, and $i$ is treating $j$ "unkind". Rabin chooses $\pi_{j}^{e}\left(b_{j}\right)$ as the average of $\pi_{j}^{h}\left(b_{j}\right)$ and $\pi_{j}^{l}\left(b_{j}\right)$, the latter being the lowest pay-off $j$ can receive among points that are Pareto-efficient. For this specification of $\pi_{j}^{e}$ it can be shown that we always have $f \in\left[-1, \frac{1}{2}\right]$.

Player $i$ 's behavior is partly determined by how he thinks player $j$ treats him. Player $i$ 's belief about how kind player $j$ is treating him is defined in a similar way to $(2.17)$, as $\tilde{f}_{j}\left(b_{j}, c_{i}\right)$. Given their shared notion of fairness, and given $b_{j}$ and $c_{i}$, each player $i$ chooses $a_{i}$ to maximize 
expected utility, given by

$$
U_{i}\left(a_{i}, b_{j}, c_{i}\right)=\pi_{i}\left(a_{i}, b_{j}\right)+\tilde{f}_{j}\left(b_{j}, c_{i}\right) \cdot\left[1+f_{i}\left(a_{i}, b_{j}\right)\right] .
$$

The first term on the right hand side is the material payoff to player $i$. The second term represents additional utility out of fairness considerations. Note that player $i$ receives additional utility from treating player $j$ kindly $\left(f_{i}>0\right)$ if and only if he believes that player $j$ is treating him kindly as well $\left(\tilde{f}_{j}>0\right)$. But if player $i$ bellieves player $j$ is treating him badly $\left(\tilde{f}_{j}<0\right)$, then he wishes to treat player $j$ badly as well $\left(f_{i}<0\right)$. Additional utility from fairness in that case is non-positive. Another implication of this specification is that fairness considerations become less important as the amount at stake $\left(\pi_{i}\right)$ increases: since $f_{i}$ and $\tilde{f}_{j}$ are always in the interwal $\left[-1, \frac{1}{2}\right]$, their relative weight decreases as $\pi_{i}$ increases. A fairness equilibriurn is a Nash equilibrium in which both players maximize (2.18) given the action of the other player, and beliefs are fulfilled.

One implication of this model is that if a monopolist charges a price which is unfair, consumers are not willing to pay their valuation of the good. Suppose a monopolist has constant marginal cost $c$, and consumers value the product at $v$. If both make a simultaneous take-it-orleave-it offer, Rabin shows that for his definition of fairness, the highest price consistent with fairness equilibrium is ${ }^{3}$

$$
p=\left[2 v^{2}-2 c v+c\right] /[1+2 v-2 c],
$$

\footnotetext{
${ }^{3}$ This can be seen as follows. First, note that the monopolist has to decide on a price $p$ to ask, and a consumer on a maximum price for which he is willing to buy the good. If $p \leq r$ the good is sold at price $p$. With $p>r$ there is no sale, and payoffs are 0 for each player. First consider the strategy of the consumer. Given the monopolist sets $p$, the choice of the consumer gives the monopolist material payoff of either $p-c$ or 0 . With $r \geq p$, the consumer is maximizing both players" payoffs, so $f_{C}(r, p)=0$. With $<p$, the consumer is minimizing the monopolist's payoff, hence $f_{C}(r, p)=-1$. This implies that the monopolist will never feel positively towards the consumer, so $r>p$ cannot be an equilibrium. The only possibility for an equilibrium with trade is therefore $p=r$. Next consider the monopolist's strategy. Given that the consumer will set $r$ equal to some $z$, the only equilibrium with trade has $p=r=z$. If the monopolist follows this strategy, we have $\pi_{C}(z, z)=v-z, \pi_{C}^{h_{n}}=v-c, \pi_{C}^{l}=v-z, \pi_{\text {rnin }}=0$, so $f_{M}(z, z)=[c-z] / 2[v-c]$. To see whether $p=r=z$ is a fairness equilibrium for some $z$, we have to check whether the consumer would deviate by setting $r<z$. Using (2.18), total utility from doing so is $U_{C}=0+f_{M}(z, z) \cdot[1+-1]=0$. Setting $r=z$ yields total utility $U_{c}=(v-z)+f_{M}(z, z) \cdot[1+0]=(v-z) / 2[v-c]$. Equating the two and solving for $z$ yields the highest price consistent with faimess, which is $(2,19)$.
} 
which is clearly lower than the monopoly price $v$, since we necessarily have $v>c$.

We can use Rabin's case of one buyer and one seller to a generalized demand curve in the following way. Assume the demand curve represents for each consumer his valuation for 1 unit of the good. Furthermore, suppose the price the monopolist sets is interpreted as an individual take-it-or-leave-it offer. We can then use (2.19) to transpose the general demand curve to the demand curve in case the supplier is a monopolist, considered by consumers as being prone to unfair behavior. In the simplest possible case, with $v=1-q$, and $c=0$, we have for the monopolist's demand curve $p=\frac{2(1-q)^{2}}{1+2(1-q)}$. Solving for the monopoly price then yields, after some tedious algebra, $p=0.322$, and $q=0.406$, so profits equal 0.1309 . A monopolist unconstrained by consumers' idea of fairness would be able to set $p=0.5, q=0.5$ and $\pi=0.25$. The price he can set in this case is thus lower. Note that although price is lower in the fairness equilibrium, quantity also is. In the fairness equilibrium some exchanges, which are efficient from a standard economic point of view, do not take place.

Considerations of fairness can thus restrict the market power of a monopolist. There is a lot of informal evidence for this type of behavior. Firms which are making profits that are considered unreasonably high, are often regarded unfavorably. This might ultimately affect consumer loyalty, and thus sales. Also, firms that do not comply with certain social norms, run the risk of a consumer boycott. Fairness considerations thus do restrict market power. However, this does not necessarily mean that total welfare is higher. A consumer "punishing" a monopolist for treating him unfair, will still obtain negative utility from being treated that way ${ }^{4}$. Therefore, the net effect on welfare, compared to the standard monopoly case, is ambiguous.

\subsection{Conclusion}

In this chapter I discussed the standard model of monopoly behavior, which predicts that monopolists charge a high price in order to exploit their market power. However, some arguments were given why monopo-

\footnotetext{
${ }^{4} T$ This can be seen from (2.18). The second term on the right-hand side reflects total utility from the way both players are treating each other. If they treat each other badly, wave $\tilde{f}_{j}, f_{i}<0$, hence the second term is negative.
} 
lists might set a lower price than the one predicted by this model. First, if a firm produces several goods, he has to take into account how the price-setting of one good influences demand for the other. Second, high prices might induce entry, eroding longer term profits. Third, a durable goods monopolist might not be able to exploit his market power if consumers rationally postpone their purchase, anticipating lower prices in the future. Fourth, a monopolist might not be able to exploit market power, simply because consumers consider it unfair and act likewise.

In every case considered prices are lower than the static monopoly price. But this does not necessarily imply that profits are lower and total welfare is higher as a result. In the multiple goods case prices on both goods are lower than in the case they were produced by two different monopolies. Thus, welfare is higher. In the fairness case the effect on welfare is ambiguous, since we also have to take into account how welfare is affected by feelings of being treated unfair. In the durable goods case there is an increase in welfare. In a pure monopoly case, in which output can be rented, welfare is unambiguously lower than in the case of a monopolist constrained in the way described in section 2.3.4.

For limit pricing models, the picture is less clear. A host of limit pricing models does exist, and the welfare effects are highly dependent on the particular model that is used. Therefore, the next chapter reviews these limit pricing models. It gives a broad overview of the different types of models that try to explain limit pricing. One of those strands, the models based on Milgrom \& Roberts (1982), is considered in more detail in chapter 4 . 


\section{Chapter 3}

\section{Limit Pricing - A Survey}

\subsection{Introduction}

In the previous chapter I discussed the basic monopoly model, in which a monopolist sets price such that marginal revenues equal marginal costs. I also considered several theories which explain why monopolist firms might be inclined to set a lower price. One of those theories is that of the limit price. It predicts that monopolist firms will set a price lower than the one which maximizes profits, if doing so deters entry. By setting a limit price the monopolist sacrifices current profits in order to increase future profits, leaving him with fewer future competitors ${ }^{1}$.

In this chapter I review the theory of limit pricing. The survey starts with the first mention of the concept, in Bain's (1949) classic article, and discusses the attempts which have consequently been made to formalize the notion. The first one is Modigliani (1958), who combines the work of Bain (1956) and Sylos (1957), in a simple but influential model. That model is discussed in section 3.3. In the same section I discuss contestable market theory, which is closely related to Modigliani's limit price model. Both models have in common that, initially, the incumbent makes a decision, after which a potential entrant can enter. She assumes that the incumbent will not change his behavior upon entry.

A different strand of literature assumes that the behavior of the potential entrant is exogenously given, and the incumbent behaves as to maximize his profits, given her behavior. Section 3.4 reviews this lit-

\footnotetext{
${ }^{1}$ As noted earlier, $I$ will refer to the incumbent as being male, and the potential entrant as being femalie.
} 
erature. Papers in this area assume either that the potential entrant's behavior is known, or that it is subject to some uncertainty. The most influential papers include Gaskins (1971) and Kamien \& Schwartz (1971). What these models have in common is that the incumbent is a rational, maximizing agent, whereas the potential entrant's behavior is exogenously imposed. Therefore, they do not give an explanation as to why a limit price would exist. Limit pricing is not derived as an equilibrium, but assumed from the outset, and used to derive the optimal behavior of the incumbent. Friedman $(1979,1981)$ has criticized this approach. He shows that limit pricing cannot be an equilibrium if the post-entry profit functions are known, as is the case in the models considered so far. If this is the case, prices do not carry any information. They can be changed instantly should entry occur. Hence, limit pricing cannot be an equilibrium. This point is elaborated upon in section 3.5 .

In section 3.6 models are considered in which both the incumbent and the potential entrant are behaving as rational, maximizing agents. Milgrom \& Roberts (1982) show that limit pricing can occur if the marginal costs of the incumbent are private information, but a potential entrant can observe price and quantity set in the market. The incumbent will then set a price lower than his monopoly price, to try to convince the potential entrant that he has low marginal cost and entry is not profitable. The next chapter deals with the Milgrom \& Roberts model more extensively, and discusses criticisms and extensions of that particular limit pricing model.

\subsection{Bain}

In his 1949 article (Bain 1949) Bain introduced the limit price as "the highest common price which the established seller(s) believe they can charge without inducing at least one increment to entry" 2 . Bain argued that in some industries, notably cigarettes and steel, there is evidence

"of prices held persistently over many years within a range where the industry demand curve is evidently inelastic, the corresponding marginal revenue thus being negative and necessarily below long-run marginal cost. This indicates a prolonged tendency to hold price well below the level which

\footnotetext{
${ }^{2}$ Bain (1949), p. 454.
} 
would maximize the difference between aggregate revenue [...] and aggregate cost."3.

There are several reasons why established firms may choose to do so. According to Bain, the most compelling of these is that they try to deter the entry of new firms into the industry. Bain assumes there is some price above which entry will occur, and below which entry will be deterred. He refers to that price as the limit price.

It is important to note here that, different from later formalizations, Bain does not assume that the current price necessarily reflects profitability of the industry, or conditions that will prevail after entry has occurred. The potential entrant does take into account that the incumbent might simply try to fool her and set a low price in an attempt "to "bluff" [her] away from the industry"

Current price or profit in the industry need play no direct role, since the anticipated industry price after entry and the entrant's anticipated market share are the strategic considerations. And if [s] he knows the industry demand with reasonable certainty and makes calculations concerning the conditions of rivalry after [her] entry, upon which [s] he is willing to act [s] he might look entirely past any current price set by the established firm. [...] Even if [s] he does not believe the observed price will remain there for [her] to exploit, [s] he may nevertheless regard this price as an indicator both of the character of industry demand and of the probable character of rival policy after [her] entry" 5

Obviously, monopolists not always use their limit price to deter entry. Sometimes the limit price is even higher than the monopoly price. In that case, the incumbent monopolist can simply set his monopoly price, without inducing entry. This is the case of blockaded entry ${ }^{6}$. Alternatively, the limit price may be so low that, rather than setting the limit price and deterring entry, it is more profitable to set the monopoly price and induce entry. This is called ineffectively impeded entry. The

\footnotetext{
3 op. cit., p. 448 .

${ }^{4}$ op. cit., p. 452 .

${ }^{5}$ op. cit., p. 453 .

${ }^{6}$ See Biain (1956).
} 
case in which the limit price is set, is referred to as effectively impeded entry.

Bain thus argues that in an industry where firms have market power, prices are not necessarily set to maximize current industry profits. Setting a lower price may hurt current profits, but may increase future profits if setting such a price deters entry. Since Bain's contribution, a lot of effort has been put in trying to formalize this notion. One family of models imposes entrants to believe that the incumbent will set some strategic variable, which cannot be changed should entry occur. In Modigliani (1958) potential entrants assume the incumbent cannot change his quantity should entry occur. This allows the incumbent to set a limit price. Baumol et al. (1982) assume the incumbent cannot change his price should entry occur. This forces the incumbent to set price equal to marginal cost, thus setting a limit price at which profits are zero. Finally, Harrod (1952) assumes a potential entrant expects that after entry, she will get a market share equal to $1 / N$, with $N$ the number of firms in the market. These theories are discussed in more detail in the next section.

\subsection{Static Limit Pricing}

\subsubsection{The Bain-Sylos-Modigliani Model}

Modigliani (1958), in a combined review of both Bain (1956) and Sylos (1957), proposes a simple model to derive the limit price. He observes, as Bain also does, that there is an inherent problem in analyzing a limit price: the theory predicts that potential entrants will be influenced by the current price in making their entry decision, yet the price that ultimately determines whether entry is profitable or not, is the price that will prevail after entry. Nevertheless both Bain and Sylos

"[...] have wisely refused to be stopped by this difficulty. They have instead proceeded to explore systematically the implications of the following well-defined assumption: that potential entrants behave as though they expected existing firms to adopt the policy most unfaworable to them, namely the policy of maintaining output while reducing the price to 
the extent required to enforce such an output policy 7,8 .

This assumption is referred to as the Sylos postulate: potential entrants thus assume that, once they enter, the incumbent firms will not change their output. This enables the incumbents to set their pre-entry quantity strategically, such that it is just not profitable for the potential entrant to enter.

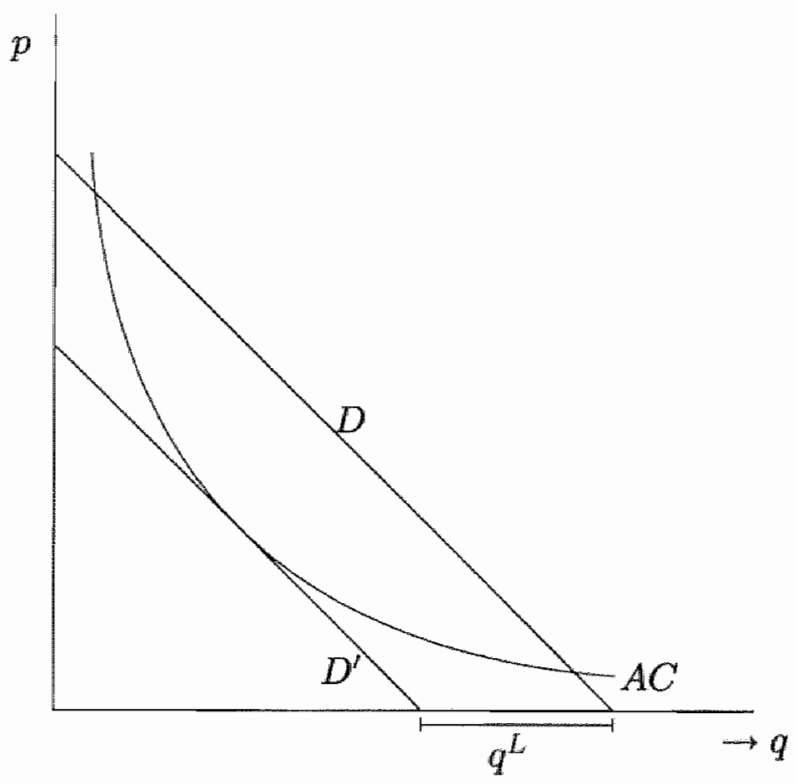

Figure 3.1: The Bain-Sylos-Modigliani Limit Price

Figure 3.1 shows how this is done. In this figure, $D$ represents industry demand, whereas $A C$ represents the average cost curve of a potential entrant. If the potential entrant has the same cost structure as an incumbent firm, then $A C$ also represents the average cost curve for the

\footnotetext{
${ }^{7}$ Modigliani (1958), p. 217.

${ }^{8}$ Obviously, this policy is not the most unfavorable to entrants that the incumbent can choose, opposite to what Modigliani indicates. For the entrant, it would be much more unfavorable if the incumbent would expand output if entry occurred. Of course, such a policy would not be subgame perfect, but the Sylos postulate isn't either. Modigliani's claim does holl if we make the additional assumption that the incumbent has to install his capacity when choosing first period output and capacity cannot be expanded should entry occur.
} 
incumbent(s). Figure 3.1 suggests increasing returns to scale. This can be interpreted, for example, as a case with constant marginal cost of production, but positive fixed cost upon entry. I will use this interpretation extensively later in this chapter and thesis. With this interpretation, the incumbent has already incurred the fixed entry cost, so only his marginal costs are relevant for his current decision.

The potential entrant assumes that any quantity $q$ the incumbent sets pre-entry, will be maintained once she has entered. The incumbent, knowing this, can then set $q$ to deter entry. For any $q$ set by the incumbent, the residual demand curve for the potential entrant can be obtained by horizontally subtracting from industry demand the quantity set by the incumbent. In figure 3.1 , if the incumbent sets $q^{L}$, residual demand for the potential entrant is given by $D^{\prime}$, which is always at or below the potential entrant's average cost curve $A C$, hence the potential entrant cannot make any profits upon entering the market. Therefore $q^{L}$ is the limit quantity and the limit price $p^{L}$ can be found using the industry demand curve $D$.

Again we have that the incumbent does not necessarily set the limit price: it might be more profitable to set monopoly price and induce entry, rather than to set a limit price and deter it. Alternatively, the limit price derived in this way may be higher than the monopoly price, in which case entry will also be deterred when setting monopoly price.

Note that this model is closely related to the Stackelberg model. The Stackelberg leader, which is the incumbent in this context, first sets a quantity. The follower, here the potential entrant, then reacts. Both firms are quantity setters, and price is determined on the market, given demand and total quantity produced. The only difference with the standard Stackelberg analysis is that in this model, the leader has the explicit possibility to set a quantity such that it is optimal for the follower to set $q=0$.

Some early authors also consider the effect of more potential entrants on the limit price in a Modigliani framework. Sherman \& Willett (1967) claim that an increase in the number of potential entrants will weaken the threat of entry. Their argument is the following. Suppose one firms considers entry. The limit price (in the sense of Modigliani) is given by some $p_{1}$. Therefore if one firm enters when the incumbent sets this price, then the potential entrant will will just earn zero profits. Now suppose there are two firms considering entry. If two firms would enter, and pre-entry price was $p_{1}$, both would necessarily incur a loss upon 
entry. Therefore, with two potential entrants, a higher limit price can be set. Suppose that at price $p_{2}$, both firms could enter and just break even. Obviously, $p_{2}>p_{1}$. The actual limit price in the case of two potential entrants depends on how both react on each other's presence. Sherman and Willett argue that this limit price will always be in the interval $\left[p_{1}, p_{2}\right]$. This yields the counterintuitive result that having more potential entrants adversely affects welfare: the higher the number of potential entrants, the higher the limit price an incumbent can set.

Goldberg \& Moirao (1973) try to restore the original intuition by introducing uncertainty for the incumbent firm. Rather than a strict limit price $p_{1}$ above which entry is certain to occur, and below which entry will certainly not occur, Goldberg \& Moirao assume that preentry price will only determine the probability that a firm will enter. Obviously, this probability is increasing in $p$. Their argument then boils down to the following. Suppose that, at some price $p$, each potential entrant enters with probability $a$. If there are two potential entrants, the probability that no entry occurs then equals $(1-a)^{2}$. With one entrant, this probability equals $1-a$. Since $0<a<1$, we always have $(1-a)^{2}<(1-a)$. Therefore, in the case there are more potential entrants, the probability that entry occurs will always be higher, and therefore the incumbent will be inclined to set a lower pre-entry price. An increase in the number of potential entrants then reduces the preentry price, which confirms the original intuition.

However, one flaw in this argument is that the probability that of entry for one potential entrant, $a$, does not depend on the total number of potential entrants. This seems a strange assumption. In a proper gametheoretic anallysis, all potential entrants will use a mixed strategy to decide whether or not to enter. If more potential entrants are considering entry, the probability that one of them will, decreases.

A small literature has emerged that considers this possibility. Dixit and Shapiro (1986) argue that both potential entrants are likely to use a mixed strategy in which they enter with some endogenously determined probability. Nti (1989) uses the same approach to show that the probability of entry then decreases with the number of potential entrants, a result in line with Sherman \& Willett (1967). Farrell (1987) shows that the coordination problem between the potential entrants can be alleviated if they use cheap talk. Hence in that case Nti's result is weaker. All these models only consider the coordination problem of the potential entrants and not the effect on the limit price. 


\subsubsection{Contestable Markets}

In the early eighties, Baumol, Panzar \& Willig (1982) proposed the theory of contestable markets, presented as an "uprising in the theory of industry structure" (Baumol, 1982). They argue that under ideal circumstances, i.e. in a perfectly contestable market, even a monopolist cannot make any profits. If he sets a price higher than total average cost, a potential entrant will enter the market. She can make a profit by setting prices slightly lower than the incumbent, and exiting the market before the incumbent firm can react. The only way in which he can prevent such "hit-and-run entry" is by equating price with average costs, thus making zero profits. With more than one incumbent firm, this logic implies that price will also equal marginal cost. In that case, the market outcome is the same as in a perfectly competitive market. The limit price then equals marginal cost.

The assumptions for this story to hold, however, are rather strict. First, entry has to be "absolutely free, and exit absolutely costless" 9 , in other words, sunk costs of entry have to be zero. There cannot be any costs upon entry which the potential entrant is not able to recover when exiting the market. Only in this case hit-and-run entry is possible. For contestable markets as a theory of limit pricing, however, this assumption is not crucial. If potential entrants have to incur sunk costs $F$ upon entry, then that simply implies that the incumbent firms can make a profit of up to $F$ without inducing hit-and-run entry. In that case, the limit price is thus somewhat higher than marginal cost.

A more crucial assumption is that potential entrants assume the incumbents will not change their price once entry has occurred. According to the theory of contestable markets, a potential entrant can set up a firm of her own, start producing, set a lower price than the incumbent does, whereafter consumers will notice that the entrant sets a lower price and will go to the entrant to buy their goods, and all this will happen before the incumbent is willing or able to lower his price. This seems even less plausible than the Sylos postulate, which requires incumbent firms not to change their quantities should entry occur. In fact, Modigliani already dismissed the possibility in his 1958 article $^{10}$ :

$[\ldots]$ the $[\ldots]$ assumption that existing firms will adopt a policy of maintaining price, by contracting their output, would

${ }^{9}$ Baumol (1982), p. 3 .

${ }^{10}$ Modigliani (1958), p. 230. 
generally be a rather foolish one for the entrant to make. It implies that established firms will graciously allow the entrant to carve out for [her]self whatever slice of the market [s he pleases, while suffering losses on two accounts: (1) by losing sales and (2) by incurring a higher average cost, at least in the short run and possibly even in the long run, if their original plant was of no more than optimal size.

Other criticisms have been raised against the theory of contestable markets as well. A lengthy review can be found in Martin (1993), chapter 11 .

In the previous subsection, I observed that the Bain-Sylos-Modigliani model can be seen as a variation on the Stackelberg model with quantity setting. In a similar way, the theory of contestable markets boils down to a Stackelberg model with price setting. First the incumbent, as a Stackelberg leader, sets his price. After that, the potential entrant decides on her price. Therefore, it is obvious that the leader cannot set a price which yields positive profits. Essentially, the model is one of Bertrand pricing, the only difference being that the incumbent cannot: react when he is being undercut.

\subsubsection{The Harrod-Chamberlin model}

A final possibility I discuss here, is for the potential entrant to suppose that, after she has entered, she will obtain the same market share as the incumbent firms, whereas prices will not change. This assumption is made by Harrod (1952), but also studied by Bain (1956). Given that the potential entrant assumes this, we can again derive how the incumbent has to behave in order to just deter entry. With $N$ incumbents, they simply have to set a price $p^{L}$ such that it just equals average costs of a potential entrant who is to produce a quantity equal to $1 /(N+1)$ times industry demand at that price ${ }^{11}$ (see Shupp 1986).

The model can be easily adapted to allow for differentiated goods. In that case, a potential entrant has some leeway to set her own price, but again the incumbents can set a price such that entry is just not profitable. This version of the model thus closely resembles Chamberlin's

\footnotetext{
${ }^{11}$ Note that, different from the theory of contestable markets, the incumbents in this model still earn positive profits when setting a limit price, if there are increasing returns to scale.
} 
(1933) model of monopolistic competition. In that model, firms produce differentiated products and there is free entry until prices equal average cost. In the limit-pricing version of this model entry will occur until the incumbents are able to set a price such that, if another entrant were to enter, she would not make any profits, given the current price in the industry.

\subsubsection{Discussion}

All models described in this section try to derive the limit price. Yet they all struggle with the same problem: to decide what will happen once entry occurs, or rather, what the potential entrant will expect to happen post-entry. All models make ad-hoc assumptions on this. Modigliani, using the Sylos postulate, assumes the incumbent will simply stick to his output once entry occurs. Models using more potential entrants make the same assumption. Baumol et al. assume he will stick to his preentry price. Harrod makes the assumption that a potential entrant will obtain a market share identical to that of the incumbents. All these assumptions suffer from the same shortcoming. In the game described, limit pricing is not a subgame perfect equilibrium ${ }^{12}$. In Modigliani, once entry has occurred, the incumbent has an incentive to change his quantity after all, since by doing so he can increase his profits, given that entry has occurred. The threat to stick to the old $q$ is not credible. In Baumol et al. the incumbent will also be inclined to react once entry has occurred. Here, it is not even obvious why, even if the incumbent were able to commit not to change his price when entry occurs, he would choose to do so. The only result of such a commitment is that he cannot make positive profits.

Once we look for a subgame perfect equilibrium, however, the whole concept of a limit price breaks down. When entry does occur, a proper subgame starts, which bears no relation to the first stage of the game, in which the incumbent sets his pre-entry price. This implies that the incumbent can set whatever price he likes in the first period, without affecting what will happen afterwards. He will therefore simply set his monopoly price, and there is no such thing as a limit price. This point will be elaborated upon in section 3.5. For now, I turn to a different strand of models, which exogenously assume a limit price does exist, and study how this will affect behavior of the incumbent.

\footnotetext{
${ }^{12}$ See Selten (1975) or, for example, Fudenberg and Tirole (1991).
} 


\subsection{Dynamic Limit Pricing}

\subsubsection{Introduction}

In the seventies a literature emerged which took a different approach to the limit price. The main differences with the classic, static approach described in the previous section, are the following. First, these new models take a dynamic approach. Rather than studying which static price an incumbent has to set to deter entry, dynamic limit pricing models study the optimal pricing behavior of an incumbent firm through time. Optimal control theory is used as a tool to analyze this. The second main difference is a result of the first one. In static models the potential entrant is assumed to optimize her behavior, given some exogenously imposed fixed behavior of the incumbent. Using the profit-maximizing choice of the potential entrant, a limit price is derived. In dynamic limit pricing models these roles are reversed. Here the entry process is mechanic, and exogenously given. The profit maximizing behavior of the incumbent is then derived. In static limit pricing models the incumbent's behavior, once entry occurs, is exogenously given. Therefore, the incumbent is not a rational, profit-maximizing economic agent. In dynamic limit pricing models this holds for the potential entrant.

An incumbent firm trying to deter entry makes an intertemporal trade-off. On the one hand he sacrifices some current profits, since current price is below static monopoly price. On the other hand a limit pricing strategy increases future profits, if entry is deterred. The first attempt to formalize this intuition in a dynamic context is Williamson (1963). In his model, pre-entry price is directly related to the probability of entry. Setting a higher pre-entry price increases the probability of entry. The problem of the incumbent is then to choose this probability $a$ such that the discounted stream of future expected profits is maximized, i.e.

$$
a=\arg \max \sum_{t=1}^{n} \frac{\left(1-a^{t}\right) \Pi_{t}(a)+a^{t} \hat{\Pi}_{i}}{(1+r)^{t}}
$$

with $\Pi_{t}(a)$ pre-entry profits as a function of a (and thus, implicitly, of price $p)$, and $\hat{\Pi}_{t}$ post-entry profits.

Pyatt (1971) also uses a dynamic model, to argue that an incumbent using a limit price will set price higher than the minimum of his average cost. The first full-fledged analysis of a dynamic limit price is provided 
by Gaskins (1971), who uses a deterministic framework to study the pricing behavior over time of an incumbent monopolist facing a competitive fringe. At the same time Kamien \& Schwartz (1971) analyze a model in which the probability of entry at any point in time depends on current price, the approach suggested by Williamson (1963). The next two subsections discuss both of these influential models in turn, and also provide some extensions that have been given in the literature.

\subsubsection{Deterministic Dynamic Limit Pricing}

In Gaskins (1971) a dominant incumbent firm faces entry from a competitive fringe. Therefore, in this model we do not have a potential entrant in the sense we had in section 3.3. Rather, there is a small fringe of price-taking firms, which is already active in the market. In this approach, entry is thus a continuous rather than a discrete phenomenon. Limit pricing is not meant to deter entry, but rather to keep the "entrants" (i.e. the competitive fringe) as small as possible. Rather than one incumbent facing potential entry, we now have a dominant firm, facing a competitive fringe.

The limit price is exogenously given, defined as the price level for which net entry (i.e. fringe growth) equals zero. The rate of entry depends on the excess of actual price over limit price, at any point in time. Total industry demand at time $t$ is given by $q(p(t))$, with $p$ price. The sales $q_{i}$ of the incumbent firm are given by

$$
q_{i}(p(t))=q(p(t))-q_{f}(t)
$$

with $q_{f}(t)$ the level of rival sales. Marginal costs for the incumbent are constant and equal $c$. The incumbent firm maximizes the present value of future profits $V$ :

$$
V=\int_{0}^{\infty}[p(t)-c]\left[q(p)-q_{f}(t)\right] e^{-r t} d t
$$

where $r$ is the incumbent's discount rate, and $c$ average cost of production, both constant over time. The rate of entry $\dot{q} f$ depends linearly on the excess of price over the limit price $\bar{p}$ :

$$
\dot{q}_{f}=k(p(t)-\bar{p}),
$$

with $k$ the response coefficient. The incumbent firm thus faces an optimal control problem in which he has to choose the time path of $p$ which 
maximizes (3.3) subject to the evolution of the state variable $g_{f}$ given by (3.4). By construction, in the steady state ${ }^{13} p=\bar{p}$. Moreover, there is a unique trajectory towards this steady state. Gaskins then interprets $\bar{p}$ as the marginal cost of the fringe. When the incumbent firm does not have a competitive advantage (i.e. $\bar{p}=c$ ), profits will gradually erode and equal zero in steady state. It can be shown that the dominant firm always sets a price lower than the monopoly price.

So far we have assumed that the economy is not growing. Suppose now that it is, and demand of the dominant firm is given by

$$
q_{i}(p(t), t)=q(p(t)) e^{\gamma t}-q_{f}(t)
$$

with $\gamma$ the growth rate of demand. The rate of entry now equals $\ddot{q}_{f}=k_{0} e^{\gamma t}(p(t)-\bar{p})$. In this case the steady state price is larger than $\bar{p}$. That means that even a dominant firm which does not have a competitive advantage will earn persistent profits. This is a disturbing result. Ireland (1972), however, points out that this is mainly due to the rather peculiar assumption that the dominant firm is able to fully monopolize the net growth in demand. When we assume that the new demand is distributed between the dominant firm and the competitive fringe in the same proportion as the original demand, (3.5) is replaced by

$$
q_{i}(p(t), t)=q(p(t)) e^{\gamma t}-q_{f}(t) e^{\gamma t}
$$

This model is formally equivalent to the original one without growth, and we again have that profits of a firm which has no competitive advantage are gradually eroded.

Gaskins" model describes the emergence of a monopolistic market to one in which no firm earns any profits, at least in case there are no competitive advantages for the initial monopolist. In the model, entry is not deterred. On the contrary: entry already exists from period zero onwards. It is necessary to have $q_{f}(0)>0$. The incumbent can only influence the rate of entry. Also, the limit price is exogenously given. Therefore, this is not a model of a monopolist using a limit price to deter entry.

Although this model has been widely applied ${ }^{14}$, it has been criticized

\footnotetext{
${ }^{13} \mathrm{By}$ definition, in a steady state, we have $\dot{q}_{f}(t)=0$, hence (3.4) then directly implies $p(t)=\bar{p}$.

${ }^{14}$ The model is even used in anti-trust policy. Judd and Petersen (1986) quote several articles in this area, including Dunfee and Stern (1975), Easterbrook (1981) and Kaplow (1982). See also Scherer (1980), pp. 236-243.
} 
as well. First and foremost, the behavior of the fringe is taken as exogenously given. Second, and closely related to the first point, the fringe expansion equation (3.4) is entirely ad-hoc. Also, Gaskins does not provide a theory as to why a limit price would exist. Rather, he assumes that a static limit price $\bar{p}$ is given from the outset, and then derives the optimal intertemporal pricing policy for the incumbent monopolist.

In some more recent dynamic limit pricing models, the behavior of the potentiai entrants is explicitly modelled, using the theory of differential games. Flaherty (1980) considers a two stage model. In the first stage there is an incumbent firm and a potential entrant considering entry. In the second stage, if the entrant has entered, both firms play a dynamic Cournot quantity setting game. As an equilibrium concept for the second stage game, Flaherty uses a dynamic, open loop version of the Nash equilibrium. Each firm incurs an adjustment cost $k$ when changing quantity. In the first stage, the incumbent sets his intitial quantity. This choice determines the initial conditions of the dynamic game played in the second period. For $k$ high enough, there are initial conditions of the second stage game where firm l's discounted future profits are positive, but firm 2's discounted future profits are negative. Hence, in the first stage, the incumbent can choose a point at which he obtains positive profits, but where entry is deterred. If doing so is more profitable than inducing entry, we have a limit price equilibrium.

What is attractive about this model is that entry is not assumed from the outset. At the start of the game there is no competitive fringe already present. Rather, there is a firm which considers entry and, when she enters, competes on equal footing with the incumbent firm. Kreps and Spence (1985, p. 350-351) and Fudenberg and Tirole (1986, p. 10-12) raise a fundamental criticism against the use of open loop equilibria. In differential games, we can have two types of equilibria. In a closed loop equilibrium firms cannot precommit to paths of future behavior. Hence, neither firm has an incentive at any point in time, to defect from the equilibrium. In open loop equilibria, players commit in advance to the full path of their behavior from now until the distant future. In the equilibrium, neither firm thus has an incentive to deviate, given the precommited equilibrium path of the competitor. By imposing this condition, the game Flaherty analyzes essentially collapses to the Modigliani model: if the incumbent firm would be able to commit himself to the strategy he will use in the future, entry can be deterred. The problem with the Modigliani model is that, should entry occur, the 
incumbent has an incentive to change his pre-announced policy. Although she uses a much more complicated dynamic model, exactly the same criticism can be raised against Flaherty. By assuming that the incumbent can precommit, a limit price in equilibrium can be derived. The problem is that such precommitment is not credible. Once entry occurs, the incumbent will rationally change his plans.

A different model, using a similar approach is Judd \& Petersen (1986). They also explicitly model the behavior of the potential entrant. Different from Flaherty, these authors use a competitive fringe, and competition in prices rather than quantities. Their main innovation is the assumption that the competitive fringe is capacity constrained, and can reinvest her profits in order to expand this capacity. Compared with the original Gaskins model, in equilibrium the incumbent sets a higher price initially and the fringe is growing faster. But, like Flaherty does, Judd \& Petersen also use an open loop equilibrium, in which both the dominant firm and the competitive fringe have to precommit on their strategy. The authors argue that the steady state in any closed loop equilibrium must be the same as the one they derive in the open loop equilibrium. But in a theory for limit pricing, exactly the path along which the steady state is reached is interesting, and not the steady state itself.

\subsubsection{Probabilistic Dynamic Limit Pricing}

Kamien and Schwartz (1971) take a different approach in modelling a dynamic limit price. In their model entry always takes place, but the time at which it does is uncertain. The probability that entry occurs at any point in time depends on the current price and the growth rate of demand. They show that the optimal policy for the incumbent is to set a constant price $p^{*}$, which is smaller than the static monopoly price. Hence, $p^{*}$ can be interpreted as a dynamic limit price.

We distinguish two periods: before and after entry. At any time $t$ before entry, the incumbent monopolist or cartel makes a profit $e^{\gamma t} \pi_{1}(p(t))$. Here, $\gamma$ is the growth rate of demand. In the period after entry the expected flow of profits for the original incumbent(s) equals $e^{\gamma t} \pi_{2}(\gamma)$. In order to make it worthwhile to deter entry, $\pi_{2}<\pi_{1}$. Let $G(t)$ denote the probability that entry has occurred by time $t$, so $G(0)=0$. The conditional probability of entry at time $t$ then equals $g(t) /(1-G(t))$. Assume that this conditional probability depends on current price and 
growth of demand. For any $t$, the higher price $p$, the higher the probability that entry occurs. The same holds for industry growth rate $\gamma$. Therefore, $G$ is implicitly defined by some hazard rate $h$, such that $h(p(t), \gamma)=g(t) /(1-G(t))$.

The incumbent's problem can now be stated as an optimal control problem. It is easy to see that the expected value of profits at any point in time equals $\pi_{1}(p(t))(1-G(t))+\pi_{2} G(t)$. The incumbent thus maximizes

$$
V=\int_{0}^{\infty} e^{-(r-\gamma) t}\left[\pi_{1}(p(t))(1-G(t))+\pi_{2} G(t)\right] d t
$$

subject to

$$
g(t)=h(p(t), \gamma)(1-G(t))
$$

Karnien and Schwartz show that the optimal strategy for the incumbent is to set a constant price $p^{*}$ at any point in time. This solution is unique. We thus have a unique dynamic limit price that is endogenously determined. It can also be shown that $p^{*}$ is smaller than the static monopoly price $p^{m}$, except in the case where entry is effectively blockaded (i.e. entry never takes place at the monopoly price: $h\left(p^{m}\right)=0$ ).

In this model, limit pricing does not deter entry, but rather retards it. Again some ad-hoc behavior of a potential entrant is assumed. Entrants are not able to undercut the price set by the incumbent. A higher $p$ will increase the probability of entry. Why this would be the case is not clear.

Baron (1973) analyzes a similar model, in discrete time. He considers the case in which entry can occur more than once and studies the effect of entry barriers and risk averseness. De Bondt (1976) uses the KamienSchwartz framework to study the implications of an entry lag between a rival's decision to enter and her appearance as an entrant. The cartel cannot observe the date of the actual entry decision, only when entry actually occurs. He finds that the limit price increases in the length of the entry lag. Bourguignon and Sethi (1981) allow for a wider range of behavior of the potential entrant. They assume the hazard rate can be written $h(p, \gamma) \cdot \Psi(F)$. Here, the probability of entry not only depends on growth rate and current market price, but also on the cumulative probability of entry itself. The authors interpret $\Psi^{\prime}(F)<0$ as the case of cautious potential entrants: the probability of entry is lower if the probability that someone else has entered is high. They also assume 
that the incumbent can use advertising which will increase consumers' goodwill. In this model it is optimal for the incumbent to use a limit pricing policy up to some critical level of $F$.

\title{
3.5 The Friedman Critique
}

All models considered so far assume that either the incumbent or the potential entrant is not a rational profit-maximizing agent. In static limit price models, the incumbent is assumed to precommit to a certain strategy, which he will not change, even if entry occurs. If entry would occur, it would be rational for the incumbent to change his behavior anyway. The threat not to do so, is therefore not credible. Differential game models make essentially the same assumption. Other dynamic limit pricing models assume some ad hoc behavior for the potential entrant or fringe firms, which is also not rational.

If we assume that both the incumbent and the potential entrant are rational, all theories of limit pricing discussed so far, run into problems. Suppose prices can be changed instantaneously. That implies that, in a world with complete information, pre-entry prices do not carry any information about future prices. Any potential entrant knows that once she enters the market, a proper subgame starts, which has no connection whatsoever with what happened in the previous period. Given that this is the case, optimal behavior of the incumbent simply implies setting monopoly price in the pre-entry period. Hence a limit price does not exist. This point has been made by Friedman $(1979,1981)$ :

\begin{abstract}
[A limit price] ought to arise as the result of an optimization process undertaken by the potential entrant [...] an entrant has no direct interest in an established firm's pre-entry policy. What matters is the price pattern which would emerge after he comes in. [...] If both participants are fully informed at the outset concerning profit functions which would prevail after entry, then it is difficult to see the relevance of pre-entry prices to the plans of the entrant ${ }^{15}$.
\end{abstract}

To still allow for the possibility of an incumbent deliberately deterring entry of a potential entrant, we thus need some link between the pre-entry and the post-entry period. Basically there are two ways to

${ }^{15}$ Friedman (1979), pp. $236-237$. 
do so, both suggested by Friedman. First, there can be a physical link between the two periods. For example, by installing extra capacity, an incumbent might be able to credibly threaten to raise output once entry occurs $^{16}$. Second, the link between the periods can also be an informational one. Suppose the potential entrant is uncertain about some of the characteristics of the industry in which she considers entry. Upon observing the price the incumbent sets, the potential entrant might then be able to obtain some additional information about the industry. This gives the incumbent an incentive to distort the pre-entry price, in an attempt to fool the potential entrant. In a seminal paper, Milgrom \& Roberts (1982) show that this can lead to limit pricing, even if both the incumbent and the potential entrant act as fully rational, profit maximizing agents. Their model is sketched in the next section, and discussed in much more detail in chapter 4 .

\subsection{Equilibrium Limit Pricing}

We saw that in the models discussed so far not all firms are rational, profit-maximizing agents. The concept of limit pricing, however, can be saved by assuming that the potential entrant is uncertain about some industry characteristics. Friedman (1983) makes a first attempt to model this. He still assumes, however, that the potential entrant considers the probability of high demand as an exogenously given function of current market price, and thus rules out the possibility that the incumbent can strategically manipulate this price in an attempt to fool the potential entrant. A consistent game-theoretic model is provided by Milgrom and Roberts (1982). They assume that the potential entrant does not know the costs of their competitor. The price the incumbent sets in the first period provides a signal about his costs. This gives the incumbent an incentive to manipulate this price in an attempt to "bluff [the potential entrant] away from the industry" 17 .

The basic set-up of the model is the following. There are two periods. In the first period there is an incumbent monopolist. He chooses a quantity $q$. After the first period a potential entrant can enter. The entrant incurs a fixed cost $F$ upon entry. Both firms have constant marginal costs. The potential entrant does not know the costs of the

\footnotetext{
${ }^{16}$ See for example Spence (1977) or Dixit (1980). This literature falls outside the scope of this chapter. For a survey, see Neven (1987) or Lyons (1986).

Bain (1949), p. 454 .
} 
incumbent. When she does enter, all costs become known, and the two firms operate as Cournot duopolists in the second period. When she does not enter, the incumbent can set a monopoly price in period 2 .

Suppose we have a case in which the marginal cost of the incumbent can take on two values. It can be either high or low. The probability that it is high equals $\mu$. Marginal cost of the potential entrant is given and commonly known. Suppose that it is always profitable to enter if the incumbent has high marginal cost, and never profitable to do so when he has low cost. In the case of perfect information any incumbent simply sets his monopoly quantity in period 1, and the potential entrant, from knowing all the industry characteristics, will know whether or not it is profitable to enter.

Now consider the case of incomplete information. First note that second period profits of the incumbent are always higher if the potential entrant does not enter. If the incumbent has low costs, he now has a problem. He can simply tell the potential entrant that his costs are low and that entry is therefore not profitable. But a potential entrant has little reason to believe such a claim. If the incumbent would have high costs, he would also try to convince the potential entrant that his costs are low, in an attempt to deter entry. If an incumbent has low costs, he thus has to look for other ways to convince the potential entrant of this fact. He can for example set his monopoly price in the first period, in the hope that this will convince the potential entrant that his costs are really low. But even such a strategy may not be credible. Again, an incumbent with high marginal cost can do exactly the same thing. Although doing so will lead to a loss in his first-period profits, this is more than compensated by an increase in his second period profits if it induces the potential entrant to believe that entry is not profitable. An incumbent with low cost will therefore set an even lower price. In fact, he will set his first period price so low that it is just not profitable for an incumbent with high cost to follow the same strategy, rather than setting his own monopoly price in the first period and thereby revealing his true identity. Then, and only then, will the potential entrant be convinced that she really faces a low cost incumbent, rather than a high cost incumbent who simply tries to fool her. In the first period, a low cost incumbent thus has to incur a cost to convince the potential entrant that entry is not profitable. This cost comes in the form of setting a price in the pre-entry period that is lower than the static monopoly price: the low cost incumbent thus sets a limit price. 
In general, as we will see in the next chapter, there are two possible equilibria in this model. In a separating equilibrium a high and a low cost incumbent will choose different strategies in the first period. When the potential entrant observes first period quantity $q$, she can thus infer whether the incumbent has high or low cost, and then decide whether or not it is profitable to enter. In a pooling equilibrium a high and a low cost incumbent choose the same action in the first period. In that case the entrant does not obtain any information from observing $q$. She will enter when expected net profits are larger than zero. In both equilibria, at least one of the two possible types of incumbent practices limit pricing, in the sense that he sets a price below his monopoly price. In the separating equilibrium, however, limit pricing does not deter entry, relative to the full information case. In a pooling equilibrium, limit pricing may involve either less, the same, or more entry, depending on the parameters.

Suppose now that there is a continuum of possible marginal cost for the incumbent, and also that the incumbent is not informed about the marginal cost of the potential entrant. In that case, any incumbent will always set a limit price, since doing so strictly decreases the probability that entry will occur. But in equilibrium, the potential entrant can always infer the exact marginal cost of the incumbent. Therefore, compared with the case of perfect competition, it is not the case that there is more entry deterred here. Nevertheless, the incumbent firm is not able to set his monopoly price in the pre-entry period. This is a strong result, that can also be applied to other fields in economics, as we will see in chapter 8 .

\subsection{Conclusion}

In this chapter I gave a survey of the theory of limit pricing. Starting with the original Bain (1949) paper, I considered three strands of literature trying to formalize the notion of a limit price. The models discussed in section 3.3 all implicitly assume that an incumbent will not change his behavior once entry occurs. Given that behavior, some policy can be chosen from the outset, such that it is just not profitable for a new firm to enter. Dynamic limit pricing models, considered in section 3.4 , take the entry-deterring effect of a low price as given and focus on the optimal behavior of the incumbent firm through time, given that assumption. Friedman, discussed in section 3.5 observed that all these models suffer from the same fundamental flaw. By assuming that be- 
havior of either the incumbent or the potential entrant is exogenously given, these models generate equilibria that are not subgame perfect. One way out of this problem is to assume asymmetric information, as Milgrom \& Roberts (1982) do. Their model was sketched in section 3.6, but also figures prominently in the next chapter. One peculiar result in their model, which was also present in dynamic limit pricing models, is that, even if limit pricing does occur in equilibrium, entry is often not deterred. This is most clear in the continuous version of their model. Therefore, also in a consistent game-theoretic model it can be an equilibrium for the incumbent firm to set a limit price. Yet, doing so will not systematically deter entry.

The next chapter equilibrium limit pricing in much more detail. There, the welfare effects of limit pricing will also be discussed. 



\section{Chapter 4}

\section{Equilibrium Limit Pricing}

\subsection{Introduction}

This chapter provides a framework to study models of equilibrium limit pricing. These models use asymmetric information to derive limit pricing in equilibrium. I will generalize Milgrom \& Roberts' (1982) model and analyze a general case in which an incumbent monopolist can provide a signal to a potential entrant. This signal gives her some information about the true state of the world, which is known to the incumbent, but not to the potential entrant. I show that the Milgrom and Roberts model is a special case of the framework developed in this chapter. Also, using this framework greatly simplifies the discussion of the literature.

Three models are analyzed, each with a slightly different information structure. For each model, a general result is derived. These three results are qualitatively the same. The general set-up of all three models is the following. There can be a number of possible states of the world. The incumbent does know which state prevails, but the potential entrant does not. In the first period, the incumbent makes a decision which affects his first period profits. This decision also serves as a signal for the potential entrant. Upon observing it, she may obtain some information about the state of the world.

First, I analyze a model in which there are two possible states of the world. This set-up allows for various interpretations. For example, in Milgrom and Roberts (1982), they can be interpreted as the case in which the incumbent has low marginal cost, and the case in which he has high marginal cost. The price the incumbent sets in the first period serves as a signal of the true state of the world. In the second 
model considered in this chapter, there is a continuum of possible states of the world. Finally, the case is considered in which again we have a continuum of states of the world, but the potential entrant also has some private information. In that case, the incumbent does not know with certainty for which values of the signal the potential entrant will enter. In section $4.5 \mathrm{I}$ discuss the literature on equilibrium limit pricing, using the framework developed. Finally, section 4.6 gives an assessment of that literature. It also discusses the welfare effects of limit pricing. These effects were the initial motivation in chapter 2 to study these models.

\subsection{A Model With Two Types}

In this section, the following set-up is used. Suppose there are two states of the world, denoted 1 and 2. For example, in Milgrom and Roberts, in state of the world 1 the incumbent has high marginal cost, and in state of the world 2, he has low marginal cost. We have two periods. In period 1 , an incumbent firm is active, and learns the state of the world. A potential entrant only knows the a priori probability $\rho$ that the world is in state 1 . The incumbent can use s, observable to the potential entrant, to signal the state of the world. His profits also depend on $s$. Denote first period profits of the incumbent $\pi_{i}(s)$, as a function of signal $s$, when the real state of the world is $i$. For example, in Milgrom and Roberts, first period price serves as a signal.

If entry does occur, post-entry profits for the incumbent are given by $\pi_{i}^{E}$. If entry does not occur, he can simply earn monopoly profits $\pi_{i}^{m}$ post-entry, where the superscript $m$ denotes monopoly values. The potential entrant has to incur some cost $F^{\prime \prime}$ upon entry. Her post-entry profits in state of the world $i$ are denoted $\pi_{i}^{e}$. The a priori probability that the state of the world is 1 is denoted $\rho$. Hence, the a priori probability that the state of the world is 2 equals $1-\rho$. We make the following assumptions:

(A-1) $\pi_{i}(s)$ is continuously differentiable, strictly concave and uniquely maximized by $s_{i}^{m}, i=1,2$.

(A-2) $\pi_{i}^{m}>\pi_{i}^{E}, i=1,2$.

(A-3) $\pi_{1}^{e}>F>\pi_{2}^{e}$. 
The second condition states that the incumbent's profits are always higher if entry does not occur, rather than when it does. The third assumption implies that entry is profitable if and only if the state of the world is 1 . Note that, by definition, $\pi_{i}^{m}=\pi_{i}\left(s_{i}^{m p}\right)$.

Denote the entry decision of the potential entrant as $e(s)$, with $e(s)$ the probability that she enters. Thus, $e(s)=1$ if she decides to enter and $e(s)=0$ if she does not. Note that the entry rule depends on the signal $s$ that is observed. The potential entrant's a posteriori belief that she faces a type 1 incumbent is denoted $\mu(s)$. Thus, with $\mu(s)=1$, she believes the true state of the world is 1 with certainty. This belief also depends on the signal $s$ that is observed.

To solve this model, we look for a sequential equilibrium (see Kreps and Wilson 1982). This requires that the strategy of the incumbent, in both states of the world, is a best response to the strategy of the potential entrant, and vice-versa. Moreover, we require that the incumbent's belief about the true state of the world is updlated using Bayes" rulle. In this framework, a sequential equilibrium is defined as follows ${ }^{1}$

Definition 1 A sequential equilibrium of the entry deterrence game described in this section consists of a strategy $s_{1}^{*}$ for the incumbent firm in state of the world 1 , a strategy $s_{2}^{*}$ for the incumbent in state of the world 2, an entry function $e(s)$, and a system of beliefs $\mu(s)$ such that the following conditions hold:

1. Optimality for the incumbent: For $i=1,2$

$$
s_{i}^{*} \in \arg \max _{s} \pi_{i}(s)+\delta e(s) \pi_{i}^{E}+\delta(1-e(s)) \pi_{i}^{m},
$$

2. Optimality for the entrant:

$$
\begin{gathered}
e(s)=\left\{\begin{array}{cll}
1 & \text { if } & E\left(\pi^{e}-F \mid \mu\right)>0 \\
0 & \text { if } & E\left(\pi^{e}-F \mid \mu\right)<0 \\
\epsilon[0,1] & \text { if } & E\left(\pi^{e}-F \mid \mu\right)=0
\end{array}\right. \\
\text { with } E\left(\pi^{e}-F \mid \mu\right)=\mu(s) \pi_{1}^{e}+(1-\mu(s)) \pi_{2}^{e},
\end{gathered}
$$

${ }^{1}$ Strictly speaking, we need a fourth condition as well, which is consistency. However, in the models in this thesis, this condition is always satisfied. 
3. Bayes" consistency of beliefs:

$$
\mu(s)=\left\{\begin{array}{ccc}
1 & \text { if } & s=s_{1}^{*} \text { and } s \neq s_{2}^{*} \\
\rho & \text { if } & s=s_{1}^{*}=s_{2}^{*} \\
0 & \text { if } & s=s_{2}^{*} \text { and } s \neq s_{1}^{*} \\
\in[0,1] & & \text { otherwise }
\end{array}\right.
$$

The maximand in (4.1) gives the profits to incumbent $i$ of using strategy $s$. If $s$ is such that it induces entry, we have $e(s)=1$, and second period profits of the incumbent are given by $\pi_{i}^{E}$. If no entry occurs, $e(s)=0$, and the incumbent's second period profits equal $\pi_{i}^{m}$. Equation (4.2) implies that the potential entrant will enter if and only if expected profits of doing so, given belief $\mu(s)$, exceed fixed entry cost $F$. When expected profits exactly equal $F, e(s)$ can take any value. Finally, (4.3) gives Bayes consistent beliefs. In a pooling equilibrium, both types of incumbent ${ }^{2}$ use the same strategy in equilibrium. In that case, observing the signal $s=s_{1}^{*}=s_{2}^{*}$ does not yield any additional information, and the a posteriori belief equals the a priori probability of facing a type 1 incumbent, hence $\mu(s)=\rho$. In a separating equilibrium, both types of incumbent use a different strategy, $s_{1}^{*} \neq s_{2}^{*}$. If this is the case, the potential entrant can exactly infer which type of incumbent she faces when she observes the signal $s$, hence $\mu\left(s_{1}^{*}\right)=1$ and $\mu\left(s_{2}^{*}\right)=0$. Finally, when an out-of-equilibrium action is observed, beliefs are arbitrary.

To give a flavor of the analysis, I will derive the separating equilibrium. In a separating equilibrium, both types of incumbent use a different signal. Take advantage of the arbitrariness of out-of-equilibrium beliefs by assuming they are such that the potential entrant believes the state of the world is 1 when she observes an out-of-equilibrium action: $\mu(s)=0$ if $s \neq s_{2}^{*}$. A separating equilibrium consists of a pair $\left(s_{1}^{*}, s_{2}^{*}\right)$, set by the incumbent in state 1 , resp. state 2 , such that the following inequalities hold

$$
\begin{gathered}
\pi_{1}\left(s_{1}^{*}\right)+\delta \pi_{1}^{E} \geq \max \left\{\pi_{1}\left(s_{2}^{*}\right)+\delta \pi_{1}^{m}, \max _{s \neq s_{1}^{*}, s_{2}^{*}} \pi_{1}(s)+\delta \pi_{1}^{E}\right\} \\
\pi_{2}\left(s_{2}^{*}\right)+\delta \pi_{2}^{m} \geq \max _{s \neq s_{2}} \pi_{2}(s)+\delta \pi_{2}^{E}
\end{gathered}
$$

\footnotetext{
"In the remainder of this chapter, the expressions "state of the world" and "type of incumbent ${ }^{\text {"s }}$ are used interchangeably.
} 
The left-hand side of (4.4) are the total discounted profits of a state 1 incumbent in a separating equilibrium. In such an equilibrium, he earns $\pi_{1}\left(s_{1}^{*}\right)$ in the first period. Upon observing $s_{1}^{*}$, the potential entrant believes she faces a state 1 incumbent, and enters. Second period profits of the incumbent then equal $\pi_{1}^{E}$. In an attempt to deter entry, the state 1 incumbent can try to fool the potential entrant by using the equilibrium signal of a state 2 incumbent, which is $s_{2}^{*}$. If she would, entry would be deterred, since the potential entrant believes she faces a state 2 incumbent when observing $s_{2}^{*}$. In that case, the incumbent's second period profits are given by $\pi_{1}^{m}$, and his first period profits by $\pi_{1}\left(s_{2}^{*}\right)$. Alternatively, the type 1 incumbent can defect by setting a signal different from either $s_{1}^{*}$ or $s_{2}^{*}$. In that case, given out-of-equilibrium beliefs, he earns $\pi_{1}^{E}$ in the second period. Equilibrium requires that defection is not profitable, hence (4.4). Discounted profits of a state 2 incumbent in the separating equilibrium are given by the left hand side of (4.5). Defecting from this equilibrium always induces entry, given the out-ofequilibrium beliefs of the potential entrant. The highest profits a type 2 can earm by defecting are thus given by the right hand side of (4.5), and equilibrium requires the inequality to hold.

Note that, trivially, if $\left(s_{1}, s_{2}\right)=\left(s_{1}^{m}, s_{2}^{m}\right)$ satisfies (4.4) and (4.5), then this is the unique separating equilibrium. Then, in each state of the world, the incumbent simply sets the signal that maximizes his first-period profits, without having to take signaling considerations into account. Now suppose $\left(s_{1}^{m}, s_{2}^{m}\right)$ does not satisfy the given inequalities. Obviously, $s_{2}^{*}=s_{2}^{m}$ always satisfies (4.5), since, by definition, $s_{2}^{m}=$ $\max \pi_{2}(s)$, and $\pi_{2}^{m}>\pi_{2}^{E}$. Therefore, $\left(s_{1}^{m}, s_{2}^{m}\right)$ must violate (4.4). In state 1 , the incumbent has an incentive to act as if the true state is 2 , by mimicking the behavior of the incumbent if 2 was the true state of the world. In any separating equilibrium, the state 2 incumbent thus uses an $s$, different from $s_{2}^{m}$, such that it is not profitable for a state 1 incumbent to mimic that strategy ${ }^{3}$.

Suppose $\left(s_{1}^{m}, s_{2}^{m}\right)$ is not a separating equilibrium. By definition, the

\footnotetext{
${ }^{3}$ For ease of exposition, here and in the remainder of this thesis, I use the fiction that the incumbent in state of the world 1 , and the incumbent in state of the world 2, are two different persons. This allows us to talk about a "type 1 incumbent mimicking a type 2 incumbent" , rather than an "incumbent in state of the world 1 acting as he would do if he were really in state of the world 2 . . This fiction dates back to Harsanyi (1967) who first noted that game with incomplete information can be analyzed as if there are several possible players, and an initial move of nature decides which of these prossible players is actually playing.
} 
maximizer of $\pi_{2}(s)$ equals $s_{2}^{m}$. Also, in any separating equilibrium we necessarily have $s_{1}^{*}=s_{1}^{m}$. Therefore, a separating equilibrium is defined by any $s_{2}^{*}$ such that

$$
\begin{aligned}
\pi_{1}^{m}+\delta \pi_{1}^{E} & \geq \pi_{1}\left(s_{2}^{*}\right)+\delta \pi_{1}^{m}, \\
\pi_{2}\left(s_{2}^{*}\right)+\delta \pi_{2}^{m} & \geq \pi_{2}^{m}+\delta \pi_{2}^{E},
\end{aligned}
$$

which implies

$$
\begin{aligned}
& \pi_{1}^{m}-\pi_{1}\left(s_{2}^{*}\right) \geq \delta\left(\pi_{1}^{m}-\pi_{1}^{E}\right), \\
& \pi_{2}^{m}-\pi_{2}\left(s_{2}^{*}\right) \leq \delta\left(\pi_{2}^{m}-\pi_{2}^{E}\right) .
\end{aligned}
$$

The right hand side of (4.7) denotes the discounted value of entry deterrence. If entry is deterred, second period profits for this type of incumbent equal $\pi_{1}^{m}$. If entry is not deterred they equal $\pi_{1}^{E}$. The left hand side denotes the cost of using the signal $s_{2}^{*}$. If the signal is used, first period profits are $\pi_{1}\left(s_{2}^{*}\right)$. If, instead, first period profits are maximized, the firm earns $\pi_{1}^{m}$. Condition (4.7) thus implies that, in any separating equilibrium, the first period cost of signaling for the state 1 incumbent, must exceed the second period value of entry deterrence. Similarly, (4.8) requires that for the state 2 incumbent, the first period cost of signaling has to be smaller than the second period value of entry deterrence. For an alternative interpretation, we can use (4.7) and (4.8) to derive as a necessary condition

$$
\frac{\pi_{2}^{m}-\pi_{2}\left(s_{2}^{*}\right)}{\delta\left(\pi_{1}^{m}-\pi_{1}^{E}\right)} \leq \frac{\pi_{1}^{m}-\pi_{1}\left(s_{2}^{*}\right)}{\delta\left(\pi_{2}^{m}-\delta \pi_{2}^{E}\right)}
$$

which says that the relative cost of signalling in state 2 have to be smaller than those in state 1.

We make the following additional assumptions:

$$
(\mathrm{A}-4) \delta\left(\pi_{2}^{m}-\pi_{2}^{E}\right)-\delta\left(\pi_{1}^{m}-\pi_{1}^{E}\right)>\pi_{1}\left(s_{2}^{m}\right)-\pi_{1}^{m}
$$

(A-5) $\partial\left(\pi_{2}-\pi_{1}\right) / \partial s$ has the same sign for all $s$.

\footnotetext{
${ }^{4}$ Suppose this were not the case. A type 1 incumbent will then defect by setting $s_{1}^{7 n}$ rather than $s_{1}$. Doing so increases first period profits, and does not affect second period profits, since out-of-equilibrium beliefs entail that the potential entrant will enter if she observes a signal that is not part of an equilibrium strategy.
} 
The first condition is a technical one, which requires that the difference in the value of entry deterrence between state 2 and state 1 is high enough. Note that, by definition $\pi_{1}\left(s_{2}^{m}\right) \leq \pi_{1}^{m}$. Therefore, sufficient for (A-4) to hold is $\pi_{2}^{m}-\pi_{2}^{E} \geq \pi_{1}^{m}-\pi_{1}^{E}$, i.e. the value of entry deterrence in state 2 is higher or equal to that in state 1 . The second assumption implies that the marginal cost of changing the signal $s$ is either always the highest in state 1 , or always the highest in state 2 , or always equal in both states. We can now prove the following theorem ${ }^{5}$;

Theorem 1 If (A-1) through (A-5) hold, a separating equilibrium always exists.

Note, however, that there is a continuum of separating equilibria in each case (see appendix). An equilibrium that is intuitively appealing is the one in which the incumbent in state 2 minimizes his signaling cost, and chooses the $s_{2}$ that maximizes $\pi_{2}\left(s_{2}\right)$, subject to (4.7). Following Milgrom and Roberts (1982), I refer to this equilibrium as the least-cost separating equilibrium (LCSE).

Theorem 2 If $(A-1)$ through $(A-5)$ are satisfied, and, moreover, $\frac{\partial \pi_{1}}{\partial s} \neq$ $\frac{\partial \pi_{2}}{\partial s}$, the LCSE is unique and given by $\left(s_{1}^{*}, s_{2}^{*}\right)=\left(s_{1}^{m}, \hat{s}_{2}\right)$. If $\frac{\partial \pi_{1}}{\partial s}<\frac{\partial \pi_{2}}{\partial s}, \hat{s}_{2}$ is the largest root satisfying $\pi_{1}\left(\hat{s}_{2}\right)=\pi_{1}^{m}-\delta\left(\pi_{1}^{m}-\pi_{1}^{E}\right)$. If $\frac{\partial \pi_{1}}{\partial s}>\frac{\partial \pi_{2}}{\partial s}$, $\hat{s}_{2}$ is the smallest root satisfying that equality.

From this theorem directly follows

Theorern 3 Equilibrium in the two-type model. Suppose (A-1) through (A-5) hold and $\left(s_{1}^{m}, s_{2}^{m}\right)$ is not a separating equilibrium. Compared with the pure monopoly case, the unique LCSE involves a distortion of the signal in period 1 with state of the world 2 . With $\frac{\partial \pi_{1}}{\partial s}<\frac{\partial \pi_{2}}{\partial s}$, there is an upward distortion, and with $\frac{\partial \pi_{1}}{\partial s}>\frac{\partial \pi_{2}}{\partial s}$, there is a downward distortion. With $\frac{\partial \pi_{1}}{\partial s}=\frac{\partial \pi_{2}}{\partial s}$, both an upward and a downward distortion are possible. In state of the world 1, the incumbent always uses his monopoly signal.

To illustrate this theorem, consider the basic Milgrom and Roberts model. There are two states of the world. Marginal cost of the incumbent can be either high or low. If they are high, entry is profitable. If

\footnotetext{
${ }^{5}$ Proofs of all theorems are given in the appendix.
} 
they are low, entry is not profitable. Demand is downward sloping. If entry occurs, post-entry competition is Cournot. Therefore (A-1) and (A-2) are satisfied. Define state of the world 1 as the case in which the incumbent has high cost, and state 2 as the case in which he has low cost, thus (A-3) is also satisfied. It is easy to show that (A-4) and (A-5) also hold. To assess the unique LCSE, we first derive $\partial \pi_{i} / \partial s$. First period profits are given by $\pi_{i}=\left(p-c_{i}\right) \cdot q(p)$, with $p$ price, $q$ demand, and $c_{i}$ marginal cost in state $i$. Price is used as a signal, hence we have $\partial \pi_{i} / \partial s=q(p)+\left(p-c_{i}\right) \partial q / \partial s$. With $\partial q / \partial s<0$ and $c_{1}>c_{2}$, this implies $\partial \pi_{1} / \partial s>\partial \pi_{2} / \partial s$. Using theorem 3 , in the LCSE we thus have a downward distortion of the signal in state of the world 2. Thus $p_{2}^{*}<p_{2}^{m}$, hence the low cost incumbent uses a limit price.

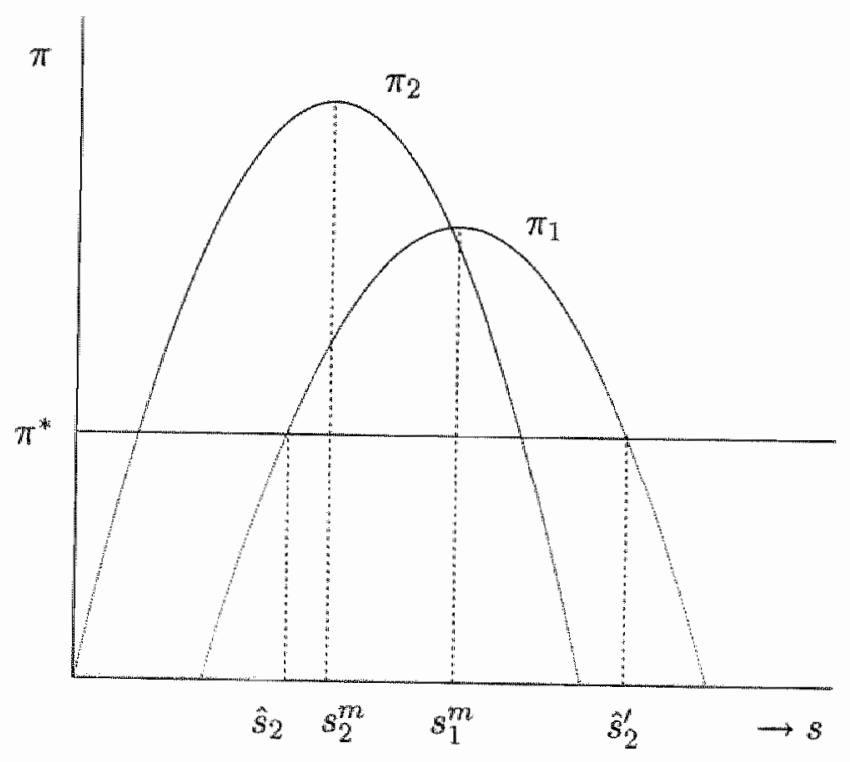

Figure 4.1: Separating equilibrium with two types.

Some intuition for this result can be given using figure 4.1. Here, first period profits of the incumbent in states of the world 1 and 2 are given as a function of signal $s$. Note that I have depicted the case in which $\partial \pi_{1} / \partial s>\partial \pi_{2} / \partial s$, hence $s_{1}^{m}>s_{2}^{m}$. A type 1 incumbent is willing to use a signal different from $s_{1}^{m}$ if doing so deters entry, and yields first period profits high enough to make such defection worthwhile. Suppose 
a type 1 incumbent is just indifferent between setting his monopoly quantity which induces entry and using a signal which deters entry, if first period profits are equal to $\pi^{*}$. Thus, any separating equilibrium either has $s_{2} \leq \hat{s}_{2}$ or $s_{2} \geq \hat{s}_{2}^{\prime}$. If type 2 sets such a signal, a type 1 has no incentive to defect from his monopoly signal $s_{1}^{\text {m }}$. From this range of separating equilibria, a type 2 incumbent chooses the one which yields the highest first period profits. From the figure, it is obvious that this is the signal $\hat{s}_{2}$, for which $\hat{s}_{2}<s_{1}^{m}$. In general, with $s_{2}^{m}<s_{1}^{m}$, the signal $\hat{s}_{2}$ which has $\hat{s}_{2}<s_{1}^{m}$, is always "closer" to $s_{2}^{m}$ than the signal $\hat{s}_{2}^{\prime}$. Hence, using $\hat{s}_{2}$ implies lower costs for the type 2 incumbent and is the unique LCSE. It involves a downward distortion of the monopoly signal in state of the world 2. With a similar argument, it can be seen that, with $\partial \pi_{1} / \partial s<\partial \pi_{2} / \partial s$, we necessarily have $s_{2}^{m}>s_{1}^{m}$, so $\hat{s}_{2}^{\prime}$ will be "closer" to $s_{2}^{m}$, and the unique LCSE involves an upward distortion of the monopoly signal in state of the world 2 .

A different way to motivate the choice of the LCsE among the continuum of possible pooling equilibria, is by invoking Cho and Kreps' (1987) Intuitive Criterion. This criterion provides a way to put more structure on out-of-equilibrium beliefs. Suppose the potential entrant observes a signal in period 1 that is not part of an equilibrium strategy in either state of the world. Thus, upon observing this out-of-equilibrium signal, the potential entrant does not know which type of incumbent she faces. Suppose, however, that she observes a signal which is equilibrium dominated in state of the world $i$. A signal $s^{\prime}$ is equilibrium dominated by a signal $s^{\prime \prime}$ in state of the world $i$ if using the signal $s^{\prime \prime}$ always yields higher profits for the type $i$ incumbent than using the signal $s^{\prime}$, regardless of the beliefs of the potential entrant. If such a signal is observed, it seems reasonable to assume that the potential entrant infers that she is not in state of the world $i$ : in that state, the incumbent can never gain by such a defection. In this model, it can be shown that the unique equilibrium surviving the Intuitive Criterion is the LCSE. ${ }^{6}$

\subsection{A Model With A Continuum of Types}

Suppose now there is a continuum of states of the world. Denote a state of the world $w$, and assume the possible states are given by the interval $\left[w_{L}, w_{H}\right]$. First period profits of the incumbent are now denoted $\pi(w ; s)$,

\footnotetext{
${ }^{6}$ Proof in appendix.
} 
with $w$ the state of the world and $s$ the signal used. Post-entry profits are $\pi^{m}(w)$ if no entry occurs, and $\pi^{E}(w)$ if entry does occur, both as a function of $w$. Again, the potential entrant has to incur fixed cost $F$ upon entry. Her post-entry profits are denoted $\pi^{e}(w)$, also as a function of the state of the world $w$. We now make the following assumptions

(B-1) $\pi(w, s)$ is twice continuously differentiable. For each $w, \pi(w, s)$ is strictly concave in $s$ and uniquely maximized by $s^{m}(w)$.

(B-2) $\pi^{m}(w)>\pi^{E}(w) \forall w$.

(B-3) $\frac{\partial \pi^{e}}{\partial w^{\beta}}<0$ and $\pi^{e}\left(w_{L}\right)>F>\pi^{e}\left(w_{H}\right)$.

(B-4) $\pi^{e}(w), \pi^{m}(w)$ and $\pi^{E}(w)$ are continuously differentiable.

Assumptions (B-1) through (B-3) are equivalent to (A-1) through (A$3)$, with (B-4) also requiring continuity of second-period profit functions. Note that continuity of $\pi^{e}$ and (B-3) imply

Lemma 1 There is a state of the world $w_{0}$ such that the net profits upon entry are exactly zero: $\pi^{e}\left(w_{0}\right)=F$.

Note that, by definition, $\pi^{m}(w)=\pi\left(w, s^{m}(w)\right)$. I also assume

(B-5) $\frac{\partial^{2} \pi}{\partial s \partial w} \neq 0 \forall s, w$

Note that this implies either $\frac{\partial^{2} \pi}{\partial s \partial w}<0$ or $\frac{\partial^{2} \pi}{\partial s \partial w}>0$ for all $s, w$. In the following analysis, I consider the case that is equivalent to case 1 in the previous section, where we had $\frac{\partial \pi_{1}}{\partial s}<\frac{\partial \pi_{2}}{\partial s}$. Generalizing this implies $\frac{\partial^{2} \pi}{\partial s \partial w}>0$. Later I will consider the case $\frac{\partial^{2} \pi}{\partial s \partial w}<0$.

Assume that the interval $\left[w_{L}, w_{H}\right]$ is large enough to allow for all interesting cases. From the discussion that follows we will see that this requires

(B-6) $\pi^{m}\left(w_{L}\right)+\delta \pi^{E}\left(w_{L}\right)>\pi\left(w_{L}, s^{m}\left(w_{0}\right)\right)+\delta \pi_{1}^{m}\left(w_{L}\right)$,

(B-7) $\pi^{m}\left(w_{0}\right)+\delta \pi^{E}\left(w_{0}\right)>\pi\left(w_{0}, s^{m}\left(w_{H}\right)\right)+\delta \pi^{m}\left(w_{0}\right)$.

Assumption (B-6) implies that $w_{L}$ is so low, that it is never profitable in state $w_{L}$ to use the monopoly signal of state $w_{0}$, even if doing so deters entry, and failing to do so does not. Assumption (B-7) implies that $w_{H}$ 
is so high that in (or rather: slightly below) state $w_{0}$ it is never profitable to use the monopoly signal of state $w_{H}$, even if doing so deters entry, and failing to do so does not. Assume again that the cost of failing to deter entry, $\pi^{m}(w)-\pi^{E}(w)$, is nondecreasing in $w$ :

(B-8) $\partial\left(\pi^{m}(w)-\pi^{E}(w)\right) / \partial w \geq 0$.

Define $g(w)$ as the a priori probability density function of $w$. A sequential equilibrium in this framework is defined as

Definition 2 A sequential equilibrium of the entry deterrence game described in this section consists of a strategy $s(w)$ for the incumbent, an entry function $e(s)$, and a belief density function $\mu(w \mid s)$ such that the following conditions hold:

1. Optimality for the incumbent: For $\forall w \in\left[w_{L}, w_{H}\right]$

$$
s^{*}(w) \in \arg \max _{s} \pi(w, s)+\delta e(s) \pi^{E}(w)+\delta(1-e(s)) \pi^{m}(w),
$$

2. Optimality for the entrant:

$$
e(s)=\left\{\begin{array}{ccc}
1 & \text { if } & E\left(\pi^{e}-F \mid \mu(w \mid s)\right)>0 \\
0 & \text { if } & E\left(\pi^{e}-F \mid \mu(w \mid s)\right)<0 \\
\in[0,1] & \text { if } & E\left(\pi^{e}-F \mid \mu(w \mid s)\right)=0
\end{array}\right.
$$

with

$$
E\left(\pi^{e}-F \mid \mu(w \mid s)\right)=\int_{\left\{w: s^{*}(w)=s\right\}}\left(\pi^{e}(w)-F\right) \mu(w \mid s) d w
$$

3. Bayes" consistency of beliefs:

$$
\mu(w \mid s)=\left\{\begin{array}{cc}
\text { arbitrary } & \text { if }\left\{w: s^{*}(w)=s\right\}=\emptyset \\
g(w) / \int_{\left\{w: s^{*}(w)=s\right\}} g(w) d w & \text { otherwise }
\end{array}\right.
$$

The first two conditions are equivalent to those in definition 1. The last condition provides the continuous-type equivalent of (4.3). The first line implies that out-of-equilibrium beliefs are arbitrary ${ }^{7}$. The second

\footnotetext{
${ }^{7}$ Obviously, these beliefs are restricted by $\int_{\underline{w}}^{\bar{w}} p(w \mid s) d w=1$.
} 
gives the Bayes-updated belief if an equilibrium signal is observed. In a separating equilibrium the true type of the incumbent can be inferred upon observing 8 . In that case, (4.13) implies that the potential entrant believes that with probability 1 she faces the type $w^{\prime}$ incumbent for whom $s\left(w^{\prime}\right)=s$.

To derive the equilibrium we proceed as follows. Formal proofs are in the appendix. First, we can show that in equilibrium, the signal $s(w)$ is non-decreasing in $w$. This is intuitive. A higher $w$ implies a higher monopoly signal $s^{m}(w)$. In general, any type will either set his own monopoly signal, or the signal of a higher type. The latter can be set in an attempt to fool the potential entrant into thinking that his actual type is higher, and entry is not profitable, since $\frac{\partial \pi^{e}}{\partial w}<0$. Therefore, it can never be part of an equilibrium if a certain type sets a signal lower than that of a lower type. But given that $s(w)$ is non-decreasing in $w$, there is necessarily some $s^{*}$ below which the potential entrant decides to enter, and above which it does not enter. This gives the types with monopoly signal $s^{m}(w)$ slightly below $s^{*}$ an incentive to set $s^{*}$ as well, if doing so deters entry. Incumbents with lower $w$ will simply set their own monopoly signal, since for them it is too expensive to deter entry. Incumbents with $s^{m}(w)>s^{*}$ will also set their monopoly signal: if $s^{*}$ deters entry, then a signal $s>s^{*}$ also does. Therefore the signalling function will look as in figure 4.2 : low and high types set their monopoly signal, whereas intermediate types pool at $s^{*}$. Note that any type with $w \in\left(w_{1}^{*}, w_{2}^{*}\right)$ will pool at $s^{*}$, where $w_{2}^{*}$ is such that $s^{m}\left(w_{2}^{*}\right)=s^{*}$, and $w_{1}^{*}$

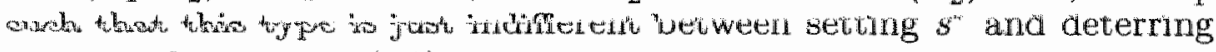
entry, and setting $s^{m}\left(w_{1}^{*}\right)$ and inducing entry. For this to be an equilibrium, however, we do need that expected profits of entering when observing $s^{*}$ are non-negative. In other words: $\int_{w_{1}^{*}}^{w^{*}}\left(\pi^{e}(w)-F\right) g(w) d w \geq 0$. This specification still allows for a continuum of equilibria: any $s^{*}$ for which this integral is non-negative, constitutes an equilibrium. However, there is only one Pareto-optimal ${ }^{8}$ equilibrium: the one in which $s^{*}$ is as low as possible, and the integral just equals zero. Therefore, we have

Theorem 4 The unique Pareto-optimal equilibrium is given by

$$
s(w)=\left\{\begin{array}{ccc}
s^{m}(w) & \text { if } & w \leq w_{l}^{*} \\
s^{m}\left(w_{h}^{*}\right) & \text { if } & w_{l}^{*}<w \leq w_{h}^{*} \\
s^{m}(w) & \text { if } & w>w_{h}^{*}
\end{array}\right.
$$

${ }^{8}$ i.e. Pareto optimal from the point of view of the different types of incumbent. 
where, given $w_{h}^{*}$, the value $w_{l}^{*}$ is the smallest root satisfying $\pi\left(w_{l}^{*}, s^{m}\left(w_{h}^{*}\right)\right)$ $(1-\delta) \pi^{m}\left(w_{l}^{*}\right)-\delta \pi^{E}\left(w_{l}^{*}\right)=0$ and $w_{h}^{*}$ is such that, given the implicit definition of $w_{l}^{*}$

$$
\int_{w_{l}^{*}}^{w_{h}^{*}}\left(\pi^{e}(w)-F\right) g(w) d w=0 .
$$

The potential entrant enters if and only if she observes a signal $s<$ $s^{m}\left(w_{h}^{*}\right)$.

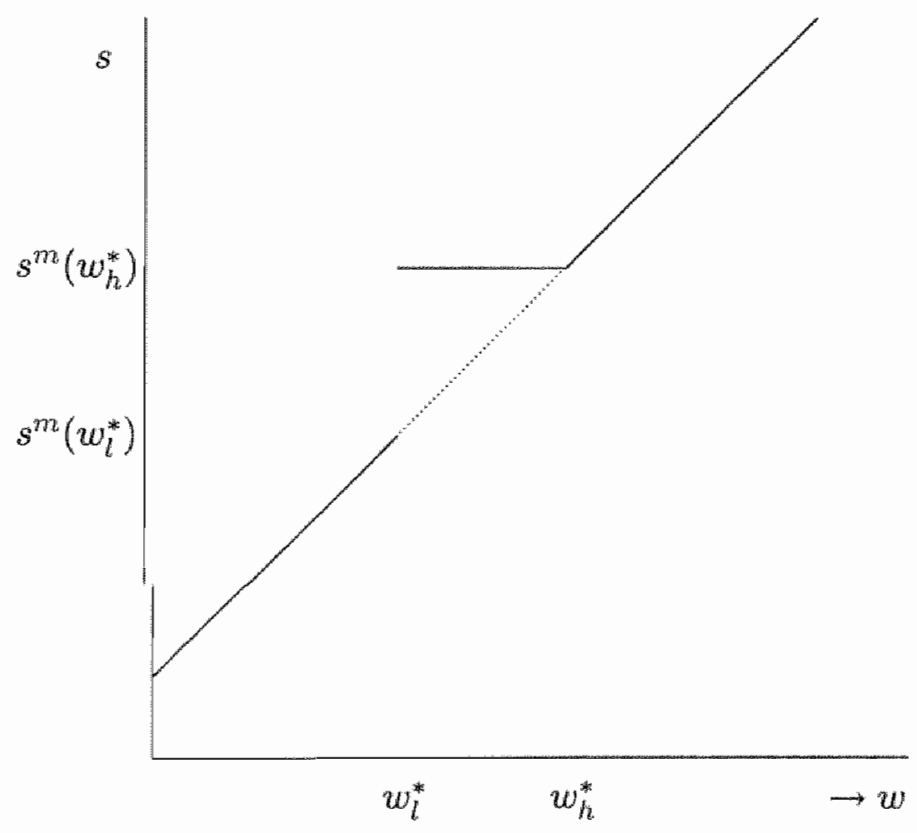

Figure 4.2: Equilibrium with a continuum of types.

This equilibrium is depicted in figure 4.2 , where the value of the signal $s$ in equilibrium is given as a function of the state of the world $w$. The diagonal line gives for each value of $w$ the monopoly signal $s^{m}(w)$. For $w$ low enough, the incumbent simply sets his monopoly signal since, here, it is too expensive to mimic a high $w$. Thus, for these values of $w$, entry is induced. For $w$ high enough, the monopoly signal is also used. In these states of the world, there is no need for the incumbent to 
distort his signal, since it is too expensive in any state of the world that induces entry, to mimic these states of the world. The interesting part is the intermediate one, where there is a pooling equilibrium, in which all states of the world use the same signal. This signal deters entry. When observing this signal the potential entrant does not enter, since her expected profits of doing so are just zero, by virtue of (4.15). The implicit definition of $w_{l}^{*}$ implies that in any state of the world $w<w_{l}^{*}$, the incumbent is better off setting his own monopoly signal, rather than the signal that deters entry, since for these incumbents we have

$$
\pi^{m}(w)+\delta \pi^{E}(w)>\pi\left(w, s^{m}\left(w_{h}^{*}\right)\right)+\delta \pi^{m}(w) .
$$

By the same argument, in any state of the world $w \in\left(w_{l}^{*}, w_{0}\right)$, where entry is also profitable, the incumbent is better off using the signal $s^{m}\left(w_{h}^{*}\right)$, since in these cases the inequality in (4.16) is reversed. Finally, also in states of the world $\left(w_{0}, w_{k}\right)$, in which entry is not profitable, the incumbent has no incentive to defect from the equilibrium, since defecting to his own monopoly quantity would induce entry, given the equilibrium strategy of the potential entrant. It is easy to see that with $\frac{\partial^{2} \pi}{\partial s \partial w}<0$, the Pareto optimal equilibrium is exactly the mirror image of the one describe above. In that case, there is an interval in which incumbent types pool by setting a signal that distorts their monopoly signal downwards. We thus have established the following result:

Theorem 5 Equilibrium in the continuous-type model. Suppose (B-1) throwgh (B-8) hold. In the Pareto optimal equilibrium, there is an interval of types $W \subset\left[w_{L}, w_{H}\right]$ in which the incumbent distorts his signal, compared with the pure monopoly case. With $\frac{\partial^{2} \pi}{\partial s \partial u}<0$, this is a downward distortion. With $\frac{\partial^{2} \pi}{\partial s \delta w}>0$, it is an upward distortion. For all states of the world $w \notin W$, the monopoly signal is used.

\subsection{A Model With A Continuum of Types And Two-Sided Uncertainty}

So far we have assumed that the incumbent has perfect knowledge about the entrant. In other words, the incumbent can exactly infer when the potential entrant enters, and when she does not. Now suppose this is not the case. For example, when the incumbent is uncertain about the marginal cost of the potential entrant, then he does not know when it 
is profitable for the potential entrant to enter, and hence cannot infer which signal will deter entry.

Denote the incumbent as firm 1, and the potential entrant as firm 2. Suppose firm $i$ has a certain type $w_{i}$, which is drawn from a probability distribution $g_{i}\left(w_{i}\right)$ on $\left[\underline{w}_{i}, \bar{w}_{i}\right]$. For each type of incumbent $w_{1}$, there is a unique type of potential entrant who is just indifferent between entry and no entry. Denote this type as $\gamma\left(w_{1}\right)$. For any $w_{2}<\gamma\left(w_{1}\right)$, entry is profitable, for any $w_{2}>\gamma\left(w_{1}\right)$, it is not. Again $\pi\left(w_{1}, s\right)$ is first-period profit of the incumbent whose type is $w_{1}$, and is using the signal $s$. In equilibrium, the potential entrant will enter if and only if $w_{2} \leq \gamma\left(\tilde{w}_{1}\right)$, where $\tilde{\omega}_{1}$ is the type of incumbent as inferred by the potential entrant. Total discounted profits of the potential entrant now equal

$$
\begin{aligned}
\Pi\left(w_{1}, \tilde{w}_{1}, s\right)= & \pi\left(w_{1}, s\right)+\delta \int_{\underline{w}_{2}}^{\gamma\left(\tilde{w}_{1}\right)} \pi^{E}\left(w_{1}, w_{2}\right) d G_{2}\left(w_{2}\right)+ \\
& \delta \int_{\gamma\left(\tilde{w}_{1}\right)}^{\bar{w}_{2}} \pi^{m}\left(w_{1}\right) d G_{2}\left(w_{2}\right)
\end{aligned}
$$

We make the following assumptions

(C-1) $\Pi\left(w_{1}, \tilde{w}_{1}, s\right)$ is continuously differentiable

(C-2) Either $\partial \Pi / \partial \tilde{w}_{1}<0$ or $\partial \Pi / \partial \tilde{w}_{1}>0$,

(C-3) Either $\frac{\partial^{2} \Pi}{\partial w_{1} \partial s}<0$ or $\frac{\partial^{2} \Pi}{\partial w_{1} \partial s}>0$,

(C-4) Entry is always profitable if $w_{1}=\underline{w}_{1}$, and always unprofitable if $w_{1}=\bar{w}_{1}$.

To solve for the signal $s$ to use, taking the first order condition of (4.17) yields

$$
\pi_{s}\left(w_{1}, s\right)+\delta \cdot \gamma^{\prime} \cdot \frac{\partial \tilde{w}_{1}}{\partial s}\left[\pi^{m}\left(w_{1}\right)-\pi^{E}\left(w_{1}, \gamma\left(\tilde{w}_{1}\right)\right)\right]=0
$$

writing $\pi_{s}$ for the first derivative of $\pi$ with respect to $s$. This implies

$$
\frac{\partial \tilde{w}_{1}}{\partial s}=\frac{\pi_{s}\left(w_{1}, s\right)}{\delta \cdot \gamma^{\prime} \cdot\left[\pi^{m}\left(w_{1}\right)-\pi^{E}\left(w_{1}, \gamma\left(\tilde{w}_{1}\right)\right)\right]}
$$


If the signaling function $s\left(w_{1}\right)$ is one-to-one, we have a separating equilibrium, thus the potential entrant can infer the true type of incumbent she faces upon observing the signal $s: \tilde{w}_{1}(s)=s^{-1}\left(w_{1}\right)$, hence

$$
\frac{\partial s}{\partial w}=\frac{\delta \cdot \gamma^{\prime} \cdot\left[\pi^{m}\left(w_{1}\right)-\pi^{E}\left(w_{1}, \gamma\left(\tilde{w}_{1}\right)\right)\right]}{\pi_{s}\left(w_{1}, s\right)}
$$

Therefore, in equilibrium we have

$$
s(w)=\frac{\delta \cdot \gamma^{\prime} \cdot\left[\pi^{m}\left(w_{1}\right)-\pi^{E}\left(w_{1}, \gamma\left(\tilde{w}_{1}\right)\right)\right]}{\pi_{s}\left(w_{1}, s\right)} \cdot w+C_{1}
$$

with $C_{1}$ the integration constant. To solve for $C_{1}$, note that the incumbent with $w_{1}=\underline{w}_{1}$ will simply set his monopoly quantity. The higher $w_{1}$, the higher the $w_{2}$ which makes entry profitable. Therefore, $\gamma^{\prime}>0$. Thus, the second term in (4.18) is strictly larger than zero. Mailath (1987) shows that, in this set-up, assumptions (C-1) through (C-3) are sufficient for a unique separating equilibrium ${ }^{9}$.

Note that, in a world with perfect information, the incurnbent simply sets a signal that maximizes first period profits: $\pi_{2}\left(w_{1}, s\right)=0$. Thus, from (4.18), the first period signal is distorted for all $w \neq w_{1}$. With $\frac{\partial^{2} I I}{\partial w_{1} \partial s}>0$, the equilibrium can be represented as in figure 4.3 , where the dotted line represents the monopoly signal, and the straight line gives the equilibrium signal in the entry deterrence game. With $\frac{\partial^{2} \Pi}{\partial w_{1} \partial s}<0$, we again have the opposite case, in which the incumbent always uses a signal below his monopoly signal. We have established the following result:

Theorem 6 Equilibrium in the continuous-type model with twosided uncertainty. Suppose (C-1) through (C-4) hold. In the unique separating equilibrium, with state of the world $w_{1}>\underline{w}_{1}$, the incumbent always distorts his signal, compared with the pure monopoly cases. With $\frac{\partial^{2} I I}{\partial w_{1} \partial s}<0$, this is a downward distortion. With $\frac{\partial^{2} I I}{\partial w_{1} \partial s}>0$, it is an upward distortion.

Note that, in all states of the world, the incumbent incurs some costs by using a signal different from the monopoly signal. Yet, the potential entrant can always infer his true type, by observing the signal. Since

\footnotetext{
Note that, with a separating equilibrium, the function $s$ is indeed monotone, as was Assumed in deriving the equilibrium.
} 


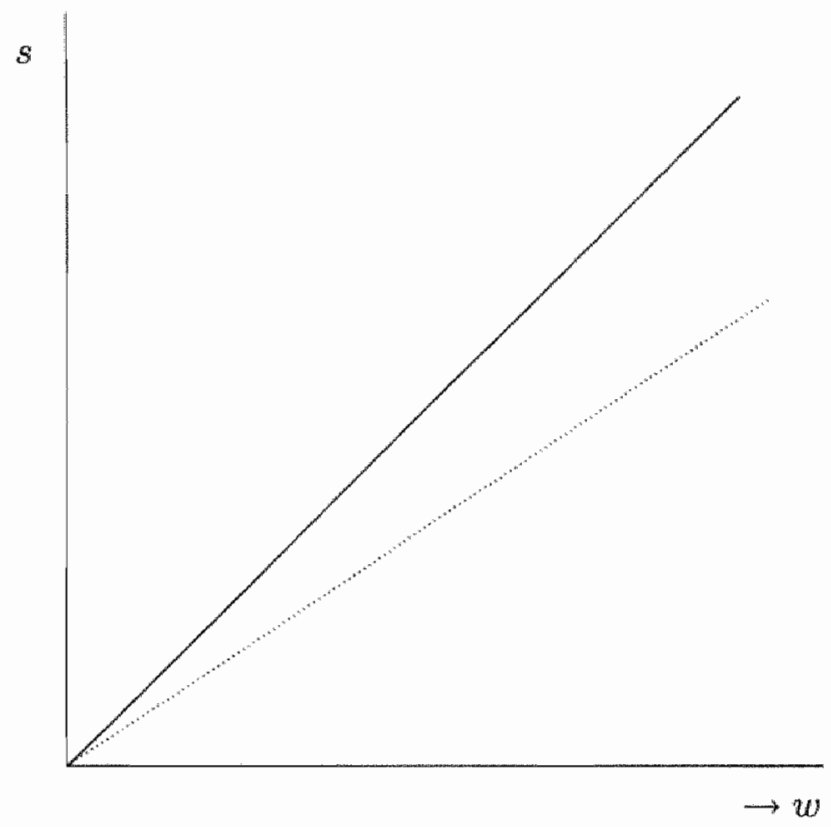

Figure 4.3: Equilibrium with two-sided uncertainty.

there is a one-to-one correspondence between incumbent type and firstperiod signal, the incumbent's signal always reveals his type. Therefore, the incumbent would always be better off if he could commit himself beforehand not to use a limit price.

\subsection{A Survey of The Literature}

\subsubsection{Introduction}

Tentatively, the results in the previous sections can be summarized as follows. If the derivative of the incumbent's first period profits with respect to the signal used, is higher in cases where entry is profitable, rather than in cases where entry is not profitable, the equilibrium involves some downward distortion compared with the pure monopoly case. If, on the other hand, the opposite is true, then the equilibrium involves some upward distortion of the monopoly signal. Naturally, some 
technical conditions have to be met as well, but this formulation does capture the gist of the results.

From this formulation, it is clear how limit pricing can be derived as an equilibrium. When price is used as a signal, all we need for limit pricing to occur is that the derivative of the incumbent's first period profits with respect to price is higher in the case where entry is profitable, rather than in the case where entry is not profitable. This condition is satisfied if we assume that the incumbent's marginal cost is private information, as Milgrom and Roberts do. It is also clear, however, that it is just as easy to construct cases in which the price set in equilibrium is higher than the monopoly price. Harrington (1986) provides an example. He also assumes the potential entrant is uncertain about the marginal cost of the incumbent. In this case, however, she is uncertain about her own costs as well. Moreover, the costs of the incumbent are correlated with those of the potential entrant. This implies that the potential entrant wants to enter if the incumbent has low costs, rather than high, as was the case in the original Milgrom \& Roberts model. Therefore, in equilibrium, the incumbent will set a price higher than the monopoly price, in an attempt to convince the potential entrant that costs are high and, therefore, entry is not profitable.

Milgrom and Roberts' paper is mostly cited because of the case of two possible types of incumbent. However, they also consider a case with a continuum of types and two-sided uncertainty. A variant on this model is provided by Matthews and Mirman (1983). In their model, the potential entrant is uncertain about a demand parameter $\theta$, which the incumbent can observe. After the incumbent makes his output choice, however, there is a demand shock. Therefore, the potential entrant can only observe the incumbent's choice with some noise $\eta$. Formally, this case is equivalent with the one described in the previous section. Upon making his own choice, the entrant cannot exactly infer whether or not the potential entrant will enter. In the analysis in section 4.4, this was due to the fact that the incumbent is uncertain about some characteristics of the potential entrant. Here, it is due to the fact that the incumbent does not know which signal the potential entrant will ultimately observe. Therefore, also in Matthews and Mirman, we always have limit pricing.

The analysis of Milgrom and Roberts has induced a considerable literature that studies the robustness of their results with respect to the underlying assumptions. Roughly, the cases of multiple incumbents, 
multiple potential entrants, multiple markets and multiple signals have been considered. The remainder of this chapter will discuss these cases in turn.

\subsubsection{Multiple Incumbents}

In Harrington (1984) there are two incumbent firms. Whether or not they form a cartel is unknown to a potential entrant. If they do form one, there is a probability that there can be a cartel with 3 firms as well. The quantity set in the first period serves as a signal of the possibility of a cartel. Note there are only two possible signals. Since any quantity below the total Cournot quantity signals that the two firms are able to cooperate, firms either set the monopoly quantity, or the Cournot quantity. If the a priori probabilities are such that there is no entry in a pooling equilibrium, both incumbents will always set a Cournot quantity and, when doing so, deter entry. Note that, in this model, there is no continuum of signals, as was the case in the analysis in the main text. Colluding incumbents set a limit price: a price that is lower than the one that would prevail without an entry threat.

Harrington (1987) considers the case of multiple incumbents, who cannot form a cartel. Marginal costs are unknown to the potential entrant, but equal for all firms. The potential entrant can only observe market price in period 1 , not the quantities the individual incumbents sets. Harrington uses a continuous-type model. Therefore, there is some interval in which a pooling equilibrium is used, and entry is deterred, by setting a price higher than monopoly price. Harrington finds that, as the initial market structure is made more competitive, i.e. the number of incumbents increases, the probability of entry can increase as well. As the initial market structure is made more competitive, each incumbent firm has less of an incentive to deter entry strategically. A countervailing effect is that the post-entry market structure also becomes more competitive as the number of incumbents increases, making entry less attractive. The total effect is ambiguous. When entry cost decreases, the probability of entry increases. The probability of entry is decreasing in the amount of potential competition. Incumbent firms have a greater incentive to prevent entry when there are many firms that might enter. Allowing entry has become more costly.

Bagwell and Ramey (1991) use a similar set-up, but assume the potential entrant can observe both incumbents' decisions. This changes the 
results fundamentally. Again, costs are equal across firms, but unknown to the potential entrant. Firm operate on differentiated goods markets. A two-type model is used. Suppose we have the case in which costs are low. For the sake of argument, assume that, initially, both incumbents adhere to the separating equilibrium prescribed by theorem 3 . Now assume one of the incumbents defects by setting his monopoly quantity. Since the potential entrants observes that the other incumbent still uses his separating quantity, she will still infer that entry is not profitable. Thus, such a defection goes unpunished, hence the configuration cannot be an equilibrium. Using the same argument it can be shown that the incumbents will not use a distortion in equilibrium, and, therefore, the outcome of the first period is the same as in the case in which there is no threat of entry. Therefore the incumbent oligopoly is actually better off than in the case of theorem 3. Since they can commit not to set anything different from the one-period profit maximizing quantity, profits are higher.

Martin (1995) builds on Bagwell and Ramey and considers the case in which the goods firms produce are strategic complements rather than strategic substitutes (see Bulow, Geneakoplos, and Klemperer (1985)), and concludes that there are circumstances in which this might change the results.

\subsubsection{Multiple Potential Entrants}

Nti (1989) considers the case in which more potential entrants consider entry. He shows that the limit price increases with the number of potential entrants, but this results seems to depend on his specification. With two potential entrants, both will also take into account that there is a probability that the other will also enter. With the parameters chosen by $\mathrm{Nti}$, the probability that entry occurs is lower with two potential entrant, than it is with two. Thus, an incumbent of a type that would induce entry, has less to lose in monopoly profits, and is therefore less inclined to mimic the behavior of the other type of incumbent. Therefore the latter can afford to set a lower limit price.

\subsubsection{Multiple Markets}

Srinivasan (1991) models the case of an incumbent monopolist operating in multiple markets, wherein the marginal cost of each market is related. The incumbent can then use his price in one market to signal 
about costs in another. Srinivasan shows that in a separating equilibrium the marginal costs of signalling are equal in all markets. Therefore, the incumbent can use the market in which signalling is most efficient to deter entry in other markets as well. Compared to the case in which different markets are served by different monopolists, the multiple market incumbent is thus able to set prices which are higher on average.

\subsubsection{Multiple Signals}

Bagwell \& Ramey (1988) study a two-type model in which the incumbent can use two signals: price and advertising. They find that in equilibrium, effectively, only one signal is used. In a separating equilibrium, the type 2 incumbent will set both the optimum price and amount of advertising of an incumbent with a slightly lower type. In the framework used in this chapter, this extension is rather straightforward. Instead of the one-dimensional signal $s$, we now have a two-dimensional vector of signals $\mathbf{s}=\left(s_{1}, s_{2}\right)$. Rather than, for example $\hat{s}_{2}<s_{2}^{m}$, as is the case in figure 4.1, we now have in equilibrium a $\hat{\mathbf{s}}_{2}<\mathbf{s}_{2}^{m}$. This analysis can be straightforwardly generalized to a case with more than two signals. In Bagwell \& Ramey (1990) a similar model is used, with demand uncertainty rather than cost uncertainty. In this case, the incumbent will use a demand decreasing distortion in equilibrium.

\subsubsection{Other Literature}

Some author variants on the Milgrom and Roberts framework, do not fit in the categories described above. Glazer and Israel (1990) observe that it is not necessarily the monopolist firm that has to incur the costs of signaling. They propose a model in which the manager carries the costs of signaling and, consequently, these costs are much lower for the firm. Suppose a manager's compensation is (partly) based on the firm's equity at the end of the second period. The manager can choose to issue some debt in period 1 , and immediately pay all the money raised as a dividend to the firm's shareholders. Issuing such a debt thus lowers his compensation, since, at the end of period 2, it has to be repaid from the firm's equity. Glazer and Israel show in a two-type model that a separating equilibrium exists where, in the state of the world in which entry is not profitable, the manager issues a debt that is higher than the debt that would be raised in the other state of the world, even if doing so deters entry. Thus, the manager rather than the firm incurs 
the costs of signaling, and monopoly prices can be set. Glazer and Israel show that such an arrangement is always cheaper for the incumbent, than incurring the costs of signaling by setting a limit price.

Finally, In Mørch von der Fehr (1992) the incumbent uses reported profits as a signal. Only reported profits yield utility. Non-reported profits are slack. Mørch von der Fehr uses a continuous-type model. There is thus some interval where reported profits are lower than actual profits. Upon observing these lower reported profits, expected profits upon entry are negative, so entry is deterred. In this model, slack therefore deters entry, rather than inducing it, as is usually the case.

\subsection{Conclusion}

In this chapter, I provided a framework for equilibrium limit pricing models. First, the case was analyzed in which there are two possible states of the world. Then, the possibility of a continuum of possible states of the world was considered. In the third model, there is a continuum of states of the world as well, but the potential entrant also has some private information. Qualitatively, these models yielded a similar result. If the derivative of the incumbent's first period profits with respect to the signal used, is higher in cases where entry is profitable, rather than in cases where entry is not profitable, the equilibrium involves some downward distortion compared with the pure monopoly case. If, on the other hand, the opposite is true, then the equilibrium involves some upward distortion of the monopoly signal. The economic implication is that it is possible to construct models in which the incumbent sets a limit price, i.e. a price below his monopoly price. But we can also have cases in which the incumbent sets a price higher than the monopoly price.

The welfare effects of limit pricing depend both on the type of model we use, and whether the limit price will be either or lower than the standard monopoly price. As a benchmark, we use the case of perfect information, in which the incumbent simply sets his standard monopoly price in the first period. First consider the case in which we have a real limit price, i.e. the price the incumbent sets in period 1 is lower than the standard monopoly price. Obviously, this lower price as such increases welfare. But this increase in welfare can be off-set by a decrease in entry in the second period. If setting a limit price really deters entry, which would not have been deterred in the case of perfect information, we have two countervailing effects. On the one hand, first period price will 
be lower, which increases welfare. On the other hand, however, there will be less competition in the second period, which decreases welfare. The net effect is ambiguous. Note that we do not have this problem in the framework described in section 4.4. There, the potential entrant can always infer the true type of the incumbent, and acts accordingly. Therefore, in that context, the limit price does cause a lower price in the first period, whereas the second period price is not affected. As a result, welfare is increased.

When the price the incumbent sets in the first period is higher than the standard monopoly price, the results changes dramatically. In that case, welfare is always lower compared to a perfect information benchmark. Both consumer surplus and profits are lower, and the deadweight welfare loss increases.

This chapter provided a framework to study how asymmetric information can affect decisions of an incumbent monopolist. One of those decisions can be the price to set. In that case, the framework can be used to study how asymmetric information can cause the incumbent to set a limit price. In the models in section 4.2 and 4.4 , the incumbent has to incur some costs in order to convince the potential entrant of his true type. Therefore, in this set-up, having private information actually hurts the incumbent rather than being to his advantage. If the potential entrant had the same information about the state of the world, the incumbent would not have to incur the cost of signalling. In section 4.3 the picture is less clear. Here, in some states of the world, the incumbent firm also has to incur signalling costs in order to avoid entry that would also have been avoided with perfect information. In other states of the world, however, the incumbent also incurs signalling costs but, as a result, deters entry which would not have been deterred with perfect information.

Thus, if the incumbent has more information than a potential entrant, he may have to incur some costs to convince the potential entrant. These costs can take the form of a limit price, a price that is lower than the monopoly price which would be set in the absence of an entry threat.

\subsection{Appendix}

Proof of Theorem 1. With $\left(s_{1}, s_{2}\right)=\left(s_{1}^{m}, s_{2}^{m}\right)$ satisfying (4.7) and (4.8), we trivially have a separating equilibrium. Suppose $\left(s_{1}^{m}, s_{2}^{m}\right)$ does not satisfy these inequalities. Consider three cases. First, $\partial \pi_{1} / \partial s<$ 
$\partial \pi_{2} / \partial s \forall s$. Second, $\partial \pi_{1} / \partial s>\partial \pi_{2} / \partial s$. Finally $\partial \pi_{1} / \partial s=\partial \pi_{2} / \partial s$.

CASE 1. Suppose $\partial \pi_{1} / \partial s<\partial \pi_{2} / \partial s$. Using strict concavity of $\partial \pi_{1} / \partial s$ and $\partial \pi_{2} / \partial s_{3}$, this implies $s_{2}^{m}>s_{1}^{m i}$. Define $\hat{s}_{2}>s_{2}^{m}$ such that

$$
\pi_{1}\left(\hat{s}_{2}\right)=\pi_{1}^{m}-\delta\left(\pi_{1}^{m}-\pi_{1}^{E}\right)
$$

Since $\pi_{1}$ is strictly concave and continuous, such $\hat{s}_{2}$ necessarily exists. Note that $\hat{s}_{2}$ is the signal for which (4.7) holds with equality. Using strict concavity of $\pi_{1}$, and the fact that $\hat{s}_{2}>s_{1}^{m}$, we have that (4.7) is satisfied for any $s_{1}^{*} \geq \hat{s}_{2}$. Also, define $\hat{s}>s_{2}^{m}$ such that

$$
\pi_{2}(\hat{s})=\pi_{2}^{m}-\delta\left(\pi_{2}^{m}-\pi_{2}^{E}\right)
$$

Thus $\hat{s}$ is the signal for which (4.8) holds with equality. Using continuity of $\pi_{2}$, a separating equilibrium exists if $\pi_{2}\left(\hat{s}_{2}\right)>\pi_{2}(\hat{s})$. An incumbent firm in state 1 can set his separating signal $s_{2}$ slightly higher than $\hat{s}_{2}$, such that (4.7) just holds. If also $\pi_{2}\left(\hat{s}_{2}\right)>\pi_{2}(\hat{s})$, then using that strategy also guarantees that (4.8) holds true. Sufficient for a separating equilibrium is thus

$$
\pi_{2}\left(\hat{s}_{2}\right)-\pi_{2}^{m}>\pi_{2}(\hat{s})-\pi_{2}^{m} .
$$

Note that, since $\partial \pi_{1} / \partial s<\partial \pi_{2} / \partial s$, we have

$$
\int_{s_{2}^{m_{2}}}^{\hat{s}_{2}} \frac{\partial \pi_{1}(s)}{\partial s} d s<\int_{s_{2}^{m}}^{\hat{s}_{2}} \frac{\partial \pi_{2}(s)}{\partial s} d s
$$

which implies

$$
\pi_{1}\left(\hat{s}_{2}\right)-\pi_{\mathbb{1}}\left(s_{2}^{m}\right)<\pi_{2}\left(\hat{s}_{2}\right)-\pi_{2}^{m} .
$$

Thus, sufficient for $(4.24)$ is

$$
\pi_{1}\left(\hat{s}_{2}\right)-\pi_{1}\left(s_{2}^{m}\right)>\pi_{2}(\hat{s})-\pi_{2}^{m} .
$$

Using (4.22) and (4.23), this reduces to

$$
\pi_{1}^{m}-\pi_{1}\left(s_{2}^{m}\right)-\delta\left(\pi_{1}^{m}-\pi_{1}^{E}\right)>-\delta\left(\pi_{2}^{m}-\pi_{2}^{E}\right),
$$

or

$$
\delta\left(\pi_{2}^{m}-\pi_{2}^{E}\right)>\delta\left(\pi_{1}^{m}-\pi_{1}^{E}\right)+\pi_{1}\left(s_{2}^{m}\right)-\pi_{1}^{m},
$$


which is satisfied because of (A-4), hence a separating equilibrium always exists.

CASE 2. For $\partial \pi_{1} / \partial s>\partial \pi_{2} / \partial s$, the proof is much along the same lines. We now have $s_{2}^{m}<s_{1}^{m}$, and define $\hat{s}_{2}<s_{2}^{m}$ such that (4.22) holds, and $\hat{s}<s_{2}^{m}$ such that (4.23) holds. A sufficient condition for a separating equilibrium is $\pi_{2}\left(s_{1}^{*}\right)>\pi_{2}(\hat{s})$, following the same argument as in case 1 . Sufficient for a separating equilibrium therefore is

$$
\pi_{2}^{m}-\pi_{2}\left(\hat{s}_{2}\right)<\pi_{2}^{m}-\pi_{2}(\hat{s})
$$

Since

$$
\int_{\hat{s}_{2}}^{s_{2}^{m n}} \frac{\partial \pi_{1}(s)}{\partial s} d s>\int_{\hat{s}_{2}}^{s_{2}^{m_{2}}} \frac{\partial \pi_{2}(s)}{\partial s} d s
$$

we have

$$
\pi_{1}\left(s_{2}^{m}\right)-\pi_{1}\left(\hat{s}_{2}\right)>\pi_{2}^{m}-\pi_{2}\left(\hat{s}_{2}\right)
$$

which implies that sufficient for (4.30) is

$$
\pi_{1}\left(s_{2}^{m}\right)-\pi_{1}\left(\hat{s}_{2}\right)<\pi_{2}^{m}-\pi_{2}(\hat{s})
$$

which is identical to (4.27). Repeating the analysis following the latter condition, we again have that a separating equilibrium exists.

CASE 3. With $\partial \pi_{1} / \partial s=\partial \pi_{2} / \partial s$ for all $s$, we necessarily have $s_{1}^{m}=$ $s_{2}^{m}$. Again define $\hat{s}_{2}>s_{2}^{m}$ and $\hat{s}>s_{2}^{m}$ as in (4.22) and (4.23). Sufficient for a separating equilibrium is (4.24). Along the same lines used to derive (4.26), we now have $\pi_{1}\left(\hat{s}_{2}\right)-\pi_{1}^{m}=\pi_{2}^{*}\left(\hat{s}_{2}\right)-\pi_{2}^{m}$. Plugging this into (4.24) and substituting for $s_{1}^{*}$ and $s_{2}^{*}$, sufficient for a separating equilibrium now is

$$
\delta\left(\pi_{2}^{m_{2}}-\pi_{2}^{E}\right)>\delta\left(\pi_{1}^{m}-\pi_{1}^{E}\right)
$$

which is satisfied because of (A-4). Hence, also in this case a separating equilibrium exists, thus proving the theorem.

To illustrate the multiplicity of separating equilibria, note that in case 1 , with $\partial \pi_{1} / \partial s<\partial \pi_{2} / \partial s$, any $s$ in the interval $\left(\hat{s}_{2}, \hat{s}\right)$ is an equilibrium. This can be seen as follows. First note that strict concavity of $\pi_{2}$ implies $\partial \pi_{2} / \partial s<0$ for all $s>s_{2}^{m}$. Also, $\partial \pi_{1} / \partial s<0$ for all $s>s_{1}^{m}$. With 
$\hat{s}_{2}, \hat{s}>s_{2}^{m}$ the result $\pi_{2}(\hat{s})<\pi_{2}\left(\hat{s}_{2}\right)$ implies $\hat{s}>\hat{s}_{2}$. Since (4.8) holds with equality for $s_{2}^{*}$, this inequality is strictly satisfied for any $s_{2} \in\left[s_{2}^{m}, \hat{s}\right]$. Also, since (4.7) holds with equality for $\hat{s}_{2}$, the condition is strictly satisfied for any $s_{2}>\hat{s}_{2}$. Therefore, for any $s_{2} \in\left(\hat{s}_{2}, \hat{s}\right)$, we have a separating equilibrium. The total number of separating equilibria can be even higher, since there is also a possibility that some $s_{2}<s_{2}^{m}$ qualify as a separating equilibrium.

Proof of Theorem 2. From theorem $1,\left(s_{1}^{m}, \hat{s}_{2}\right)$ as defined in the theorem, is a separating equilibrium. Consider the case $\partial \pi_{1} / \partial s<\partial \pi_{2} / \partial s$. First, note that any $s<\hat{s}_{2}$ violates (4.7), and is therefore not a separating equilibrium. Second, since $\hat{s}_{2}>s_{2}^{m}$ and $\pi_{2}$ is strictly concave, any $s>\hat{s}_{2}$ has $\pi_{2}(s)<\pi_{2}\left(\hat{s}_{2}\right)$ and thus involves higher signaling costs. Therefore $\hat{s}_{2}$ is the unique LCSE among all signals with $s>s_{2}^{m}$. However, this does not imply that there is no separating equilibrium with $s_{2}<s_{2}^{m_{i}}$, which still has lower cost. To prove that this is not the case, define $\hat{s}_{3}<s_{2}^{m}$, which has the same cost as $\hat{s}_{2}$, thus $\pi_{2}\left(\hat{s}_{3}\right)=\pi_{2}\left(\hat{s}_{2}\right)$. If $\hat{s}_{3}>s_{1}^{m}$, it cannot be a separating equilibrium. With $\hat{s}_{2}>\hat{s}_{3}>s_{1}^{m}$, strict concavity implies $\pi_{1}\left(\hat{s}_{3}\right)>\pi_{1}\left(\hat{s}_{2}\right)$, thus with $s_{2}=\hat{s}_{3},(4.7)$ is violated. Now suppose $\hat{s}_{3}<s_{1}^{m}$. From the definition of $\hat{s}_{3}$, we have

$$
\int_{\dot{s}_{3}}^{\dot{s}_{2}} \frac{\partial \pi_{2}(s)}{\partial s} d s=0
$$

Since $\partial \pi_{1} / \partial s<\partial \pi_{2} / \partial s$

$$
\int_{\hat{s}_{3}}^{\hat{s}_{2}} \frac{\partial \pi_{1}(s)}{\partial s} d s<0,
$$

thus $\pi_{1}\left(\hat{s}_{2}\right)<\pi_{1}\left(\hat{s}_{3}\right)$, so $\hat{s}_{3}$ violates $(4.7)$. Therefore, any separating equilibrium with $s_{2}<s_{2}^{m}$ necessarily involves higher signaling costs than $\hat{s}_{2}$, so $\hat{s}_{2}$ is the unique LCSE. The proof for the case $\partial \pi_{1} / \partial s>\partial \pi_{2} / \partial s$ is along the same lines.

To show that the LCSE is the unique equilibrium satisfying the Intuitive Criterion, I first give a formal definition of this concept.

Definition $3 A$ sequential equilibrium of the entry deterrence game, refined by using the Intuitive Criterion, consists of strategies $s_{1}^{*}$ and $s_{2}^{*}$, 
an entry function $e(s)$, and a system of beliefs $\mu(s)$, such that (4.1) and (4.2) hold, and, moreover

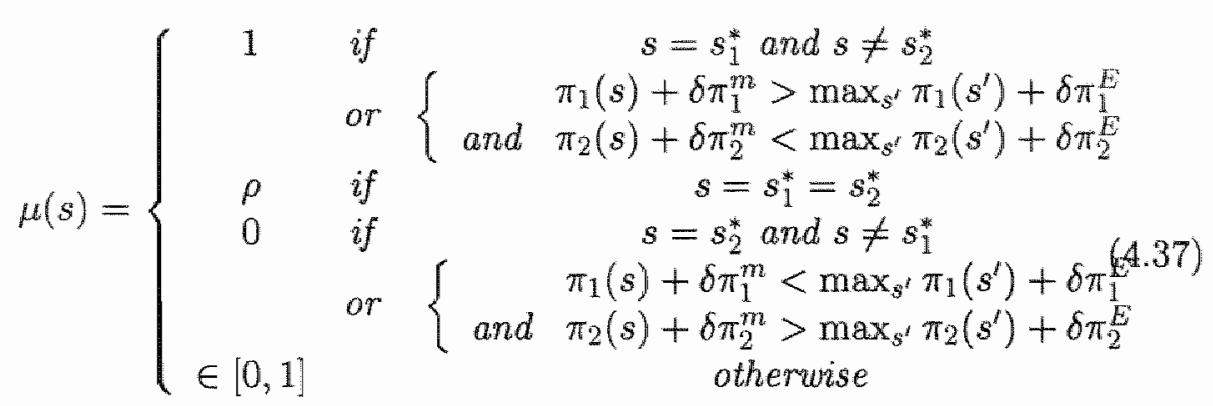

To see that (2) describes the unique separating equilibrium surviving the Intuitive Criterion, suppose we have some other separating equilibrium $\left(s_{1}^{\prime}, s_{2}^{\prime}\right)$ satisfying (4.6) and (4.6). Necessary for a separating equilibrium is $s_{1}^{*}=s_{1}^{m}$. Suppose $s_{2}^{*} \neq \hat{s}_{2}$, with $\hat{s}_{2}$ the LCSE. Suppose a type 2 incumbent would defect by setting $\hat{s}_{2}$ rather than $s_{2}^{*}$. By construction, it is just not profitable for a type 1 incumbent to set $\hat{s}_{2}$ rather than $s_{1}^{m}$, even if doing the former deters entry, whereas doing the latter does not. Hence $\hat{s}_{2}$ is equilibrium dominated for a type 1 incumbent. Therefore, upon observing $\hat{s}_{2}$ the potential entrant will conclude that she faces a type 2 incumbent, and $\mu\left(\hat{s}_{2}\right)=0$. Given this belief, it is profitable for the type 2 incumbent to defect from $s_{2}^{*}$, since doing so will yield a higher first period profit, whereas second period profits are unaffected. Thus, $\left(s_{1}^{m}, s_{2}^{*}\right)$ does not survive the Intuitive Criterion. From this argument it is clear that $\left(s_{1}^{m}, \hat{s}_{2}\right)$ is the only separating equilibrium that does survive this criterion.

The proof of theorem 3 is trivial and follows directly from theorem 2 .

To proof theorem 4, we proceed as follows. First, establish

Lemma $2 s(w) \geq s^{m}(w) \forall w$.

Proof. Note that any type will only use $s(w) \neq s^{m}(w)$ if setting $s(w)$ deters entry, whereas setting $s^{m}(w)$ does not. Therefore, if any $w^{\prime}>w_{0}$ uses this strategy in equilibrium, it implies that setting his monopoly signal invites at least one type, say $w^{\prime \prime}$ to use the same signal, whereas that type would not do so when he sets $s\left(w^{\prime}\right)$. But from the proof of theorem 2, it can be shown in this case as well, it is less expensive 
for type $w^{\prime}$ to deter entry by setting some $s\left(w^{\prime}\right)>s^{m}\left(w^{\prime}\right)$ rather than $s\left(w^{\prime}\right)<s^{m}\left(w^{\prime}\right)$. Thus, in any equilibrium, any $w^{\prime}>w_{0}$, will set $s(w) \geq$ $s^{m}(w)$. Next, consider a $w<w_{0}$. Such a type will only set $s(w) \neq s^{m}(w)$ if doing so deters entry. But since $s(w) \geq s^{m}(w)$ for all $w>w_{0}$, we necessarily have that the potential entrant will enter if she observes $s<s^{r n}\left(w_{0}\right)$, since she knows that such a signal is never set in a state of the world in which entry is not profitable. Thus, in equillibrium, no $w<w_{0}$ will set $s(w)<s^{m}(w)$, since doing so does not deter entry, and hence, the incumbent is better off setting $s^{m}(w)$.

Then, we have

Lemma $\mathbf{3} s(w)$ is nondecreasing.

Proof. Suppose the opposite is true. Hence, suppose we have $w_{1}<$ $w_{2}$, but $s_{1}>s_{2}$, with $s_{1}=s\left(w_{1}\right)$ and $s_{2}=s\left(w_{2}\right)$. Because of (B-5) and strict concavity, $w_{1}<w_{2}$ implies $s^{m}\left(w_{2}\right)>s^{m}\left(w_{1}\right)$. Using the previous lemma, we have $s_{1}>s_{2} \geq s^{m}\left(w_{2}\right)>s^{m}\left(w_{1}\right)$. Since $s_{1}>s^{m}\left(w_{1}\right)$, necessary for this to be an equilibrium is that $s_{1}$ deters entry. There are two possibilities for $s_{2}$. First suppose $s_{2}$ also deters entry. For $s_{1}$ to be an equilibrium for $w_{1}$, we need $\pi\left(w_{1}, s_{1}\right)+\delta \pi^{m}>\pi\left(w_{1}, s_{2}\right)+\delta \pi^{m}$, thus

$$
\pi\left(w_{1}, s_{1}\right)>\pi\left(w_{1}, s_{2}\right)
$$

Similarly, for $s_{2}$ to be an equilibrium for $w_{2}$, we need

$$
\pi\left(w_{2}, s_{2}\right)>\pi\left(w_{2}, s_{1}\right) \text {. }
$$

Condition (4.38) implies $\int_{s_{2}}^{s_{1}}\left(\frac{\partial \pi\left(w_{1}, s\right)}{\partial s}\right) d s>0$. But (B-5) then implies $\int_{s_{2}}^{s_{1}}\left(\frac{\partial \pi\left(w_{2} s\right)}{\partial s}\right) d s>\int_{s_{2}}^{s_{1}}\left(\frac{\partial \pi\left(w_{1} s\right)}{\partial s}\right) d s>0$, which contradicts (4.39), hence this cannot be an equilibrium. The other possibility is that $s_{2}$ does not deter entry. In that case for an equilibrium we need for $w_{1}$ : $\pi\left(w_{1}, s_{1}\right)+\delta \pi^{m}\left(w_{1}\right)>\pi\left(w_{1}, s_{2}\right)+\delta \pi^{E}\left(w_{1}\right)$, thus

$$
\pi\left(w_{1}, s_{1}\right)-\pi\left(w_{1}, s_{2}\right)>\delta\left(\pi^{E}\left(w_{1}\right)-\pi^{m}\left(w_{1}\right)\right) .
$$

For $w_{2}$ we need $\pi\left(w_{2}, s_{1}\right)+\delta \pi^{m}\left(w_{2}\right)<\pi\left(w_{2}, s_{2}\right)+\delta \pi^{E}\left(w_{2}\right)$, thus

$$
\pi\left(w_{2}, s_{1}\right)-\pi\left(w_{2}, s_{2}\right)<\delta\left(\pi^{E}\left(w_{2}\right)-\pi^{m}\left(w_{2}\right)\right) .
$$

Since, because of (B-8), the RHS of (4.41) is smaller or equal to the RHS of (4.40), the same argument as in the previous case shows that this cannot be an equilibrium, thus proving the lemma.

Note that lemma 3 immediately implies 
Lemma 4 In any equilibrium, the potential entrant will enter if and only if $s$ is larger or equal to some $s_{0}$.

Proof. With the equilibrium signaling function $s(w)$ non-decreasing, expected profits upon entry for the entrant are non-increasing in $s$. Thus if entry is unprofitable when a signal $s^{\prime}$ is observed, then entry has to be unprofitable for any $s<s^{\prime}$ as well. Also, if entry is profitable when a signal $s^{\prime \prime}$ is observed, then entry has to be profitable for any signal $s>s^{\prime \prime}$ as well.

To solve for the equilibrium in this model, first consider the most extreme states of the world. Suppose in some state of the world $w$, entry is not deterred by setting $s^{m}(w)$. Moreover, suppose that using some other signal $s$ does deter entry. In state $w$, the incumbent will set $s$ if and only if and only if

$$
\pi^{m}(w)+\delta \pi^{E}(w)<\pi(w, s)+\delta \pi^{m}(w) .
$$

Alternatively, define $M(w, s)$ as the net profit in state of the world $w$ of using the signal $s$ rather than $s^{m}(w)$, when using $s$ deters entry, whereas using $s^{m}(w)$ does not:

$$
M(w, s)=\pi(w, s)-(1-\delta) \pi^{m}(w)-\delta \pi^{E}(w) .
$$

Note that strict concavity of $\pi$ implies that $\pi(w, s)$ is decreasing in $w$ if $s>s^{m}(w)$. Using (B-9) then implies that $M(w, s)$ is decreasing in $w$ if $s>s^{m}(w)$. Note also that $M(w, s)$ is increasing in $s$ for $s>s^{m}(w)$, and is continuous. Since, by (B-6), $M\left(w_{1}, s^{m}\left(w_{0}\right)\right)<0$, and, by construction, $M\left(w_{0}, s^{m}\left(w_{0}\right)\right)=\delta\left(\pi^{m}\left(w_{0}\right)-\pi^{E}\left(w_{0}\right)\right)>0$, there is necessarily some $w_{l} \in\left(w_{L}, w_{0}\right)$ such that $M\left(w_{l}\right)=0$. Thus, $w_{l}$ is the state of the world in which the incumbent is just indifferent between setting his own monopoly quantity and that of $w_{0}$, the type that just deters entry. It is now easy to proof

Lemma 5 For any $w<w_{l}, s(w)=s^{\text {mn }}(w)$.

Proof. Suppose we have some $w^{\prime}<w_{l}$. That implies $M\left(w^{\prime}, s^{m n}\left(w_{0}\right)\right)<$ 0 . From lemma $2, s\left(w_{0}\right) \geq s^{m}\left(w_{0}\right)$. thus also $M\left(w^{\prime}, s\left(w_{0}\right)\right)<0$. From lemma 3 , all types that deter entry will set $s \geq s\left(w_{0}\right)$, thus for any $s$ that deters entry, we have $M\left(w^{\prime}, s\right)$. Thus, $w^{\prime}$ is always better off using his own monopoly signal, rather than try to deter entry by using a different signal. 
Next define $w_{h}$ such that $M\left(w_{0}, s^{m}\left(w_{h}\right)\right)=0$. Thus, $w_{h}$ is the state of the world such that in $w_{0}$, the incumbent is just indifferent between setting his own quantity and inducing entry, rather than setting the monopoly quantity of $w_{h}$ and inducing it. Note that, as noted earlier, if $s^{m}(w)<s, M(w, s)$ is increasing in $s$. Since, by $(\mathrm{B}-7) M\left(w_{0}, s^{m}\left(w_{h}\right)\right)<$ 0 , and by construction, $M\left(w_{0}, s^{m}\left(w_{0}\right)\right)>0$, such a $w_{h}$ exists and $w_{h} \in$ $\left(w_{0}, w_{H}\right)$. We can now proof

Lemma 6 For any $w>w_{h}, s(w)=s^{\pi n}(w)$.

Proof. Suppose we have some $w^{\prime}>w_{h}$. That implies $M\left(w_{0}, s^{m}\left(w^{\prime}\right)\right)$ $<0$. That implies that $w_{0}$ will not use $s^{m}\left(w^{\prime}\right)$, even if doing so deters entry, and using $s^{m}\left(w_{0}\right)$ does not. Since also $M\left(w, s\left(w^{\prime}\right)\right)<0$ there is no need for $w^{\prime}$ to use a signal other than $s^{m}\left(w^{\prime}\right)$. A potential entrant, upon observing $s^{m}\left(w^{\prime}\right)$ infers that such a signal will never be set if the true state of the world is $w<w_{0}$, and thus that entry is not profitable. Thus, $s^{m}\left(w^{\prime}\right)$ deters entry, and there is no need for $w^{\prime}$ to use a different signal.

We thus have that if the state of the world is either low enough or high enough, the incumbent simply sets his monopoly quantity. If that state is low enough, he will do so since deterring entry is too expensive. If the state is high enough, he can do so since it is too expensive in any state that does not deter entry, to mimic this behavior. The remaining problem is to analyze what will happen in the interval $\left(w_{l}, w_{k_{k}}\right)$.

Consider any $w_{2}^{*}$ in the interval $\left(w_{0}, w_{h}\right)$. Define $w_{1}^{*}\left(w_{2}^{*}\right)$ such that $M\left(w_{1}^{*}, s^{m}\left(w_{2}^{*}\right)\right)=0$. Thus, for any $w_{2}^{*}, w_{1}^{*}$ is the type who is just indifferent between setting the monopoly signal of type $w_{2}^{*}$ if doing so deters entry, and setting his own monopoly quantity, if doing so induces entry. We necessarily ${ }^{10}$ have $w_{1}^{*}\left(w_{2}^{*}\right) \in\left(w_{l}, w_{0}\right)$.

Lemma 7 An equilibrium is given by

$$
s(w)=\left\{\begin{array}{ccc}
s^{m}(w) & \text { if } & w \leq w_{1}^{*}\left(w_{2}^{*}\right) \\
s^{m}\left(w_{2}^{*}\right) & \text { if } & w_{1}^{*}\left(w_{2}^{*}\right)<w \leq w_{2}^{*} \\
s^{m n}(w) & \text { if } & w>w_{2}^{*}
\end{array}\right.
$$

${ }^{10}$ Since $s^{m}\left(\tilde{w}_{2}\right)>\bar{w}_{1}, M\left(\bar{w}_{1}, s^{m}\left(\bar{w}_{2}\right)\right)$ is decreasing in its first, and increasing in its second argument. Since, by definition $M\left(w_{0}, s^{m}\left(w_{2}^{*}\right)\right)=0$ and $\bar{w}_{2}<w_{2}^{*}$, the fact that $M\left(\bar{w}_{1}, s^{m}\left(\bar{w}_{2}\right)\right)=0$ implies $\bar{w}_{1}<w_{0}$. Also, by definition, $M\left(w_{1}^{*}, s^{m m}\left(w^{*}\right)\right)=0$, thus $\bar{w}_{2}>w_{0}$ and $M\left(\bar{w}_{3}, s^{m}\left(\bar{w}_{2}\right)\right)=0$ imply $\bar{w}_{1}>w_{1}^{*}$ qed. 
for any $w_{2}^{*} \in\left(w_{0}, w_{h}\right)$ such that

$$
\int_{w_{1}^{*}\left(w_{2}^{*}\right)}^{w_{2}^{*}}\left(\pi^{e}(w)-F^{*}\right) G(w) d w \leq 0 .
$$

The potential entrant will enter if and only if she observes $s>s^{m}\left(w_{2}^{*}\right)$.

PROOF. First, note that, given the strategy of the incumbent, the strategy of the potential entrant is a best response. In any state of the world in which the incumbent sets $s<s^{m}\left(w_{2}^{*}\right)$, entry is profitable, since any type doing so has $w<w_{0}$. For any state of the world in which $s>s^{m}\left(w_{2}^{*}\right)$, it is not profitable to enter, since any type doing so has $w>w_{0}$. When the signal $s^{m}\left(w_{2}^{*}\right)$ is observed, the potential entrant does not know which type of incumbent she faces. She does know, however, that the true state of the world is in the interval $\left(w_{1}^{*}\left(w_{2}^{*}\right), w_{2}^{*}\right)$. Given $G(w)$, the probability distribution of the true state of the world $w$, expected profits upon entry are given by the integral in (4.44). If this expression is smaller or equal to zero, the potential entrant will not enter, hence her strategy given in the theorem is a best response.

Second, note that, given the strategy of the potential entrant, the strategy of the incumbent is a best response. Any $w>w_{2}^{*}$ sets his monopoly signal and deters entry, hence is behaving in an optimal matter. For any $w \in\left(w_{1}^{*}\left(w_{2}^{*}\right), w_{2}^{*}\right)$ entry is deterred, but a signal different from the monopoly signal is used. Since, by definition, $M\left(w_{1}^{*}\left(w_{2}^{*}\right), s^{m}\left(w_{2}^{*}\right)\right)$ $=0$, for any $w \in\left(w_{1}^{*}\left(w_{2}^{*}\right), w_{2}^{*}\right)$ we have $M\left(w, s^{m}\left(w_{2}^{*}\right)\right)>0$, hence these types prefer setting $s^{m}\left(w_{2}^{*}\right)$ which deters entry, rather than setting their own monopoly signal $s^{m}(w)<s^{m}\left(w_{2}^{*}\right)$, which induces entry, given the equilibrium strategy of the potential entrant. Finally in all states of the world $w<w_{1}^{*}\left(w_{2}^{*}\right)$ entry can be deterred by setting $s^{m}\left(w_{2}^{*}\right)$, but with $w<w_{1}^{*}\left(w_{2}^{*}\right)$ we have $M\left(w, s^{m}\left(w_{2}^{*}\right)\right)$, hence these types prefer to set their own monopoly quantity, even if doing so induces entry.

Lemma 8 In the Pareto-optimal equilibrium, we have $w_{2}^{*}$ such that (4.44) holds with equality.

Proof. Define $w_{h}^{*}$ such that (4.44) holds with equality. All equilibria are given by lemma 7 with $w_{2}^{*} \in\left[w_{h}^{*}, w_{h}\right]$. Suppose we use the equilibrium with $w_{2}^{*}$ equal to some $w_{2}^{\prime}$. Consider what happens if we move to the equilibrium with $w_{2}^{*}$ equal to some $w_{2}^{\prime \prime}$. For all states of the world $w \in\left[w_{2}^{\prime \prime}, w_{2,}^{\prime}\right.$, this would be an improvement: in the new equilibrium, they can set their monopoly signal, which was not the case in the 
initial equilibrium. In states of the world $w \in\left[w_{1}\left(w_{2}^{\prime}\right)\right.$, w $\left.w_{2}^{\prime \prime}\right]$, the incumbent set $s^{m}\left(w_{2}^{\prime}\right)$ in the initial equilibrium, and $s^{m}\left(w_{2}^{\prime \prime}\right)$ in the new one. In these states of the world $s^{m}(w)<s^{m}\left(w_{2}^{\prime \prime}\right)<s^{m}\left(w_{2}^{\prime}\right)$, hence concavity of $\pi$ implies that profits are higher in the new equilibrium. In states of the world $w \in\left[w_{1}\left(w_{2}^{\prime \prime}\right), w_{1}\left(w_{2}^{\prime}\right)\right]$ the monopoly signal was set in the original equilibrium, but the signal $s^{m}\left(w_{2}^{\prime \prime}\right)$ is used in the new equilibrium. In the initial equilibrium, entry was not deterred, whereas in the new equilibrium, it is. With $M\left(w, s^{m}\left(w_{2}^{\prime \prime}\right)\right)>0$ for these types, they are better off in the new equilibrium as well. All other types are not affected by the change in equilibrium. Hence a lower $w_{2}^{*}$ in lemma 7 is Pareto improving for the incumbent in all possible states of the world. Hence, the Pareto-optimal equilibrium is the one with the lowest possible $w_{2}^{*}$, with is the one given in lemma 8. 


\section{Chapter 5}

\section{Stackelberg and Cournot Competition under Equilibrium Limit Pricing}

\subsection{Summary and Overview}

${ }^{1}$ This chapter is an application of the Milgrom and Roberts limit pricing model, discussed in the previous chapter. I show that the claim that the price in a Stackelberg model is lower than the price in a Cournot model, does not necessarily hold in such a framework. When post-entry competition is Stackelberg instead of Cournot, this might influence the entry decision of a potential entrant in such a way that expected average price can actually be higher under Stackelberg competition. In a simple framework with linear demand and constant marginal costs, I derive conditions under which this holds.

\subsection{Introduction}

In a simple duopoly model, the price in a Stackelberg equilibrium is lower than that in a Cournot equilibrium ${ }^{2}$. When both firms have con-

${ }^{1}$ A slightly different version of this chapter is published in Journal of Economic Studies, 1996, 23(5/6), pp. 110-127. It is co-written by J.A.H. Maks. For reasons of consistency, however, in this chapter I use the pronouns "I", and "me", rather than "we" and "our", where appropriate.

${ }^{2}$ Levin (1988) shows that this is the case when Hahn's (1962) conditions for stability of the Cournot equilibrium hold. Anderson \& Engers (1992) prove it in 
stant marginal costs, Stackelberg competition is thus superior from a welfare point of view. In this chapter however, I show that Stackelberg competition is not necessarily welfare enhancing in an entry-deterrence framework.

Suppose we have one incumbent firm, which tries to deter entry from one potential entrant. If the original incumbent acts as a Stackelberg leader when entry has taken place, post-entry profits for the entrant will be lower than in case of Cournot competition. Therefore, entry is less attractive. In this chapter I show that in a Milgrom \& Roberts (1982) limit pricing framework, average prices might be higher with post-entry Stackelberg competition than they are when post-entry competition is Cournot. The threat that a firm will act as a Stackelberg leader thus decreases welfare relative to Cournot competition, instead of increasing it, as it does in a standard model.

In my model, an incumbent firm tries to deter entry from a potential entrant. The incumbent can have either high or low marginal cost. The potential entrant does not know the incumbent's marginal cost. When she ${ }^{3}$ enters, she has to incur some fixed costs which cannot be recovered. I assume that if post-entry competition is Cournot, it is profitable to enter if and only if the incumbent has high cost. The incumbent uses his price in the first period to signal his marginal costs. In this type of model, limit pricing in the sense of Bain (1949) can occur in equilibrium. A limit price is a price set by a monopolist, which is below the static monopoly price. In the model, a low cost incumbent sets a price in the first period to convince the potential entrant that it is not profitable to enter. But the potential entrant can only be convinced of the latter, if the price set is so low that it is just not profitable for a high cost incumbent to set that same price in the first period, instead of just setting his own monopoly price and inducing entry. In this case, a low cost incumbent applies limit pricing, by setting a price which is lower than the price which maximizes his first period profit. Under some circumstances however, a high incumbent can mimic a low cost incumbent. In that case, a high cost incumbent applies limit pricing.

When we change the model by assuming that post-entry competition is Stackelberg instead of Cournot, some things change in equilibrium.

\footnotetext{
hierarchical Stackelberg model with a restricted class of demand functions, which
includes linear demand. female.

"Again, I refer to the incumbent as being male, and the potential entrant as being
nale.
} 
First, we can have that firms which did consider entry in the Cournot case, do not consider entry in the Stackelberg case. Entry occurs less frequently, enabling the incumbent to set his monopoly price more often. Second, the probability that a high cost incumbent can mimic a low cost one, is smaller. Third, the limit price the low cost incumbent sets, is higher. All these effects influence the market price in the pre- and postentry period, and thus also the expected average price. In this chapter I derive conditions in which the expected average price will be higher under Stackelberg competition. In those cases the standard result of Stackelberg competition yielding lower prices, no longer holds.

The remainder of this chapter is organized as follows. In section $5.3 \mathrm{I}$ restate the basic results of a standard duopoly model, with both Cournot and Stackelberg competition. In section 5.4 I introduce my model. The outcome of the model with Cournot and Stackelberg competition will be derived in section 5.5 resp. 5.6. Section 5.7 compares price and welfare effects in both models, and section 5.8 concludes the paper.

\subsection{The Standard Model}

This section reviews the basic results of both Cournot and Stackelberg competition in a static linear demand model. The setup is the following. We have two firms, $i=1,2$. Marginal costs of firm $i$ are constant and given by $c_{i}$. Market demand is determined by $p=a-b q$, with $q$ quantity, $p$ price, and $a$ and $b$ parameters. With Cournot competition, the firms play a quantity setting game with simultaneous moves. In case of Stackelberg competition, the two firms also play a quantity setting game, but one of the firms, the Stackelberg leader, moves first. Assume parameters are such that in both the Stackelberg and the Cournot model all firms supply non-negative amounts. In table $1 \mathrm{I}$ list the basic results in both models: the quantity supplied $(q)$ and profit achieved $(\pi)$ by every firm, and the resulting market price $(p)$. In the Stackelberg equilibrium, firm 1 is the leader, and firm 2 the follower.

I will use $\pi_{i}^{C}\left(c_{1}, c_{2}\right)$ to denote the profit of firm $i$ in a static Cournot game when marginal costs of firm 1 are given by $c_{1}$, and those of firm 2 are $c_{2}$. Analogously, $\pi_{1}^{S}\left(c_{1}, c_{2}\right)$ is the profit of a Stackelberg leader when his marginal costs are $c_{1}$, and that of his competitor equal $c_{2}$, and $\pi_{2}^{S}\left(c_{1}, c_{2}\right)$ is the profit of the follower under the same cost configuration. Furthermore, I will use $p^{C}$ for the price in a static Cournot equilibrium, and $p^{S}$ for the price in a static Stackelberg equilibrium. 


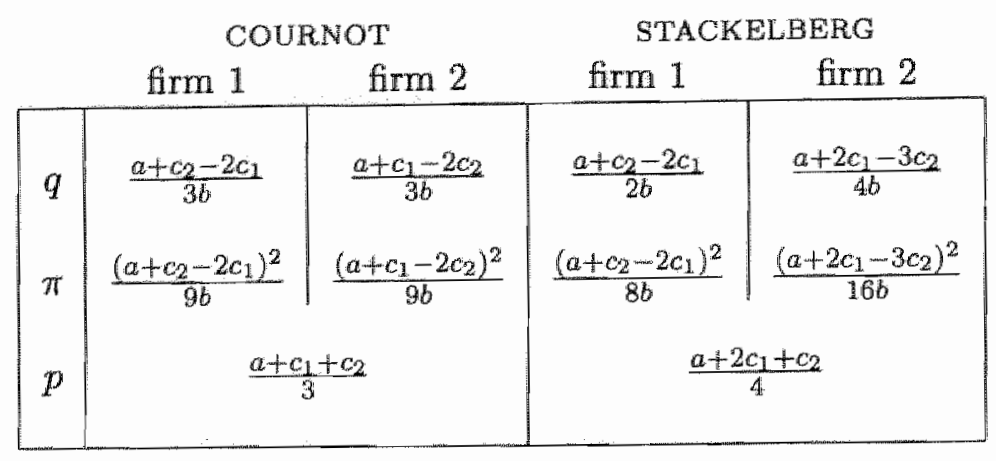

Table 5.1: Equilibrium with Cournot and Stackelberg competition

Levin (1988) shows that the Stackelberg price is always smaller than the Cournot price, provided both firms produce positive quantities and Hahn's (1962) two conditions for the stability of the Cournot model hold. The latter is clearly the case in this linear setup. From the results in table 1 it is straightforward to show that the Stackelberg price is indeed lower than the Cournot price, since existence of Cournot equilibrium requires $a+c_{2}-2 c_{1}>0$. Using this condition, we can also show that the profit of the Stackelberg leader is higher than his Cournot profit, whereas the profit of the Stackelberg follower is lower than his Cournot profit $^{4}$. For this model I have thus established the following facts:

$$
\begin{aligned}
& p^{S}<p^{C} \\
& \pi_{1}^{S}>\pi_{1}^{C} \\
& \pi_{2}^{S}<\pi_{2}^{C} .
\end{aligned}
$$

\footnotetext{
"Note from table 1 that the quantity supplied by a Stackelberg follower is higher than the quantity supplied by a Cournot duopolist iff $\left(a+2 c_{1}-3 c_{2}\right) / 4 b>(a+$ $\left.c_{1}-2 c_{2}\right) / 3 b$. This implies $\left(3 a+6 c_{1}-9 c_{2}\right) / 12 b>\left(4 a+4 c_{1}-8 c_{2}\right) / 12 b$, which requires $a+c_{2}-2 c_{1}<0$. The latter condition is the same one that is necessary for the existence of a Cournot equilibrium. Therefore, the quantity supplied by a Stackelberg follower is always lower than the quantity supplied by a Cournot duopolist. Since Stackelberg price is lower than Cournot price, this implies that Stackelberg follower profits are lower than Cournot profits.
} 


\subsection{The Entry Deterrence Model}

In this section I describe the entry deterrence model, which is a simplified version of Milgrom \& Roberts (1982). In the model, an incumbent firm tries to deter entry in a situation where he has some private information. By the decision he makes before entry, the incumbent firm tries to manipulate the potential entrant's assessment of that information. Milgrom and Roberts show that in this context limit pricing in the sense of Bain (1949) can occur. If limit pricing occurs, the incumbent sets a pre-entry price which is lower than his monopoly price in an attempt to convince the potential entrant that entry is not profitable. In this way, Milgrom \& Roberts provide a model in which limit pricing is fully consistent with profit maximization of the incumbent and the potential entrant, both before and after entry might take place ${ }^{5}$.

Consider the following model. There are two periods in which a homogeneous good is supplied. Market demand in each period is given by $p=a-b q$. We have two firms: one incumbent and one potential entrant. Both have constant marginal costs. The potential entrant is able to produce against marginal $\cos t s \bar{c}$. However, the potential entrant does not know whether the incumbent has the same marginal costs $\bar{c}$, or, because he has more experience in producing the good, the incumbent has succeeded in obtaining the lower marginal cost $\underline{c}$. The probability that the incumbent has the lower marginal cost is given by $\rho$. Of course, the incumbent knows his true marginal cost. In period 1, the pre-entry period, only the incumbent is producing. He sets a quantity ${ }^{6}$, which I denote by $q^{1}$. Based upon this quantity and her own beliefs, the potential entrant decides whether or not to enter. If she does, competition will take place in period 2 , the post-entry period ${ }^{7}$. If she does not, the incumbent can simply set his monopoly price in the second period. Assume that the potential entrant has to incur fixed cost $F$ upon entry,

\footnotetext{
Why earlier models of limit pricing are not consistent in this sense, is made clear in Friedman (1979). See also Roberts (1987), and chapter 3 of this thesis.

${ }^{6}$ Note that for a monopolist and a given demand function, quartity setting and price setting are formally equivalent. For ease of exposition, in the remainder of this chapter I will use the convention that the monopolist sets a quantity in period 1. Setting a limit price (i.e. a price below monopoly price) is then equivalent with setting a limit quantity (i.e. a quantity above monopoly quantity) in the pre-entry period.

${ }^{7}$ The term post-entry thus refers to the period after entry could have taken place. It is not necessary that entry actually has taken place.
} 
where $F$ is such that, given that post-entry competition is Cournot, it is profitable for the potential entrant to enter if the incumbent has high marginal cost, but it is not profitable to do so if he has low cost. Both firms maximize the sum of their profits in period 1 and 2. For simplicity, the discount factor equals one. I restrict attention to pure strategy equilibria.

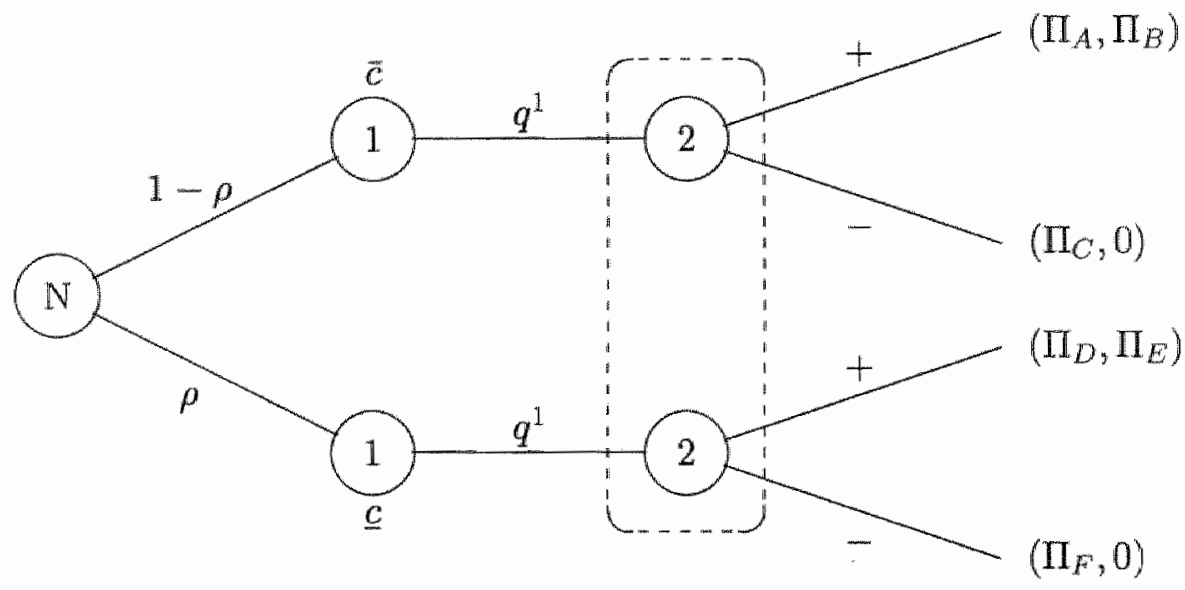

The game both firms play can be depicted by the game tree in figure 5.4. At the first node (on the left hand side) a move by Nature decides whether the incumbent (firm 1) has high or low marginal cost. This choice becomes known to the incumbent firm, which then sets a quantity $q^{1}$ in period 1. He can choose from a continuum of possible $q^{2} \mathrm{~s}$, but for simplicity $I$ have represented his decision by a single branch in figure 1. The potential entrant (firm 2) then observes $q^{1}$, but does not know whether it was set by a high cost or a low cost incumbent, as indicated by the information set given by the dashed box. The potential entrant decides to enter $(+)$ or not to enter $(-)$. The resulting payoff vectors in figure 1 will be elaborated upon in the next sections. For each outcome, the first element of the vector represents the payoff to the incumbent firm and the second element the payoff to the potential entrant.

As equilibrium concept I use a sequential equilibrium (see Kreps and Wilson 1982). Sequential equilibrium requires that the strategy of every player $i$ is rational at each node of the game, given the equilibrium strategies of the other players, and given the beliefs the players have at each information set. Moreover, the beliefs must be consistent with 
the equilibrium strategies. Sequential equilibrium thus requires that the strategies constitute a subgame perfect equilibrium, and that all beliefs are updated according to Bayes' rule.

My model differs in one important aspect from Milgrom \& Roberts. They assume that the marginal costs of the potential entrant are unknown to the incumbent firm. I assume they are known, and equal to $\bar{c}$, the high marginal cost of the incumbent firm. This simplifies calculations, and gives an interpretation of the incumbent's marginal cost: I implicitly assume that before entering an industry all firms have access to the same technology, which yields constant marginal costs. However, a incumbent firm which is already producing, might be able to produce more efficiently.

In the next section I will solve for the equilibrium in case post-entry competition is of the Cournot type. In section $5.6 \mathrm{I}$ do so for post-entry Stackelberg competition.

\subsection{Equilibrium with Cournot Competition}

I now solve the model outlined in 5.4, when post-entry competition is Cournot. I first introduce some additional notation. Define $\pi^{\mathbb{1}}\left(q^{1}, c_{1}\right)$ as the profit the incumbent firm (firm 1) makes in the first period when he sets a quantity $q^{1}$. It is easy to see that

$$
\pi^{1}\left(q^{1}, c_{1}\right)=\left(a-b q^{1}-c_{1}\right) q^{1} .
$$

Second, as in section 5.3, I use $\pi_{i}^{C}\left(c_{1}, c_{2}\right)$ to denote firm $i$ 's Cournot profit when marginal costs of firm 1 are $c_{1}$ and that of firm 2 are given by $c_{2}$. Finally, $\pi^{m}\left(c_{1}\right)$ are firm 1's monopoly profits when he has marginal cost $c_{1}$, and $q^{m}\left(c_{1}\right)$ is the corresponding monopoly quantity. It is easily seen that

$$
\begin{aligned}
q^{m}\left(c_{i}\right) & =\left(a-c_{i}\right) / 2 b \\
\pi^{m}\left(c_{i}\right) & =\left(a-c_{i}\right)^{2} / 4 b .
\end{aligned}
$$

Next, I will give the payoffs in figure 5.4. Consider the upper righthand branch. Here we have that the incumbent has high rnarginal costs, and the potential entrant has decided to enter. In the second period we thus have Cournot competition. Therefore,

$$
\begin{aligned}
& \Pi_{A}=\pi^{1}\left(q^{1}, \bar{c}\right)+\pi_{1}^{C}(\bar{c}, \bar{c}) \\
& \Pi_{B}=\pi_{2}^{C}(\bar{c}, \bar{c})-F .
\end{aligned}
$$


By assumption, we have $\Pi_{B}>0$.

Now consider the case the incumbent has high cost and the potential entrant does not enter. The latter then necessarily has pay-off 0 . The incumbent can set a monopoly price in period 2 , hence we have

$$
\Pi_{C}=\pi^{1}\left(q^{1}, \bar{c}\right)+\pi^{m}(\bar{c}) .
$$

In the lower half of figure 1 , we have similar payoffs, with the difference that here, the incumbent has low marginal cost. Along similar lines, we can show

$$
\begin{aligned}
& \Pi_{D}=\pi^{1}\left(q^{1}, \underline{c}\right)+\pi_{1}^{C}(\underline{c}, \bar{c}), \\
& \Pi_{E}=\pi_{2}^{C}(\underline{c}, \bar{c})-F \\
& \Pi_{F}=\pi^{1}\left(q^{1}, \underline{c}\right)+\pi^{m}(\underline{c}),
\end{aligned}
$$

where $\Pi_{E}<0$.

After having defined the payoffs in figure 1, I now solve for the equilibrium in this model. As usual, I use backwards induction. At the last node, the potential entrant must decide whether or not to enter. She would want to enter if the incumbent is of the high cost type. However, this is unknown to the potential entrant. She will make her decision based on the belief she has that the incumbent is of the low cost type. This belief is denoted $\mu ; \mu$ is thus the probability the potential entrant attaches to the event that the incumbent is of the low cost type. Given that belief, the decision to enter is an easy one. Entering will result in a profit of $\Pi_{E}$ with probability $\mu$, and a profit of $\Pi_{B}$ with probability $1-\mu$. Not entering yields zero profits. The potential entrant thus enters iff

$$
\mu \Pi_{E}+(1-\mu) \Pi_{B} \geq 0 .
$$

The next step is to determine the potential entrant's beliefs. In order to do that we first note that we can have two types of equilibria. In a pooling equilibrium, an incumbent always sets the same quantity in the first period, regardless of his type: $q^{1}(\bar{c})=q^{1}(\underline{c})$. In that case, the potential entrant does not obtain any additional information by observing $q^{1}$, since both types of incumbent set the same quantity in perjod 1 . Her belief that she faces a low cost incumbent thus simply equals the a priori probability that an incumbent has low cost: $\mu=\rho$. In a separating equilibrium the quantity the incumbent sets in the first period does depend 
on his type: $q^{1}(\bar{c}) \neq q^{1}(c)$. Upon observing $q^{1}$, the potential entrant thus knows which type of incumbent she faces. Her beliefs are $\mu=1$ when she observes $q^{1}(c)$, and $\mu=0$ when she observes $q^{1}(\bar{c})$. The only remaining problem is to specify the potential entrant's bellefs when the incumbent firm takes an out-of-equilibrium action. Suppose the potential entrant observes a $q^{1}$ which, according to her beliefs, meither type of incumbent was allowed to choose in equilibrium. I will follow Cho \& Kreps (1987) in assuming that the incumbent will never send a dominated message, which in this case means that in period 1 an incumbent will never choose a quantity which is always dominated by a different quantity, regardless of the action of the potential entrant in period 2.

After deriving the beliefs and strategy of the potential entrant in period 2, I now derive the strategy of the incumbent firm in period 1 . Consider a low cost incumbent. If the potential entrant had full information, the incumbent would simply set his monopoly quantity $q^{m}(\underline{c})$ in period 1. The potential entrant would then decide not to enter, for, by assumption, it is not profitable to do so when she faces a low cost incumbent. The incumbent could then also set his monopoly quantity in period 2. However, in this model the potential entrant has incomplete information. If setting $q^{m}(c)$ would deter entry, then a high cost incumbent might also set $q^{m}(\underline{c})$ and enjoy a monopoly in period $2 .{ }^{8}$ In this case, the incumbent would fool the potential entrant into thinking that he has low cost, by mimicking the behavior of a low cost incumbent.

Suppose that $\rho$ is such that the potential entrant does not enter in a pooling equilibrium. Since in a pooling equilibrium $\mu=\rho$, we have from (5.7) that this is the case iff

$$
\rho>\frac{\Pi_{B}}{\Pi_{B}-\Pi_{E}} .
$$

I will refer to the right hand side of 5.8 as $\rho^{*}$. Suppose (5.8) does hold. In that case a potential entrant will not enter in a pooling equilibrium. Both types of incumbent can then safely set $q^{m i}(\underline{c})$ in period 1 . The potential entrant does not enter since she runs too high a risk that the incumbent is of the low cost type. A high cost incumbent sets $q^{m}(\underline{c})$ instead of his own monopoly quantity $q^{m}(\vec{c})$, since the latter will induce entry, and I assumed that a high cost incumbent has a higher profit

\footnotetext{
${ }^{8}$ It is more profitable for a high cost incurnbent to do this, than it is to set his own monopoly quantity in period 1 , and having a Cournot profit in period 2. See appendix.
} 
by setting $q^{m}(\underline{c})$ and deterring entry, than he has by setting $q^{m}(\bar{c})$ and inducing it.

Suppose now (5.8) does not hold. In that case, the potential entrant would enter if both types of incumbent set the same quantity in the first period. The case in which both types of incumbent set $q^{m}(c)$ in period 1 is therefore no longer an equilibrium. A low cost incumbent prefers to set a different quantity, which signals that he is a low cost incumbent, and thus deters entry. He will therefore set a quantity for which it is just not profitable for a high cost incumbent to mimic it. I call this quantity $\hat{q}$. If a high cost incumbent mimics a low-cost one by setting $\hat{q}$ in period 1 , he will deter entry. If he sets his monopoly quantity $q^{m}(\bar{c})$, he does not. From figure 1 , we can see that $\hat{q}$ should satisfy

$$
\Pi_{A}\left(q^{m}(\bar{c})\right)=\Pi_{C}(\hat{q})
$$

where the argument of both functions denotes the quantity $q^{1}$ set in period 1. Using (5.4) and (5.5), we have that (5.9) holds iff

$$
\pi^{m}(\bar{c})+\pi_{1}^{C}(\bar{c}, \bar{c})=\pi^{1}(\hat{q}, \bar{c})+\pi^{m}(\bar{c}) \text {. }
$$

Using (5.2) and table 5.1 it can be shown that this implies ${ }^{9}$

$$
\hat{q}=\left(1+\frac{1}{3} \sqrt{5}\right)(a-\vec{c}) / 2 b
$$

Only when a low cost incumbent sets this $\hat{q}$, he can convince the potential entrant that he is of the low cost type, since it is not profitable for a high cost incumbent to mimic this strategy. The latter is better off setting his monopoly quantity in the pre-entry period. We thus have that for any $q^{\Perp} \geq \hat{q}$, the potential entrant will be convinced that the incumbent is of the low cost type ${ }^{10}$. The best a high cost incumbent can do is thus simply set his monopoly quantity in period 1 , which induces entry and yields Cournot profits in the pre-entry period.

Thus, when the potential entrant enters in a pooling equilibrium, a low cost incumbent can only deter entry when he sets $\hat{q}$. Note that $\hat{q}$ is

Note that (5.10) has two solutions, the other one being $\hat{q}-=\left(1-\frac{1}{3} \sqrt{5}\right)(a-\bar{c}) / 2 b$. But since $\bar{c}>c$, we have $(a-\bar{c}) / 2 b<(a-c) / 2 b=q^{m}(c)$, which implies that the Euclidian distance between $q^{m}(c)$ and $\hat{q}$, as defined in $(5.11)$, is always smaller than the Euclidian distance between $q^{m}(c)$ and $\hat{q}$. . Since the profit function is quadratic, this implies that setting $\hat{q}$ is always more profitable for the low cost incumbent than setting $\hat{q}_{-,}$, thence $(5.11)$.

${ }^{10}$ Applying Cho and $K_{r e p s}{ }^{2}$ Intuitive Criterion. 
larger than a low cost incumbent's monopoly quantity ${ }^{11}$. This implies that a low cost incumbent sets a lower price than his monopoly price. A low cost incumbent thus applies limit pricing. If the potential entrant does not enter in a pooling equilibrium, a high cost incumbent would apply limit pricing: he sets the quantity $q^{m}(\underline{c})$, which is larger than his monopoly quantity $q^{m}(\vec{c})$.

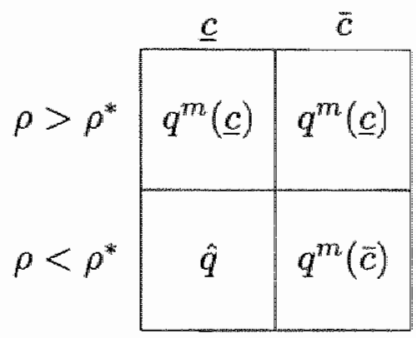

Table 5.2: $q^{1}$ in equilibrium.

The results in this section are summarized in table 5.2. The two columns give the possible type of the incumbent, the rows denote whether or not $\rho<\rho^{*}$ holds. The entries in the table give the quantity each type of incumbent sets in the first period. Here we again see that with $\rho>\rho^{*}$, we have a pooling equilibrium. Both types of incumbent then set quantity $q^{m}(\underline{c})$. The potential entrant cannot observe whether she faces a low cost or a high cost incumbent. Since the risk is too high that the incumbent is of the low cost type, the potential entrant decides not to enter. In this case, by mimicking the behavior of a low cost incurnbent, a high cost incumbent can deter entry. When $\rho<\rho^{*}$, the strategies mentioned in the top row of table 1 can no longer constitute an equilibrium. We then have a separating equilibrium. When both types of incumbent would set $q^{m}(\underline{c})$, the potential entrant would enter. Therefore, a low cost incumbent has an incentive to set that quantity which distinguishes him from a high cost incumbent, that is, the quantity $\hat{q}$, where a high cost incumbent is better of setting his own monopoly quantity and inducing entry, than he is setting $\hat{q}$ and deterring it. The best a high cost incumbent can do is then simply setting $q^{m}(\bar{c})$. In equilibrium the potential entrant will enter either if $\rho>\rho^{*}$ and $q^{1}<q^{m}(\underline{c})$, or if $\rho<\rho^{*}$ and $q^{1}<\hat{q}$.

\footnotetext{
${ }^{11 .}$ Proof in appendix.
} 


\subsection{Equilibrium with Stackelberg Competition}

In the previous section I derived an equilibrium for the case in which post-entry competition is Cournot. First, we saw that a potential entrant only considers entry when her fixed cost of entry $F$ are smaller than the maximum profit entry can result in ${ }^{12}$. Second, when both types of incumbent set the same quantity in the first period, the entry decision will depend on the probability that the incumbent is of the low cost type. Third, if a potential entrant would decide to enter in such a pooling equilibrium, a low cost incumbent sets a limit price which cannot be profitably set by a high cost incumbent.

In this section I show in which ways the equilibrium changes when post-entry competition is Stackelberg instead of Cournot. I will show first that, with post-entry Stackelberg competition, there is a lower probability that a potential entrant considers entry. Second, even if the potential entrant does consider entry, the probability that she will enter in a pooling equilibrium is lower. Third, the limit price set by a low cost incumbent will be higher.

I start the analysis with redefining the variables used in figure 1. This is a straightforward change in the analysis in section 5.5. We now have

$$
\begin{aligned}
& \Pi_{A}=\pi^{1}\left(q^{1}, \bar{c}\right)+\pi_{1}^{S}(\bar{c}, \bar{c}), \\
& \Pi_{B}=\pi_{2}^{S}(\bar{c}, \bar{c})-F \\
& \Pi_{C}=\pi^{1}\left(q^{1}, \bar{c}\right)+\pi^{m}(\bar{c}), \\
& \Pi_{D}=\pi^{1}\left(q^{1}, \underline{c}\right)+\pi_{1}^{S}(\underline{c}, \bar{c}), \\
& \Pi_{E}=\pi_{2}^{S}(\underline{c}, \bar{c})-F \\
& \Pi_{F^{\prime}}=\pi^{1}\left(q^{1}, c\right)+\pi^{m}(\underline{c}) .
\end{aligned}
$$

When we repeat the analysis of the previous section, some things are changed. First, we now have that the upper bound on fixed costs $F$ to make entry attractive in the first place, will be lower. Note that in section $5.4 \mathrm{I}$ have assumed that $F$ is such that it is profitable for the potential entrant to enter if the incumbent has high marginal costs, and post-entry competition is Cournot. In other words, I assumed $F^{\prime}<\pi_{2}^{C}(\bar{c}, \bar{c})$. But if the incumbent has high cost, gross post-entry

${ }^{12}$ Later in this chapter I will also say that the potential entrant considers entry when her fixed cost of entry $F$ are smaller than the maximum profit entry can result in. 
profit with Stackelberg competition, equals $\pi_{2}^{S}(\bar{c}, \bar{c})$. This, from $(5.1)$, is lower than $\pi_{2}^{C}(\bar{c}, \bar{c})$. Therefore, if $F$ satisfies $\pi_{2}^{S}(\bar{c}, \bar{c})<F<\pi_{2}^{C}(\bar{c}, \bar{c})$, the potential entrant would never consider entry with Stackelberg competition, whereas she would with Cournot competition. If this is the case, the potential entrant can thus always set his monopoly quantity in both the pre- and post-entry period.

Second, if post-entry competition is Stackelberg, $\rho^{*}$ also changes. In (5.8) $\rho^{*}$ was defined as that $\rho$ for which the potential entrant is just indifferent between entering and not entering in a pooling equilibrium: $\rho^{*}$ equals $\frac{\Pi_{B}}{\Pi_{B}-\Pi_{E}}$. From $(5.4),(5.12)$ and (5.1) we have that both $\Pi_{B}$ and $\Pi_{E}$ are smaller under Stackelberg competition than under Cournot competition. This implies that with Stackelberg competition $\rho^{*}$ is smaller ${ }^{13}$. In other words, there is a larger range of $\rho$ 's for which the potential entrant will not enter in a pooling equilibrium. Therefore, a high cost incumbent will now apply his limit price $q^{m}(\underline{c})$ more often, whereas a low cost incumbent will apply his limit price $\hat{q}$ less often.

Third, suppose that a low cost incumbent does set his limit price. From (5.9) and (5.12) we now have

$$
\pi_{1}^{S}(\bar{c}, \bar{c})=\pi^{1}(\hat{q}, \bar{c})
$$

Since $\pi_{1}^{S}>\pi^{C}$, and $\pi^{1}$ is decreasing in $\hat{q}^{14}$ we have that under Stackelberg competition $\hat{q}$ is smaller than under Cournot competition. If a low cost incumbent sets a limit price, this price will thus be higher under Stackelberg competition. In that case $\hat{q}$ equals

$$
\hat{q}=\left(1+\frac{1}{2} \sqrt{2}\right)(a-\bar{c}) / 2 b .
$$

Summing up, we have that under Stackelberg competition the potential entrant will be less inclined to consider entry. If she does consider entry, she will be less inclined to enter in a pooling equilibrium. If a low cost incumbent sets a limit price, this limit price will be higher. Note that in the case a potential entrant still considers entry, we can again use table 5.2 to describe the equilibrium. The only difference is that under Stackelberg competition both $\rho^{*}$ and $\hat{q}$ are lower.

${ }^{13}$ Proof in appendix.

${ }^{14}$ Since we have $\hat{q}>q^{m}(c)$, and $\pi^{1}$ strictly concave. 


\subsection{Cournot and Stackelberg Compared}

In this section I consider the ultimate effect on price and welfare of both Stackelberg and Cournot competition. To do this, I use the results derived in the previous sections. Since marginal costs are constant, a decrease in price unambiguously increases welfare, either defined as consumer surplus, or as the sum of consumer surplus and firm profits. When we again use a discount factor of one, the average price in the pre- and post-entry period is thus an unambiguous measure of discounted welfare. As ultimate measure of welfare I therefore use the expected average price, taking into account that the incumbent will have low marginal costs with probability $\rho_{\text {n }}$ and high marginal costs with probability $1-\rho$.

I will use the situation with post-entry Cournot competition as a starting point and consider what happens if post-entry competition becomes Stackelberg instead. For simplicity I will refer to the model with post-entry Cournot competition as the Cournot model and to the model with post-entry Stackelberg competition as the Stackelberg model. Analogously, the Cournot equilibrium is the equilibrium in the Cournot model, and the Stackelberg equilibrium the equilibrium in the Stackelberg model.

First consider $F$. In the Cournot equilibrium we had $\pi_{2}^{C}(\underline{c}, \bar{c})<F<$ $\pi_{2}^{C}(\bar{c}, \bar{c})$. In a Stackelberg equilibrium we need $\pi_{2}^{S}(\underline{c}, \bar{c})<F^{\prime}<\pi_{2}^{S}(\bar{c}, \bar{c})$. For any $F$ which satisfies $\pi_{2}^{S}(\bar{c}, \bar{c})<F<\pi_{2}^{C}(\bar{c}, \bar{c})$, we thus have that a potential entrant would consider entry in a Cournot model, whereas she would not in a Stackelberg model. This unambiguously raises expected average price. When a potential entrant considers entry, either a high cost or a low cost incumbent will set a limit price in the pre-entry period, as we saw in table 5.2. In case the potential entrant does not consider entry, the incumbent can simply set his monopoly quantity in both the first and the second period. Expected average price will then be higher.

Note that for the potential entrant to consider entry in both a Stackelberg and a Cournot equilibrium, we need

$$
\pi_{2}^{C}(c, \bar{c})<F<\pi_{2}^{S}(\bar{c}, \bar{c}) .
$$

Such an $F$ cannot exist when $\pi_{2}^{C}(\underline{c}, \bar{c})>\pi_{2}^{S}(\bar{c}, \bar{c})$. Using table 1 it is easy to see that this is the case iff

$$
\Delta c<(a-\bar{c}) / 4
$$


with $\Delta c=\bar{c}-\underline{c}$ the difference between high and low marginal costs. Thus, if (5.16) holds, expected average price will be higher under Stackelberg competition.

Now suppose (5.15) does hold. We then have that a potential entrant would consider entry in both a Cournot and a Stackelberg model. What happens to expected average price, and thus to welfare, now depends on $\rho$. In the previous section I showed that $\rho^{*}$, defined as that $\rho$ for which a potential entrant is just indifferent between entering and not entering in a pooling equilibrium, is lower in the Stackelberg model than it is in the Cournot model. We thus have $\rho^{* S}<\rho^{* C}$, where the extra superscripts again denote either the Stackelberg or the Cournot model. We can therefore have three possibilities for $\rho$ : either $\rho<\rho^{* S}$, or $\rho^{* S}<\rho<\rho^{* C}$, or $\rho>\rho^{* C}$.

First suppose $\rho>\rho^{* C}$. We are then in the upper row of table 5.2, in both the Stackelberg and the Cournot case. Both types of incumbent set $q^{m}(c)$ in the pre-entry period, and deter entry in that way. In this case the same happens in both the Stackelberg and the Cournot model, and the expected average price will be the same.

Next suppose $\rho<\rho^{*} S$. In that case we are, in both the Stackelberg and the Cournot model, in the lower row of table 5.2. A low cost incumbent sets the limit quantity $\hat{q}$, which deters entry, whereas a high cost incumbent sets his monopoly quantity $q^{m}(\bar{c})$, which induces entry. Suppose the incumbent has low costs. He then sets a higher pre-entry price in a Stackelberg model than in a Cournot model, since the limit price is higher under Stackelberg competition. In the post-entry period the two models yield the same result: in both cases the low cost incumbent sets his monopoly price. When the incumbent turns out to be a low cost one, we thus have here that average price is higher in the Stackelberg model. Now suppose the incumbent has high costs. In the first period he sets his monopoly quantity, in both the Cournot and the Stackelberg model. Then entry takes place, and we have a post-entry price which is higher in the Cournot model then it is in the Stackelberg model. When the incumbent turns out to be a high cost one, we thus have here that average price is lower in the Stackelberg model. Since average price is lower when the incumbent turns out to have high cost, and higher when he turns out to have low cost, the effect on the expected average price depends on $\rho$. There is a $\tilde{\rho}$ such that average expected price is lower in the Stackelberg model whenever $\rho<\tilde{\rho}$, and higher whenever $\rho>\tilde{\rho}$, provided of course that $\tilde{\rho}<\rho^{* S}$. 
Finally, suppose $\rho^{* S}<\rho<\rho^{* C}$. We then have that in the Stackelberg model we are in the upper row of table 5.2 , whereas in the Cournot model we are in the lower row. We thus have that a low cost incumbent in the Stackelberg model sets his monopoly quantity in both periods, but a low cost incumbent in the Cournot model sets his limit price in the pre-entry period. The average price with a low cost incumbent is then higher in the Stackelberg model. When the incumbent is of the high cost type, things are more complicated. We then have that if $\Delta c<(a-\bar{c}) / 3$, the average price for a high cost incumbent is also higher in the Stackelberg model. Therefore, in that case, the expected average price is higher as well ${ }^{15}$. However, if this condition does not hold, the Stackelberg price will be lower for a high cost incumbent. In that case we have a $\vec{\rho}$ such that expected average price in the Stackelberg model is higher if $\rho>\bar{\rho}$, provided of course that $\rho$ is in the relevant interval.

We thus have the following result:

Theorem 7 The expected average price will be higher in a Stackelberg equilibrium than in a Cournot equilibrium if any one of the following conditions holds:

1. $\Delta c<(a-\bar{c}) / 4$,

2. $F>\pi_{2}^{S}(\bar{c}, \bar{c})$,

3. $\rho<\rho^{* S}$ and $\rho>\tilde{\rho}$,

4. $\rho^{* S}<\rho<\rho^{* C}$ and $\Delta c<(a-\bar{c}) / 3$,

5. $\rho^{* S}<\rho<\rho^{* C}$ and $\rho>\bar{\rho}_{2}$

with

$$
\begin{array}{r}
\Delta c=\bar{c}-\underline{c} \\
\rho^{* C}=\frac{\pi_{2}^{C}(\bar{c}, \bar{c})-F}{\pi_{2}^{C}(\bar{c}, \bar{c})-\pi_{2}^{C}(\underline{c}, \bar{c})}, \\
\rho^{* S}=\frac{\pi_{2}^{S}(\bar{c}, \bar{c})-F}{\pi_{2}^{S}(\bar{c}, \bar{c})-\pi_{2}^{S}(c, \bar{c})}, \\
\tilde{\rho}=\frac{1}{1+2 \sqrt{5}-3 \sqrt{2}}, \\
\bar{\rho}=\frac{3 \Delta c-(a-\bar{c})}{(\sqrt{5}-1)(a-\bar{c})} .
\end{array}
$$

${ }^{15}$ See appendix. 
Proof: see appendix.

Conditions (1) and (2) of the theorem imply that the fixed cost upon entry are higher than maximum Stackelberg follower profits. This implies that a potential entrant under Stackelberg competition never considers entry, so the incumbent can always set his monopoly price. Under condition (3) we have a separating equilibrium in both the Cournot and Stackelberg model. However, given $\rho$, the lower second period Stackelberg price in the case the incumbent is of the high cost type, is more than offset by a higher first period limit price of a low cost incumbent. In cases (4) and (5) we have that the incumbent is pooling under Stackelberg competition, but separating under Cournot competition. This has opposite effects on price. On the one hand, expected average prices under Stackelberg competition are higher, because of two reasons. First, a low cost incumbent no longer sets a limit price in period 1, but rather his monopoly price. Second, a high cost incumbent is now able to deter entry, which increases second period price. On the other hand, prices under Stackelberg competition are lower, since a high cost incurnbent now sets a limit price in the first period, rather than his monopoly price. Under (4) and (5) the first two effects dominate the last one.

\subsection{Conclusion}

In this chapter I showed that the clairn that the price in a Stackelberg model is lower than the price in a Cournot model, does not necessarily hold in an entry-deterrence framework. Using a signaling model of entry deterrence, I showed that when post-entry competition is Stackelberg instead of Cournot, this influences the entry decision of a potential entrant and the limit price of a low cost incumbent in such a way that expected average price can actually be higher under Stackelberg competition. In a simple framework with linear demand and constant marginal costs, I derived the conditions under which this holds.

\subsection{Appendix}

In this appendix I prove some of the statements made in the main text. First, I prove that we always have $\hat{q}>q^{m}(\bar{c})$. Second, I prove that it is more profitable for the high cost incumbent to set $q^{m}(\underline{c})$ and deter entry, than to set $q^{m}(\bar{c})$ and induce entry. Third, I prove that a low cost 
incumbent will always prefer setting $\hat{q}$ and deterring entry, then setting $q^{m}(c)$ and inducing it. Then we prove that $\rho^{* S}<\rho^{* C}$. Finally, I prove theorem 1.

First, in section 5.5 I claimed that the following proposition holds.

Proposition 1 In a Cournot equilibrium we always have $\hat{q}>q^{m}(c)$.

ProOF. Suppose $\hat{q}<q^{m}(\underline{c})$. From (5.11) and (5.3) we have that this is the case if and only if

$$
\left(1+\frac{1}{3} \sqrt{5}\right) \frac{a-\bar{c}}{2 b}<\frac{a-\underline{c}}{2 b},
$$

which is equivalent with

$$
\Delta c>\frac{1}{3} \sqrt{5}(a-\bar{c}) .
$$

From the assumption that the Stackelberg equilibrium exists however, we have $q_{2}^{S}\left(c_{2}, c_{1}\right)>0$, which implies from table 1 that $a+2 \underline{c}-3 \bar{c}>0$. The latter condition is equivalent with

$$
\Delta c<\frac{1}{2}(a-\bar{c}) .
$$

Since $\frac{1}{3} \sqrt{5}>\frac{1}{2},(5.20)$ implies that (5.19) can never hold, which proves the proposition.

Proposition 1 immediately implies

Proposition 2 In the Cournot model it is more profitable for the high cost incumbent to set $q^{m}(\underline{c})$ and deter entry, than it is to set $q^{r n}(\bar{c})$ and induce it.

PROOF". $\hat{q}$ is, by definition, that $q^{\mathbb{1}}$ for which a high cost incumbent is just indifferent between on the one hand setting that quantity and deterring entry, and on the other hand, setting $q^{m}(\vec{c})$ and inducing entry. The profit function of a high cost incumbent is decreasing for $q^{1}>q^{m}(\vec{c})$. Since $q^{m}(c)>q^{m}(\bar{c}), \hat{q}>q^{m}(\bar{c})$ implies proposition 2 .

For the equilibrium in section 5.5 to hold we also need, apart from the conditions mentioned in the text, that a low cost incumbent prefers setting $\hat{q}$ and deterring entry, above setting $q^{m}(\underline{c})$ and inducing entry. We thus need 
Proposition 3 In the Cournot model the following condition holds:

$$
\pi^{1}(\hat{q}, \underline{c})+\pi^{m}(\underline{c})>\pi^{m}(\underline{c})+\pi_{1}^{C}(\underline{c}, \tilde{c}) .
$$

PROOF. Subtracting $\pi^{m}(\underline{c})$ from both sides and using (5.2) and table $\mathbb{1}$, we obtain that the condition in the lemma is equivalent with

$$
(a-b \hat{q}-c) \hat{q}>(a+\bar{c}-2 \underline{c})^{2} / 9 b,
$$

which, using (5.11), is equivalent with

$$
\frac{1}{2}\left(1+\frac{1}{3} \sqrt{5}\right)(a-\bar{c})>\frac{4}{9}\{\Delta c+(a-\bar{c})\} .
$$

This holds if and only if

$$
0<\Delta c<\frac{1}{8}(1+3 \sqrt{5})(a-\bar{c})
$$

Since $\frac{1}{2}<\frac{1}{8}(1+3 \sqrt{5})$, condition (5.20) implies that (5.24) always holds, which proves the proposition.

Next, $\mathbb{I}$ prove

Proposition $4 \rho^{* S}<\rho^{* C}$.

PROOF. From (5.8) we have in general

$$
\rho^{*}=\frac{\Pi_{B}}{\Pi_{B}-\Pi_{E}} .
$$

Using (5.4) and (5.6) for the Cournot case and (5.12) for the Stackelberg case, we have

$$
\begin{aligned}
\rho^{* C} & =\frac{\pi_{2}^{C}(\bar{c}, \bar{c})-F}{\pi_{2}^{C}(\bar{c}, \bar{c})-\pi_{2}^{C}(\underline{c}, \bar{c})}, \\
\rho^{* S} & =\frac{\pi_{2}^{S}(\bar{c}, \bar{c})-F}{\pi_{2}^{S}(\bar{c}, \bar{c})-\pi_{2}^{S}(\underline{c}, \bar{c})} .
\end{aligned}
$$

Using table 5.1 , this simplifies to

$$
\begin{aligned}
\rho^{* C} & =\frac{(a-\bar{c})^{2}-9 b F}{\Delta c\{2(a-\bar{c})-\Delta c\}} \\
\rho^{* S} & =\frac{(a-\bar{c})^{2}-16 b F}{\Delta c\{4(a-\bar{c})-4 \Delta c\}} .
\end{aligned}
$$


Note that the numerator of $\rho^{* S}$ is smaller than that of $\rho^{* C}$. Moreover, we have that the denominator of $\rho^{* S}$ minus the denorminator of $\rho^{* C}$ equalls $\Delta c\{2(a-\bar{c})-3(\Delta c)\}$, which is larger than zero because of condition (5.20). Therefore, the denominator of $\rho^{* S}$ is larger than that of $\rho^{* C}$. Since the numerator of $\rho^{* S}$ is smaller, and the denominator is larger, we necessarily have $\rho^{* S}<\rho^{* C}$, which proves the proposition.

Finally, I prove the theorem in section 5.7. The theorem consists of 5 conditions, which I will prove in that same order.

1. In the text I already proved that $\Delta c<(a-\bar{c}) / 4$ implies $\pi_{2}^{C}\left(\underline{c}_{y} \bar{c}\right)>$ $\pi_{2}^{S}(\tilde{c}, \vec{c})$. This means that there cannot exist an $F$ such that the potential entrant considers entry in both the Cournot and the Stackelberg model. If the potential entrant does not consider entry, we have that the expected average price in the Stackelberg equilibrium will be higher than that in the Cournot equilibrium, which proves that condition 1 is sufficient for the theorem to hold.

2. When $F>\pi_{2}^{S}(\bar{c}, \bar{c})$, the potential entrant does not consider entry in the Stackelberg model, whereas I assumed that she did in the Cournot model. Using the same argument as in condition 1 , we thus have that condition 2 is also sufficient for the theorem to hold.

3. Suppose conditions 1 and 2 do not hold, and $\rho<\rho^{* S}$. In that case we are, both in the Stackelberg and the Cournot model, in the lower row of table 5.2. This means that a low cost incumbent now sets the limit quantity $\hat{q}$ and deters entry, whereas a high cost incumbent sets $q^{m}(\vec{c})$ and induces entry. We have that price is a linear function of quantity: $p(q)=a-b q$. Denote the average price in case the incumbent has low costs by $\bar{p}(\underline{c})$. In the case of Cournot competition this equals

$$
\begin{array}{r}
\bar{p}^{C}(c)=\frac{1}{2} p\left(\left(1+\frac{1}{3} \sqrt{5}\right) \frac{a-\bar{c}}{2 b}\right)+\frac{1}{2} p\left(\frac{a-\underline{c}}{2 b}\right) \\
=\frac{1}{4}(a+\bar{c})-\frac{1}{12} \sqrt{5}(a-\bar{c})+\frac{1}{4}(a+\underline{c}) .
\end{array}
$$

The average price for a low cost incumbent under Stackelberg competition equals

$$
\begin{aligned}
\bar{p}^{S}(c)=\frac{1}{2} p & \left(\left(1+\frac{1}{2} \sqrt{2}\right) \frac{a-\bar{c}}{2 b}\right)+\frac{1}{2} p\left(\frac{a-c}{2 b}\right) \\
& =\frac{1}{4}(a+\bar{c})-\frac{1}{8} \sqrt{2}(a-\bar{c})+\frac{1}{4}(a+c) .
\end{aligned}
$$


With a high cost incumbent, the price in the first period equals the price related with his monopoly quantity: $p\left(q^{m}(\vec{c})\right)=(a+\bar{c}) / 2$. In the post-entry period the market price will be either the Cournot or the Stackelberg price, given that both firms have high costs: define these prices by $p^{C}(\bar{c}, \bar{c})$ and $p^{S}(\bar{c}, \bar{c})$. We thus have

$$
\begin{aligned}
& \bar{p}^{C}(\bar{c})=\frac{a+\bar{c}}{4}+\frac{1}{2} p^{C}(\bar{c}, \bar{c})=\frac{5 a+7 \bar{c}}{12} \\
& \bar{p}^{S}(\bar{c})=\frac{a+\bar{c}}{4}+\frac{1}{2} p^{S}(\bar{c}, \bar{c})=\frac{3 a+5 \bar{c}}{8}
\end{aligned}
$$

Note that for the expected average price in the Cournot model, which I will call $E\left(\bar{p}^{C}\right)$ and for the expected average price in the Stackelberg model, $E\left(\bar{p}^{S}\right)$, we have

$$
\begin{array}{r}
E\left(\bar{p}^{C}\right)=\rho \cdot \bar{p}^{C}(\underline{c})+(1-\rho) \cdot \breve{p}^{C}(\bar{c}), \\
E\left(\bar{p}^{S}\right)=\rho \cdot \bar{p}^{S}(\underline{c})+(1-\rho) \cdot \bar{p}^{S}(\bar{c}) .
\end{array}
$$

When we equate $E\left(\bar{p}^{C}\right)$ and $E\left(\bar{p}^{S}\right)$ we find that the two are equal if

$$
\tilde{\rho}=\frac{1}{1+2 \sqrt{5}-3 \sqrt{2}}
$$

Since the average Stackelberg price is higher for a low cost incumbent and lower for a high cost incumbent, we thus have that the expected average price is higher when $\rho>\tilde{\rho}$.

4. Suppose conditions 1 and 2 do not hold and we have $\rho^{* S}<\rho<$ $\rho^{* C}$. We then have that in the Stackelberg model we are in the upper row of table 2, whereas in the Cournot model we are in the lower row. We thus have that a low cost incumbent in the Stackellberg model sets his monopoly quantity in both periods, whereas in the Cournot model he sets his limit price in the preentry period. The average price for a low cost incumbent is thus higher in the Stackelberg model.

A high cost incumbent in the Stackelberg model sets $q^{m}(\underline{c})$ in the pre-entry period, and deters entry. The average price then equals

$$
\vec{p}^{S}(\bar{c})=\frac{1}{2}\left\{\frac{a+\underline{c}}{2}+\frac{a+\bar{c}}{2}\right\} .
$$


A high cost incumbent in the Cournot model sets $q^{m}(\bar{c})$ in the pre-entry period and induces entry, which then yields a Cournot price. The average price then equals

$$
\bar{p}^{C}(\bar{c})=\frac{1}{2}\left\{\frac{a+\bar{c}}{2}+\frac{a+2 \bar{c}}{3}\right\} .
$$

It is now easy to show that $\Delta c<(a-\bar{c}) / 3$ is sufficient for $\bar{p}^{S}(\bar{c})>$ $\bar{p}^{C}(\bar{c})$. Since I already showed that in this case $\bar{p}^{S}(\underline{c})>\bar{p}^{C}(\underline{c})$, I have proven that condition 3 in the theorem is sufficient for the theorem to hold.

5. Now suppose $\rho^{* S}<\rho<\rho^{* C}$, but $\Delta c>(a-\bar{c}) / 3$. For a low cost incumbent we have

$$
\bar{p}^{S}(\underline{c})=\frac{a+c}{2}
$$

whereas $\bar{p}^{C}(c)$ is the same as the one in $(5.28)$;

$$
\bar{p}^{C}(\underline{c})=\frac{1}{4}(a+\bar{c})-\frac{1}{12} \sqrt{5}(a-\bar{c})+\frac{1}{4}(a+c) .
$$

Using (5.30), and (5.33) through (5.36), it can be shown that $E\left(\bar{p}^{C}\right)=E\left(\bar{p}^{S}\right)$ if

$$
\vec{\rho}=\frac{3 \Delta c-(a-\bar{c})}{(\sqrt{5}-1)(a-\bar{c})} .
$$

We thus have that expected average price under Stackelberg competition is higher if $\rho>\bar{\rho}$,

which proves the theorem. 


\section{Chapter 6}

\section{Vaporware as a Means of Entry Deterrence}

\subsection{Summary and Overview}

This chapter also contains an application of the Milgrom \& Roberts (1982) limit pricing model. The model described in this chapter combines limit pricing with the theory of durable goods, also discussed in chapter 2.

Firms in the computer industry are often accused of vaporware, the untruthful pre-announcement of a new version of their product. By claiming they have a new product, critics argue, these firms try to deter potential entrants. This chapter analyzes this phenomenon. First, it shows that vaporware is an equilibrium strategy in a signaling game in which the possibility to market a new good is private information. Second, it shows that vaporware is an anti-competitive strategy. The possibility of vaporware has adverse effects on welfare, also in the case the incumbent does have a new version of his product.

\subsection{Introduction}

Producers of both hardware and software often announce a new version of their product well in advance. For some reason, however, it often seems to happen that this new version is released much later than was originally scheduled. The introduction of Windows 95 was delayed by more than two years. DBase for Windows took nearly five years longer 
to develop than was originally thought. The first graphical version of Lotus 1-2-3 for OS/2 was announced in April 1987 but was not delivered until September 1990. ${ }^{1}$

In all these cases, producers claim that they originally thought they were able to market the product in time, but ran into unforeseen difficulties while developing it. But cynics argue that these firms, which often have a dominant position in their market, make the premature announcements on purpose, in an attempt to deter other firms from developing a similar product. When consumers believe the incumbent monopolist will market a new and improved version of his product in the near future, they might be tempted to refrain from buying the good a competitor supplies. Given that this will happen, supplying such a good might not be profitable in the first place, so entry will be deterred. This practice is known as vaporware: the false announcement of a new product in an attempt to deter entry.

Competition policy has been concerned with vaporware as well. In the antitrust case against Microsoft in the early nineties, vaporware was one of the accusations made ${ }^{2}$. In the case against IBM, in the late seventies, one of the claims was that IBM had engaged in premature announcements, and in some sense announced products sooner than he should have (Fisher, McGowan, and Greenwood 1983). Nevertheless, vaporware has hardly received any attention from economists ${ }^{3}$, and a satisfactory theoretical model does not exist. In this chapter, I try to fill this gap.

I address the following questions. First, can vaporware (i.e. falsely claiming that a new version of a good will be marketed in the next period) be a profitmaximizing strategy in a model in which both consumers and potential entrants rationally anticipate that the incumbent monopolist has an incentive to do so? Second, should this be the case,

\footnotetext{
'For these and many other examples, see Byte Maganine, September 1995, "Famous Vaporware Products".

${ }^{2}$ See for example the opinion in which the court decided to reject the proposed settlement between the Justice Depeartment and Microsoft (Us District Court of Columbia, 1995)

"One exceptions is Farrell \& Saloner (1986). They show that within the framework of network externalities a preannouncement might affect the technology that will ultimately be chosen by all consumers. This can be either welfare enhancing or welfare decreasing, depending on circumstances. However, Farrell \& Saloner implicitly assume that preannouncements are always truthful, and thus do not assess the welfare effect of a false preannouncement.
} 
is vaporware an anti-competitive strategy? I show that the answer to both questions is affirmative.

At first sight, it is not obvious that in a world with perfectly rational firms and consumers, vaporware can ever be an equilibrium. First, Fisher et al. (1983. p. 299) argue that "there is [...] no reason to suppose that failure to deliver as promised goes unpunished in the marketplace": if a firm has practiced vaporware in the past, he has established a reputation for doing so, and potential entrants will not be fooled again. Levy (1997) basically uses the same argument. Second, announcing a new product also has disadvantages for the incumbent. If a firm announces there will be a new, better version of his product next year, demand for the current product will decrease if the announcement induces consumers to wait for the new version, rather than purchase the current one. The model presented here, takes these effects into account.

I use a two-period signaling model to study vaporware. In the first period, an incumbent monopolist can have one of two possible types: he either has an innovation which will be marketed in the next period, or he does not have one. His type is private information. The quantity the incumbent sets serves as a signal of his type. In the second period, a potential entrant can enter the market and produce a good which is a perfect substitute for the good the incumbent produced in period 1 . Upon entry, fixed costs have to be incurred. The potential entrant is able to make a net profit upon entry if and only if the incumbent does not have an innovation.

However, having an innovation also implies that the good the incumbent is currently producing, will soon be out of date. The price consumers are willing to pay for that good depends on their beliefs about the incumbent's type. When consumers know there will be an innovation in the next period, the price they are willing to pay now will be lower. For simplicity I assume that a new product will make the old one useless. Therefore, the current good is a durable one, but only if there is no innovation.

The model fits into the tradition of entry deterrence models with asymmetric information, introduced by Milgrom and Roberts in their seminal paper (Milgrom and Roberts 1982). They show that an incumbent monopolist will practice limit pricing if the marginal costs of both the incumbent monopolist and the potential entrant are private informam tion. Other papers in this field include for example Matthews \& Mirman (1983), Harrington (1986), Bagwell \& Ramey (1991), and Haan \& Maks 
(1996) ${ }^{4}$. In the model presented here, consumers also play a role: their willingness to pay depends on the expected durability of the good. If there is a new good next period, the current one can only be used for one period. If this is not the case, the current good can be used for two periods, so the price consumers are willing to pay for the good now, is higher. In that sense, the model follows the durable good tradition, pioneered by Coase (1972), and formalized in a two-stage framework by Bulow (1982). A related paper in this field is Bucovetsky \& Chilton (1986), which considers a durable goods monopolist faced with an entry threat.

The remainder of this chapter is structured as follows. Section 6.3 presents the vaporware model. From an analytical point of view, the model boils down to an entry deterrence model with imperfect information, in which the good the incumbent produces is either a durable or a non-durable good. The equilibria in the model are derived in sections 6.4 and 6.5 , for the complete and incomplete information case. In section 6.6 I show that vaporware is an equilibrium, while section 6.7 discusses the welfare implications. I show that, first, vaporware is anti-competitive, and, second, the possibility of vaporware also adversely affects consumer welfare in the case the incumbent firm does have a new version of his product.

\subsection{The Model}

The basic setup is the following. There are two periods. Marginal costs of production always equal zero. In the first period there is one incumbent firm, which I will call firm 1. He can have two types: either he has an innovation or he does not have an innovation. I will refer to the former as an incumbent of type $I$ (for innovation), and to the latter as one of type $N$ (for no innovation). If the incumbent has an innovation, he will market a new version of his product in the next period. The incumbent's type is only known to himself. The incumbent sets a quantity in the first period, which can be observed, and therefore serves as a signal. The a priori probability that the incumbent does not have a new product equals $\rho$. There is one potential entrant, firm 2, which can enter the market after the first period. Upon entry, firm 2 has to incur sunk costs $F$. For simplicity, assume that in period 2, the potential

\footnotetext{
${ }^{4}$ For a review, see chapter 4 .
} 
entrant can produce a product which is a perfect substitute for the one the incumbent is currently producing. This is intuitive: the potential entrant can always buy the current good in the first period, analyze it, and produce something with the same specifications in period 2. When the incumbent is of type $N$ and entry occurs, both firms play a Cournot game in the second period, and the potential entrant is able to make a net profit upon entering the market.

Assume that when the incumbent introduces a new product, the old one is worthless, so the one produced by a potential entrant also is. If there is a new good, consumers are not willing to pay anything for the old one. There can be several reasons for this. For example, the new good might be technologically superior, or the incumbent might no longer actively support the old good. Alternatively, because a lot of consumers are switching to the new good, the network of consumers of the old good falls below some critical level ${ }^{5}$. This implies that in that case, the potential entrant cannot make any profits upon entering the market. Again, this assumption is made just for simplicity. In general the only thing we need for entry to be deterred, is that, if there is an new version, the old version is worth so little that the highest profit the potential entrant can make is not enough to cover fixed entry costs $F$. Finally, I assume that the old good is always worthless after two periods. This allows us to study the model as a two-period game.

In this model, entry is unprofitable if the incumbent has an innovation. But if the incumbent has an innovation, this also implies that the good he is producing now will soon be out of date. The price consumers are willing to pay for that good depends on their expectations about what will happen in the second period. When consumers know a good will be worthless by then, the price they are willing to pay now will be lower than when this is not the case. The incumbent thus faces a trade-off when setting his first-period quantity: ideally, he wants the potential entrant to believe that he does have an innovation, but wants consumers to believe that he does not have a new product.

The timing of the game is as follows. First, Nature decides whether or not firm 1 has an innovation. Second, the incumbent decides which quantity to set in the first period. Upon observing that quantity, con-

\footnotetext{
${ }^{5}$ Note however that I do not model the good as one exhibiting network externalities. The argument here is that these network externalities are only present when the number of consumers is small. This view is in line with, for example, Liebowitz and Margolis (1994).
} 
sumers and firm 2 make a simultaneous decision. Consumers decide how much they are willing to pay, and firm 2 decides whether or not to enter. After that, market price is determined, and transactions take place. In the second period, either firm 1 sets a monopoly price or, in the case there was entry and no innovation, Cournot competition takes place.

Demand is linear. Inverse demand for the services provided by the good in every period are given by

$$
p=a-b Q \text {. }
$$

Note that (6.1) reflects demand for the good per period, with $Q$ the total stock available. The equation thus gives an implicit rental, rather than a price. The price that will prevail in the first period also depends on the expected resale price in period 2. In general, in this two-period framework, if $q_{1}$ is the amount sold in period 1 , price $P$ in the first period equals

$$
P\left(q_{1}\right)=\left(a-b q_{1}\right)+\delta p_{2}\left(q_{1}\right)
$$

with $p_{2}$ the expected resale value of the good in period 2 , and $\delta$ a discount factor. For example, as Bulow (1982) notes, if we have a simple durable goods monopoly, consumers will anticipate that in period 2 the monopolist will have an incentive to satisfy residual demand $q_{2}=\frac{a-p_{2}}{b}-q_{1}$, by setting second-period quantity $q_{2}=\frac{1}{2 b}\left(a-b q_{1}\right)$. Consumers therefore know that in period 2, the total stock of goods $Q$ equals $q_{1}+q_{2}=\frac{1}{2}\left(\frac{a}{b}+q_{1}\right)$, thus $p_{2}=\frac{1}{2}\left(a-b q_{1}\right)$, and substituting in (6.2) yields $P=\left(1+\frac{\delta}{2}\right)\left(a-b q_{1}\right)$. By backward induction, the monopolist then sets $q_{1}$ such that intertemporall profits are maximized.

But in the vaporware model, things are more complicated. There are several possibilities. Suppose there is a new version in the second period. The old one is then worthless, so we have $p_{2}=0$. If there is no new good in the second period, and entry does not take place, we have $p_{2}=\left(a-b q_{1}\right) / 2$, just as in the example described above. Finally, suppose that there is no innovation, and entry does occur. The duopolists then behave in a Cournot fashion, and second period price can be shown to equal $p_{2}=\left(a-b q_{1}\right) / 3$. To save on notation, in the remainder of this chapter I will simply write $q$ instead of $q_{1}$ for first period output. For anallytical convenience, $I$ assume $\delta=1$.

As solution concept I use Kreps and Wilson's (1982) sequential equilibrium, as is also common in a limit pricing model. Sequential equilibrium requires that the strategies of the incumbent, the potential entrants 
and the consumers are best responses to the strategies of the other players, given beliefs. Moreover, beliefs are Bayes consistent with a priori probabilities and strategies of the other players. I also impose that consumers and the potential entrant allways have the same beliefs. This is in line with the Harsanyi doctrine (see Harsanyi 1967/8), which states that two individuals having access to the same information will necessarily come up with the same subjective probability assessments. In this model, consumers and the potential entrant do have access to the same information. They can all observe the quantity $q$ the incumbent sets in the first period, and I also assume they have access to the same information to determine their prior belief $\rho$.

\subsection{Equilibrium with Perfect Information}

First, I will solve the model for the case of perfect information, when consumers and the potential entrant do know the incumbent's type. In the next section I will solve it for the case of asymmetric information. There, I also give a definition of vaporware in the context of this model.

The perfect information equilibrium is easy to solve. In such an equilibrium, both the consumers and firm 2 know the type of incumbent they face. First, assume that firm 1 does not have a new product, and is thus of type $N$. Firm 2 then enters in the second period, and total profits of firm 1 can be written

$$
\Pi_{N}(q)=(a-b q) P(q) q+(a-b q)^{2} / 9 b .
$$

The first term on the right hand side of (6.3) is the first period profit of firm 1, the second term his Cournot profits in the second period. Both are a function of first period quantity $q$. Substituting (6.2), using $p_{2}=(a-b q) / 3$ yields

$$
\Pi_{N}(q)=(4 / 3)(a-b q) q+(a-b q)^{2} / 9 b
$$

Now suppose firm 1 does have a new product, and is thus of type I. Under perfect information, firm 2 does not enter. First period price simply equals $a-b q$, since consumers know that the good they purchase this period, will be worthless in the next. Total profits for the incumbent then equal

$$
\Pi_{I}(q)=(a-b q) q+\pi_{i n n o}
$$


Here, $\pi_{\text {inno }}$ denotes the second period profit the new good will generate, which does not depend on $q .{ }^{6}$ For the purposes of this chapter, we do not need a further specification of this magnitude. By maximizing profits with respect to $q$, we can use (6.4) and $(6.5)$ to derive

$$
\begin{array}{rlrl}
q_{I}^{*} & =\frac{1}{2} \frac{a}{b} ; & \Pi_{I}^{*}=\frac{1}{4} \frac{a^{2}}{b}+\pi_{i \pi n \omega} ; \\
q_{N}^{*}=\frac{5}{11} \frac{a}{b} ; & \Pi_{N}^{*}=\frac{4}{11} \frac{a^{2}}{b} .
\end{array}
$$

where $q_{i}^{*}$ and $\Pi_{i}^{*}$ denote respectively profit-maximizing first-period output, and total discounted profits of a type $i$ incumbent.

\subsection{Equilibrium with Imperfect Information}

In this section I will solve for the vaporware model in the case of imperfect information. Nate that the incumbent's first period quantity $q$ now serves as a signal of his type. Obviously, in this model, we can have two types of equilibria. In a separating equilibrium, both types of incumbent set a different quantity in the first period ( $q_{I} \neq q_{N}$, with $q_{i}$ first-period quantity of a type $i$ incumbent). By doing so, they thus reveal their type. In a pooling equilibrium, both types of firm 1 set the same quantity, $q_{I}=q_{N}$. In this case, both the consumers and firm 2 cannot infer which type of firm 1 they are facing, upon observing $q$. They only know the a priori probability $\rho$ that they face a type $N$ incumbent.

To judge whether vaporware is an equilibrium in this model, we first have to define when a firm uses vaporware. I will say that a firm uses vaporware or falsely claims that he has an innovation when we have a pooling equilibrium, and a type $N$ incumbent behaves as a type $I$ would behave in a perfect information equilibrium. We then have $q_{N}=q_{I}=q_{I}^{*}$. Two remarks are in order. First, note that claiming one has an innovation requires more than just cheap talk: a firm not only says that he is of type $I$, but also acts as a firm which is known to be of type $I$. Second, note that, according to this definition, not every pooling equilibrium qualifies as vaporware: when both types of firm pool at a quantity different from $q_{I}^{*}$, firms do not claim that they have an innovation, but rather do not make a statement at all regarding their

\footnotetext{
${ }^{6}$ Of course we have $\pi_{i m n a}>(a-b q)^{2} / 9 b$. Otherwise firm 1 would prefer Cournot competition with the old product above introducing the new product.
} 
type. Claiming that one has an innovation therefore requires acting as a type $I$ incumbent would under perfect information.

To see whether vaporware is possible, according to this definition, I will first derive which pooling equilibria exist in the model. In a pooling equilibrium, the quantity set does not reveal the type of the incumbent. The other agents do not obtain any additional information. Whether or not firm 2 enters depends on the parameters of the model. If she enters, she earns post-entry profits zero with probability $1-\rho$, and some profit $\pi_{e}$ with probability $\rho$. She will therefore not enter if and only if $\rho \pi_{e}<F$. I assume that this condition holds: if not, there would be no use in trying to deter entry by using vaporware in the first place. The a-priori probability $\rho$ also affects market price in the first period. Suppose consumers are risk-neutral. In a pooling equilibrium, there will be no entry. Therefore, with probability $1-\rho$, consumers know that the good they are purchasing now will be worthless in the next period, and with probability $\rho$, we again have $p_{2}=(a-b q) / 2$. Therefore, from (6.2) $P(q)=\left(1+\frac{\rho}{2}\right)(a-b q)$, and profits in a pooling equilibrium equal

$$
\begin{aligned}
& \Pi_{N}^{P}(q)=\left(1+\frac{\rho}{2}\right)(a-b q) q+(a-b q)^{2} / 4 b \\
& \Pi_{I}^{P}(q)=\left(1+\frac{\rho}{2}\right)(a-b q) q+\pi_{\text {inno. }}
\end{aligned}
$$

with $\Pi_{i}^{P}$ total profits of a type $i$ incumbent in a pooling equilibrium.

If the incumbent firm defects from the pooling equilibrium, the quantity set reveals the type of incumbent ${ }^{7}$. Obviously, profits as a function

"Note the assumption on the consumers" and potential entrant's out-of-equilibrium beliefs: I implicitly assume that any firm defecting from a pooling equilibrium immediately reveals his true type. This can be justified in a number of ways. First, we can endow consumers and firm 2 with an extreme out-of-equilibrium rationality. When an out-of-equilibrium action occurs, they are somehow able to rationalize the type of incumbent they face. Alternatively, we can impose a kind of risk-averseness on firm 1 , and make him assume that by defecting from a pooling equilibrium he always reveals his true type. Finally, an even more rigorous assumption would be that when consumers observe an out of equilibrium action, they judge the incumbent as being unreliable, and refuse to buy the good altogether. In that case, the range of pooling equilibria is even larger than the one I derive, which makes the results even stronger.

However, the assumption on out of equilibrium beliefs is not crucial in this model. For example, assuming that out of equilibrium beliefs are such that the other actors always believe that a firm deviating from an equilibrium is of type $I_{2}$ would change the range of possible pooling equilibria, but not the conclusion that vaporware is an equilibrium for large enough $p$. 
of that quantity then equal those in the case of perfect information:

$$
\begin{aligned}
& \Pi_{N}^{D}(q)=(4 / 3)(a-b q) q+(a-b q)^{2} / 9 b, \\
& \Pi_{I}^{D}(q)=(a-b q) q+\pi_{\text {inno. }} .
\end{aligned}
$$

with $\Pi_{i}^{D}$ total profits of a type $i$ incumbent when defecting from the pooling equilibrium. For a pooling equilibrium we need $a q^{P}$ such that

$$
\begin{array}{ll}
\Pi_{I}^{P}\left(q^{P}\right) \geq \Pi_{I}^{S}(q) & \forall q \neq q^{P}, \\
\Pi_{N}^{P}\left(q^{P}\right) \geq \Pi_{N}^{S}(q) & \forall q \neq q^{P} .
\end{array}
$$

The first condition requires that, given a pooling equilibrium $q^{P}$, the type $I$ incumbent does not have an incentive to deviate by setting a different $q$, and thereby revealing his type. The second requires the same for type $N$. Note that $\mathbb{M}_{i}^{S}\left(q_{i}^{S}\right)$ is maximized at the perfect information equilibrium $q_{i}^{*}$. From the first condition in $(6.11),(6.7)$ and $(6.6)$, we thus have that a necessary condition for a pooling equilibrium $q^{P}$ to exist is that

$$
q^{P} \in \frac{1}{2} \frac{a}{b}\left[1-\sqrt{\frac{\rho}{2+\rho}}, 1+\sqrt{\frac{\rho}{2+\rho}}\right] .
$$

Solving for the second condition yields as a second necessary condition

$$
q^{P} \in \frac{a}{b}\left[\frac{(1+\rho)-\sqrt{\rho^{2}+\frac{12}{11} \rho-\frac{4}{11}}}{(3+2 \rho)}, \frac{(1+\rho)+\sqrt{\rho^{2}+\frac{12}{11} \rho-\frac{4}{11}}}{(3+2 \rho)}\right]
$$

Note there is no pooling equilibrium if the square root in (6.13) does not exist, i.e. for $\rho \leq-\frac{6}{11}+\frac{4}{11} \sqrt{5} \approx 0.268$.

We thus have a pooling equilibrium for any $(\rho, q)$ such that both (6.12) and (6.13) hold ${ }^{8}$. Note that both intervals are widening when $\rho$

Note that the usual equilibrium refinement, Cho and Kreps' (1987) intuitive criterion cannot be used in this model. With the intuitive criterion, the other actors assume that neither type of incumbent will send a dominoted message, an action that it can always improve upon by a different action, no matter how the others react. In this model, such dominated messages do not exist, at least not in a way that restricts the range of possible pooling equilibria.

${ }^{8}$ The model in the text also has a weak separating equilibrium: $\left(q_{T}^{S}, q_{N}^{S}\right)=$ $\left(\frac{1}{2} \frac{a}{b}, \frac{1}{4} \frac{a}{b}\right)$, for any $p$. The equilibrium is weak in the sense that type $N$ is indifferent between setting $q_{N}^{S}$ and defecting to $q_{T}^{S}$. However, we do not need this equilibrium for the purpose of this paper. 
increases. That implies that the range of possible pooling equilibria also increases with $\rho$. This is intuitive. I have assumed that entry is always deterred in a pooling equilibrium. However, in any pooling equilibrium, the price consumers are willing to pay for a good increases with $\rho$, the probability that the good they are currently buying will not be useless in the next period. Therefore, with increasing $\rho$, both types of firm 1 are less inclined to defect to a separating equilibrium, which implies that the range of pooling equilibria from which neither type will defect, increases.

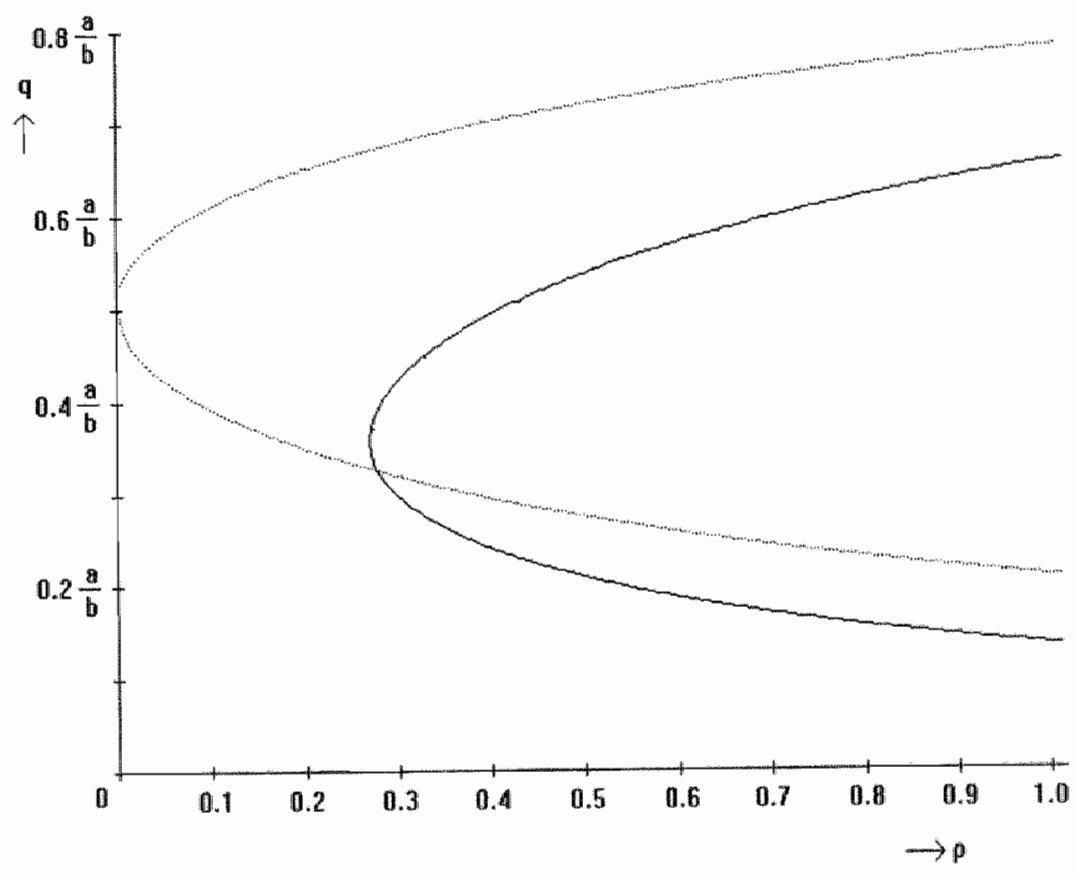

Figure 6.1: Ranges of possible pooling equilibria.

In figure 6.1 the possible range of pooling equilibria is plotted, with $\rho$ on the horizontal, and $q$ on the vertical axis. The heavy curve represents the boundaries of the area within which (6.12) holds, and the light curve the boundaries of the area within which (6.13) holds. The range of possible pooling equilibria is given by the area in which both intervals 
overlap.

\subsection{Vaporware as a Means of Entry Deterrence?}

In the previous section, I solved for the all the possible pooling equilibria in the model. I now return to the questions originally posed. First, is vaporware a rational strategy? Second, is vaporware an anti-competitive strategy? The first question will be answered in this section, the second question in the next.

I defined vaporware as a pooling equilibrium in which $q_{N}=q_{I}=q_{I}^{*}$. First, note that for $\rho<0.268$ vaporware can never be an equilibrium, since no pooling equilibrium exists. Figure 6.2 gives a graph of the range of possible pooling equilibria.

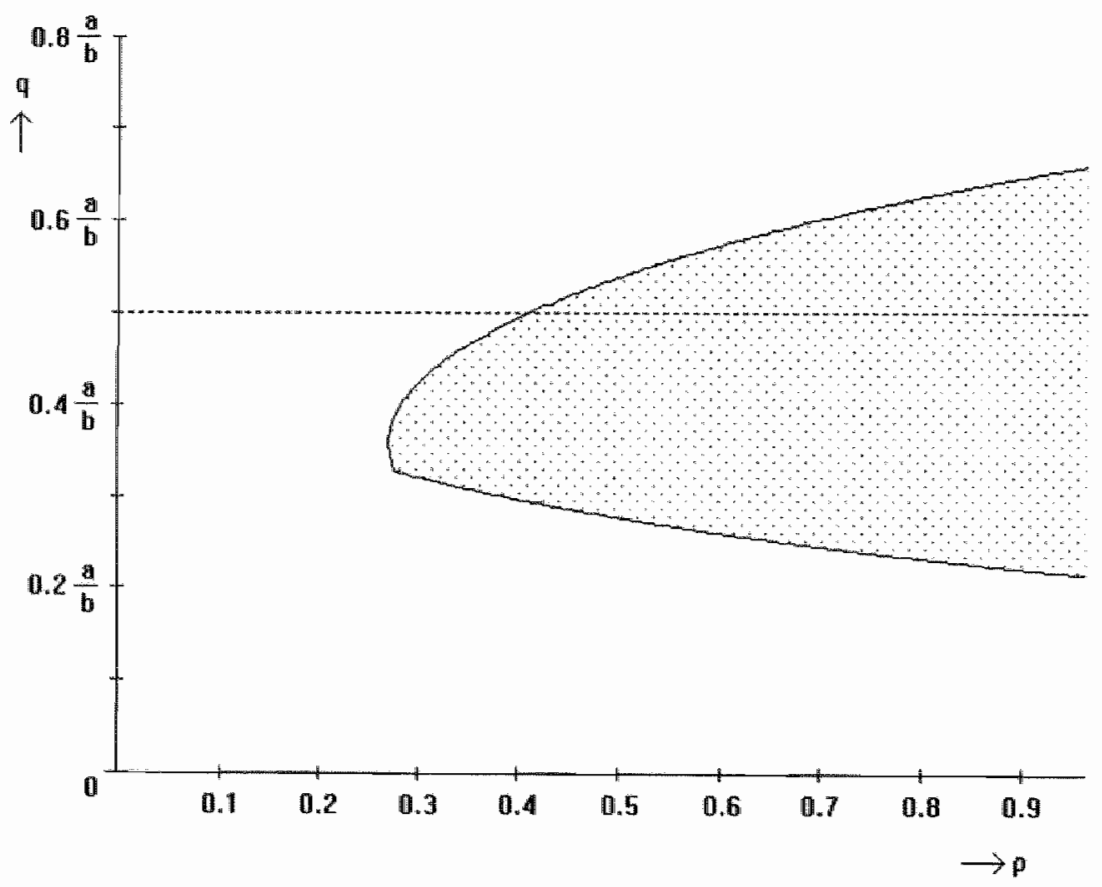

Figure 6.2: Possible Pooling Equilibria. 
At the horizontal axis, we have the range of possible $\rho$ 's, on the vertical axis, the values of $q^{P}$. The shaded area between the two curves represents the possible pooling equilibria, for each value of $\rho$. I defined vaporware as a situation in which both types of incumbent pool at the quantity a type $I$ incumbent would set in the case of perfect information, thus (from (6.6)) $q^{P}=q_{I}^{*}=\frac{1}{2} \frac{a}{b}$. Vaporware is thus an equilibrium whenever $q=\frac{1}{2} \frac{a}{b}$ is in the range of possible pooling equilibria. In figure 6.2 , the horizontal line represents $q^{P}=\frac{1}{2} \frac{a}{b}$. It is easy to see that $q_{I}^{*}=$ $\frac{1}{2} \frac{a}{b}$ is a possible pooling equilibrium for any $\rho$ larger or equal to some $\rho_{w}$. Using (6.12) and (6.13) we can calculate that this is the case for $\rho_{v}=0.409$. For $\rho \geq 0.409$, vaporware is thus an equilibrium. With the probability of an innovation low enough, it is an equilibrium for the incumbent firm always to claim that he has an innovation.

However, vaporware is only one equilibrium from an infinite number of possible equilibria. Nevertheless, the case for vaporware is stronger than this suggests. Schelling (1960) argued that in games which have a lot of equilibria, there are often equilibria where people naturally focus on, for reasons that are not explicitly modelled. For example, consider a game in which two people simultaneously have to claim part of a pie, but only receive that part if their claims are compatible. In this game, any division of the pie is a Nash equilibrium. Nevertheless, the strategy which is almost always played, is for both players to propose to cut the pie in half, even though there is no strict game-theoretic reason for doing so. Such equilibria, which for psychological reasons are particularly compelling, are referred to as focal equilibria.

Just like in the game described above, there is a continuum of possible equilibria in our vaporware model as well. Therefore, one can ask whether in this model, there are also equilibria which somehow stand out, and are more likely to be played than others. The equilibria in the perfect information model seem natural candidates, especially for an incumbent that uses cheap talk in order to try to convince the other agents of his actual type. Consequently, one equilibrium which is particularly compelling, is the pooling equilibrium in which both types of incumbent would set the quantity a type $N$ incumbent sets in the case of perfect information. A second one is the pooling equilibrium in which both types of incumbent would set the quantity a type $I$ incumbent sets in the case of perfect information. In the first equilibrium, an incumbent simply claims he does not have an innovation, and acts likewise by setting $q^{p}=\frac{5}{11} \frac{a}{b}$. In the second, he claims he has an imnovation, and acts 
likewise by setting $q^{p}=\frac{1}{2} \frac{a}{b}$. In both cases, the incumbent firm takes exactly the same action as some incumbent would take in a game with perfect information, dependent on his type. In every other equilibrium, firms do not make a statement about whether they have an innovation, and produce a quantity which cannot be interpreted in terms of the perfect information model. Therefore the two equilibria described above, are focal. One of the two is exactly vaporware: a pooling equilibrium with $q^{p}=\frac{1}{2} \frac{a}{b}$. Therefore, vaporware is a focal equilibrium ${ }^{9}$.

\subsection{The Welfare Implications of Vaporware}

In the previous sections I have proven that vaporware is a focal equilibrium for large enough $\rho$. In this section I show that vaporware is anti-competitive, in the sense that it lowers entry compared with the perfect information case. Moreover, I prove that the possibility of vaporware is welfare-decreasing, even if firm 1 does have an innovation.

The proof of the anti-competitiveness of vaporware is easy. Note that in a perfect information equilibrium, entry occurs if and only if the incumbent is of type $N$. For any $\rho>0.268$, we have a pooling equilibrium, and entry does not occur. When the incumbent turns out to be of type $N$, any pooling equilibrium is thus anti-competitive, in the sense that it deters entry which would not have been deterred in a situation in which firm 1 truthfully reveals his type, so when competition would have been "on the merits". Therefore, vaporware is anti-competitive.

But the possibility of engaging in vaporware has other welfare decreasing effects as well. Note that in a perfect information equilibrium, t type $I$ incumbent produces quantity $q_{I}^{*}=\frac{1}{2} \frac{a}{b}$, for which consumers are willing to pay $p=\frac{1}{2} \frac{a}{b}$. In a pooling equilibrium, consumers do not know which type of incumbent they face, and hence are willing to pay $\left(1+\frac{f}{2}\right)(a-b q)$ for the same good. With vaporware, we have a pooling equilibrium with $q^{P}=\frac{1}{2} \frac{a}{b}$, so first period price equals $p=\left(\frac{1}{2}+\frac{\rho}{4}\right) \frac{a}{b}$. Vaporware therefore not only decreases consumer welfare because entry

${ }^{9}$ A possible refinement is to look for the a priori profit maximizing Nash equilibrium (APPMNE), which is the pooling equilibrium that maximizes expected profits of the incumbent, before he even knows himself what type he has (thus, the $q^{p}$ that maximizes $\left.\rho \Pi_{N}^{P}\left(q^{P}\right)+(1-\rho) \Pi_{I}^{P}\left(q^{P}\right)\right)$. The $q^{P}$ that maximizes this expression does not have $q^{P}=\frac{1}{2}$ (apart from a pathological case), but one could argue that any pooling equilibrium constitutes vaporware. Also note that there is a continuma of Pareto optimal pooling equilibria. 
is deterred in the case an incumbent firm does not have an innovation, but also because an incumbent which does have an innovation is able to set a higher price, since consumers take the possibility into account that the good they are purchasing now, might also be used in period $2{ }^{10}$

\subsection{Conclusion}

In this chapter I modelled vaporware, the practice whereby an incumbent monopolist falsely claims that he has a new version of the product he is currently producing, in an attempt to deter entry. I have used a signalling model in which the probability that an incumbent firm has an innovation is common knowledge, but the fact whether or not he does have such an innovation is private information. Only if the firm does not have an innovation, a potential entrant can enter profitably. However, having an innovation also implies that the price consumers are willing to pay now is lower, since the good currently produced will be worthless in the next period. An incumbent firm with no innovation uses vaporware if he behaves as a firm with an innovation would in the case of perfect information.

I have showed that using vaporware is an equilibrium in this model, if the probability of innovation is not too high. Moreover, $I$ argued that the equilibrium is a focal one. I also showed that engaging in vaporware is anti-competitive. Not only because it deters entry, but also because it decreases consumer welfare if the incumbent firm does have an innovation. The possibility of vaporware allows a firm with an innovation to set a higher price for the "old" product. If vaporware can occur, consumers are not sure whether a firm which claims that he has an innovation, is being truthful. If he is not, the good consumers are buying in this period, will also have some value in the next. Because of that possibility, the firm is able to charge a higher price now.

In the introduction, I cited the doubts Fisher et al. (1983) have about the possibility of vaporware. Firms are usually not inclined to use vaporware, they argue, since doing so will damage their reputation. Notice however, that according to the model presented here, such a rep-

\footnotetext{
${ }^{10}$ Note that the latter effect does not hold for every pooling equilibrium. The price consumers pay in a pooling equilibrium is given by $\left(1+\frac{R}{2}\right)\left(1-q^{P}\right)$, following the same logic as in deriving (6.8). Pooling thus allows a type $I$ incumbent to set a higher price than in the case of perfect information, iff $\left(1+\frac{g}{2}\right)\left(1-q^{P}\right)>\frac{1}{2}$. Using (6.12) and (6.13), it can be shown that this is not always the case.
} 
utation effect does not occur. When the probability of an innovation is exogenously given and we are in the vaporware equilibrium, consumers and potential entrants know that any incumbent firm will claim that he has innovation. When this happens, they only know that with probability $1-\rho$ there will be a new version in the next period. When it turns out that this is not the case, the reputation of the incumbent is not adversely affected, since the other agents will only regard this as a result of chance, i.e. the initial move by Nature which decided the incumbent's type. If the game is played again, with the same probability $\rho$, the incumbent will again claim he has an innovation, and the credibility of this claim is independent on the actual outcome of the previous game. Therefore, claiming one has an innovation when this is not the case, goes unpunished in this model.

According to this model, the possibility of vaporware decreases consumer welfare, both in the case the incumbent firm has an innovation, and in the case he does not have an innovation. Therefore, it is a relevant issue in competition policy. According to this model it is welfare increasing if all claims about new products are closely scrutinized, and firms making false claims are punished. 


\section{Chapter 7}

\section{Cruising Taxis on Hotelling's Main Street}

\subsection{Summary and Overview}

In chapter $2 \mathrm{I}$ argued that there might be cases in which a monopolist sets a price lower than the static monopoly price. But there can also be circumstances in which perfect competition, in the sense of free entry and zero profits, does not yield the socially optimal prices textbook theory predicts. This chapter studies such a case. It presents a model for the cruising taxi market. A circular street is used on which taxis are searching for consumers, and consumers are waiting for a taxi. Demand depends on both price and expected waiting time. I solve for the deregulation equilibrium, in which taxi drivers can choose their own price, but profits are driven to zero, because of free entry. I show that a regulator can improve upon this outcome, by setting a fare.

\subsection{Introduction}

The market for taxi services used to be one of the most heavily regulated sectors. In almost every market there was some regulation: with respect. to the number of taxis which are allowed to operate, with regard to the fare they are allowed to set, or both. But recently, there has been a tendency to deregulate. Less regulation, the argument goes, will lead to a better functioning of the market, and therefore to lower prices and more and better taxi services. During the eighties, several cities in the 
US deregulated their taxi market. New Zealand deregulated partially in 1989 (Gaunt 1996). In 1990, Sweden applied a full deregulation. In the Netherlands, government is currently considering a full deregulation of the taxi market. Even Japan plans to fully deregulate taxi services by the year 2002 (The Economist 1997).

Nevertheless, preliminary results suggest that the effects of deregulation may be disappointing. Teal and Berglund (1987) survey the effects in some cities in the US, which deregulated their taxi market in the early eighties. They conclude that "taxicab deregulation cannot be demonstrated to have produced, in most cases, the benefits its proponents expected" ${ }^{1}$. Burdett and Fölster (1994) report that in Stockholm, two years after full deregulation in 1990 , the number of taxis had increased, but prices also did, by $33 \%$ in real terms. Nevertheless, the authors claim that consumers were better off, because of a reduction in waiting time.

Not all economists agree that taxicab deregulation is necessarily welfare enhancing. Some argue that the market is inherently inefficient, and therefore regullation might be called for. 'This tradition dates back to Orr (1969) and De Vany (1975). The argument is that demand for taxi services depends on both price and expected waiting time. Therefore every taxi driver imposes a positive externality on the other taxi drivers. Every additional taxi means that expected waiting time for all consumers decreases, so demand for taxi services will increase. Nevertheless this literature, which also includes e.g. Beesley and Glaister (1983) and Rometsch and Wolfstetter (1993), usually takes fares as given, and only looks at the effect of deregulation of the number of licenses. Moreover, only aggregated demand and supply functions are used, and therefore individual behavior is not studied. The only exception is Cairns and Liston-Heyes (1996). They dismiss the possibility of the existence of a competitive taxi market, on the ground that a Nash equilibrium in such a market does not exist ${ }^{2}$.

But to fully appreciate the effects of deregulation, it is obvious that the pricing decision has to be taken into account as well. This chapter provides a model which does just that. Behavior of all consumers and taxi drivers is determined endogenously. I restrict attention to the cruising taxi market, which is that part of the taxi market where taxis simply drive around and are flagged down by consumers. To study this

\footnotetext{
Teal and Berglund (1987), p. 54

This point will be elaborated in section 3 of this chapter.
} 
market, I use the circular variant of the Hotelling model (see Hotelling 1929 and Salop 1979). A given number of taxis drive around on a circular road, and encounter consumers. Taxis are driver-owned, and there are no barriers no entry. In equilibrium, only those consumers will look for a taxi, whose valuation exceeds expected price plus waiting time. Profits of taxis are driven to zero, since the entry of new taxis will decrease utilization rate up to the point where revenues are equal to costs. I solve for the equilibrium in this model for a general fare $p$, and for the case taxi drivers are allowed to set their own fare. The latter case is the deregulation equilibrium. I show that such deregulation will not lead to prices which are socially optimal.

Government can thus improve upon the deregulation equilibrium by setting a price ceiling. With full deregulation equilibrium prices are too high. The number of customers served is too low. Vacancy rates are too high, and taxis have to search too long for a customer. Nevertheless, in a deregulation equilibrium waiting times for consumers are minimized. But the beneficial effect of lower waiting times do not outweigh the detrimental effect of higher prices. In this case, full deregulation is therefore not the best solution.

The chapter is structured as follows. In section 7.3 I sketch the basic model. In section 7.4 the equilibrium is derived for a given fare $p$. Section 7.5 looks for the deregulation equilibrium and section 7.6 evaluates the social welfare function. In section $7.7 \mathrm{I}$ show that deregulation does not achieve the welfare optimum, and discuss how the variables in the model are affected by this suboptimality. Section 7.8 gives a numerical example, and a discussion and conclusion follow in section 7.9 .

\subsection{The Model}

Suppose we have a circular road on which taxis are driving in a given direction. All taxis are owned by their driver. Driving around, taxis encounter potential customers for their services. For simplicity, assume that all taxi trips are identical. Every consumer flagging down a taxi wants to travel a fixed distance down the road. As a normalization, suppose the time it takes to accomplish such a trip equals 1 time unit. For a consumer, a taxi trip has two relevant characteristics. First, the price she has to pay, $p$, and second, the total time it takes to reach her required destination. Define $t_{w}$ as the average time one has to wait for a taxi. This variable will be determined endogenously in the model. Total 
travel time equals the time spent waiting for a taxi, plus the time the actual trip takes. Since the latter is normalized to 1 , total travel time equals $1+t_{w}$.

Consumers are heterogeneous. They differ in the value they attach to time. Consumers with a low valuation will only take a taxi if doing so saves them a lot of time. If it does not, they will use other means of transport, or will simply walk to their destination. Consumers with a high valuation of time will be more inclined to use a taxi, and will only use alternative modes of transport if the waiting time is very high. For analytical convenience, assume that, for a taxi trip with total travel time $1+t_{w}$, consumer $i$ has a valuation equal to $1-v_{i}\left(1+t_{w}\right)$. Here, $v_{i}$ is some individual parameter. A high value of $v_{i}$ reflects a low value of time. People with high $v_{i}$ are willing to pay a relatively low amount for a given taxi trip. They are inclined to use other modes of transport, unless the waiting time for a taxi is very low. I assume that the individual $v_{i}$ 's are uniformly distributed across the population: $v_{i} \sim U[0,1]$. This assumption is innocuous. Suppose someone has $v_{i}>1$. Since the taxi trip itself already lasts 1 unit of time, this person's valuation for a taxi trip is always negative. Hence, she will never take a taxi, and we can restrict attention to consumers with $v_{i} \leq 1$. Any consumer with a positive expected surplus of taking a taxi, will actually try to flag one down. Therefore, everyone with $v_{i}$ such that $p \leq 1-v_{i}\left(1+t_{w}\right)$, will look for a taxi. This condition is equivalent to $v_{i} \leq \frac{1-p}{1+t_{w}}$. Since $v_{i} \sim U[0,1]$, this implies that the fraction of all potential consumers which is going to look for a taxi, also equals $\frac{1-p}{1+t_{\mathrm{w}}}$.

Every unit of time $n$ potential customers arrive on random points on the circle. Not all of these potential customers will look for a taxi: this depends on the price of a taxi, and on the expected waiting time. It takes one taxi $2 X$ units of time to drive around the circle. Therefore, if 1 taxi were to drive around, it would, on average, potentially meet a consumer every $\frac{n}{2 X}$ units of time $e^{3}$. Again, "potentially meeting a consumer" here reflects the fact that not every potential consumer will actually try to flag down taxi. She will only do so when her expected surplus of doing so exceeds 0 , hence if $v_{i} \leq \frac{1-p}{1+t_{t i t}}$. Thus, if one taxi is driving around charging price $p$, and everyone knows that price, the time it takes on

\footnotetext{
${ }^{3}$ Note that his implicitly assumes that a consumer will drop out of the market when she has not found a taxi within $2 X$ time units. This is obvious: since it takes $2 X$ time units for taxi to drive around the circle, a customer either take a taxi within $2 X$ time units, or never take one.
} 
average to find a consumer equals $\frac{n}{2 X X} \cdot \frac{1+t_{w}}{1-p}$, since a fraction $\frac{1-p}{1+t_{w}}$ of all potential consumers actually looks for a taxi. To save on notation, I will write $a \equiv \frac{n}{2 X}$.

Now suppose there are $T$ taxis driving around looking for a consumer, all charging the same price $p$. The taxis drive equal distances from each other. That implies that each taxi spends on average $a T \cdot \frac{1+t_{w i}}{1-p}$ time units to find a customer. But not all taxis are always vacant. A taxi which is serving a consumer is not able to pick up another one ${ }^{4}$. Say that the fraction of taxis that is vacant equals $e .{ }^{5}$ On average the time it takes for one vacant taxi to find one customer then equals

$$
t_{s}=\operatorname{aeT} \cdot \frac{1+t_{w}}{1-p}
$$

For the fraction of taxis that is vacant, note that every taxi spends $t_{3}$ units of time looking for a consumer, and 1 unit of time serving one. Therefore

$$
e=\frac{t_{s}}{1+t_{s}}
$$

Next consider the revenue per time unit of one taxi driver. If he charges price $p$, he will serve one consumer every $1+t_{s}$ units of time: again $t_{s}$ to find one and 1 unit to serve one. Total revenues per time unit thus equal:

$$
R=\frac{p}{1+t_{s}}
$$

Assume that the cost of operating a taxi equals $K$ per time unit. These costs are independent on whether or not the taxi is actually serving a customer. Every taxi always drives around the circle. For its operating cost it does not matter whether it does so with or without a customer.

To solve for the consumer side of the model, note that we have assumed that it takes one taxi $2 X$ time units to drive around the circle. Therefore, if one taxi was to continually drive around vacantly, it would take on average $X$ units of time before it passes a particular consumer. With $T$ taxis driving around, of which a fraction $e$ is vacant, expected

${ }^{4}$ In some markets, however, it is not uncommon that a new costumer is picked up before the previous one is delivered at her requared destination. In this model, such a practice is welfare enhancing.

${ }^{5} \mathrm{Or}$, alternatively, the utilization rate of taxis equals $u=1-e$. 
wating time for a particular consumer thus equals $X / e T$. Therefore we have

$$
t_{w}=\frac{X}{e T}
$$

We now have a model in which taxis drive around searching for a consumer, and consumers wait at the street until they find a taxi. Revenues $R$ for a taxi depend on the price $p$ it sets, and the time $t_{s}$ it takes to find a customer. Demand for taxis depends on expected waiting time $t_{w}$, and price $p$. Waiting time $t_{w}$ depends on the number of vacant taxis $e T$. Search time $t_{s}$ depends on both prices $p$, and the number of vacant taxis $e T$. In the next section $I$ will solve for the equilibrium in this model, for a given price $p$. Section 7.5 then solves for individual behavior of taxi drivers and consumers in a deregulation equilibrium.

\subsection{Solving The Model}

In this section I will solve for the model described in the previous section, by assuming free entry of taxis, and taking the price of a trip as exogenously given. That price $p$ can either be set by a regulator, or by individual profit maximizing taxi owners. Thus, taking the values of $p$, $K$, and $a$ as given, I will solve for the equilibrium value of $t_{s}, t_{w}, e$, and the equilibrium number of taxis $T$.

With free entry, new taxis will enter the market until expected profits are driven to zero. Costs of operating a taxi equal $K$ per time unit, while revenues are given by (7.3). Thus, we can solve for the equilibrium by imposing $R=K$, which yields

$$
\frac{p}{1+t_{\text {s }}}=K \text {. }
$$

Using (7.1), this implies

$$
T=\frac{(1-p)(p-K)}{\operatorname{Kae}\left(1+t_{w}\right)}
$$

To solve for the fraction of vacant taxis $e$, note that rewriting (7.5) implies

$$
t_{s}=\frac{p-K}{K} .
$$


Using (7.2) yields

$$
e=\frac{p-K}{p} .
$$

Note that, with $p$ and $K$ exogenously given, the equilibrium search time $t_{s}$ and vacancy rate $e$ are uniquely determined. This is intuitive. If both $p$ and $K$ are given, the only way in which equilibrium can be achieved in this market, is by varying the amount of time taxis have to spend searching a consumer. In equilibrium, profits are always zero. Therefore, with higher $p$, each taxi will spend more of its time searching consumers, until total profits are again zero. Plugging (7.8) back into (7.6) yields for the supply of taxis

$$
T=\frac{p(1-p)}{a K\left(1+t_{w}\right)} .
$$

This equation thus gives the equilibrium supply of taxis, given consumers' average waiting costs $t_{w}$, and price $p$.

Next consider consumers. From (7.4) we have, rewriting in terms of $T$

$$
T=\frac{X}{e t_{w}}
$$

We now have equation (7.9) which gives supply of taxis and equation (7.10) which can be said to represent demand. Obviously, these function are not traditional supply and demand curves, in which the total quantity of a good is given as a function of its price. For example, to derive supply (7.9) we have already used information about demand conditions, notably (7.1). Rather, these functions give supply and demand for taxis as a function of waiting time $t_{w}$. To solve for equilibrium waiting time, equating (7.9) and (7.10) gives

$$
\frac{(1-p)(p-K)}{K a e\left(1+t_{w}\right)}=\frac{X}{e t_{w}}
$$

Solving for $t_{w}$ then yields

$$
t_{w}=\frac{a K X}{(1-p)(p-K)-a K X}
$$

Note that for an equilibrium to exist in this market we need

$$
(1-p)(p-K)-a K X>0 .
$$


If this condition does not hold, $t_{w}$ is undefined. In that case prices are such that, for any positive value of waiting time $t_{w}$, the demand for taxis is larger than their supply. Therefore an equilibrium does not exist. Alternatively, note that, since $a=n / 2 X,(7.13)$ implies $n<$ $2(1-p)(p-K) / K$. Therefore, if the market is too small, in the sense that the number of consumers arriving per time unit is too low, there is no equilibrium. This also explains why in some cities there is a cruising taxi market, whereas in other cities, such a market does not exist.

To solve for the equilibrium number of taxis, we can simply substitute (7.12) back in either (7.9) or (7.10).

\subsection{The Deregulation Equilibrium}

In the previous section, I have solved for the market equilibrium for any $p$. In this section, I will solve for individual behavior in this model, in the case of full deregulation. I will show that in equilibrium all taxi drivers charge the same price. Moreover, every consumer takes the first taxi she encounters. I assume that taxi drivers use posted prices. Therefore, the timing is sequential. First, taxis announce and post their prices. Second, knowing all prices, consumers decide whether or not they will actually take a taxi.

First, it is easy to see that, in equilibrium, all taxi drivers charge the same price. Suppose the opposite is true, and the average price equals $\bar{p}$. In that case, only consumers with $v_{i} \leq \frac{1-\tilde{p}}{1+t_{w}}$ will go down the street to look for a taxi. Consider taxi driver $j$ who charges a price $p_{j}<\bar{p}$. Since not all taxis charge the same price, such a driver necessarily exists. Suppose $y$ increases its price to $\bar{p}$. Its revenues per ride then increase. But, given the strategies of the other agents, the probability of finding a costumer does not change, since no one with a value of time in the interval $\left[\frac{1-\bar{p}}{1+t_{w}}, \frac{1-p_{p}}{1+t_{w}}\right]$ is looking for a taxi. Therefore, in equilibrium, no driver charges a price below the average price, and all drivers necessarily charge the same price.

Suppose that in equilibrium all drivers charge $p$. We then have to check whether an individual taxi driver has an incentive to defect from this equilibrium. From the above argument it is clear that it never pays to defect by setting $p_{j}<p$, since this will not attract additional consumers. Now suppose taxi driver $j$ defects by charging $p_{j}>p$. Note from the discussion in the previous section that with $T$ taxis, every taxi 
will potentially meet a consumer every ae $T$ units of time. For taxi $j$, the average time to find a customer equals ae $T \frac{1+t_{w 0}}{\mathbb{1}-p_{j}}$, with $p_{j} \geq p$. This taxi driver thus has to search longer for a customer than his colleagues, since he will be turned down by some of the customers, who are waiting for a cheaper taxi. The time it takes to serve one consumer, equals 1 time unit. Expected total revenue per time unit then equals

$$
R=\frac{p_{j}}{1+a e T \frac{1+t_{w j}}{1-p_{j}}} .
$$

For an individual taxi driver, both $e$ and $t_{w}$ are given. Maximizing with respect to $p_{j}$ yields

$$
\frac{\partial R}{\partial p_{j}}=\frac{\left(1-p_{j}\right)^{2}+\operatorname{Tae}\left(1-2 p_{j}\right)\left(1+t_{w}\right)}{\left(1-p_{j}+\operatorname{aeT}\left(1+t_{w}\right)\right)^{2}}=0 .
$$

The roots of this equality are

$$
p^{*}=1+\operatorname{aeT}\left(1+t_{w}\right) \pm \sqrt{\operatorname{ae} T\left(1+t_{w}\right)\left(1+\operatorname{ae} T\left(1+t_{w}\right)\right)} .
$$

The square root in (7.15) is necessarily non-negative. Since the maximum valuation consumers have for a trip equals 1 , prices cannot exceed 1. The first term of (7.15) does exceed 1. Therefore only the negative root is an admissible solution.

Every taxi driver has an incentive to defect from an equilibrium in which $p$ is smaller than $p^{*}$. Thus, in any Nash equilibrium, all taxi drivers charge the same price $p$, with $p \geq p^{*}$, and provided (7.13) holds. Moreover, all consumers with a value of time $v_{i} \leq \frac{1-p}{1+t_{w}}$ will search a taxi, and take the first one they encounter. All consumers with a higher value of time have a negative expected surplus from trying to flag down a taxi. For consumers who are looking for a taxi, once one has been flagged down, there is no use to wait for another, since it will charge the same price and the consumer incurs extra waiting costs doing so.

Note that this result allows for a continuum of equilibria. The most obvious one, however, is $p=p^{*}$. From the derivation of (7.15) it is clear that for this price, individual profits for all taxi drivers are maximized. Therefore, rather than a least cost equilibrium, as is often used in the limit pricing literature ${ }^{6}$, we have a highest profit equilibrium in this

\footnotetext{
${ }^{6}$ See for example Milgrom \& Roberts (1982).
} 
model. Moreover, $p^{*}$ is the lowest price that can be set in equilibrium. Therefore, if we show that $p^{*}$ is too high from a welfare point of view, as we do in section 7.7 , then it immediately follows that the same holds for any equilibrium price $p^{e}>p^{*}$.

To solve for the equilibrium in this deregulation case, again impose $R=K$. Using (7.6) we have

$$
\operatorname{aeT}\left(1+t_{w}\right)=\frac{(1-p)(p-K)}{K} .
$$

Substituting in (7.15) yields

$$
p^{*}=1+\frac{\left(1-p^{*}\right)\left(p^{*}-K\right)}{K}-\sqrt{\frac{\left(1-p^{*}\right)\left(p^{*}-K\right)}{K}\left(1+\frac{\left(1-p^{*}\right)\left(p^{*}-K\right)}{K}\right)} .
$$

This equality has three solutions: $p^{*}=0, p^{*}=1$, and $p^{*}=\frac{1}{2}+\frac{1}{2} K$. Obviously the latter one is the only viable solution: any $p<K$ will always yield negative profits, and with $p^{*}=1$ consumption is zero. "Thus with full deregulation we have

$$
p^{*}=\frac{1}{2}(1+K) \text {. }
$$

Cairns and Liston-Heyes (1996) argue that a Nash equilibrium in prices does not exist in the cruising taxi market. To show this, they use an argument developed by Salop and Stiglitz (1982) for a model in which shops set prices, and consumers have to incur search costs when looking for the cheapest one. For the taxi model, the argument runs as follows. Assume that, different from the model in this chapter, all consumers have to incur identical waiting costs $d$ when waiting for a taxi, but differ in their valuation for a trip. Suppose we have a Nash equilibrium in which all taxi drivers charge some price $p$. Any individual taxi driver now has an incentive to defect from the equilibrium and charge a price $p+d$. When he meets a consumer, she has already incurred her waiting costs $d$. Therefore it is rational to accept the offer. If the consumer does not take this particular taxi, she will have to wait for another one, and again incur waiting costs $d$. Therefore the expected cost of waiting for the next taxi, given that all the others stick to the equilibrium, also equals $p+d$. We thus have a hold-up problem. There is no price $p$ that is a Nash equilibrium, since all drivers have an incentive to defect to $p+d$, which implies that only consumers with valuation higher than 
$p+2 d$ will look for a taxi, which again gives the taxis an incentive to increase their price by $d$, so ultimately the market breaks down.

For our cruising taxi market model, however, this argument does not hold. In the appendix I prove that, even considering that every consumer has already incurred her waiting costs once a taxi has been flagged down, there is still no price increase which can take advantage of this. Intuitively, the argument is as follows. In a Nash equilibrium, profits are maximized. Therefore, increasing price by a very small amount does not increase profits. However, doing so does decrease the probability that a given consumer will accept the price charged. Thus, it is not profitable to defect from the equilibrium.

\subsection{Social Welfare}

As a next step in solving the model, consider social welfare. Since total profits are zero, social welfare simply equals total consumer surplus. Consider consumer $i$. If the price she is charged equals $p$, consumer surplus for this particular consumer equals

$$
s_{i}=1-v_{i}\left(1+t_{w}\right)-p
$$

Consumers that are served, have a $v_{i}$ which is uniformly distributed on $\left[0, \frac{1-p}{1+t_{w}}\right]$. The average value for all consumers served thus equals $\bar{v}=\frac{1}{2} \frac{1-p}{1+t_{w}}$. Average consumer surplus per consumer is then given by

$$
\bar{s}=\frac{1}{2}(1-p) .
$$

The number of consumers served per time unit per taxi equals $\frac{1}{1+t_{s}}$, thus the total number of consumers served unit of time is $\frac{T}{1+t_{g}}$. Total consumer surplus can then be written

$$
S=\frac{\bar{s} T}{1+t_{s}}=\frac{1}{2} \cdot \frac{T}{1+t_{s}} \cdot[1-p] .
$$

Substituting from (7.7) and (7.9) this implies

$$
S=\frac{(1-p)^{2}}{2 a\left(1+t_{w}\right)} .
$$


From (7.12)

$$
1+t_{w}=\frac{(1-p)(p-K)}{(1-p)(p-K)-a K X}
$$

Thus

$$
S=\frac{(1-p)}{2 a} \cdot \frac{(1-p)(p-K)-a K X}{(p-K)}
$$

To evaluate whether the deregulation equilibrium $p^{*}$ can be improved upon, we need the first derivative of $S$ with respect to $p$. This yields

$$
\begin{aligned}
\frac{\partial S}{\partial p} & =\frac{a K X(1-K)-2(1-p)(p-K)^{2}}{2 a(p-K)^{2}} \\
& =\frac{K X(1-K)}{2(p-K)^{2}}-\frac{(1-p)}{a} .
\end{aligned}
$$

Solving aralytically for the socially optimal price from (7.23) yields messy results. However, it is possible to do so for given values of $a$, $K$ and $X$. In section $7.8 \mathrm{I}$ will solve for one numerical example.

\subsection{Deregulation Is Not Optimal}

To judge whether deregulation is a social optimum, we evaluate the derivative of social welfare, at the deregulation equilibrium. Plug $p^{*}=$ $\frac{1}{2}(1+K)$ into $(7.23)$ to find

$$
\frac{\partial S}{\partial p}=\frac{4 a K X-(1-K)^{2}}{2 a(1-K)} .
$$

But from (7.13), using (7.16), we have that necessary for an equilibrium to exist is

$$
\frac{1}{4}(1-K)^{2}-a K X>0
$$

which implies that the numerator of $(7.24)$ is negative. Since $K<1$, the denominator is positive, which establishes

$$
\left.\frac{\partial S}{\partial p}\right|_{p^{*}}<0
$$


This implies that, in the deregulation equilibrium, welfare can be increased by setting a lower price. In the appendix, 1 prove that the price that maximizes social welfare, is also lower than the price set in 8 deregulation equilibrium. Thus, prices in the deregulation equilibrium are too high from a welfare point of view.

For the other variables used in the model, we can also compare their value under a deregulation equilibrium, with their value in the social optimum. For waiting time $t_{w}$ we have, using (7.12)

$$
\frac{\partial t_{w}}{\partial p}=\frac{a K X(2 p-K-1)}{((1-p)(p-K)-a K X)^{2}}=0 .
$$

This implies

$$
\left.\frac{\partial t_{w}}{\partial p}\right|_{p^{*}}=0
$$

Also, it can be shown that $t_{w}$ is strictly convex in p. Thus, in a deregulation equilibrium, expected waiting time $t_{w}$ is minimized. Total welfare depends on both price and waiting time. Under deregulation, waiting costs are lower than those in the social optimum, but this beneficial effect is more than off-set by an increase in prices. For $e$ we have, using $(7.8)$

$$
\frac{\partial e}{\partial p}=\left(\frac{K}{p}\right)^{2}>0
$$

This implies that the fraction of vacant taxis in the deregulation equilibrium is too high. For $t_{s}$, using (7.7)

$$
\frac{\partial t_{s}}{\partial p}=\frac{1}{K}>0 \text {. }
$$

Search times are also too high. Another variable of interest is $e T$; the total number of vacant taxis. We have, from (7.6) and (7.12)

$$
e T=\frac{(1-p)(p-K)-a K X}{a K} .
$$

Therefore

$$
\left.\frac{\partial e T}{\partial p}\right|_{p^{*}}=0
$$


which, with the observation that $e T$ is strictly concave in $p$, implies that the number of vacant taxis is maximized. The effects on the total number of taxis $T$ are ambiguous, since $\frac{\partial T}{\partial p}$ is not monotone.

In this section I showed that the deregulation equilibrium derived in section 7.5 is not optimal from a social point of view. Prices are too high. A regulator can improve by regulating prices. To illustrate the model, and to get more insight into the possible order of magnitude of the effects of a move from full deregulation to the social optimum, I give a numerical example in the next section.

\subsection{A Numerical Example}

In this section I give a numerical example in order to illustrate the model and the possible effects of deregulation. Suppose we have a situation in which $K=0.1, X=2$ and $a=0.025$. These values are rather arbitrary. We only have to make sure that (7.13) holds for relevant values of $p$. For these parameters, the derivative of the social welfare function, given by (7.23), reads

$$
\frac{\partial S}{\partial p}=\frac{0.09}{(p-0.1)^{2}}-40+40 p .
$$

Equating this derivative to zero yields three possible values for the socially optimal fare: $p_{1}=0.0513, p_{2}=0.15149$ and $p_{3}=0.9972$. Checking the second order condition, we obtain that only $p=0.15149$ is a maximum. The deregulation equilibrium in this case is $p^{*}=\frac{1}{2}(1+K)=0.55$. Table 1 gives the value of some of the variables in this modell for the considered values of $p$.

\begin{tabular}{|c|r|r|r|r|r|r|r|r|}
\hline & $p$ & $S$ & $t_{s}$ & $t_{w}$ & $e$ & $T$ & $e T$ & $\frac{T}{1+t_{s}}$ \\
\hline Social apt. & 0.15 & 12.75 & 0.515 & 0.129 & 0.340 & 45.53 & 15.48 & 30.06 \\
\hline Deregulation & 0.55 & 3.95 & 4.500 & 0.025 & 0.818 & 96.56 & 79.00 & 17.56 \\
\hline
\end{tabular}

In this particular case, social welfare (the third column) is considerably higher in the social optimum than it is in the deregulation equilibrium. Under deregulation taxis have to search much longer for a customer (column 4), but consumers have to wait a much shorter time for a taxi (column 5). Under deregulation, taxis are vacant for a considerable amount of time. In the social optimum, this figure is much 
lower (column 6). The number of taxis in a deregulation equilibrium is more than double the amount of taxis in the social optimum (column 7), again, of course, given the parameters of this particular case. The number of empty taxis (column 8) under deregulation even outweighs that in a social optimum by more than a factor 5 in this example. Nevertheless, the total number of consumers served (column 9) is much higher in the social optimum.

In this particular example, the number of taxis in the deregulation equilibrium is too high. This, however, is not a universal effect. If we take, for example, $a=0.001, K=0.7$ and $X=4$, then the number of taxis in the deregulation equilibrium equals 159 whereas that in the social optimum is 201 . It can be shown that the price that maximizes the number of taxis is smaller than the deregulation equilibrium, but larger than the social optimum. Therefore, whether the number of taxis is lower in the deregulation equilibrium or in the social optimum, depends on the value of the parameters.

\subsection{Discussion and Conclusion}

In this chapter, I modelled the cruising taxi market. On a circular street, taxis are searching for consumers, and consumers are waiting for a taxi. Demand depends on both price and expected waiting time. All taxis are driver-owned, and there are no entry barriers. I solved for the deregulation equilibrium, in which taxi drivers can choose their own price, but profits are driven to zero, because of free entry.

In a deregulation equilibrium, all taxi drivers can set their own price. But, when doing so, they charge a price which is higher than the social optimum. Social welfare can be increased by regulating fares. The intuition behind this result is the following. When driving around, even in the case when profits are always driven to zero, individual taxi drivers have some monopoly power. The usual argument for competitive behavior is that no firm can abuse market power, since by doing so some other firm will undercut its price. This argument, however, does not hold in the cruising taxi market. Lowering price will not attract more costumers. A consumer is not able to go to whatever taxi charges the lowest price, but simply meets her supplier by chance. For an individual taxi, the probability of meeting a customer is not increased when a lower price is charged, since consumers will only take the average price into account when they decide whether or not to take a taxi. Therefore, 
prices will be higher than what is socially optimal. Nevertheless, profits in this model are zero, because of the free entry condition.

Of course, the results in this chapter do not imply that regulation is always better than no regulation. A regulator, especially one which is highly influenced by a lobby of taxi drivers, can always do worse than the deregulation equilibrium. Another problem is that it might be difficult to implement the social optimum. To do so requires precise knowledge of the parameters of the model. But setting a price ceiling seems a relatively easy way to improve upon full deregulation. When consumers order a taxi by phone, they are able to choose the cheapest supplier, and there is more room for price competition. But in such a market, operators need a large fleet of taxis to be able to always supply a taxi within a sufficiently short amount of time. Therefore, in this case, suppliers of taxi services necessarily have market power, and deregulation is also suboptimal. Indeed, preliminary evidence suggests that in taxi-markets where deregulation takes place, prices go up, and waiting times go down (see for example Burdett and Fölster 1994), which is exactly the prediction of the model presented in this chapter.

\subsection{Appendix}

In this appendix I first show that the Nash equilibrium in this model is not sensitive to the fact that a consumer has already incurred her waiting costs when she takes a taxi. Second, it is shown that the price that maximizes social welfare, is lower than the deregulation equilibrium.

Suppose one taxi driver were to defect from the equilibrium, in order to take advantage of the fact that any consumer who flags down a taxi, has already incurred her waiting costs $v_{i} t_{w}$. In equilibrium, every consumer with $v_{i} \leq \frac{1-p}{1+t_{w}}$ will try to flag down a taxi. Suppose one taxi driver were to defect from the equilibrium by charging $p+\delta$, rather than $p$, with $\delta$ some positive constant. By virtue of a Nash equilibrium, consumers will only find out once they have stopped this particular taxi. Having incurred their waiting costs, they will take the taxi, despite its higher price, whenever $p+\delta+v_{i} \leq p+v_{i}\left(1+t_{w}\right)$, i.e. $v_{i} \geq \delta / t_{w}$. The total number of consumers, as a fraction of all consumers waiting, that will not accept the offer, therefore equals

$$
f=\frac{\delta / t_{w}}{\frac{1-p}{1+t_{w}}}=\frac{\delta\left(1+t_{w}\right)}{t_{w}(1-p)} .
$$


If a consumer accepts the offer, which happens with probability $1-f$, the taxi driver will earn an additional profit of $\delta$. However, if the consumer does not accept the offer, which happens with probability $f$, the taxi driver loses an amount $p$, relative to the situation in which he does stick to the Nash equilibrium. Bargaining is not possible, since taxi drivers use posted prices. The taxi driver thus gains from raising price if and only if

$$
(1-f) \delta>f p
$$

Hence

$$
\frac{t_{w}-t_{w} p-\delta-\delta t_{w}}{t_{w}(1-p)} \delta>\frac{\delta\left(1+t_{w}\right)}{t_{w}(1-p)} p .
$$

The inequality holds with equality if

$$
t_{w}-t_{w} p-\delta-\delta t_{w}-\left(1+t_{w}\right) p=0
$$

hence if

$$
\delta=\frac{t_{w}-2 t_{w} p-p}{1+t_{w}} .
$$

But this value $\delta$ is smaller than zero. Therefore the left hand side of (7.36) is always smaller than the right hand side, which can be checked using $\delta=0$. Taxi drivers thus have no incentive to defect from the Nash equilibrium derived in the text, even when they consider the fact that the customers they meet have already incurred their waiting costs.

The proof of the fact that $\delta$ as given by (7.38) is negative, is as follows. Define the function $\operatorname{sgn}(x)$ as equal to 1 whenever $x>0$, equal to -1 when $x<0$ and equal to zero if $x=0$. Since $1+t_{y}>0$, we have $\operatorname{sgn}(\delta)=\operatorname{sgn}\left(t_{w}-2 t_{w} p-p\right)$. Using $(7.4)$

$$
\begin{aligned}
& \operatorname{sgn}\left(t_{w}-2 t_{w} p-p\right)= \\
= & \operatorname{sgn}\left(\frac{a K X}{(1-p)(p-K)-a K X}-2 \frac{a K X}{(1-p)(p-K)-a K X} p-p\right) \\
= & \operatorname{sgn}\left(\frac{a K X(1-p)+p K(1-p)-p^{2}(1-p)}{(1-p)(p-K)-a K X}\right) \\
= & \operatorname{sgn}\left((1-p)\left(-p^{2}+p K+a K X\right)\right) \\
= & \operatorname{sgn}(a K X-p(p-K)) .
\end{aligned}
$$


Using $(7.16)$

$$
\operatorname{sgn}(a K X-p(p-K))=\operatorname{sgn}\left(a K X-\frac{1}{4}(1-K)^{2}\right) .
$$

Thus, using (7.25)

$$
\operatorname{sgn}(\delta)=-1
$$

Next, I show that the price in the deregulation equilibrium is higher than the price that maximizes social welfare. Social welfare as a function of price is given by (7.22), and its first derivative by (7.23). Both functions are continuously differentiable. Necessarily, $p \in(K, 1)$. Note that $\lim _{p \downarrow K} S(K)=-\infty$ and $S(1)=0$. Thus, if there is a $p$ such that $S(p)>0$, we necessarily have an internal maximum. But such a $p$ exists, since $S\left(p^{*}\right)>0$.

For the first derivative of $S$, we have $\lim _{p \downarrow K} S^{\prime}(p)=+\infty$, and $S^{\prime}(1)=$ $\frac{K X}{1-K}>0$. If there is a $p$ such that $S^{\prime}(p)<0$, then $S^{\prime}(p)$ has an internal minimum. But such a $p$ exists, since $S^{\prime}\left(p^{*}\right)<0$. The second derivative of $S$ is given by

$$
\frac{\partial^{2} S}{\partial p^{2}}=\frac{1}{a}-\frac{3 K X(1-K)}{(p-K)^{3}} .
$$

This expression is undefined at $p=K$, and has three roots at $p_{3}^{*}=K+$ $\sqrt[3]{a K X(1-K)}$. Further inspection of the second derivative reveals that it: is negative in the interval $\left(K, p_{3}^{*}\right)$, and positive in $\left(p_{3}^{*}, 1\right)$. Therefore, the second derivative has a global minimum at $p_{3}^{*}$, where it is, necessarily, negative. Also, for any $p>p_{3}^{*}$, the derivative is increasing, whereas, for any $p<p_{3}^{*}$, it is decreasing. With both $\lim _{p \downarrow K} S^{\prime \prime}(p)>0$, and $S^{\prime}(1)>0$, this implies that the equality $S^{\prime}(p)=0$ has two roots, $p_{2,1}^{*}$ and $p_{2,2}^{*}$, with $p_{2,1}^{*}<p_{3, \text { and }}^{*} p_{2,2}^{*}>p_{3}^{*}$. Since $S^{\prime}$ is decreasing at $p_{2,1}^{*}$ and increasing and $p_{2,2}^{*}$, we have a local minimum at $p_{2,2}^{*}$, and the global maximum at $p_{2,1}^{*}$. Since $S^{\prime}\left(p^{*}\right)<0$, we have $p_{2,1}^{*}<p^{*}<p_{2,2}^{*}$. Hence the price in a deregulation equilibrium, $p^{*}$, is always larger than the price that maximizes social welfare, $p_{2,1}^{*}$. 


\section{Chapter 8}

\section{Promising Politicians, Rational Voters, and Election Outcomes}

\subsection{Summary and Overview}

This chapter shows that two candidates competing in an election always have an incentive to make election promises that differ from the policies they really want to implement. In equilibrium, a left-wing candidate will make a promise that is to the right of her true position, whereas a right-wing candidate will make a promise that is to the left of her true position. Voters, however, are not fooled by these promises. They can rationally infer the true position of each candidate, and act likewise. These effects occur both in case candidates try to maximize their share of the vote, and in case merely they try to convince the median woter.

\subsection{Introduction}

Overwhelming anecdotal evidence suggests that politicians often promise more during an election campaign than they are willing or able to deliver once elected. One of the most notorious examples is George Bush, who, in the campaign for the 1988 US Presidential elections, made a "read my lips, no new taxes"-pledge, yet, while in office, introduced new taxes anyway. In France, Jacques Chirac promised to decrease taxes and unemployment. When in office, both increased. Other pieces of evidence, 
for all kinds of elections, are easy to find.

This phenomerion poses problems for the model of rational, utilitymaximizing, economic agents. It is hard to imagine that rational voters are systemically fooled by untruthful promises of politicians. Indeed, evidence suggests that this is not the case. In the 1996 US Presidential elections, for example, $71 \%$ of all respondents in a survey indicated they did not believe Bob Dole's promise to lower taxes by $15 \%$ and ballance the budget at the same time. In France, Lionel Jospin broke several of his major election promises during the first 100 days of his government. Yet, his approval rate stood at $55 \%{ }^{1}$. But if voters are rational and do not believe these promises, we face a different problem. Why do politicians make promises which voters do not believe?

In this chapter I propose a way to solve this paradox. I present two models. In the first model, candidates maximize their share of the vote. In the second model both candidates try to convince the median voter. In each model, candidates rationally distort their true policy position. Voters, observing the promise each candidate makes, can rationally infer the true position of each candidate, and act likewise. Therefore, voters are not fooled by election promises. Nevertheless, politicians still have an incentive to promise more than they will deliver, since, in equilibrium, vaters expect thern to do so.

I assume that voters' preferences on policies can be represented in a single dimension, and are distributed on a line. There are two candidates. Both have a preferred policy, which they want to implement. Each candidate knows her ${ }^{2}$ own preferred policy, but voters and the competing candidate do not. What everyone knows, however, is that the true policy position of one candidate is to the left of the median voter, while the position of the other candidate is to the right. This assumption is unusual, but I believe it is a sensible one, and in line with reality. Elections are often held with two major parties, of which one is known to be on the left-hand side of the political spectrum, while the other is known to be on the right-hand side, even though their exact position is unknown. Also, if a particular candidate wants to run for office, she will do so for the party that best fits her personall preferences.

In order to convince voters, each candidate announces a policy that she promises to implement when elected. This election promise thus

\footnotetext{
${ }^{1}$ For details, see The Economist, $1997 \mathrm{~b}$.

${ }^{2}$ As a convention, I will refer to candidates as being female and to voters as being male.
} 
serves as a signal of her true preference. It provides voters with some information about what to expect from her, even though her exact preferences are unclear. There will always be some discrepancy between what a candidate wants and what voters want. Therefore, both contestants have an incentive to make promises which are different from their true position, in an attempt to convince voters to vote for them. This misrepresentation of one's preferred policy, however, comes at a cost. There are several reasons for this. First, chances of future reelection may be lower. Second, the winning candidate will face some difficulty in implementing her preferred policy while in office. Pressure groups favoring the promised policy will put the elected candidate under strong pressure to implement her election promise. Third, she may obtain disutility from going into history as, for example, the president that promised to lower taxes, but raised them while in office. Fourth, even conscience might play a role. I therefore assume that the cost of announcing a policy that is different from the one a candidate really wants to implement, is increasing in the distance between the true and announced policy position.

In the two models considered, the equilibrium involves both candidates misrepresenting their true policy position during the election campaign. Yet, upon observing these promises, and by taking into account the candidates' incentives to misrepresent their true views, voters can infer the true policy position each candidate enjoys. The models explain why it is rational for politicians to lie in an election campaign, and, at the same time, why voters do not believe these lies.

This chapter fits into the tradition of modeling elections as spatial competition, which started with Hotelling (1929) and Downs (1957). In the standard model, two candidates compete in an election. They are both free to choose their policy position. Each candidate chooses her position in a way that maximizes her chance of being elected. Voters, observing these positions, then vote for one candidate. The models presented here differ in two fundamental aspects from this standard approach. First, in the standard model it is implicitly assumed that candidates will always implement the policy they have promised during the election. In the models presented here, this is not the case. Second, contrary to the standard model, I assume that candidates cannot choose their policy position at will. They have their own preference or ideology, which they want to see implemented. Whereas in the Hotelling-Downs model candidates choose their position in order to get elected, I assume 
that candidates want to get elected in order to implement their preferred policy.

The possibility of the announced policy position serving as a signal for the true policy position was introduced by Banks (1990). His model differs with the ones presented here in two ways. First, in his model, voters do not have any information on the true policy position of each candidate. They do not know whether candidates are on the left or the right of the political spectrum. In the models presented here, they do know. Second, in Banks' model, there are always some candidates that use a pooling equilibrium, provided the costs of misrepresenting are not prohibitively high. Voters therefore cannot directly infer the true policy position upon observing the announced one. In the models presented here, they can. A related paper is Potters, Sloof and van Winden (1997). They use a signaling model in which a challenger tries to convince voters of her true policy position, by using either campaign expenditures, contributions or direct endorsements. In their model, only the challenger's position is unknown to the voters, and the challenger only has two possible types. She can be either better or worse than the incumbent. I assume that the exact positions of both candidates is unknown, and that there is a continuum of possible types.

The remainder of this chapter is structured as follows. In the next section, I discuss the rationale behind the candidates' objective function in the two different models. Section 8.4 sketches the basic framework and analyzes the share-of-the-vote model, while section 8.5 considers an extension of this model. In section 8.6 the median-voter model is discussed. Section 8.7 concludes the chapter.

\subsection{The Candidates' Objective Function}

A common assumption in spatial models of political competition, is that each candidate only tries to capture the median voter (for example in Downs 1957, but also in Banks 1990). In an election with two candidates, the argument goes, the candidate that captures the median voter necessarily gets the majority of the vote, and, by definition, wins the election.

This assumption, however, is not appropriate for every election. In some circumstances, it makes more sense to assume that candidates maximize their share of the vote. This approach is used, for example, by Harringtion and Hess (1996). First, real world elections in which only 
two candidates are competing, often use some kind of first-past-the-post system. In that case, a candidate or party that wins in the highest ${ }^{3}$ number of states or districts, wins the election. In such a system, getting an absolute majority of the popular vote does not guarantee winning the election. But the probability of winning the election does increase with the share of the vote, hence it makes sense to model candidates' behavior as maximizing this share. Second, rather than being concerned with only winning or losing the election, candidates will often also be interested in the exact margin with which they do so. A candidate winning the election will find it easier to implement her preferred policy, the higher her share of the vote in the election. Also, for a candidate losing the election, the loss in reputation may be lower in case of a small defeat than in case of a big one. Third, elections are often held with more than two candidates. In that case, convincing the median voter is not enough to win the election. In parliamentary elections, candidates will be much more interested in their share of the vote rather than in appealing to the median voter.

Summarizing, for some elections the median voter will indeed be the decisive one. Other elections, however, may be modelled more appropriately by assuming that candidates maximize their share of the vote. In this chapter, I will therefore consider both possibilities. The equilibria in the two models are qualitatively the same. They both involve candidates distorting their true policy positions, in an attempt to win the election. In section 8.4 , I model the case in which candidates maximize their share of the vote. Section 8.6 considers the median voter model.

\subsection{A Maximal Support Model}

In this section I will present the basic framework of the model, and use that framework to solve for the case in which candidates try to maximize their share of the vote. There is a continuum of voters. Without loss of generality, voters' preferences are uniformly distributed on the interval $[0,1]$. The median voter thus prefers policy $\frac{1}{2}$. In an election, there are two candidates, $L$ and $R$. Candidate $L$ has some true policy position $P_{L}$, which is unknown to voters and to the other candidate, but known to be to the left of the median voter: $P_{L} \sim F_{L}(p)$, with $F_{L}$ some wellbehaved probability distribution defined on the interval $\left[0, \frac{1}{2}\right]$. The true

\footnotetext{
${ }^{3}$ Possibly weighted.
} 
policy position of $L$ is referred to as the type of $L$. Candidate $R$ has a position $P_{R,}$ known to be to the right of the median voter: $P_{R} \sim F_{R}(p)$, defined on $\left[\frac{1}{2}, 1\right]$. In the election campaign, each candidate promises to implement a certain policy. That promise is a function of her true policy position: $A_{i}=A_{i}\left(P_{i}\right), i=L, R$. Note that, for example, the position candidate $L$ announces is not restricted to the interval which defines her possible types. Each candidate is free to announce a policy position which is impossible to be her true one. Upon observing election promises, each voter decides which candidate to vote for. This choice depends on his preference ${ }^{4} v_{k} \in[0,1]$, and the observed election promises of the two candidates. If we denote the choice made as $V_{k}$, we have $V_{k}=$ $V\left(v_{k}, A_{L}, A_{R}\right)$, with $V_{k} \in\{L, R\}$. Note that I do not allow voters to abstain, a phenomenon studied by Feddersen and Pesendorfer (1996).

Voters care about the true policies a candidate wants to implement, rather than those promised during an election campaign. True policy positions, however, cannot be observed. For the sake of argument, suppose they can. Knowing $P_{L}$ and $P_{R}$, any voter would choose the candidate with the policy closest to his own preference. For the marginal voter, $v_{k}-P_{L}=P_{R}-v_{k}$, and we have

$$
V\left(v_{k}, P_{L}, P_{R}\right)=\left\{\begin{array}{ll}
L & \text { if } v_{k} \leq \frac{P_{L}+P_{R}}{2} \\
R & \text { otherwise }
\end{array} .\right.
$$

The share of the vote of candidates $L$ resp. $R$ therefore equals

$$
\begin{aligned}
\lambda_{L} & =\frac{P_{L}+P_{R}}{2}, \\
\lambda_{R} & =1-\frac{P_{L}+P_{R}}{2},
\end{aligned}
$$

using the fact that $v_{k}$ is uniformly distributed on $[0,1]$. Next, consider both candidates. Utility of candidate $i$ depends on both voter behavior and the loss she incurs due to misrepresenting her true beliefs:

$$
U_{i}\left(A_{i} \mid P_{i}\right)=u_{i}\left(\lambda_{i}\right)-l_{i}\left(\left|A_{i}-P_{i}\right|\right)
$$

Assume that $l_{i}$ is increasing, and equal to zero if the amnounced position coincides with the true one: $l_{i}(0)=0, l_{i}^{\prime}(x)>0$ for $x>0$, and $l_{i}^{\prime}(x)=0$. Moreover, $l_{i}$ is strictly concave. In this specification, misrepresenting

\footnotetext{
Subscripts $i$ and $j$ are reserved for candidates, $k$ for woters.
} 
one's position comes at a loss. This loss is increasing in the absolute difference between the announced and the true policy position.

We can rescale utility to read

$$
U_{i}^{*}\left(A_{i} \mid P_{i}\right)=\lambda_{i}\left(A_{i}, A_{j}\right)-g_{i}\left(\left|A_{i}-P_{i}\right|\right),
$$

noting that the fraction of voters $\lambda_{i}$ voting for candidate $i$ only depends on the observables $A_{i}$ and $A_{j}$. Assume $g_{i}$ satisfies the same conditions as I put on $l_{i}$.

As solution concept, I use a sequential equilibrium (Kreps and Wilson, 1982). This requires that each player maximizes utility given beliefs and strategies of all other players. Moreover, equilibrium beliefs are consistent with Bayesian updating. With regard to the strategy used by the two candidates, we can have different types of equilibria. In a separating equilibrium, each type of candidate $i$ uses a different promise: $A_{i}\left(P_{i}\right) \neq A_{i}\left(P_{i}^{\prime}\right), \forall P_{i}^{\prime} \neq P_{i}$. In a pooling equilibrium, each type of candidate $i$ makes the same announcement: $A_{i}\left(P_{i}\right)=A_{i}\left(P_{i}^{\prime}\right), \forall P_{i}^{\prime}, P_{i}$. Finally, in a hybrid, or semi-pooling equilibrium, some types of candidate $i$ are making the same announcement, but not all of them are: $\exists P_{i}, P_{i}^{\prime}, P_{i}^{\prime \prime}$, such that $A_{i}\left(P_{i}\right)=A_{i}\left(P_{i}^{\prime}\right)$, but $A_{i}\left(P_{i}\right) \neq A_{i}\left(P_{i}^{\prime \prime}\right)$. Note that in a separating equilibrum, voters can always infer the true type of the candidates they are facing. Since every type makes a different promise, observing that promise is enough to infer the actual type of the candidate. A sufficient condition for a separating equilibrium is that the announcement function $A_{i}$ is strictly one-to-one. In that case, in equilibrium voters can simply infer the type of candidate $i$ they face by using $P_{i}=A_{i}^{-1}\left(A_{i}\right)$.

In solving for the equilibrium, I will restrict attention to the left-wing candidate $L$. Since the model is fully symmetric, it is clear that a similar analysis also holds for $R$. Denote the belief voters have about the type of $j$ by $\tilde{P}_{j}$. This belief depends on the position the particular candidate announces: $\tilde{P}_{j}=\tilde{P}_{j}\left(A_{j}\right)$. For the strategy of $L$ we need.

$$
\begin{aligned}
A_{L} & =\arg \max _{A_{L}} U_{L}^{*}\left(P_{L}, A_{L} \mid \tilde{P}_{L}, \tilde{P}_{R}\right) \\
& =\arg \max _{A_{L}} \frac{\tilde{P}_{L}+\tilde{P}_{R}}{2}-g_{L}\left(\left|A_{L}-P_{L}\right|\right), \forall P_{L} \in\left[0, \frac{1}{2}\right],
\end{aligned}
$$

using (8.4). Maximizing yields the first-order condition

$$
\frac{d U_{L}^{*}}{d A_{L}}=\frac{\partial U_{L}^{*}}{\partial A_{L}}+\frac{\partial U_{L}^{*}}{\partial \tilde{P}_{L}} \frac{d \tilde{P}_{L}}{d A_{L}}=0 .
$$


Next, assume that $A_{L}$ is monotone. This implies that in equilibrium, voters are able to infer directly the type of candidates they are facing, since equilibrium requires $\tilde{P}_{L}\left(A_{L}\right)=A_{L}^{-1}\left(A_{L}\right)=P_{L}$, hence $d \tilde{P}_{L} / d A_{L}=$ $1 /\left(d A_{L} / d P_{L}\right)$. Rearranging (8.6) and differentiating (8.5) yields ${ }^{5}$

$$
\frac{d A_{L}}{d P_{L}}=\frac{-\partial U_{L}^{*} / \partial \tilde{P}_{L}}{\partial U_{L}^{*} / \partial A_{L}}=\frac{1}{2 g_{L}^{\prime}} .
$$

The differential equation (8.7) gives an implicit expression for the announcement function $A_{L}\left(P_{L}\right)$. From this differential equation it is clear that only for one specific loss function, all candidates announce their true type. For truth-telling to be an equilibrium for all types, we need $A_{L}\left(P_{L}\right)=P_{L} \forall P_{L}$. That implies $\partial A_{L} / \partial P_{L}=1$, which is only compatible with (8.7) if the loss function $g_{L}$ has the form $g_{L}\left(\left|A_{L}-P_{L}\right|\right)=\frac{1}{2}\left|A_{L}-P_{L}\right|$. In that case the gain from misrepresenting one's true type is always just off-set by the disutility of doing so. For any other loss function, hardly ary type ${ }^{6}$ of candidate reveals her true type in equilibrium.

Note that, for all cases in which the equilibrium implies that candidates distort their true position, we actually have two possible equilibria, since the equilibrium is only defined in terms of $\left|A_{L}-P_{L}\right|$. In one equilibrium, the true policy position is understated by some amount $\left|A_{L}-P_{L}\right|$, and in the other the true policy position is overstated by exactly the same amount. For candidate $L$, only the latter can be a sequential equilibrium. This can be seen as follows. Note that for a sequential equilibrium we need, first, that all strategies are best responses to the other players' strategies, and, second, all beliefs are consistent with Bayesian updating. Suppose that in equilibrium we have $A_{L}<P_{L}$ for all possible types of $L$. For some $P_{L}^{\prime}$ we therefore have an equilibrium announcement

Alternatively, we can directly invoke Mailath (1987). He considers the general class of signaling games with a continum of types, in which utility of the sender is given by $U\left(\alpha, \tau^{-1}(y), y\right)$, with $\alpha$ her true type, and $\tau^{-1}(y)$ the type inferred by the receiver, as a function of the sigmal $y$. Mailath shows that the solution to such games are given by

$$
\frac{d \tau}{d \alpha}=\frac{-U_{2}}{U_{3}}
$$

where subscripts denote partial derivatives. The above solution holds, if some conditions are met, the most important being type monotonicity and belief monotonicity. The first requires that $U_{2}$ always has the same sign, and the second that $U_{13}$ always has the same sign. It is easy to see that, in the framework used here, both conditions are satisfied, given the restrictions put on $g_{L}$.

The only exception being $P_{L}=0$. 
$A_{L}^{\prime}<P_{L}^{\prime}$, while every voter observing $A_{L}^{\prime}$, believes that he faces a candidate with true position $P_{L}^{\prime}$. Now consider a candidate with a position $P_{L}^{\prime \prime}$ which is slightly lower than $P_{L}^{\prime}$, such that $A_{L}^{\prime}<P_{L}^{\prime \prime}<P_{L}^{\prime}$. This type then has an incentive to mimic a type $P_{L}^{\prime}$ candidate, and defect from her equilibrium strategy by setting $A_{L}^{\prime}$ rather than the $A_{L}^{\prime \prime}<A_{L}^{\prime}$ her equilibrium strategy prescribes. Given that voters believe that the true position of candidates announcing $A_{L}^{\prime}$ is $P_{L}^{\prime}$, defecting in this way yields utility $\frac{1}{2} P_{L}^{\prime}+\frac{1}{2} P_{R}-g_{L}\left(\left|A_{L}^{\prime}-P_{L}^{\prime \prime}\right|\right)$, rather than equilibrium utility $\frac{1}{2} P_{L}^{\prime \prime}+\frac{1}{2} P_{R}-g_{L}\left(\left|A_{L}^{\prime \prime}-P_{L}^{\prime \prime}\right|\right)$. Since ${ }^{7}\left|A_{L}^{\prime \prime}-P_{L}^{\prime \prime}\right|>\left|A_{L}^{\prime}-P_{L}^{\prime \prime}\right|$, we have $g_{L}\left(\left|A_{L}^{\prime \prime}-P_{L}^{\prime \prime}\right|\right)>g_{L}\left(\left|A_{L}^{\prime}-P_{L}^{\prime \prime}\right|\right)$. Using $P_{L}^{\prime \prime}<P_{L}^{\prime}$, a candidate with position $P_{L}^{\prime \prime}$ is strictly better off making election promise $A_{L}^{\prime}$, and the equilibrium breaks down. Therefore, the only possible equilibria involve $A_{L} \geq P_{L} \forall P_{L}$. In that case, provided (8.7) also holds, no candidate with $P_{L}^{\prime \prime}<P_{L}^{\prime}$ has an incentive to use the same election promise as $P_{L}^{\prime}$ does: the first-order condition (8.6) implies that such mimicking is just not worthwhile for any $P_{L}^{\prime \prime}$ arbitrarily close to $P_{L}^{\prime}$. Moreover, note that, in equilibrium, a candidate with $P_{L}^{\prime \prime \prime}>P_{L}^{\prime}$ never has an incentive to mimic a candidate with type $P_{L}^{\prime}$ : doing so decreases her share of the vote in a way that more than offsets her decrease in disutility from misrepresenting her position. A straightforward application of this argument to the right-wing candidate $R$ yields $A_{R} \leq P_{R} \forall P_{R}$.

The above discussion also provides an intuition for the result that candidates almost always misrepresent their position. Suppose that all candidates would reveal their true position: $A_{i}\left(P_{i}\right)=P_{i}$. This cannot be an equilibrium. Any left-wing candidate now has an incentive to claim a position that is to the right of her true one. Any right-wing candidate has an incentive to claim a position that is more to the left. Given that $g$ is strictly concave, the costs of doing so, which is the disutility of lying, are more than outweighed by the benefits, consisting of a higher share of the vote in the election. Truth-telling therefore cannot be an equilibrium. The only possible equilibrium has the marginal casts of lying equal to the marginal benefit of getting a larger share of the vote, which is exactly (8.6). Although this equilibrium implies that every candidate is lying, voters are not fooled. Upon observing election promises, they can exactly infer each candidate's true position.

As an illustration of the model, consider the case in which the disutility of misrepresenting preferred policy is linear in the distance between

${ }^{7}$ With $A_{L}^{\prime \prime}<P_{L}^{\prime \prime}$ and $A_{L}^{\prime}<P_{L}^{\prime \prime}$, we have $\left|A_{L}^{\prime \prime}-P_{L}^{\prime \prime}\right|=P_{L}^{\prime \prime}-A_{L}^{\prime \prime}$ resp. $\left|A_{L}^{\prime}-P_{L}^{\prime \prime}\right|=$ $P_{L}^{\prime \prime}-A_{L}^{\prime}$. Since $A_{L}^{\prime \prime}<A_{L,}^{\prime}$, this implies the inequality given in the text. 
the two policies ${ }^{8}: g_{L}=\alpha\left|A_{L}-P_{L}\right|$, with $\alpha \in\left(0, \frac{1}{2}\right)$ some constant. Using the fact that any equilibrium requires $A_{L} \geq P_{L} \forall P_{L},(8.7)$ reduces to

$$
\frac{\partial A_{L}}{\partial P_{L}}=\frac{1}{2 \alpha}
$$

Solving then yields

$$
A_{L}=\frac{1}{2 \alpha} P_{L}+C
$$

with $C$ the integration constant. To solve for $C$, note that the most unfavorable belief voters can have about the true type of the candidate is $\tilde{P}_{L}=0$. Therefore, necessary for an equilibrium is $A_{L}(0)=0$. To see why this is the case, suppose, by contradiction, that we would have an equilibrium with $A_{L}(0)>0$. For the candidate with type $P_{L}=0$, defecting from this equilibrium can never lead to less favorable beliefs of voters. But claiming $A_{L}=0$ does decrease the loss of misrepresentation, so $A_{L}(0)>0$ cannot be part of an equilibrium.

Plugging $A_{L}(0)=0$ in 8.9 yields $C=0$, thus

$$
A_{L}=\frac{1}{2 \alpha} P_{L}
$$

In equilibrium, each candidate with $P_{L}>0$ overstates her true position. Note that election promises are not restricted to the interval $\left[0, \frac{1}{2}\right]$, containing all possible types of a left-wing candidate. For example, for a candidate whose true position happens to coincide with that of the median voter, we have $A_{L}\left(\frac{1}{2}\right)=\frac{1}{2}+\frac{1}{4 \alpha}$. The equilibrium thus involves candidates claiming a position which they cannot possibly have. But making such a claim is the only way to convince voters that their true position is close to that of the median voter. Also note that $A_{L}$ is monotone, which is required for a separating equilibrium.

Straightforward application of the above analysis implies for candidate $R$

$$
A_{R}=1-\left(1+\frac{1}{2 \alpha}\right)\left(1-P_{R}\right)
$$

${ }^{8}$ Note that, with this specification, the model only generates weak separating equilibrith, in which types are indifferent between, on the one hand, making the announcement prescribed by the separating equilibrium and, on the other hand, defecting to a different announcement. For strong separation, we need that $g_{i}$ is either strictly convex or strictly concave (see Mailath 1987). 
The strategy for a candidate $R$ is the mirror image of that of a candidate $L$. A right-wing candidate has an incentive to clairn that her position is more left-wing than it really is. For $R$ low enough, she will promise a policy that is more left-wing than her true policy position can possibly be.

\subsection{A Digression: More Candidates}

The model given in the previous section can easily be extended to a case in which more than two candidates are competing. Again, voters have some information with respect to the relative positions of all candidates. Suppose we have $n>2$ candidates. In a straightforward generalization of the two-candidate model, assume that candidates' true policy positions are known to be on equally spaced intervals on the unit line. Thus, for each candidate $i$, with $i \in\{1, \ldots, n\}$, it is known that her true position $P_{i} \in[(i-1) / n, i / n]$. For example, with $n=4$, candidate 1 's true position is known to be on the interval $[0,1 / 4]$, candidate 2 's position on $[1 / 4,1 / 2]$, etc. First suppose voters know the candidates ${ }^{3}$ true policy positions. Generalizing ( 8.2$)$, we then have

$$
\lambda_{i}= \begin{cases}\frac{P_{1}+P_{2}}{2} & i=1, \\ \frac{P_{i+1}-P_{i-1}}{2} & i=2, \ldots, n-1, . \\ 1-\frac{P_{n-1}}{2}+P_{n 1} & i=n .\end{cases}
$$

For the two most extreme candidates, 1 and $n$, the analysis is similar to the one given in the previous section. For example, candidate 1 still has an incentive to announce a position that is more right-wing than her true one. But for the intermediate candidates, with $i=2, \ldots, n-1$, things change. Note from (8.12) that for any such candidate $i$, the share of the wote is only dependent on the position of her immediate neighbors $i-1$ and $i+1$, and not on her own position. This is intuitive. Suppose $i$ 's position would shift slightly to the left. In that case, she would gain votes from candidate $i-1$, being now closer to her. At the same time, however, she would lose the same number of votes from candidate $i+1$. This implies that, in the incomplete information model, the election promise of candidate $i$ does not influence her own share of the vote, only that of candidates $i-1$ and $i+1$. Therefore, for intermediate candidates, there is no gain from misrepresenting their true position. Since there 
is always a loss of such misrepresentation, in equilibrium we necessarily have $A_{i}\left(P_{i}\right)=P_{i}$, for $i=2, \ldots, n-1$.

\subsection{A Median Voter Model}

In the previous sections I considered a model in which candidates try to maximize their share of the vote. I showed that, in the simple linear example, left-wing candidates have an incentive to promise a policy that is to the right of the policy they really want to implement, and rightwing candidates have an incentive to promise a policy that is to the left of the policy they really want to implement. Such distortion can even be beyond the position of the median voter. In equilibrium, candidates might announce a policy they cannot possibly want to implement. I also showed that in elections with more than two candidates, only the two extreme candidates have an incentive to distort their true policy position. Candidates with an intermediate position will reveal their type truthfully.

In this section I will use essentially the same framework, but now assume that candidates are only interested in winning the election, and not in their share of the vote. That implies that they are only interested in convincing the median voter. For example, if the median voter prefers candidate $L$, every voter with a preference to the left of the median voter will also prefer that candidate, which implies that candidate $L$ wins the election. In this model, there is a clear winner of the election, and a clear loser. The loser will not be able to hold any office whatsoever, different from the case in which candidates try to maximize their share of the vote, and also the candidate with the lower share obtains, for example, some seats in parliament. Therefore, in this median-voter model, if one loses the election, there are no costs attached to the initial misrepresentation of one's beliefs: no one can observe that there was such a misrepresentation.

Using the same notation as in section 8.4 , we now have ${ }^{10}$ that utility

\footnotetext{
${ }^{9}$ This result does hinge, however, on the assumption that voters are uniformlly distributed in policy space. If that is not the case, the result will be weaker. But then we will still have that, with more candidates, the intermediate ones will face less of an incentive to lie.

${ }^{10}$ With the same argument as in section (8.4), it can be shown that any equilibrium necessarily has $A_{L} \geq P_{L}$. Using this, in the remainder of this section, notation is simplified to read $l\left(A_{i}-P_{i}\right)$ rather than $l\left(\left|A_{L}-P_{L}\right|\right)$.
} 
of a candidate with type $i$ equals

$$
U_{i}\left(A_{i} \| P_{i}\right)=\left\{\begin{array}{ll}
U-l\left(A_{i}-P_{i}\right) & \text { if } V_{k}\left(\frac{1}{2}, A_{L}, A_{R}\right)=\dot{i}, \\
0 & \text { if } V_{k}\left(\frac{1}{2}, A_{L}, A_{R}\right)=j .
\end{array},\right.
$$

where $U$ is some fixed, positive utility of winning the election, which is equal for both candidates. The voting behavior of the median voter (for whom $\left.v_{k}=\frac{1}{2}\right)$ is denoted $V_{k}\left(\frac{1}{2}, A_{L}, A_{R}\right)$, given the election promises $A_{L}$ and $A_{R}$.

For ease of argument, rescale the policy space for candidate $R$ such that it is equivalent with that of candidate $L$ (i.e. in the new space $P_{R}=1-P_{R}^{O}$, with $P_{R}^{O}$ candidate $R$ 's position in the original policy space). The most extreme right-wing position thus implies $P_{R}=0$, rather than the $P_{R}^{O}=1$ in the original notation. This rescaling allows us to formulate both candidates" strategy in a similar way. I will show that, in equilibrium, both candidates will make a claim that is as "high" as possible. In the analysis that follows, I will first assume that the median voter chooses the candidate that makes the highest claim, and solve for candidates' behavior. I will then show that it is indeed rational for the median voter to vote for the candidate making the highest claim.

First note that, in the new notation, we have for both candidates $P_{i} \sim F_{i}(p)$. For simplicity, assume the loss function $l_{i}$ is identical for both candidates, and $P_{i}$ follows the same distribution for both candidates: $P_{i} \sim F(p), i=L, R$. For candidate $i$, expected utility of making a claim $A_{i}$ equals

$$
U_{i}\left(A_{i}\right)=\left(U-U\left(A_{i}-P_{i}\right)\right) \operatorname{Pr}\left(A_{j}<A_{i}\right) \text {, }
$$

where $\operatorname{Pr}\left(A_{j}<A_{i}\right)$ is the probability that the other candidate makes a lower claim. The first term on the right hand side of (8.14) represents the surplus candidate $i$ obtains from winning an election when her real position is $P_{i}$, while she claims that her position is $A_{i}$. The second term is the probability that she wins, given that she announces $A_{i}$. Suppose the announcement strategy of the other candidate, $j$, is given by $A_{j}=A\left(P_{j}\right)$. Define $\sigma\left(A_{j}\right) \equiv A^{-1}\left(A_{j}\right)$. Given the distribution of $P_{j}$, (8.14) can be written

$$
U_{i}\left(A_{i}\right)=\left(U-l\left(A_{i}-P_{i}\right)\right) F\left(\sigma\left(A_{i}\right)\right)
$$

Taking the first order condition

$$
\frac{d U_{i}}{d A_{i}}=\left[U-l\left(A_{i}-P_{i}\right)\right] f\left(\sigma\left(A_{i}\right)\right) \cdot \sigma^{\prime}-l^{\prime}\left(A_{i}-P_{i}\right) F\left(\sigma\left(A_{i}\right)\right)=0
$$


which implies

$$
\sigma^{\prime}=\frac{l^{\prime}\left(A_{i}-P_{i}\right) F\left(\sigma\left(A_{i}\right)\right)}{\left[U-l\left(A_{i}-P_{i}\right)\right] f\left(\sigma\left(A_{i}\right)\right)}
$$

In equilibrium, both candidates use the same strategy. Therefore we can use (8.17) to derive a differential equation that implicitly defines $A_{i}:^{11}$

$$
\frac{d A_{i}}{d P_{i}}=\frac{U-l\left(A_{i}-P_{i}\right)}{l^{\prime}\left(A_{i}-P_{i}\right)} \cdot \frac{f\left(P_{i}\right)}{F\left(P_{i}\right)}
$$

Using the same argument as in section 8.4 , it is easy to see that, in general, truth-telling will not be an equilibrium. It only is if the righthand side of (8.18) equals 1 for all $P_{i}$.

Again, I use a simple example to illustrate the analysis. Suppose we have the easiest conceivable loss function: $l\left(A_{i}-P_{i}\right)=\alpha\left(A_{i}-P_{i}\right)$, with, necessarily $A_{i}>P_{i}$. Assume that $\alpha<4 U$, and that the possible type of candidate $i$ follows a uniform distribution: $P_{i} \sim U\left[0, \frac{1}{2}\right]$. Using (8.18) implies

$$
\frac{\partial A_{i}}{\partial P_{i}}=\frac{U-\alpha\left(A_{i}-P_{i}\right)}{\alpha} \cdot \frac{2}{2 P_{i}}
$$

The general solution to this differential equation is given by

$$
A_{i}\left(P_{i}\right)=\frac{1}{2} \frac{2 U P_{i}+\alpha P_{i}^{2}+2 C \alpha}{\alpha P_{i}},
$$

with $C$ the integration constant. Imposing $A_{i}(0)=0$ yields $C=0$, thus

$$
A_{i}\left(P_{i}\right)=\frac{1}{\alpha} U+\frac{1}{2} P_{i} .
$$

The condition $\alpha<4 U$ is sufficient for $A_{i}>P_{i}$. The announcement function $A_{i}$ is monotone increasing and one-to-one. Therefore, a median voter that observes both claims can immediately infer the true policy position of each candidate. Given that both candidates follow the same strategy, the one with the highest claim always has the position which is

${ }^{11}$ This differential equation can also be derived directly by interpreting the game described here as a signaling game in which, for each candidate, $P_{i}$ is the real type, $A_{i}$ the sigmal, and $\sigma\left(A_{i}\right)$ the type inferred by the receiver. We can then use Mailath (1987) directly to derive (8.17). (see footnote 5). 
closest to that of the median voter. Hence, it is rational for the median voter to vote for the candidate with the highest claim.

Again we have that all candidates with $P_{i}>0$ overstate their true position in the direction of the median voter. Again some candidates will even announce a position that they cannot possibly have. An increase in the exogenously given utility of winning the election $U$, always leads to higher claims in equilibrium. An overall increase in the disutility of misrepresenting one's views, measured as an increase in $\alpha$, always implies election announcements that are more moderate ${ }^{12}$.

Note that the game described in this section can be interpreted as an auction. In an auction (see for example McAfee and McMillan 1987 or Wolfstetter 1996) a number of bidders make a bid $b_{i}$ that depends on their valuation $v_{i}$ of a good being auctioned, and the probability distribution of the valuations of all other bidders. The bidder with the highest bid wins the auction and obtains a surplus $v_{i}-b_{i}$. The optimal bid can be derived by maximizing expected utility, taking into account that posting a lower bid increases utility if the auction is won, but decreases the probability of winning the auction. In the game described here, two candidates make a "bid" $A_{i}$ that depends on $P_{i}$ and the probability distribution of $P_{j}$. The candidate with the highest "bid" wins the election and obtains a surplus $U-l\left(A_{i}-P_{i}\right)$. The optimal "bid" can be derived by maximizing expected utility, taking into account that making a higher promise decreases utility if the election is won, but increases the probability of winning the election.

\subsection{Conclusion}

In this chapter I showed that two candidates participating in an election have an incentive to make untruthful promises during the election campaign. More precisely, it was shown that each candidate will make an announcement about her policy position that does not coincide with her true position. Any left-wing candidate will make a promise that is to the right of her real position, while every right-wing candidate will make a promise that is to the left of her real position. Voters, however, are not fooled by these promises, since, upon observing election promises,

\footnotetext{
${ }^{12}$ The latter effect aiso occurs in the share-of-the-wote model, the difference being that in that model a change in $\alpha$ changes the slope of the announcement function, whereas, in this case, it causes a shift in the announcement function.
} 
they can rationally infer the true position of each candidate. This phenomenon seems robust with respect to the type of model chosen. Both in a model in which candidates try to maximize their share of the vote, and in a model in which they try to attract the median voter, the same effect occurs.

The intuition behind this result is that candidates can only convince voters of their true position if they send a costly signal, which is such that it is just not worthwhile for a different candidate to use that same signal. In the models considered here the costs consist of a disutility of misrepresenting one's true position. For example, any candidate can claim that she has the same position as the median voter has. But voters will only be convinced of this, if the particular candidate is willing to incur a cost which is only worthwhile to incur for a candidate which really has the same position the median voter has. This particular candidate will therefore make an extreme election promise, that is actually beyond that of the median voter. The voters know that only a candidate that really has the same position as the median voter can afford to make this extreme claim. Thus, upon observing this announcement, they will infer that they are really facing such a candidate. A similar logic holds for candidates who have a position that is more remote from that of the median voter. Upon observing any promise, voters can infer the type of candidate they are facing, since for every promise there is a unique type for whom it is worthwhile to make exactly that promise.

The effect found is sensitive to the number of candidates participating in an election. I showed that with more candidates in a share-ofthe-vote model, only candidates with the most extreme position have an incentive to be untruthful. Candidates with an intermediate position do not have such an incentive, since their share of the vote does not depend on their own announcement, but only on those of their two, in an ideological sense, closest neighbors. Technically, the median voter model could easily be extended to more candidates (for example, by assuming there are $n_{L}$ left-wing, and $n_{R}$ right-wing candidates). But in such a model, it is no longer clear why any candidate wants to attract the median voter: with more than two candidates, attracting the median voter does no longer imply winning the elections. A more sensible extension of the model would be to assume that coalitions rather than candidates are running in the election. This is not uncommon in, for example, Italy or France. Suppose we have two left-wing and two right-wing parties. The two left-wing parties form a coalition, as do the two-right wing-parties. 
Suppose the position of the extreme left-wing party is known to be on $\left[0, \frac{1}{4}\right]$, and the position of the intermediate left-wing party on $\left[\frac{1}{4}, \frac{1}{2}\right]$. In that case, the intermediate party is the only one that can ascertain that the coalition will win the election: she is the only one that is able to attract the median voter. Knowing this, the extreme left-wing candidate will use her announcement to gain voters from the intermediate left-wing party. We then have a mixture of both models described here: the intermediate party has to make sure that the coalition will attract the median voter, while the extreme party can maximize her share of the vote.

Another possible extension of the model takes into account that, before candidates can stand for election, they first have to gain support of the party for which they want to run. A left-wing candidate then faces the problem of attracting the (left-wing) members of the party, without compromising her chances in the general election that will follow. As a final possibility, suppose voters abstain when they feel there is no candidate which is close enough to their own preferences. In that case, candidates have a countervailing incentive to make a claim which is more extreme rather than more towards the median voter. In that case, therefore, we can have that a left-wing candidate makes claims to the left of her true position, while a right-wing candidate makes a claim to the right of her true position.

I showed that, in equilibrium, every candidate is forced to incur some costs to credibly signal her true position. Yet, in equilibrium, voters can always infer the true position of each candidate. Therefore, in welfare terms, the equilibrium derived here is worse than that in the case in which voters are able to observe the true policy position of a candidate. In the latter case, there is no necessity for candidates to incur the cost of lying about their policy position. Yet the outcome of the election is the same since, ex post, voters do have the same information under both information regimes. Therefore, any device that decreases the cost for all possible types of candidates to signal their true policy position, would enhance welfare. 



\section{Chapter 9}

\section{A Fairness Explanation to Intertemporal Choice Anomalies}

\subsection{Summary and Overview}

In chapter 2 I discussed Rabin's (1993) fairness model. This model assumes that people are willing to sacrifice some of their material payoffs, in order to either punish someone who is nasty to them, or reward someone who is nice to them. If people behave this way, I argued, monopolists will not set prices as high as standard theory suggests. This chapter applies the same model, but to a different field: that of intertemporal choice.

The standard life cycle model predicts that agents use a constant discount rate. But experimental evidence shows this is typically not the case. Implicit discount rates are higher than interest rates. They decline with time to be waited, and size of the sum at stake. For speeding up a reward they are lower than for delaying. This chapter shows that these anomalies can be explained using Rabin's fairness model, by assuming that when deciding on the intertemporal allocation of a windfall gain, an agent acts as if a "Future Self" were to divide the money, taking considerations of fairness into account. 


\subsection{Introduction}

The standard model of intertemporal choice assumes that an individual maximizes lifetime utility, defined as the discounted sum of instantaneous utility, or felicity, in every future period. The assumption is made that the discount rate is constant for an individual across time and situations. But experimental evidence suggests that this is typically not the case. This chapter considers four anomalies which contradict the assumption, and provides a framework in which they can be explained.

When individuals are making choices regarding the future, they have to strike a balance between current costs and future benefits, or current benefits and future costs. The decision to save involves foregoing current consumption in order to increase future consumption. When buying an electrical device, there is often a trade-off between current purchase price and future costs of electricity. Economists make the assumption that to decide on these matters, individuals use an implicit discount rate to weigh these costs and benefits. This discount rate is assumed to be equal over time, and across situations. If an individual would not behave this way, it would behave dynamically inconsistent (Strotz, 1956), and it is easy to show that, in that case, there is some way to change the original plan, such that the individual is better off.

Nevertheless, several studies suggest that individuals do not use a constant discount rate when making intertemporal decisions. Thaler (1981) conducts the following experiment. Subjects are told that they have won an amount $x$, to be received immediately. However, they can also wait and receive an amount at some specified future date. They are asked which future amount $y$ they would require in order to make waiting just as attractive as getting $x$ right now. According to the standard model, the answer is easy and we have $y=(1+r)^{T} x$, with $T$ time to be waited, and $r$ the individual discount rate. If an individual were to behave according to standard theory, $r$ should equal the market interest rate at which the individual can save. However, Thaler finds that the subjects use an implicit discount rate which is much higher than the relevant interest rate. Median responses imply discount rates of up to $345 \%$, in the case of $x=\$ 15$ and $T=1$ month. In empirical studies a high individual discount rate is also often found. For example, Hausman (1979) uses data on air conditioners to estimate an implicit discount rate of $26.4 \%$, using trade-offs between current purchase price and future energy costs. Gately (1980) finds discount rates ranging from 
$45 \%$ to $300 \%$ in a similar study on refrigerators.

In his study, Thaler (1981) finds other irregularities as well. Implicit discount rates are decreasing in both the amount to be paid and the length of time to be waited. For example, with $x=\$ 15$ but $T=1$ year, the median response implies a discount rate of $120 \%$, instead of the $345 \%$ with $T=1$ month. With $T=1$ month but $x=\$ 3,000$ a median discount rate of $39 \%$ is found. Similar questions as in Thaler (1981) are also posed in a study by Benzion, Rapoport and Yagil (1989). But, apart from the case of the postponement of a windfall gain, these authors also look at the amount subjects want to get paid in order to speed-up the receipt of a windfall gain. Individuals are then told that they will receive a windfall gain of $y$ in $T$ periods. However, rather than wait for the gain for $T$ periods, they can also choose the receive an amount of $x$ now. The question then is which $x$ makes the individual just indifferent. The results Benzion et al. find, are in both cases qualitatively the same to those in Thaler (1981): discount rates are very high but decreasing in the amount at stake and length of time to be waited. These findings are also confirmed by the similar experiments in Loewenstein (1987). Finally, Loewenstein (1988) reports an asymmetry between postponement and speedup of consumption. He finds that the amount subjects required to compensate for receiving a reward by a given interval, from $t$ to $t+s$, was two to four times greater than the amount they were willing to sacrifice to speed consumption up by the same interval, from $t+s$ to $s$, although the two options are analytically the same. Although not mentioned explicitly, the same effect can also be found in the results of Benzion et al. (1989).

Summarizing from these results, we have four anomalies about individual discount rates (see also Loewenstein and Thaler, 1989, and Loewenstein and Prelec, 1992) ${ }^{1}$;

1. Discount rates for short periods of time are much higher than relevant interest rates,

2. Discount rates decrease in the amount at stake,

${ }^{1}$ Note therefore, that I do not try to explain individual rates as such, as is done, in for example Uzawa (1968), Epstein and Hynes (1983), and Becker and Mulligan (1997). In this literature, it is still assumed that discount rates for an individual at a certain point in time, are constant with respect to the time to be waited and the amount at stake. This chapter tries to explain the observation that this assumption does not holl. 
3. Discount rates decrease in the length of time to be waited,

4. Discount rates for delaying a reward are larger than discount rates for speeding up a reward under identical circumstances.

Several explanations have been put forward to solve for these intertemporal choice anomalies. Shefrin and Thaler (1988) suggest an explanation which relies on notions of mental accounting: small windfall gains are entered into a mental checking account and are largely consumed, while larger windfall gains are entered into a mental savings account, with a much smaller propensity to consume. The cost of waiting for a small windfall gain is then perceived to be foregone consumption, while the cost of waiting for a large windfall is perceived as just foregone interest. A number of authors, for example Thaler and Shefrin (1981) or Schelling (1984) have proposed models that view economic behavior as an internal struggle between multiple selves with conflicting preferences. A rational, far-sighted self takes actions to constrain or alter the behavior of a myopic self. This might explain why people behave in a way which seems dynamically inconsistent. Loewenstein (1987) argues that positive utility is obtained from anticipating future pleasant outcomes (savoring), while negative utility is obtained from anticipating future negative outcomes (dread). Finally, Loewenstein and Prelec (1992) propose a specification of the utility function, which allows for all the anomalies which are found.

None of the explanations, however, are fully satisfactory. Most of them can only account for one of the anomalies stated, and they often do not provide an analytical framework. Others (notably Loewenstein and Prelec, 1992) do account for all anomalies, but fail to give an intuitive interpretation of the utility function individuals are using. In this paper I therefore propose a model which not only provides an analytical framework which can be used to prove that all anomalies can be explained, but also gives an intuitive explanation of the thought process which lies behind this framework, and thus behind the anomalies. In my model, different selves are also used. Rather than a rational self which constrains the behavior of a myopic self, I use a Current Self which views its part of the windfall gain as a gift of the Future Self. But since this Current Self is able to already take its own part of the windfall gain, it can impose on the Future Self how it must behave. I assume the Current Self will impose a behavior on the Future Self which is consistent with Rabin's (1993) notion of fairness. 
This chapter fits in the behavioral game theory literature (for a survey see Camerer 1997). Its aim is to find a mechanism that can explain certain behavior. I do not claim that people necessarily behave in the way described in this chapter. I merely observe that a lot of anomalous behavior can be explained by assuming that they do behave in this way. My explanation uses a model that can also explain anomalous behavior in other contexts. Therefore the model in this chapter provides a step towards a more general model of behavior, which is able to explain several behavioral anomalies that cannot be explained by models assuming full rationality ${ }^{2}$.

In the next section, I will first give an intuitive interpretation for the framework I am using. I describe a thought experiment which is supposed to be used by an individual deciding on the timing of a windfall gain. Rabin's (1993) model of fairness is discussed in section 3. Section 4 applies that model to the thought experiment, and section 5 shows that in the resulting model, all the anomalies mentioned above can be explained. Section 6 draws some conclusions.

\subsection{A Thought Experiment}

In the introduction $\mathbb{I}$ discussed a class of experiments, which indicate that individuals typically do not use a constant discount rate when making intertemporal choices. When a subject is confronted with a future windfall gain, (s) he is usually willing to pay an amount to speed up that gain, which is much higher than the standard model of intertemporal choice predicts. In a similar way, the amount a person wants to get paid in order to postpone a windfall gain is much higher than the standard model predicts. The discount rate individuals seem to use when making such a decision, appears much higher than what reasonably can be expected. However, this implicit discount rate is higher for postponing than it is for speeding-up a windfall gain. Also, the discount rate is decreasing in both the amount at stake and the time to be waited.

These results can all be explained, however, if we assume that an individual, when faced with such a choice, reasons as follows. Suppose an individual is suddenly confronted with a windfall gain. For ease of exposition, suppose it can divide that gain between now and some fixed future date. Imagine that the individual regards these two points in

\footnotetext{
${ }^{2}$ For more on this see Haan (1997).
} 
time as two different persons between which it can divide the money. One of those persons is the Current Self. The other is the Future Self. The individual has to decide how to divide the money between now and the future: therefore it is the Current Self which ultimately decides. When making the decision, the Future Self is regarded as someone else. Dividing the money between now and some future date boils down to giving some part of the money to the Future Self, and keeping the other part to itself, thus giving it to the Current Self.

If this was all that was going on, the Current Self would simply keep all the money now, without "giving" anything to its Future Self. However, the individual realizes that its Future Self is not just a different person, but rather the same one in a different guise. Therefore, if the Current Self gives some money to the Future Self, the Current Self receives some utility from doing that as well. For simplicity, assume that if a person gives an amount $A$ to its Future Self, this implies that the Current Self is getting the discounted value of the amount the Future Self receives, which equals $\delta^{T} A$, with $\delta$ the discount factor per period and $T$ the number of periods the Current and Future Self are removed from each other. More general, I assume that the utility the Current Self receives from dividing an amount $A$, by keeping a fraction $\lambda$ to itself and giving $1-\lambda$ to its Future Self, equals $\lambda A+\delta^{T}(1-\lambda) A$. Here, the felicity function is thus simply identity, and total utility of the Current Self equals the sum of lifetime felicities, weighed in the appropriate way, using discount factor $\delta$. In an analog way, the amount the Future Self gets in this example, equals $\delta^{T} \lambda A+(1-\lambda) A$ : it receives $(1-\lambda) A$ itself, and an amount $\lambda A$ is received by another self, $T$ periods removed. The implicit assumption here is thus that in the total utility function, felicity received in the past is weighed equally to felicity to be received in the future, if the length of time is equal.

Standard game theory would still predict that in this set-up the Current Self keeps the full windfall gain to itself. However, from other experiments, it is well known that in cases like this, people do not behave that way. In Dictator Games for example, individuals receive some windfall gain, and are asked to give some of it to other people. Although it is a dominant strategy not to give anything, people usually do give a positive amount. In an Ultimatum Game, two persons are playing. Player 1 is offered a certain amount of money. It has to offer some of it to player 2. Player 2 can either accept or reject the offer. If it accepts, the division player 1 suggested, is executed. But if player 2 rejects the 
affer, both players get nothing. Clearly, a dominant way to play this game is for player 1 to offer the smallest amount possible and for player 2 to accept. But in experiments, this behavior is hardly ever observed. Player 1 usually offers a much higher share to player 2, and player 2 often rejects a positive offer. (For a survey on the literature on both dictator games and ultimatum games, see Thaler, 1988, and Camerer \& Thaler, 1995).

These types of behavior suggest that people do not always behave as game theory predicts. But it cannot be explained by plain altruism as well. Rabin (1993) suggests that individuals take fairness considerations into account when making a decision. First, people are willing to sacrifice their own material well-being to help those who are being kind to them. But, second, they are also willing to sacrifice their own material wellbeing to punish those who are being unkind to them. Both motivations have a stronger effect on behavior as the material cost of sacrificing becomes smaller (Rabin, 1993, p. 1281).

Rabin offers a formal framework to study behavior if these fairness considerations are taken into account. Using this fairness framework it is possible to show that in the thought experiment sketched above, all intertemporal choice anomalies can be explained. The Current Self can choose which part of a windfall gain to keep for itself, and how much to give to the Future Self. However, different from Rabin, I assume that the Current Self takes an opportunistic view towards fairness. Instead of giving to the Future Self the amount of money which would be fair if it would take fairness considerations into account, it rather takes the amount of money it would get if the Future Self were dividing the money, taking faimess into account. In this way, the Current Self ultimately receives more than in the case it would act as if it divided the money itself. The Current Self thus already executes the decision which would be made by a fair Future Self. In this way, the Current Self ultimately receives more, as can be seen in the model described in the next section. Rather than dividing the money itself in a fair way, the Current Self thus imposes the Future Self to behave in that manner. In this way the Current Self can get the largest possible share of the money, whilst still having the feeling of behaving in some way that it consistent with faimess. In this view of the world, people do take fairness into account when making their decisions. But they do so in the way which best suits their own material well-being.

This interpretation also suggests why individuals are behaving as 
they are found to behave in intertemporal choice experiments, rather than they are ought to behave according to the standard model. As the stakes increase, the relative importance of the fairness consideration decreases, and the person starts to behave more according to the standard model, implying a lower discount rate. The same holds as the length of time to be waited increases. Furthermore, if we assume that the individual takes what he is initially promised as a reference point, we can show that implicit discount rates for postponement are indeed higher than discount rates for speeding up gains. The reason for this is that in the case of a postponement money is taken away from the Current Self, whereas in the case of a speed-up, he is given more than he originally expected ${ }^{3}$.

In the next section I will present Rabin's (1993) fairness model, which discusses the same fairness issues as are considered in this paper. In section 4 I use that model to formalize the thought experiment described in this section, and in section 5 I show that in the interpretation I have given above, the anomalies can indeed be explained.

\subsection{Fairness}

Rabin (1993) models fairness as follows. Consider a two-player normal form game with pure strategy sets $A_{1}$ and $A_{2}$. Let $\pi_{i}: A_{1} \times A_{2} \rightarrow \mathbf{R}$ be player $i$ 's material payoff. The strategies actually chosen by the two players are given by $a_{1}$ and $a_{2}$. Player $j$ 's belief about what strategy player $i$ is choosing, is denoted by $b_{i}$. Finally, $c_{i}$ represents player $i$ 's beliefs about what player $j$ believes player $i$ 's strategy is. Obviously, in any equilibrium $a_{i}=b_{i}=c_{i}, i=1,2$. Player $i$ 's kindness to player $j$ is defined as

$$
f_{i}\left(a_{i}, b_{j}\right)=\frac{\pi_{j}\left(b_{j}, a_{i}\right)-\pi_{j}^{e}\left(b_{j}\right)}{\pi_{j}^{h}\left(b_{j}\right)-\pi_{j}^{\min }\left(b_{j}\right)} .
$$

Here, $\pi_{j}^{\min }\left(b_{j}\right)$ is the payoff player $j$ gets if player $i$ takes the action that minimizes $j$ 's payoff, given $i$ 's belief that $j$ is playing $b_{j}$. It thus represents the minimum $i$ can "give" to $j$, given $b_{j}$. Similarly, $\pi_{j}^{h}$ is the highest amount $i$ can give, $\pi_{j}$ is what he actually gives, and $\pi_{j}^{e}\left(b_{j}\right)$ is some reference point against which to judge whether or not player $i$ is treating player $j$ kindly. If $i$ gives $j$ more than its "share" (thus: $\pi_{j}^{e}$ ),

\footnotetext{
${ }^{3}$ All these claims are proved in section 5 .
} 
the numerator of (9.1) is larger than zero, and player $i$ treats player $j$ "kind". If, on the other hand, $i$ gives $j$ less than its share, the numerator is negative, and $i$ is treating $j$ "unkind". Rabin chooses $\pi_{j}^{e}\left(b_{j}\right)$ as the average of, on the one hand, the lowest pay-off $j$ can receive among points that are Pareto-efficient, and, on the other hand, the highest pay-off $j$ can receive. For this specification of $\pi_{j}^{e}$ it is easy to see that we always have $f \in\left[-1, \frac{1}{2}\right]$.

Player $i$ 's behavior is partly determined by how he thinks player $j$ treats him. Player $i$ 's belief about how kind player $j$ is treating him is defined in a similar way to $(9.1)$, as $\widetilde{f}_{j}\left(b_{j}, c_{i}\right)$. Given their shared notion of fairness, each player $i$ now chooses $a_{i}$ to maximize expected utility, given by

$$
U_{i}\left(a_{i}, b_{j}, c_{i}\right)=\pi_{i}\left(a_{i}, b_{j}\right)+\tilde{f}_{j}\left(b_{j}, c_{i}\right) \cdot\left[1+f_{i}\left(a_{i}, b_{j}\right)\right] .
$$

The first term on the right hand side is the material payoff to player $i$. The second term represents additional utility out of fairness considerations. Note that player $i$ receives additional utility from treating player $j$ kindly $\left(f_{i}>0\right)$ if and only if he believes that player $j$ is treating him kindly as well $\left(\tilde{f}_{j}>0\right)$. But if player $i$ believes player $j$ is treating him badly $\left(\tilde{f}_{j}<0\right)$, then he wishes to treat player $j$ badly as well $\left(f_{i}<0\right)$. Nevertheless, additional utility from fairness in that case is non-positive. Another implication of the model is that fairness considerations become less important as the amount at stake $\left(\pi_{i}\right)$ increases: since $f_{i}$ and $\widetilde{f}_{j}$ are always in the interval $\left[-1, \frac{1}{2}\right]$, their relative weight decreases as $\pi_{i}$ increases.

\subsection{A Formalization of the Thought Experiment}

In the thought experiment described in section 2, we also have two players: the Current Self and the Future Self. Either one of them receives a windfall gain, which has to be divided among the two. However, the Current Self is not interpreting it this way. Rather, the amount it receives is interpreted as the amount given to it by the Future Self. The Current Self is then using its own utility function to evaluate what would be fair for the Future Self to give to the Current Self. In this case, we thus have only one player taking an action (the Future Self), and the other person (the Current Self) judging fairness as the way it "is treated". The Current Self takes the opportunistic view, that the 
money is divided by the Future Self, and it can already take its part now. If we denote the Current Self by $C$ and the Future Self by $F$, we can use (9.2) to write $C^{\prime \prime}$ s utility as

$$
U_{C}\left(a_{C}, b_{F}, c_{C}\right)=\pi_{C}\left(a_{C}, b_{F}\right)+\tilde{f}_{F}\left(b_{F}, c_{C}\right) \cdot\left[1+f_{C}\left(a_{C}, b_{F}\right)\right] .
$$

But in the thought experiment, the Current Self does not take any action. We thus have $f_{C}=0$ by definition, and (9.3) simplifies to

$$
U_{C}\left(b_{F}\right)=\pi_{C}\left(b_{F}\right)+\tilde{f}_{F}\left(b_{F}\right)
$$

In this paper I generalize on this fairness-based utility function, by writing

$$
U_{C}\left(b_{F}\right)=\pi_{C}\left(b_{F}\right)+F \cdot \tilde{f}_{F}\left(b_{F}\right)
$$

with $F$ some constant representing the intensity of the fairness consideration: with higher $F$, the relative weight of the fairness term is higher as well. Moreover, I assume that, ceteris paribus, being treated unfair gives a higher disutility than the utility obtained from being treated fair. This is intuitive: people always have much stronger emotions when being treated unfair, then they have when being treated fair. This is especially the case if they do not have the possibility to retaliate, as they do have in the original Rabin model. Therefore, I generalize (9.5) to read

$$
U_{C}\left(b_{F}\right)=\left\{\begin{array}{ll}
\pi_{C}\left(b_{F}\right)+F_{G} \cdot \tilde{f}_{F}\left(b_{F}\right) & \text { iff } \tilde{f}_{F}>0 \\
\pi_{C}\left(b_{F}\right)+F_{L} \cdot \tilde{f}_{F}\left(b_{F}\right) & \text { iff } \tilde{f}_{F}<0
\end{array},\right.
$$

with $F_{G}<F_{L}$.

Consider the thought experiment described in section 2 , where a windfall gain can be divided between the Current Self and the Future Self. First consider the case in which the Future Self receives an amount $A$, and has to divide it between the Current Self and the Future Self. The highest amount it can give to the Current Self equals $A$, (by giving it the full sum), the lowest it can give is $\delta^{T} A$ (by keeping all the money itself, thus giving the Current Self only its discounted value to enjoy). If the Future Self keeps a fraction $\lambda$ of the total sum to itself, then the Current Self receives $\left[(1-\lambda)+\delta^{T} \lambda\right] A$. Therefore, in (9.1) we have $\pi_{j}^{\min }\left(b_{j}\right)=\delta^{T} A$, whereas $\pi_{j}^{h}=A$. I assume that the reference point the 
Current Self uses, is the amount it was originally promised. Originally, the Current Self thought to obtain a certain amount. Therefore, it will feel badly treated if the amount it ultimately gets is lower than this original promise. It will feel well treated, if the amount is higher. In this case, the Future Self was promised the money, so $\pi_{C}^{e}=\delta^{T} A$. If we define $\lambda$ as the action taken by the Future Self, using (9.1) implies

$$
\widetilde{f_{F}}(\lambda)=\frac{\left[(1-\lambda)+\delta^{T} \lambda\right] A-\delta^{T} A}{\left(1-\delta^{T}\right) A}=1-\lambda .
$$

Since $\widetilde{f_{F}}(\lambda) \geq 0 \forall \lambda$, using (9.6) we can write

$$
U_{C}(\lambda)=\left[(1-\lambda)+\delta^{T} \lambda\right] A+F_{G}(1-\lambda) .
$$

So far we have assumed that $A$ was to be received by the Future Self. Now suppose that the Current Self is promised the windfall gain A. Again we look at utility of the Current Self when it behaves as if the Future Self divides the money between the two Selves. The difference with the first case is that the reference point of the Current Self changes. Rather than starting from a situation in which the Future Self was promised the gain, we now start from a situation in which the Current Self is promised all the money. Therefore $\pi_{C}^{e}=A$. We still have $\pi=\left[(1-\lambda)+\delta^{T} \lambda\right] A, \pi_{j}^{\min }\left(b_{j}\right)=\delta^{T} A$, and $\pi_{j}^{h}=A$ so the fairness of the Future Self towards the Current Self can now be shown to equal

$$
\widetilde{f_{F}}(\lambda)=\frac{\left[(1-\lambda)+\delta^{T} \lambda\right] A-A}{\left(1-\delta^{T}\right) A}=\frac{\lambda\left(\delta^{T}-1\right)}{1-\delta^{T}}=-\lambda .
$$

Since $\widetilde{f_{F}}(\lambda) \leq 0 \forall \lambda$, using $(9.6)$ we can write

$$
U_{C}(\lambda)=\left[(1-\lambda)+\delta^{T} \lambda\right] A-F_{L} \lambda
$$

Note that in the case of the speed-up of a windfall gain, the Current Self will always feel treated well, since it gets more than it originally thought it would get. However, in the case of the postponement of a windfall gain, the Current Self always feels badly treated, since it receives less than it was originally promised.

\subsection{Explaining the Anomalies}

In the experiments described in the introduction, typically the following question was asked. Suppose you get a windfall gain of $y$ in $T$ periods. 
Which amount $x$ do you want to receive now in order to make you indifferent between receiving $x$ now and $y$ in $T$ periods? Or, alternatively, suppose you receive a windfall gain of $x$ now. In case your receipt of the gain would be postponed for $T$ periods, then which amount $y$ do you want to receive then in order to be just indifferent with the original situation? In this section, I will show that the anomalies mentioned in the introduction can be explained when we assume that individuals use the framework of the previous section to make their decisions.

In terms of the utility functions (9.7) and (9.9), note that the individual only has two choices: either to give everything to the Future Self $(\lambda=1)$, or to give everything to the Current Self $(\lambda=0)$. First consider the case of speeding up a windfall gain. Using (9.7), utility when the Future Self gets everything (so $\lambda=1$ ) equals $U_{c}(1)=\delta^{T} y$. Utility when the Current Self gets everything equals $U_{c}(0)=x+F_{G}$. The individual can thus determine the amount $x$ by equating $U_{c}(0)$ and $U_{c}(1)$. Doing this yields ${ }^{4}$

$$
x=\delta^{T} y-F_{G}
$$

Now consider the case of postponing a windfall gain. Again we have that the individual can only choose between giving everything to the Current Self and giving everything to the Future Self. Using (9.9), utility when the Future Self gets everything (so $\lambda=1$ ) equals $U_{c}(1)=\delta^{T} y-F_{L}$. Utility when the Current Self gets everything equals $U_{c}(0)=x$. This implies that $y$ can be solved using

$$
x=\delta^{T} y-F_{L} .
$$

Now consider the case in which we did not have fairness considerations. We are then in the standard model, and simply have $x=\delta^{T} y$. Suppose someone is using this standard model to calculate discount rates. The implicit discount rate, say $r$, can be found by calculating

$$
r=\left(\frac{y}{x}\right)^{T}-1
$$

\footnotetext{
${ }^{4}$ Obviously, (9.10) only holds for $F_{G}<\delta^{T} y$. If this were not the case the model would predict that an individual would be willing to poy an amount now rather than to receive a windfall gain later. The model in this paper is kept as simple as possible, in order to keep the discussion as clear as possible. A richer model would of course take this into account. The same holds for $(9.11)$, which assumes $F_{L}<\delta^{T} y$.
} 
But now suppose that the 'true model' is the one described in this chapter. If behavior is governed by (9.10), applying (9.12) yields

$$
r=\left(\delta^{T}-\frac{F_{G}}{y}\right)^{-\frac{3}{T}}-1,
$$

and if behavior is given by (9.11), it yields

$$
r=\left(\delta^{T}-\frac{F_{L}}{y}\right)^{-\frac{1}{T}}-1
$$

Consider the case in which we have $F_{L}=F_{G}=F$, so $r=\left(\delta^{T}-\frac{F}{y}\right)^{-\frac{1}{T}}$ 1. In the appendix I proof that the following results then hold:

$$
\begin{gathered}
r>\frac{1}{\delta}-1 \\
\frac{\partial r}{\partial y}<0 \\
\frac{\partial r}{\partial T}<0 \\
\frac{\partial r}{\partial F}>0
\end{gathered}
$$

The first result, (9.15) implies that discount rates $(r)$ calculated from the observed responses of the individual, are higher than the "actual" discount rate $\left(\frac{1}{\delta}-1\right)$ - our first anomaly. The second result implies that as the amount at stake increases, the measured discount rate $r$ decreases - the second anomaly ${ }^{5}$. From the third result, the measured discount rate decreases as $T$ increases, solving the third anomaly. Finally, note that I have argued that $F_{L}>F_{G}$. From (9.18), this implies that the discount rate for speeding-up a gain (9.13) is lower than the discount rate for postponing a gain (9.14) in the case which analytically boils down to the same choice. This is the fourth anomaly.

${ }^{5}$ Strictly speaking, in order to prove that $r$ is decreasing in the amount at stake in the case of speeding up a windfall gain, we have to write (9.13) in terrss of $x$ rather than $y$, and calculate $\frac{\partial x}{\partial x}$. However, it is very easy to see that this will yield the same result, i.e. $\frac{\partial r}{\partial x}>0$. 


\subsection{Conclusion}

In this chapter I presented a model of behavior which can explain four anomalies in intertemporal choice. By assuming that an individual treats the division of a windfall gain over time as if a Future Self were dividing the money, and imposing fairness considerations upon that Future Self, I was able to show that, first, measured discount rates will be much higher than interest rates, second, measured discount rates decrease with the amount of money at stake, third, they decrease with the length of time to be waited, and fourth, measured discount rates for postponing a windfall gain are higher than those for speeding up a windfall gain.

Obviously, the functional specifications I have used in this chapter are oversimplified. Felicity, total utility and kindness functions are probably much more complicated in the real world, than the ones used in this paper. The oversimplified functional forms used here, are mainly used for easte of exposition. If this framework is to be applied in empirical or experimental research, a more general specification is obviously needed. An estimation of such a more general model would be very useful, both to gain a greater insight into how people actually behave when making intertemporal choices, and to get a better understanding for which factors influence people's behavior towards fairness.

Although the model as it stands is very successful in explaining the four anomalies described, there is still one intertemporal choice anomaly which it cannot explain. In this paper, I have only considered windfall gains. But another result from the experiments mentioned in the introduction, is that discount rates for windfall losses are always much lower than discount rates for windfall gains. This effect cannot be explained by the model discussed here. Apparently, for windfall losses something different is happening in the mind of the individual decision-maker. To explain this, we need a different model.

\subsection{Appendix}

In this appendix I proof (9.15) through (9.18). First note that the implicit discount rate is found using $r=\left(\delta^{T}-\frac{E}{y}\right)^{-\frac{1}{T}}-1$. Obviously, $\delta^{T}-\frac{F}{y}<\delta^{T}$, so $\left(\delta^{T}-\frac{F}{y}\right)^{\frac{1}{T}}<\delta$, thus $\left(\delta^{T}-\frac{F}{3}\right)^{-\frac{1}{T}}>\frac{1}{\delta}$, and $r>\frac{1}{\delta}-1$, which proves $(9.15)$. 
For simplicity, in what follows, I write $K$ for $\delta^{T}-\frac{F}{y}$. Note, from footnote 2, that $K>0$. Taking the first derivative of $r$ with respect to $y$ yields

$$
\frac{\partial r}{\partial y}=-\frac{F K^{-\frac{3+T}{T}}}{T y^{2}}
$$

Since $F, K, T$ and $Y$ are all non-negative, this implies $\frac{\partial r}{\partial y}<0$, thus (9.16). Next, take the first derivative of $r$ with respect to $F$. This yields

$$
\frac{\partial r}{\partial F}=\frac{K^{-\frac{1+T}{T}}}{T y}
$$

Since $K, T$ and $Y$ are all non-negative, this implies $\frac{\partial r}{\partial F}>0$, thus (9.18). The proof of (9.17) is more involved. Taking the first derivative of $r$ with respect to $T$ yields

$$
\frac{\partial r}{\partial T}=K^{-\frac{1}{T}}\left(\frac{1}{T^{2}} \ln K-\frac{1}{T} \frac{\delta^{T} \ln \delta}{K}\right) .
$$

First, note that, since $K>0$, the first term on the right hand side of (9.21) is positive. For the term in brackets to be negative, we need

$$
\frac{1}{T^{2}} \ln \left(\delta^{T}-\frac{F}{y}\right)-\frac{1}{T} \frac{\delta^{T}}{\delta^{T}-\frac{F}{y}} \ln \delta<0,
$$

by substituting for $K$. Multiplying by $T^{2}$, this implies

$$
\ln \left(\delta^{T}-\frac{F}{y}\right)<T \cdot \frac{\delta^{T}}{\delta^{T}-\frac{F}{y}} \ln \delta .
$$

Since $F, y>0$ and $\delta^{T}-\frac{F}{y}>0$, we have $\frac{\delta^{T}}{\delta^{T}-\frac{F}{y}}>1$. A sufficient condition for (9.23) to hold, is therefore

$$
\ln \left(\delta^{T}-\frac{F}{y}\right)<T \ln \delta
$$

which implies

$$
\ln \left(\delta^{T}-\frac{F}{y}\right)<\ln \delta^{T}
$$

thus

$$
\delta^{T}-\frac{F}{y}<\delta^{T}
$$

which always holds, thus establishing (9.18). 



\section{Chapter 10}

\section{Summary and Conclusion}

This thesis dealt with the theory of monopoly pricing. Chapter 2 surveyed the literature, focusing on theories in which a price is set below the standard monopoly price. Chapter 3 and 4 surveyed one strand within this literature, the theory of limit pricing. Chapter 5 through 9 gave extensions and applications of theories discussed in chapter 2 through 4. This final chapter summarizes and concludes the thesis. It gives the main results and indicates shortcomings.

In chapter 2 I study the theory of monopoly pricing. Textbook theory suggests that a monopolist will set marginal revenue equal to marginal cost, thus setting a price that exceeds marginal cost, causing a deadweight welfare loss. But under some circumstances, the monopolist's behavior will be different. When he produces complementary goods, for example, he may be inclined to lower price on one good in order to increase demand on another. Also, high monopoly prices may induce other firms to enter the industry. Therefore, by setting a limit price, a price below the standard monopoly price, the monopolist may be able to deter entry. If the monopolist produces a durable good, setting a high price may induce rational consumers to postpone their purchase, in anticipation of a future price decrease. Finally, consumers may simply boycott a firm which charges prices that are considered to be too high.

Although in all of these cases the price set by the monopolist is lower than when the standard monopoly price is used, this does not always imply that social welfare is higher as a result. When the monopolist produces a durable good, welfare is unambiguously higher than in the standard case. With a multiple good monopoly this is the case as well. If the monopolist is forced to set a lower price since consumers refuse to 
buy at any higher price, feelings of being badly treated by the monopolist also have to be taken into account when assessing the total welfare effect. The net effect on welfare is ambiguous. Finally, in the case of limit pricing, the effect on welfare depends on the particular model that is used. This has been further studied in chapters 3 and 4 .

Chapter 3 discusses the different strands of thought in limit pricing. The concept was introduced by Bain (1949), yet the first influential model was provided by Modigliani (1958). He considers a two stage model. In the first period, an incumbent monopolist sets a price and a quantity. Upon observing those, a potential entrant decides whether or not to enter in the second period. Obviously, the potential entrant's decision depends on the profits she expects to earn if she enters. Modigliani invokes the Sylos ${ }^{2}$ postulate: the potential entrant expects that the incumbent will not change his output when entry occurs. Therefore, the incumbent can derive which quantity he has to set in the first period such that entry is just not profitable for the potential entrant. The corresponding price is the limit price. A second strand of thought is that of dynamic limit pricing. In these models, initiated by Gaskins (1971), the optimal pricing behavior of an incumbent firm through time is studied. Given some exogenous behavior of a potential entrant, or a competitive fringe, the optimal intertemporal pricing policy of the incumbent firm is derived. Friedman (1979) criticizes both types of models. His argument is the following. In a model that predicts that an incumbent firm will set a price such that a potential entrant will decide not to enter, both the incumbent and the potential entrant should be modelled as rational, maximizing agents. Nevertheless, static limit pricing models, like Modigliani, assume that the incumbent will not change his behavior upon entry, even if it is profit maximizing to do so. Similarly, dynamic limit pricing models assume that the behavior of the potential entrant is exogenously given, and is not the result of some rational optimization process. With perfect information, Friedman argues, a limit price will not be set. In that case, the pre-entry price does not influence post-entry competition whatsoever. Therefore, there is no need for the incumbent to set a limit price. If entry occurs, the incumbent firm can always lower his price. There is no need for him to do so beforehand.

Milgrom and Roberts (1982) show that limit pricing can occur in equilibrium if we assume asymmetric information. In their model, the incumbent can have low or high marginal costs, unknown to the potential entrant. Entry is profitable if his costs are high, it is not if his costs 
are low. To deter entry, an incumbent with low marginal costs needs to convince the potential entrant that his costs really are low. Under certain circumstances, simply setting his monopoly quantity will not suffice. An incumbent with high marginal costs might do the same thing, if doing so deters entry. The low-cost incumbent thus has to set a limit price, a price lower than his monopoly price, which is so low that it is not profitable for a high-cost incumbent to set the same price, even if doing so deters entry. Only in that case does the potential entrant believe that she faces a low-cost incumbent, and refrain from entry.

Chapter 4 I develop a framework that can be used to study these equilibrium limit pricing models. I generalize Milgrom \& Robert's model by assuming there is some state of the world that is unknown to the potential entrant, but known to the incumbent. Moreover, the incumbent can use some costly signal. Three types of models are used. In the first, there are two passible states of the world. In the second, there is a continuum of states. In the third model, we also have a continuum of possible states, but here the potential entrant has some private information as well. Most equilibrium limit pricing models in the literature easily fit in this framework. It is shown that, under some technical conditions, all three models yield qualitatively the same outcome. If the derivative of the incumbent's first period profits with respect to the signal used, is higher in cases where entry is profitable, rather than in cases where entry is not profitable, the equilibrium involves some downward distortion compared with the pure monopoly case. If, on the other hand, the opposite is true, then the equilibrium involves some upward distortion of the monopoly signal. For the theory of limit pricing, this implies that it is possible to build models in which, indeed, the incumbent monopolist sets a limit price, a price that is downward distorted compared with the pure monopoly case. However, it is just as easy to think of circumstances in which the monopolist will set a price higher than the monopoly price.

The welfare effects are ambiguous. First, they depend on whether the price a monopolist sets is higher or lower than the monopoly price. If they are higher, welfare is obviously lower than the case in which a monopoly price is set. If they are lower, there is a trade-off between a lower price in the first period, and a higher price in the second, if more entry is deterred. The most interesting case occurs if we are in the third model: a continuum of possible states of the world, and the potential entrant has some private information as well. In that case, 
there is a one-to-one relation between the state of the world, and the signal the incumbent uses. In other words, upon observing the signal, the potential entrant can exactly infer which state of the world prevails. Therefore, the entry decision will not be influenced compared to the case of perfect information. Nevertheless, the monopolist does have to incur some costs in order to convince the potential entrant of his type. Therefore, if a limit price is used in this set-up, welfare is always higher. If the price the monopolist sets is higher than the monopoly price, welfare is lower. Therefore, the main conclusion of these models is not that the monopolist will always set a price lower than the monopoly price. Rather, when a monopolist has some private information, he has to incur costs in order to convince a potential entrant. Under some circumstances these costs imply that the price the consumer has to pay, is lower.

Chapter 5 is the first application of the theory discussed in the first part of this thesis. In this chapter, an equilibrium limit pricing model is studied, in which second-period competition is Stackelberg rather than Cournot, as is the usual assumption. In a Stackelberg model, prices are always lower than in a Cournot model. In chapter 5, however, I show that this result does not necessarily hold in an entry deterrence framework. This is due to two effects. First, if the potential entrant will be the Stackelberg follower upon entry, her profits will be lower compared to the case of Cournot competition. Therefore, she will have less of an incentive to enter. Second, the incumbent's profits are higher under Stackelberg competition than they are under Cournot competition. Therefore, a high-cost incumbent has less of an incentive to mimic the behavior of a low-cost incumbent. Therefore, the latter can set a higher limit price than would be the case under Cournot competition.

Chapter 6 also uses equilibrium limit pricing as a basis. Firms in the computer industry are often accused of vaporware, the untruthful preannouncement of a new version of their product. By claiming they have a new product, critics argue, these firms try to deter potential entrants. Vaporware has also been a concern for the us anti-trust authorities. Nevertheless, there is no satisfactory economic model that analyzes vaporware. Chapter 6 fills that gap. To do so, it combines the theories of equilibrium limit pricing with that of durable goods, which was also discussed in chapter 2. In the model, the incumbent monopolist has one of two possible types: either he has an innovation that can be marketed 
in the second period, or he does not have such an innovation. His first period quantity serves as a signal. One complicating factor, however, is that consumers also play a role in this set-up. If they believe there is an innovation in the next period, they price they are willing to pay for the current good is lower than when they believe this is not the case. This is the durable goods effect. I show that vaporware is an equilibrium strategy in a signaling game in which the possibility to market a new good is private information. Moreover, vaporware is an anti-competitive strategy. The possibility of vaporware has adverse effects on welfare, also in the case the incumbent does have a new version of his product.

In chapter 2 theories were discussed that predicted that monopolies may set a price lower than the standard monopoly price. Chapter 7, however, shows that there can also be circumstances in which perfect competition, in the sense of free entry and zero profits, does not yield the socially optimal price textbook theory predicts. The chapter considers the cruising taxi market. Recently, there has been a tendency to deregulate the market for taxi services. Countries that have deregulated their taxi market, or that are considering doing so, include the Us, Sweden, the Netherlands, and Japan. The issue has drawn attention from theoretical economists as well. Their models, however, do have some shortcomings. They either take fares as given, or they fail to study individual behavior of taxi drivers and customers. Chapter 7 therefore provides a model which does not suffer from these shortcomings. In the model, individual behavior is studied, and fares are set by taxi drivers. A circular street is used on which taxis are searching for consumers, and consumers are waiting for a taxi. Demand depends on both price and expected waiting time. I solve for the deregulation equilibrium, in which taxi drivers can choose their own price, but profits are driven to zero, because of free entry. I show that a regulator can improve upon this outcome, by setting a fare. Of course, it is difficult for such a regulator to obtain all necessary information and determine the optimal fare. It is easy to see, however, that an easy way to improve upon the market outcome is for the regulator to imposes a maximum price.

Chapter 8 is not concerned with the theory of monopoly pricing per se, but rather uses insights obtained from that theory to a different field in economics. Anecdotal evidence suggests that politicians often promise more during an election campaign than they are willing or able to deliver once elected. This phenomenon poses problems for the model of rational, utility-maximizing, economic agents. It is hard to imagine that rational 
voters are systemically fooled by untruthful promises of politicians. But if voters are rational and do not believe these promises, we face a different problem. Why do politicians make promises which voters do not believe? Chapter 8 proposes a way to solve this paradox. In the models presented in that chapter, the promise a politician makes in an election campaign serves as a signal for her true preference, just as in limit pricing models the price a monopolist sets serves as a signal for his true marginal cost. In equilibrium, any left-wing candidate makes a promise that is to the right of her real position, while every right-wing candidate will make a promise that is to the left of her real position. Voters, however, are not fooled by these promises, since, upon observing election promises, they can rationally infer the true position of each candidate. This is equivalent to the third model discussed in chapter 4, in which a potential entrant could always infer the true type of incumbent she faces.

Finally, chapter 9 applies the fairness model, which was also discussed in chapter 2. This model assumes that people are willing to sacrifice some of their material payoffs, in order to either punish someone who is nasty to them, or reward someone who is nice to them. If people behave this way, I argued in chapter 2, monopolists will not set prices as high as standard theory suggests. Chapter 9 applies the same model, but to a different field: that of intertemporal choice. The standard life cycle model predicts that agents use a constant discount rate. But experimental evidence shows this is typically not the case. Implicit discount rates are higher than interest rates. They decline with time to be waited, and size of the sum at stake. For speeding up a reward they are lower than for delaying. Several explanations have been put forward to solve for these intertemporal choice anomalies. None of the explanations, however, are fully satisfactory. Most of them can only account for one of the anomalies stated, and they often do not provide an analytical framework. Others do account for all anomalies, but fail to give an intuitive interpretation of the utility function individuals are using. In chapter $9 \mathrm{I}$ show that it is possible to explain all anomalies in an intuitive framework. To do so, I use the fairness model, and assume that when deciding on the intertemporal allocation of a windfall gain, an agent acts as if a "Future Self" were to divide the money, taking considerations of fairness into account.

In this thesis, a wide range of topics is covered. Therefore, general con- 
clusions are hard to draw. Nevertheless, some points do figure prominently. First, in competition policy, it is important to make a full analysis of the industry that is considered. Just looking at the number of firms is not enough to assess welfare effects. Obviously, this insight is hardly new. Especially the literature on entry barriers argued that public policy does not have to be to concerned with monopolized industries in which entry barriers are low. But the examples given in this thesis move beyond that. In fact, in chapter 7 we have a market in which, even if entry barriers are absent, a price above the social optimum is set. Also, the models in chapter 2 show that there are more circumstances in which the adverse effects of monopolies are much lower than the standard monopoly model suggests. Moreover, in chapter 4 we saw that, even if monopolists are prone to set a limit price, which is welfareenhancing, they may also be inclined to set a price even higher than the standard monopoly price which, obviously, adversely affects welfare.

Second, there are circumstances in which having private information can actually hurt economic agents, rather than being to their advantage, as intuition suggests. Both in limit pricing models and in the voting model described in chapter 8 , agents have to incur costs to convince others of the information they have. In both cases, they would be better off if their private information were common knowledge. But the welfare effects of this phenomenon are ambiguous. Limit pricing is desirable from a welfare point of view, compared with a case where the incumbent does not have any private information. The discussion in chapter 4 shows that the incumbent's desire to convince the potential entrant of his private information, might just as well lead to prices that are higher than the monopoly price. In chapter 8 , a situation without private information is desirable from a welfare point of view. When politicians could commit themselves not to lie in election campaigns, their utility would increase, without affectng the election result.

Third, this thesis shows how methods and insights from industrial organization theory can also be fruitfully applied to other, non-related fields. The same mechanism that causes incumbents to set a limit price in chapter 4, also causes politicians to lie in chapter 8 . The same mechanism that causes monopolists to set a price lower than the standard monopoly price in chapter 2 , also causes individual agents to act in a way inconsistent with the standard lifecycle model in chapter 9 . Hence, industrial organization theory is not only relevant to industrial economists. Insights gained here can also be applied to other fields. 
The analyses in these thesis are only of a theoretical nature. This does not imply, however, that they are void of any empirical observation. On the contrary. Chapter 6 gives an explanation of the observation that software producers often fail to meet the deadline they set themselves. Chapter 7 explains why the results of taxicab deregulation are often disappointing. Chapter 8 explains why politicians always lie in election campaigns. Chapter 9 provides a model in which some regularities that are often found in both empirical and experimental research, can be explained. Nevertheless, before any policy implications of these models are to be implemented, more empirical and experimental research of the assumptions made and their implications, is obviously necessary. Especially in the taxi model in chapter 7 there are possibilities for empirical research. In the other models, however, this is more difficult. In models of asymmetric information, by construction, agents have some private information, which is also unknown for someone doing empirical research. Therefore, to assess the relevance of these models, experiments in which the information available to each agent can be controlled directly, seem a more promising avenue of research. 


\section{Bibliography}

Anderson, S., and M. Engers (1992): "Stackelberg versus Cournot oligopoly equilibrium," International Journal of Industrial Organization, 10(1), 127-135.

BAGwell, K., and G. RAMEY (1988): "Advertising and Limit Pricing," Rand Journal of Economics, 19(1), 59-71.

(1990): "Advertising and Pricing to Deter or Accommodate Entry When Demand is Unknown," International Journal of Industrial Organization, 8, 93-113.

(1991): "Oligopoly Limit Pricing," Rand Journal of Economics, 22(2), 155-172.

Bain, J. S. (1949): "A Note on Pricing in Monopoly and Oligopoly," American Economic Review, 39(2), 448-464.

(1956): Barriers to New Competition. Harvard University Press, Cambridge, Mass.

BANKS, J. S. (1990): "A Model of Electoral Competition with Incomplete Information," Journal of Economic Theory, 50, 309-325.

Baron, D. P. (1973): "Limit Pricing, Potential Entry, and Barriers to Entry," American Economic Review, 63(4), 666-674.

Baumol, W. J. (1982): "Contestable Markets: An Uprising in the Theory of Industry Structure," American Economic Review, 72(1), $1-15$.

BAumol, W. J., J. PANZAR, and R. Willig (1982): Contestable Markets and the Theory of Industry Structure. Harcourt, Brace, and Jovanovich, New York. 
Becker, G. S., and S. C. B. Mulligan (1997): "The Endogenous Determination of Time Preference," Quarterly Joumal of Economics, $112(3), 729-758$.

BeEsLey, M., and S. Glaister (1983): "Information for regulating: The case of taxis," The Economic Journal, 93(371), 594-615.

Benzion, U., A. RAPOPORT, and J. YAGIL (1989): "Discount Rates Inferred from Decisions: An Experimental Study," Management Science, 35(3), 270-284.

Bourguignon, F., and S. P. Seth (1981): "Dynamic Optimal Pricing and (Possibly) Advertising in the Face of various Kinds of Potential Entrants," Journal of Economic Dynamics and Control, 3(3), 119140 .

Bucovetsky, S., and J. Chilton (1986): "Concurrent Renting and Selling in a Durable-Goods Monopoly under the Threat of Entry," Rand Journal of Economics, 17(2), 261-275.

BuLow, J. I. (1982): "Durable-Goods Monopolists," Journal of Political Economy, 90(2), 314-332.

Bulow, J. I., J. Geneakoplos, and P. D. Klemperer (1985): "Multimarket Oligopoly: Strategic Substitutes and Strategic Complements," Journal of Political Economy, 93, 488-511.

BurdeTt, K., and S. Fölster (1994): "Analyzing the effects of taxicab deregulation: A new empirical approach," Working Paper 410, Industrial Institute for Economic and Social Research, Stockholm.

Cairns, R. D., and C. Liston-Heyes (1996): "Competition and Regulation in the taxi industry," Journal of Public Economics, 59(1), $1-15$.

Camerer, C. F. (1997): "Progress in Behavioral Game Theory," Journal of Economic Perspectives, 11(4), 167-188.

Camerer, C. F., and R. H. Thaler (1995): "Ultimatums, Dictators and Manners," Journal of Economic Perspectives, 9(2), 209-219.

Chamberlin, E. H. (1983): The Theory of Monopolistic Competition. Harvard University Press, Cambridge. 
Cho, 1.-K., and D. M. KrePs (1987): "Signaling Games and Stable Equilibria," Quarterly Journal of Economics, 102(2), 179-221.

CoAsE, R. H. (1972): "Durability and Monopoly," Journal of Law and Economics, 15(1), 143-149.

DE VANY, A. S. (1975): "Capacity Utilization under Alternative Regulatory Restraints: An Analysis of Taxi Markets," Journal of Political Economy, 83(1), 83-94.

DeBondt, R. R. (1976): "Limit Pricing, Uncertain Entry, and the Entry Lag," Econometrica, 44(5), 939-946.

DIXIT, A. (1980): "The Role of Investment in Entry Deterrence," Economic Journal, 90(357), 95-106.

Dixit, A., and C. Shapiro (1986): "Entry Dynamics and Mixed Strategies," in Economics of Strategic Planning, ed. by L. Thomas. Lexington Books, Lexington, Mass.

Downs, A. (1957): An Economic Theory of Democracy. Harper \& Row, New York.

DUNFEE, T., and L. STERN (1975): "Potential competition theory as an anti-merger tool under section 7 of the Clayton act: A decision model," Northwestern University Law Review, 69, 821-871.

EASTERBROOK, F. (1981): "Maximum price fixing," University of Chicago Law Review, 48, 886-910.

Epstein, L. G., and A. J. Hynes (1983): "The Rate of Time Preference and Dynamic Economic Analysis," Journal of Political Economy, 91(4), 611-635.

FARrell, J. (1987): "Cheap Talk, Coordination, and Entry," Rand Journal of Economics, 18(1), 34-39.

FARrell, J., and G. SALONER (1986): "Installed Base and Compatibility: Innovation, Product Preannouncements, and Predation," American Economic Review, 76(5), 940-955.

Feddersen, T. J., and W. Pesendorfer (1996): "The Swing Voter's Curse," American Economic Review, 86(3), 408-424. 
Fisher, F., J. MCGowAN, and J. Greenwood (1983): Folded, Spinaled, and Mutilated: Economic Analysis and U.S. v. IBM. MIT-Press, Cambridge, Mass.

FlaherTy, M. T. (1980): "Dynamic Limit Pricing, Barriers to Entry and Rational Firms," Journal of Economic Theory, 23(2), 160-182.

Friedman, J. W. (1979): "On Entry Preventing Behavior," in Applied Game Theory, ed. by S. Brams, A. Schotter, and G. Schwodiauer, pp. 236-253. Physica-Verlag, Vienna.

(1981): "Limit Pricing and Entry" Journal of Economic Dynamics and Control, 3(3), 319-323.

(1983): "Limit Price Entry Prevention When Complete Information Is Lacking," Journal of Economic Dynamics and Control, $5(2-3), 187-199$.

FudenberG, D., and J. Tirole (1986): "Dynamic Models of Oligopoly," No. 4 in Fundamentals of Pure and Applied Economics, ed. by J. Lesourne and H. Sonnenschein: Theory of the Firm and Industrial Organization section, ed. by A. Jacquemin. Harwood Academic Publishers, Chur.

- (1991): Game Theory. MIT-Press, Cambridge, Mass.

Gaskins, D. (1971): "Dynamic Limit Pricing: Optimal Pricing under Threat of Entry," Journal of Economic Theory, 3(3), 306-322.

Gately, D. (1980): "Individual Discount Rates and the Purchase and Utilization of Energy-Using Durables: Comment," Bell Journal of Economics, 11(1), 373-374.

GAUNT, C. (1996): "Taxicab Deregulation in New Zealand," Joumal of Transportation Economics and Policy, 30(1), 103-106.

Glazer, J., and R. Israel (1990): "Managerial Incentives and Financial Signaling in Product Market Competition," International Journal of Industrial Organization, 8, 271-280.

Goldberg, V., and S. Morrao (1973): "Limit Pricing and Potential Competition," Journal of Political Economy, 81(6), 1460-1466. 
HAAN, M. (1997): "A Reply to C. Mackenzie's "Where are the motives? A problem with evidence in the work of Richard Thaler" " Journal of Economic Psychology, 18, 705-709.

HAAN, M., and H. MAKs (1996): "Stackelberg and Cournot Competition under Equilibrium Limit Pricing," Journal of Economic Studies, $23(5 / 6), 110-123$.

HaHn, F. H. (1962): "The Stability of the Cournot Oligopoly Solution," Review of Economic Studies, 29(3), 329-331.

HARRINGTON, J. E. (1984): "Noncooperative behavior by a cartel as an entry-deterring signal," Rand Joumal of Economics, 18(2), 211-231.

(1986): "Limit Pricing when the Potential Entrant is Uncertain of its Cost Function," Econometrica, 54(2), 429-437.

(1987): "Oligopolistic Entry Deterrence under Incomplete Information," Rand Journal of Economics, 18(2), 211-231.

Harrington, J. E., and G. D. Hess (1996): "A Spatial Theory of Positive and Negative Campaigning," Games and Economic Behavior, $17,209-229$.

HARROD, R. (1952): The theory of imperfect competition revisited, Economic essays. MacMillan, New York.

HARSANYI, J. C. (1967-8): "Games with Incomplete Information Played by 'Bayesian' Players," Management Science, 14, 159-182, $320-334,486-502$.

Hausman, J. (1979): "Individual Discount Rates and the Purchase and Utilization of Energy Using Durables," Bell Journal of Economics, $10(1-2), 33-54$.

Holmstrom, B. R., and J. Trrole (1989): "The Theory of The Firm," in Handbook of Industrial Organization, ed. by R. Schmalensee, and R. Willig, no. 10 in Handbooks in Economics, chapter 2, pp. 61-134. North-Holland, Amsterdam.

HOTELLING, H. (1929): "Stability in competition," Economic Journal, $39,41-57$. 
IRELAND, N. (1972): "Concentration and the Growth of Market Demand: A Comment on Gaskins Limit Pricing Model," Journal of Economic Theory, 5(2), 303-305.

Judd, K. L., and B. C. Petersen (1986): "Dynamic Limit Pricing and Internal Finance," Journal of Economic Theory, 39(2), 368-399.

Kahneman, D., J. L. Knetsch, and R. Thaler (1986): "Fairness as a Constraint on Profit Seeking: Entitlements in the Market," American Economic Review, 76(4), 728-741.

Kamien, M. I., and N. Schwartz (1971): "Limit Pricing and Uncertain Entry," Econometrica, 39(3), 441-454.

KAPLOW, L. (1982): "The accuracy of traditional market power analysis and a direct," Harvard Law Review, 95, 1817-1848.

Kreps, D. M., and A. M. Spence (1984): "Modelling the Role of History in Industrial Organization and Competition," in Issues in Contemporary Microeconomics and Welfare, ed. by G. Feiwel. MacMillan, London.

KrePs, D. M., and R. Wilson (1982): "Sequential Equilibria," Econometrica, 50(4), 863-894.

Levin, D. (1988): "Stackelberg, Cournot and collusive monopoly: Performance and Welfare Comparisons," Economic Inquiry, 26(2), 317330.

LeVy, S. M. (1997): "Should "vaporware" be an antitrust concern?," The Antitrust Bulletin, pp. 33-49.

LiebowITz, S., and S. MARgolis (1994): "Network Externality: An Uncommon Tragedy," Journal of Economic Perspectives, 8(2), 133 150.

LOewenstein, G. (1987): "Anticipation and the Valuation of Delayed Consumption," Economic Journal, 97, 666-684.

(1988): "Frames of Mind in Intertemporal Choice," Management Science, 34, 200-214. 
Loewenstein, G., and D. Prelec (1992): "Anomalies in Intertemporal Choice: Evidence and an Interpretation," Quarterly Journal of Economics, 107(2), 573-597.

LoEw poral Choice," Journal of Economic Perspectives, 3(4), 181-193.

MAILATH, G. J. (1987): "Incentive compatibility in signaling games with a continuum of types," Econometrica, 55(6), 1349-1365.

Marrin, S. (1993): Advanced Industrial Economics. Blackwell, Oxford, Cambridge.

(1995): "Oligopoly Limit Pricing: Strategic Substitutes, Strategic Complements," International Journal of Industrial Organization, $13(1), 41-65$.

Matuhews, S. A., and L. J. Mirman (1983): "Equilibrium Limit Pricing: The Effects of Private Information and Stochastic Demand," Econometrica, 51(4), 981-996.

MCAFEe, R. P., and J. MCMillan (1987): "Auctions and Bidding," Journal of Economic Literature, 25(2), 699-738.

Milarom, P., and J. Roberts (1982): "Limit Pricing and Entry under Incomplete Information: An Equilibrium Analysis," Econometrica, $50(2), 443-457$.

Modigliani, F. (1958): "New Developments on the Oligopoly Front," Journal of Political Economy, 66(3), 215-232.

Mørch von DER FEHR, N.-H. (1992): "How Entry Threats Induce Slack," International Journal of Industrial Organization, 10, 231-249.

NEvEN, D. J. (1987): "Strategic Entry Deterrence: Recent Developments in the Economics of Industry," Journal of Economic Surveys, $3(3), 213-233$.

Nrt, K. O. (1989): "More Potential Entrants May Lead to Less Competition," Journal of Economics, 49(1), 47-70.

OrR, D. (1969): "The taxicab problem: A proposed solution" Journal of Political Economy, 77(1), 141-147. 
Phlips, L. (1983): The Economics of Price Discrimination. Cambridge University Press.

POTTERS, J., R. SLOOF, and F. VAN WINDEN (1997): "Campaign expenditures, contributions and direct endorsements: The strategic use of information and money to influence voter behavior," European Journal of Political Economy, 13, 1-31.

Pyatry, G. (1971): "Limit Pricing, Potential Entry, and Barriers to Entry," Economic Journal, 81(322), 242-255.

RABIN, M. (1993): "Incorporating Fairness into Game Theory and Economics," American Economic Review, 83(5), 1281-1302.

RoBERTS, J. (1987): "Battles for market share: incomplete information, aggressive strategic pricing, and competitive dynamics," in Advances in Economic Theory, ed. by T. Bewley, Fifth World Congress, Econometric Society Monograph Series, No. 12, pp. 157-195. Cambridge University Press, Cambridge.

Rometsch, S., and E. Wolfstetter (1993): "The Taxicab Market: An Elementary Model," Journal of Institutional and Theoretical Economics, 149(3), 531-546.

SALOP, S. (1979): "Monopolistic Competition with Outside Goods," Bell Journal of Economics, 10, 321-332.

SAlop, S., and J. E. STiglirz (1982): "The Theory of Sales: A Simple Model of Equilibrium Price Dispersion with Identical Agents," American Economic Review, 72(5), 1211-1230.

SCherling, T. (1960): The Strategy of Conflict Harvard University Press, Cambridge, Mass.

- (1984): "Self-Command in Practice, in Policy, and in a Theory of Rational Choice," American Economic Review, 74(2), 1-11.

SCHERER, F. M. (1980): Industrial Market structure and Economic Performance. Rand McNally, Chicago.

SElten, R. (1975): "Reexamination of the Perfectness Concept for Equilibrium Points in Extensive Games," International Journal of Game Theory, 4(1), 25-55. 
SHEFRIN, H., and R. H. Thaler (1988): "The Behavioral Life-Cycle Hypothesis," Economic Inquiry, 26(4), 609-643.

Sherman, R., and T. D. Willetr (1967): "Potential Entrants Discourage Entry," Journal of Political Economy, 75(4), 400-403.

Shupp, F. R. (1986): "Limit Pricing in a Mature Market," Journal of Economic Dynamics and Control, 10(1-2), 67-71.

SPENCE, M. (1977): "Entry, Capacity, Investment and Oligopolistic Pricing," Bell Journal of Economics, 8(1), 49-70.

Srintvasan, K. (1991): "Multiple Market Entry, Cost Signalling and Entry Deterrence," Management Science, 37(12), 821-841.

Stokey, N. L. (1981): "Rational Expectations and Durable Goods Pricing," Bell Journal of Economics, 12(1), 112-128.

STrotz, R. (1956): "Myopia and Inconsistency in Dynamic Utillity Maximization," Review of Economic Studies, 23(3), 165-180.

Sylos Labini, P. (1957): Oligopolio e progresso tecnico. Giuffrè, Milan.

Teal, R. F., and M. Berglund (1987): "The Impacts of Taxicab Deregulation in the USA," Journal of Transport Economics and Policy, 21, 37-56.

Thaler, R. H. (1981): "Some Empirical Evidence on Dynamic Inconsistency," Economics Letters, 8(3), 201-207.

(1988): "Anomalies: The Ultimatum Game," Journal of Economic Perspectives, 2(4), 195-206.

ThAlER, R. H., and H. SHEFrin (1981): "An Economic Theory of Self-Control," Journal of Political Economy, 89, 392-410.

The Economist (1997a): "France's Curious New Smile," September 13.

(1997b): "Taxing Times for Tokyo Taxis," March 1.

TIROLE, J. (1988): The Theory of Industrial Organization. MIT-Press, Cambridge, Mass. 
us District Court of Columbia (1995): United States of America vs. Microsoft Corporation. Civil Action No. 94-1564.

UZAWA, H. (1968): "Time Preference, the Consumption Function, and Optimum Asset Holdings," in Value, Capital, and Growth: Papers in Honour of Sir John Hicks, ed. by J. Wolfe. University of Edinburgh Press, Edinburgh, Scotland.

Williamson, O. E. (1963): "Selling Expense as a Barrier Entry," Quarterly Journal of Economics, 78(1), 112-128.

WOLFSTETTER, E. (1996): "Auctions: An Introduction," Journal of Economic Surveys, 10(4), 367-420. 


\section{Samenvatting}

In dit proefschift wordt ingegaan op het prijszettingsgedrag van monopolisten. De eerste drie hoofdstukken geven een overzicht van de theorie over dit onderwerp. De overige hoofdstukken bestaan uit een aantal op zichzelf staande artikelen. Al deze artikelen zijn gebaseerd op, of naww verbonden met die theorie.

Meestal wordt verondersteld dat een monopolist een prijs zet zodanig dat de marginale kosten gelijk zijn aan de marginale opbrengsten. Door het zetten van zo'n monopolieprijs wordt de monopoliewinst gemaximaliseerd. Vanuit maatschappelijk oogpunt is dit echter niet optimaal. Er komt immers een prijs tot stand die hoger is dan de marginale kosten. Dat betekent dat de prijs die een consument betaalt voor een extra eenheid van het goed, hoger ligt dan de kosten om die extra eenheid te produceren, en daarmee ook hoger dan de prijs die tot stand komt bij volledige mededinging. De maatschappelijke welvaart is daarom hoger als de prijs verlaagd wordt. De winstdaling die het gevolg is van zo'n prijsverlaging wordt meer dan gecompenseerd door het voordeel dat consumenten er van ondervinden.

Een monopolist is echter niet altijd in staat de monopolieprijs te zetten. Er kunnen zich situaties voordoen waarin hij genoodzaakt is een lagere prijs te hanteren. Deze situaties worden besproken in hoofdstuk 2 . Ten eerste, als een monopolie meerdere, complementaire goederen produceert, dan zal hij woor elk van die goederen een prijs zetten die lager is dan de monopolieprijs. Zo'n verlaging stimuleert immers niet alleen de vraag naar het desbetreffende goed, maar ook de vraag naar het complementaire goed, dat hij ook produceert. Ten tweede, bij een relatief hoge prijs bestaat het risico dat andere bedrijven snel geneigd zullen zijn om ook op de desbetreffende markt toe te treden. Immers, als op een bepaald produkt hoge winsten worden gehaald, dan zullen anderen al snel een soortgelijk produkt willen produceren. Het zetten van een 
lagere prijs kan er dan toe leiden dat de monopolist weliswaar op dit moment lagere winsten haalt, maar dat de winsten op lange termijn hoger zijn, omdat toetreding wordt voorkomen. Zo'n prijs, waarbij toetreding juist wordt voorkomen, wordt een limietprijs genoemd. Ten derde, ook wanneer een monopolist een duurzaam goed produceert, zal hij niet in staat zijn een hoge prijs te zetten. In dat geval zal hij immers een prikkel hebben om zijn prijs in de toekomst te verlagen, om het goed aan meer consumenten te kunnen verkopen. Rationele consumenten zullen daarom wachten tot het monopolie zijn prijzen verlaagd. In het meest extreme geval betekent dat, dat de monopolist helemaal niet meer in staat is een winst op duurzame goederen te maken. Alle consumenten zullen dan immers wachten met hun aankoop, totdat de prijs verlaagd wordt. Ten vierde kan een monopolist niet de volledige monopoliewinst behalen wanneer er sociale weerstand bestaat tegen zijn positie. In dat geval kunnen consumenten simpelweg weigeren het goed aan te schaffen, als ze het gevoel hebben dat het monopolie een onredelijk hoge prijs in rekening brengt.

In al deze vier gevallen geldt dat de prijs die de monopolist zet, lager is dan die in het eerder beschreven standaard model. Dat betekent echter niet dat deze lagere prijs ook altijd leidt tot een hogere maatschappelijke welvaart. Bij een duurzaam goed is dat wel het geval. Ook bij een monopolie dat complementaire goederen produceert, is de welvaart hoger dan wanneer afzonderlijke monopolisten de goederen zouden produceren. Wanneer consumenten weigeren een goed aan te schaffen, omdat ze vinden dat de monopolist misbruikt maakt van zijn positie, is het effect op de maatschappelijke welvaart niet eenduidig. Bij een evaluatie zullen ook deze gevoelens van onvrede moeten worden meegenomen. Bij een limietprijs hangt het effect op de welvaart mede af van de manier waarop zo'n limietprijs gemodelleerd wordt. In het volgende hoofdstuk wordt hier dieper op ingegaan.

Hoofdstuk 3 gaat in op de theorie van de limietprijs, en behandelt de verschillende stromingen die in de literatuur bestaan. Het concept werd geïntroduceerd door Bain (1949), en voor het eerst gemodelleerd door Modigliani (1958). De laatste gaat uit van een statisch model met twee perioden. In de eerste periode zet een zittende monopolist een prijs, en produceert de daarbij horende hoeveelheid. Een potentiële toetreder besluit vervolgens, op basis van deze informatie, om al dan niet op de markt toe te treden. Vanzelfsprekend hangt die beslissing in eerste instantie af van de winst die zij denkt te behalen, als zij toetreedt. Deze 
moet opwegen tegen de kosten van toetreding. Om de verwachte winst na toetreding te bepalen, hanteert Modigliani het Sylos postulaat. Dat postulaat gaat er van uit dat de toetreder verwacht dat de zittende monopolist zijn hoeveelheid niet verandert als er toetreding plaatsvindt. Gegeven dat de toetreder zich op deze manier gedraagt, kan de zittende monopolist dan exact nagaan welke hoeveelheid hij in de eerste periode moet zetten, om toetreding net niet winstgevend te laten zijn. De prijs waarbij deze hoeveellheid precies verkocht wordt, is de limietprijs. Een tweede stroming in de literatuur bestudeert de dynamische limietprijs. In deze modellen, geïntroduceerd door Gaskins (1971), wordt het optimale prijsgedrag van een monopolist door de tijd bestudeerd. Onder bepaalde aannames over het gedrag van een potentiële toetreder, wordt het optimale intertemporele prijsgedrag voor een monopolist afgeleid. Friedman (1979) bekritiseert beide typen modellen. Hij argumenteert dat als er volledige informatie is, er geen limietprijs gezet zal worden. In dat geval heeft de prijs die wordt gezet voordat toetreding plaatsvindt, geen enkel effect op de situatie na toetreding. Het heeft voor de zittende monopolist dan ook geen zin om een limietprijs te zetten. Als toetreding plaatsvindt, kan hij altijd nog zijn prijs verlagen. Er is geen enkele reden dat bij voorbaat al te doen.

Milgrom en Roberts (1982) laten zien dat een limietprijs wel een evenwicht kan zijn als er sprake is van asymmetrische informatie. In hun model kan de zittende monopolist hoge of lage marginale kosten hebben. De toetreder weet niet hoe hoog die kosten zijn. Zijn ze hoog, dan is toetreding winstgevend. Zijn ze laag, dan is dat niet het geval. Stel dat de kosten laag zijn. Om toetreding te voorkomen, zal de monopolist de toetreder er van moeten overtuigen dat zijn kosten daadwerkelijk laag zijn, en toetreding niet winstgevend is. Onder bepaalde omstandigheden zal het zetten van een monopolieprijs niet een voldoende signaal zijn. Een zittende monopolist met hoge kosten zou immers diezelfde prijs kumnen zetten, om zo toetreding te voorkomen. Een monopolist met. lage kosten moet daarom een limietprijs zetten, een prijs die zo laag is dat het voor een monopolist met hoge kosten niet de moeite waard is diezelfde prijs te zetten, zelfs als daardoor toetreding voorkomen wordt. Alleen in dat geval zal een potentiële toetreder er van overtuigd zijn dat zij te maken heeft met een monopolist met lage kosten, en niet toetreden.

In hoofdstuk 4 wordt een raamwerk ontwikkeld voor de bestudering van dit type limietprijsmodellen, door het model van Milgrom \& Roberts te generaliseren. Uit die generalisatie blijkt dat het inderdaad mogelijk 
is modellen te construeren waarin de monopolist een prijs zet die lager is dan de standaard monopolieprijs. Het is echter net zo goed mogelijk gevallen te construeren waarin de monopolist een prijs zet die hoger is dan die standaard monopolieprijs.

De welvaartseffecten van een limietprijs zijn niet eenduidig. Allereerst zijn ze afhankelijk van de vraag of de monopolist een prijs zet die lager of hoger is dan de monopolieprijs. Is die prijs hoger, dan is de maatschappelijke welvaart lager dan wanneer een monopolieprijs wordt gezet. Is ze lager, dan is er enerzijds een lagere prijs in de eerste periode, maar anderzijds ook minder concurrentie in de tweede periode, indien de limietprijs er toe leidt dat er daadwerkelijk minder toetreding plaatsvindt. Het meest interessante geval doet zich voor als er een continuum van mogelijke toestanden bestaat, en de potentiële toetreder ook bepaalde privé-informatie heeft. In dat geval vertoont de monopolist in elke toestand een ander gedrag. De toetreder kan daarom, als hij dat gedrag waarneemt, precies nagaan welke toestand actueel is, en dus over welke informatie de zittende monopolist beschikt. De toetredingsbeslissing zal daarom niet anders zijn dan in het geval waarin er volledige informatie is. Desalniettemin moet de monopolist toch bepaalde kosten maken om de toetreder van zijn informatie te overtuigen, bijvoorbeeld door het zetten van een lagere prijs. Als er daarom in dit model een limietprijs wordt gebruikt, dan leidt dat altijd tot een hogere maatschappelijke welvaart. De belangrijkste conclusie van de modellen in hoofdstuk 4 is niet dat de monopolist altijd een prijs zal zetten die lager is dan de monopolieprijs. De conclusie is eerder dat, wanneer de monopolist bepaalde informatie heeft, hij kosten moet maken om een potentiële toetreder van die informatie te overtuigen. Onder bepaalde omstandigheden impliceert dit dat de prijs die de consument moet betalen, lager is, en de maatschappelijke welvaart hoger.

Hoofdstuk 5 is de eerste toepassing van de theorie die besproken is in het eerste gedeelte van dit proefschrift. In dit hoofdstuk wordt een limietprijsmodel bestudeerd, waar in de tweede periode sprake is van Stackelberg-concurrentie, en niet van Cournot-concurrentie, zoals meestal wordt verondersteld. In een statisch model zijn prijzen bij Stackelberg-concurrentie altijd lager dan bij Cournot-concurrentie. In hoofdstuk 5 wordt echter aangetoond dat dat resultaat niet noodzakelijk opgaat in een limietprijsmodel. Dat is een gevolg van twee effecten. Ten eerste, als de potentiele toetreder Stackelberg-volger is als zij toe- 
treedt, dan zullen haar winsten lager zijn dan in het geval van Cournotconcurrentie. Daarom zal zij een kleinere prikkel hebben om toe te treden. Ten tweede zijn de winsten van de zittende monopolist hoger bij Stackelberg-concurrentie dan bij Cournot-concurrentie. Daarom heeft een zittende monopolist met hoge kosten een kleinere prikkel om het gedrag van een monopolist met lage kosten te imiteren. Een zittende monopolist met lage kosten kan daarom een hogere limietprijs zetten dan het geval zou zijn bij Cournot-concurrentie.

Hoofdstuk 6 gaat ook uit van de limietprijstheorie. Bedrijven in de computerindustrie worden vaak beschuldigd van vaporware, een vooraankondiging van een nieuwe versie van hun produkt dat pas veel later op de markt komt dan aanvankelijk werd beloofd. Door al in een vroeg stadium een nieuwe versie aan te kondigen, zo is de redenering, proberen deze bedrijven de toetreding van mogelijke concurrenten te voorkomen. Ook mededingingsautoriteiten houden zich hier al geruime tijd mee bezig, bijvoorbeeld in de rechtszaak tegen Microsoft enkele jaren geleden in de VS. Desalniettemin is er geen bevredigend economisch model dat het fenomeen analyseert. Hoofdstuk 6 probeert in deze lacune te voorzien. Het combineert de theorie van de limietprijs met die van duurzame goederen, die ook in hoofdstuk 2 werd besproken. In het model zijn er twee mogelijkheden voor de zittende monopolist. Hij heeft een imnovatie die in de volgende periode op de markt kan worden gebracht, of hij heeft geem innovatie. De hoeveelheid die hij in de eerste periode op de markt brengt, fungeert als signaal. Een complicerende factor is echter dat consumenten in dit model ook een rol spelen. Als zij denken dat er in de volgende periode een innovatie is, dan is de prijs die zij bereid zijn woor het huidige goed te betalen lager dan wanneer zij denken dat dat niet het geval is. In het hoofdstuk wordt aangetoond dat vaporware een evenwicht is in dit model. Tevens wordt aangetoond dat de mogelijkheid van vaporware nadelige effecten heeft op de maatschappelijke welvaart, ook als de zittende monopolist wel degelijk een nieuwe versie van zijn produkt heeft. Bij de asnkondiging van een nieuwe versie zullen consumenten er immers rekening mee houden dat de nieuwe versie pas veel later komt, en ze nog langer met de huidige versie moeten werken. Dat betekent dat de prijs die ze bereid zijn voor de oude versie te betallen, hoger is.

In hoofdstuk 2 werden theorieën besproken die voorspellen dat monopolisten een prijs zetten die lager is dan de standaard monopolieprijs. In hoofdstuk 7 wordt echter aangetoond dat er zich ook situaties kunnen 
voordoen waarin volledige mededinging, met vrije toetreding en nulwinsten, niet leidt tot de optimale maatschappelijke welvaart die meestal wordt voorspeld. Het hoofdstuk bestudeert de taxi-markt. Steeds meer landen gaan over tot deregulering wan deze markt, zoals Zweden, de VS, Japan en Nederland. Verscheidene theoretisch economen hebben deze kwestie bestudeerd. Hun modellen kennen echter enkele tekortkomingen. Vaak worden prijzen als exogeen beschouwd, of wordt niet het gedrag van een individuele taxi-chauffeur in beschouwing genomen. In hoofdstuk 7 wordt daarom een model gepresenteerd dat aan deze tekortkomingen tegemoet komt. Het model gaat uit van een rondweg waar taxi's rondrijden op zoek naar een klant, en waar klanten op een taxi wachten. In het dereguleringsevenwicht mogen taxi-chauffeurs zelf hun prijs zetten, maar gaan door vrije toetreding de winsten naar nul. Het blijkt echter dat de prijs die dan tot stand komt, vanuit maatschappelijk oogpunt te hoog is. Het gebruikelijke argument voor deregulering, dat meer concurrentie leidt tot lagere prijzen, gaat in de taxi-markt niet op. Consumenten die een taxi willen nemen zijn niet altijd in staat de prijzen van aanbieders te vergelijken en naar de goedkoopste aanbieder te gaan, maar zullen genoegen moeten nemen met de eerste taxi die langskomt. Individuele taxi-chauffeurs hebben daardoor marktmacht, en hoeven niet een prijs te zetten die gelijk is aan hun marginale kosten, zoals normaal gesproken bij volledige mededinging het geval is. In het hoofdstuk wordt aangetoond dat door het zetten van een prijsplafond een betere uitkomst kan worden bereikt.

Hoofdstuk 8 gaat niet over monopolieprijzen, maar past de theorie over dat onderwerp toe op een ander gebied binnen de economie. Politici lijken tijdens werkiezingen meer te beloven dan ze waar kunnen of willen maken als ze eenmaal gekozen zijn. Het lijkt echter onwaarschijnlijk dat rationele kiezers systematisch worden misleid door valse beloftes van politici. Vaak blijkt ook dat dat niet het geval is. Maar als kiezers rationeel zijn en deze beloftes niet geloven, ontstaat de vraag waarom politici überhaupt zulke beloftes doen. Hoofdstuk 8 geeft een verklaring voor deze paradox. In de modellen in dat hoofdstuk fungeert de belofte die een politicus doet als signaal voor haar voorkeur, net als in limietprijsmodellen de prijs die een monopolist in de eerste periode zet, een signaal is voor zijn marginale kosten. In het evenwicht doet een linkse kandidaat een belofte die rechtser is dan haar werkelijke positie, terwijl een rechtse kandidaat een belofte doet die linkser is dan haar werkelijke voorkeur. Beide proberen op deze manier de kiezers in het midden 
aan zich te binden. Kiezers worden echter niet misleid, maar kunnen op basis van de beloftes precies nagaan wat de werkelijke voorkeur is van elke kandidaat. Als een politicus een belofte doet, gaan kiezers er van uit dat ze die belofte niet waar zullen maken, maar wel jets zullen doen dat op zijn minst in de richting van die belofte gaat. Politici zullen hun voorkeur dus altijd overdrijven, en kiezers houden daar rekening mee.

Hoofdstuk 9 is een toepassing van het fairness model, dat ook in hoofdstuk 2 besproken werd. Dat model veronderstelt dat individuen bereid zijn mensen te straffen die hen slecht behandelen, en mensen te belonen die hen goed behandelen, zelfs als dat hen geld kost. Als mensen zich op deze manier gedragen, zo werd beweerd in hoofdstuk 2, dan zullen monopolisten genoodzaakt zijn een prijs te zetten die lager is dan de monopolieprijs. Hoofdstuk 9 gebruikt hetzelfde model, maar past het toe op een ander gebied: dat van intertemporele keuzes. In de theorie wordt er van uit gegaan dat bij het verdelen van inkomsten over de tijj, agenten gebruik maken van een constante disconteringsvoet die gelijk is aan de relevante rentevoet. Maar experimenteel onderzoek wijst uit dat dat niet het geval is. Zo blijkt dat disconteringsvoeten die individuen impliciet hanteren, vaak veel hoger zijn dan rentevoeten. Bovendien blijken ze lager naarmate er langer gewacht moet worden, en naarmate het bedrag dat op het spel staat, hoger is. Wanneer een bedrag eerder uitgekeerd kan worden dan aanvankelijk verwacht werd is de impliciete disconteringsvoet lager dan wanneer dit bedrag later uitgekeerd kan worden. In de literatuur zijn verschillende verklaringen gesuggereerd die deze anomalieën kunnen verklaren. Geen enkele verklaring is echter volledig bevredigend. De meeste kunnen slechts enkele van bovenstaande effecten verklaren, andere geven geen intüitieve interpretatie van de nutsfunctie die individıen gebruiken. In hoofdstuk 9 toon ik aan dat het mogelijk is alle anomalieën in een intuitief raamwerk te verklaren. Voor dat doel maak ik gebruik van het faimess model, en veronderstel dat bij dit soort beslissingen een individu zich gedraagt alsof een toekomstige zelf het bedrag verdeelt, rekening houdend met fairness overwegingen.

In dit proefschrift wordt een groot aantal onderwerpen behandeld. Het is daarom lastig om algemene conclusies te trekken. Toch zijn er een aantal terugkerende thema's. Ten eerste, bij het voeren van een mededingingsbeleid is het belangrijk een volledige analyse te doen van de betreffende industrie. Slechts het aantal aanbieders op een markt is 
niet voldoende om een conclusie te trekken over mogelijke welvaartseffecten. Natuurlijk is dit inzicht niet nieuw. Vooral de literatuur over toetredingsbelemmeringen betoogt dat overheidsbeleid zich geen zorgen hoeft te maken over gemonopoliseerde industrieën waar toetredingsbelemmeringen laag zijn. Maar de voorbeelden in dit proefschrift gaan verder. In hoofdstuk 7 is er sprake van een markt waarin, zelfs zonder toetredingsbelemmeringen, een prijs wordt gezet die boven het sociaal optimum ligt. De modellen in hoofdstuk 2 laten zien dat er meer omstandigheden zijn waarin de nadelige effecten van een monopolie veel lager zijn dan het standaard monopoliemodel voorspelt. En in hoofdstuk 4 zagen we dat, zelfs als monopolisten geneigd zijn een limietprijs te zetten, wat leidt tot een hogere welvaart, ze ook geneigd kunnen zijn een prijs te zetten boven de monopolieprijs, wat vanzelfsprekend nadelig is voor de maatschappelijke welvaart.

Ten tweede, er zijn omstandigheden waarin het hebben van informatie waar anderen geen beschikking over hebben, nadelig kan zijn, terwijl men juist zou verwachten dat dat een voordeel zou zijn. Zowel in het limietprijsmodel als in het verkiezingsmodel in hoofdstuk 8 , moeten agenten kosten maken om anderen te overtuigen van hun informatie. In beide gevallen zou men beter af zijn als de privé-informatie algemeen bekend was. De welvaartseffecten van dit verschijnsel zijn niet eenduidig. Een limietprijs is gunstig voor de welvart, vergeleken met het geval waarin de zittende monopolist geen privé-informatie heeft. Maar in hoofdstuk 4 bleek dat de pogingen van de zittende monopolist om de potentiële toetreder te overtuigen niet toe te treden, ook kunnen leiden tot prijzen die hoger zijn dan de monopolieprijs. In hoofdstuk 8 is een situatie zonder privé-informatie maatschappelijk gewenst. Als politici zich zouden kunnen committeren om niet te liegen tijdens verkiezingscampagnes, dan zou dat hun nut verhogen, zonder van invloed te zijn op de verkiezingsuitslag, en zonder het nut van de kiezers te verlagen.

Ten derde laat dit proefschrift zien hoe methoden en technieken uit de industriële organisatie toegepast kunnen worden op andere, nietgerelateerde gebieden. Hetzelfde mechanisme dat er toe leidt dat monopolisten een limietprijs zetten in hoofdstuk 4, leidt er ook toe dat politici liegen in hoofdstuk 8 . Hetzelfde mechanisme dat er toe leidt dat monopolisten een prijs zetten lager dan de monopolieprijs in hoofdstuk 2 , kan een verklaring geven voor een aantal anomalieën in intertemporeel keuzegedrag in hoofdstuk 9 . Industriële organisatie is dus niet alleen relevant voor industrieel economen. Inzichten die hier opgedaan worden, 
kunnen ook in andere gebieden worden toegepast.

De analyses in dit proefschrift zijn allen theoretisch van aard. Dat wil natuurlijk niet zeggen dat er geen empirische observaties aan ten grondslag liggen. Integendeel. Hoofdstuk 6 verklaart waarom softwareproducenten vaak de deadline missen die ze voor zichzelf zetten. Hoofdstuk 7 legt uit waarom de uitkornsten van taxi-deregulering vaak tegenvallen. Hoofdstuk 8 verklaart waarom politici liegen tijdens verkiezingscampagnes. Hoofdstuk 9 presenteert een model waarin een aantal verschijnselen die vaak in empirisch en experimenteel onderzoek worden gevonden, kunnen worden verklaard. Uiteraard is aanvullend empirisch en experimenteel onderzoek noodzakelijk voordat de beleidsimplicaties die in een aantal hoofdstukken worden gegeven, kunnen worden ingevoerd. Vooral in het taxi-model van hoofdstuk 7 lijken er mogelijkheden voor empirisch onderzoek. In de andere modellen is dat minder eenvoudig. In modellen met asymmetrische informatie hebben economische agenten per definitie bepaalde privé-informatie, die ook onbekend is voor degene die empirisch onderzoek doet. Om de relevantie van deze modellen te toetsen, lijkt experimenteel onderzoek daarom een meer voor de hand liggende methode. 

Marco Haan werd geboren in 1969. Na het succesvol doorlopen van het VWO in Assen, studeerde hij van 1987 tot 1993 Econometrie en Algemene Economie aan de Rijksuniversiteit Groningen. De laatste studie voltooide hij cum laude. Van 1993 tot 1998 was hij werkzaam aan de Universiteit Maastricht, als AIO en als toegevoegd onderzoeker. In 1997 bracht hij, in het kader van zijn promotie-onderzoek, een half jaar door aan de Katholieke Universiteit te Leuven, België. Met het paper Vaporware as a means of entry deterrence, hoofdstuk 6 van dit proefschrift, won hij in 1997 de Young Economists Essay Competition op het congres van de European Association for Research in Industrial Economics. Sinds 1 januari 1998 werkt hij als post-doc op de Rijksuniversiteit Groningen.

Marco Haan was born in 1969. After finishing high school in Assen, he studied Economics and Econometrics from 1987-1993 at the University of Groningen. The latter he completed cum laude. Between 1993 and 1998 he worked as a Ph.D.-student and as a researcher at Maastricht University. In 1997, he spent half a year as a visiting scholar at the Catholic University of Leuven, Belgium. With the paper Vaporware as a means of entry deterrence, chapter 6 of this thesis, he won the 1997 Young Economists Essay Competition at the annual conference of the European Association for Research in Industrial Economics. From the 1st of January 1998 onwards, he has been working as a post-doc at the University of Groningen. 